Universidad deValladolid

PROGRAMA DE DOCTORADO EN INVESTIGACIÓN BIOMÉDICA

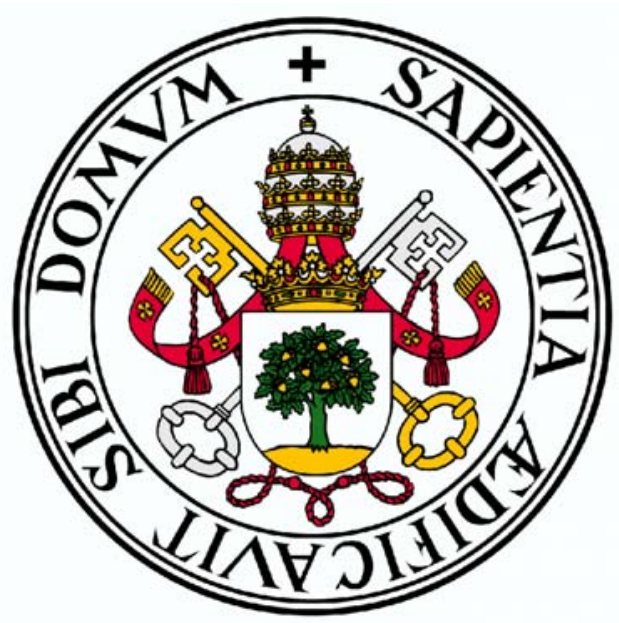

TESIS DOCTORAL:

\title{
Dinámica del calcio reticular en astrocitos corticales
}

\author{
Presentada por Macarena Rodríguez Prados para optar \\ al grado de \\ Doctor/a por la Universidad de Valladolid
}

Dirigida por:

Dra. María Teresa Alonso Alonso

Dr. Javier García-Sancho Martín

Valladolid, Septiembre de 2017 



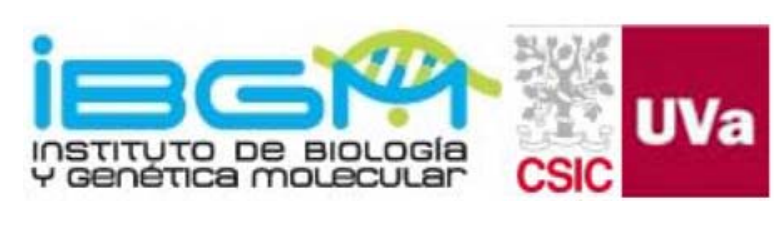

La Dra. María Teresa Alonso Alonso, profesora Titular de Bioquímica del Departamento de Bioquímica y Biología Molecular y Fisiología,

y el Dr. Javier García-Sancho Martín, Catedrático de Fisiología del Departamento de Bioquímica y Biología Molecular y Fisiología de la Facultad de Medicina de la Universidad de Valladolid,

CERTIFICAN que Dña. Macarena Rodríguez Prados, Licenciada en Biotecnología por la Universidad Nacional de Tucumán, ha realizado bajo su dirección los estudios y experimentos necesarios para la elaboración de la memoria titulada "Dinámica del calcio reticular en astrocitos corticales", presentada para optar por el grado de Doctora por la Universidad de Valladolid.

Y para que así conste, a los efectos legales, firman la presente en Valladolid, a 20 de septiembre de 2017.

Dr. Javier García Sancho Martín

Dra. María Teresa Alonso Alonso 



\section{A mis padres Mónica y Rudy}

"La cienencia es el alma de la prosperidad de las naciones y la fuente de vida de todo progreso"

Louis Pasteur 

En primer lugar agradecer a mis directores, a Maite, una gran maestra, que tuvo la enorme paciencia y entrega para la conducción de este proyecto, y a Javier por su apertura a mi incorporación al laboratorio, por invalorable ayuda, su guía y apoyo.

A mis compañeros del laboratorio, a Jonathan, por su gran corazón, brindado siempre lo mejor de sí y ayudando a todos con su sabiduría y experiencia, con la gran paciencia que lo caracteriza; a Sonia, quien me recibió en un principio, por su dedicación y enseñanzas para introducirme en el apasionante mundo del calcio; a Miriam por su ayuda profesional y personal, estando siempre dispuesta a aconsejarme; a Paloma, por compartir este camino conmigo, en el laboratorio codo a codo, y también en momentos de esparcimiento; a Alba, que con su buena onda y cariño pone la nota de alegría y amistad en el día a día y a Raquel, por toda su ayuda, manifestándo siempre su admirable carácter y entrega.

A Jesús F. por que con su sabiduría siempre está dispuesto a brindar la ayuda que los demás necesitan con la mejor disposición.

A los compañeros de otros laboratorios, Iris y Beatriz que me han ayudado en incontables ocasiones. A Espe, Pilar, Virginia, África, y Sandra que siempre han estado dispuestas a aconsejarme.

A Inés, por su apoyo, por haber estado siempre y haber compartido inolvidables momentos conmigo desde el principio.

A los amigos que hice en el IBGM, mis compañeros del master con los cuales compartí el inicio de este apasionante trayecto, y a todos los amigos que hice en el camino.

A los amigos que hice en Valladolid que con su cariño y apoyo constante me ayudaron a seguir siempre adelante. A mi querida Sole D. por ser una gran amiga que siempre me ha apoyado. A Carlos P. por estar en los momentos más difíciles y aportar siempre alegría y positivismo. A Clarita por brindarme su 
amistad y cariño, ayudándome en mi adaptación a un nuevo mundo. A Sandra, Ana, David, Rober, Luis, Juanjo, Juandi, Rober, Josemi, Lorena, María, Eli, Eva, Feli, Raquel, Jesús, Raúl, Miriam, Diego, Pilar, Sonia, Marta y todos los amigos que forman parte de mi vida y han compartido conmigo buenos momentos a lo largo de estos años.

A mi familia que siempre me ha apoyado y alentado, y porque gracias a ellos he podido cumplir este gran sueño. Especialmente a mis padres Mónica y Rudy, a mi abuela Tola, Marieli, Nito, Sergio, Jany y Nuria.

Gracias a todos

Macarena 
Una parte de los resultados que se exponen en este trabajo han sido publicados en las siguientes revistas:

- Rodríguez-Prados M., Rojo-Ruiz J., Aulestia F.J., García-Sancho J., Alonso M.T. (2015). A new low-Ca(2+) affinity GAP indicator to monitor high $\mathrm{Ca}(2+)$ in organelles by luminescence. Cell Calcium. 58:558-64

- Paloma Navas-Navarro, Jonathan Rojo-Ruiz, Macarena RodríguezPrados, María Dolores Ganfornina, Loren L. Looger, María Teresa Alonso and Javier García-Sancho. (2016). GFP-Aequorin Protein Sensor for Ex Vivo and In Vivo Imaging of $\mathrm{Ca}(2+)$ Dynamics in High-Ca(2+) Organelles. Cell Chem Biol. Jun 23;23

- Alonso M.T., Rodríguez-Prados M., Navas-Navarro P., Rojo-Ruiz J., García-Sancho J. (2017). Using aequorin probes to measure Ca2+ in intracellular organelles. Cell Calcium. 64:3-11. Review.

- Alonso M.T., Rojo-Ruiz J., Navas-Navarro P., Rodríguez-Prados M., García-Sancho J. (2017). Measuring Ca2+ inside intracellular organelles with luminescent and fluorescent aequorin-based sensors. Biochim Biophys. Jun;1864(6):894-899. Review.

Se han presentado también comunicaciones en los siguientes congresos:

- Rodríquez-Prados, M, Rojo-Ruiz, J., Navas-Navarro P., García-Sancho $\mathrm{J}$. and Alonso M.T. Calcium dynamics in the endoplasmic reticulum of astrocytes. Evidence for a CICR mechanism. International meeting of the European Calcium Society (ECS Meeting)-XIV Valladolid, (Spain). 2529/09/16. Poster.

- Rojo-Ruiz J., Navas Navarro, P., Rodríguez-Prados, M., Alonso M.T., García-Sancho, J. $\mathrm{Ca}^{2+}$ Dynamics in the endoplasmic reticulum of nervous tissue monitored with the new fluorescent $\mathrm{Ca}^{2+}$ sensor GAP1. European Calcium Society (ECS Meeting)-13 ${ }^{\circ}$ Aix-en-Provence (Francia) 13-17/09/14. Poster.

- $\quad$ Alonso M.T., Rodríguez-Prados, M., Navas-Navarro P., Rojo-Ruiz J., García-Sancho, J. Calcium dynamics in the endoplasmic reticulum of astrocytes monitored with GAP, a new class of fluorescente aequorinbased biosensors. International Astrocytes School. Bertinoro, (Italy) 612/04/14. Comunicación oral.

- Rodríquez-Prados, M., Rojo-Ruiz J., Alonso M.T., García-Sancho, J. Evidencia de un mecanismo de liberación de Calcio inducida por Calcio (CICR) en astrocitos corticales murinos. XXXIV Reunión del Grupo de Neurotransmisión y Neuroprotección. San Lorenzo de El Escorial-Madrid (España) 11-13/12/13. Comunicación oral.

- Rodríguez-Prados, M., Rojo-Ruiz J., Alonso M.T., García-Sancho, J. $\mathrm{Ca}^{2+}$ Dynamics in the endoplasmic reticulum of cortical astrocytes: Direct monitoring of $\mathrm{Ca}^{2+}$-induced $\mathrm{Ca}^{2+}$-release. Sociedad Española de 
Neurociencias (SENC)- $15^{\circ}$ Congreso Nacional- Congreso. Oviedo (España) 25-27/09/13. Poster.

- Rojo-Ruiz J., Gallego-Sandín S., Rodríguez-Prados, M., Alonso M.T., García-Sancho, J. Disturbances in calcium handling by intracellular organelles in Alzheimer disease models. Network of European Funding for Neuroscience Research (ERA-Net NEURON)-Berlin (Alemania) 2728/10/11. Poster. 


\section{Indice}

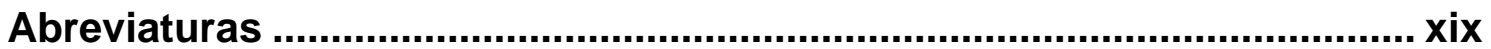

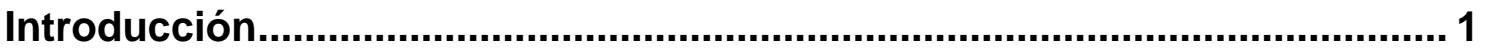

1. Morfología y función de los astrocitos ..................................... 3

2. Principios de la señalización por $\mathrm{Ca}^{2+}$ en astrocitos ........................ 12

2.1. Canales de $\mathrm{Ca}^{2+}$ de la membrana plasmática ................................. 13

2.1.1. Canales de $\mathrm{Ca}^{2+}$ operados por voltaje (VOCs) ......................... 13

2.1.2. Canales TRP ..................................................................... 15

2.1.3. Canales de $\mathrm{Ca}^{2+}$ activados por vaciamiento de los depósitos

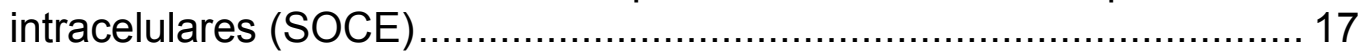

2.1.4. Canales/receptores operados por ligando .............................. 18

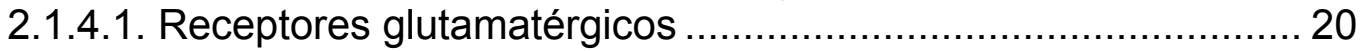

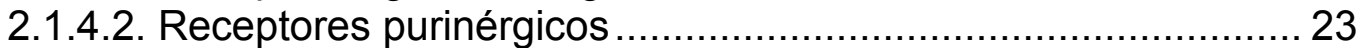

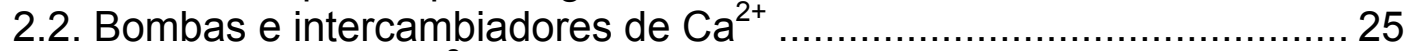

2.2.1. Bombas de $\mathrm{Ca}^{2+}$ PMCA, SERCA y SPCA ............................... 26

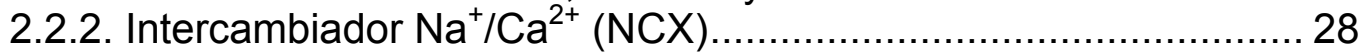

2.2.3. Uniportador de $\mathrm{Ca}^{2+}$ mitocondrial (MCU) ............................... 29

2.2.4. Proteínas amortiguadoras que unen $\mathrm{Ca}^{2+}(\mathrm{CBP}) \ldots \ldots \ldots \ldots \ldots \ldots \ldots . . . . . . . . . .31$

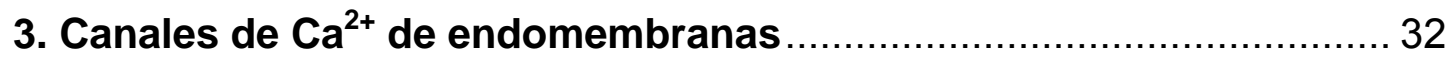

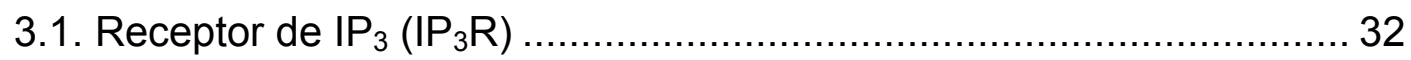

3.2 Receptor de rianodina (RyRs) ................................................. 35

3.3 Canales de fuga de $\mathrm{Ca}^{2+}$ (leak channel) …………........................ 39

4. Ondas y oscilaciones de $\mathrm{Ca}^{2+}$ en astrocitos ...................................... 40

4.1. Ondas de $\mathrm{Ca}^{2+}$ en astrocitos ...................................................... 40

4.2. Oscilaciones de $\mathrm{Ca}^{2+}$ en astrocitos ................................................ 42

5. Patologías relacionadas con la astroglía ........................................... 47

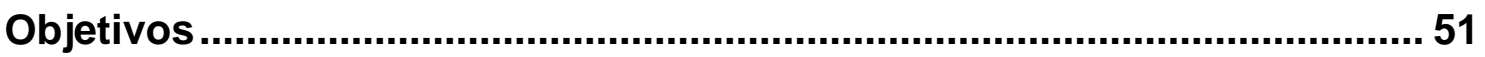

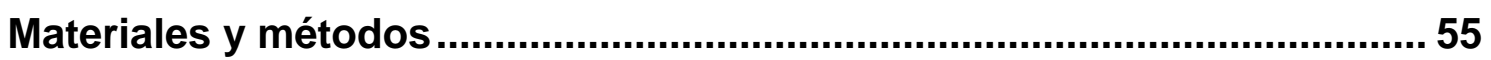

Reactivos

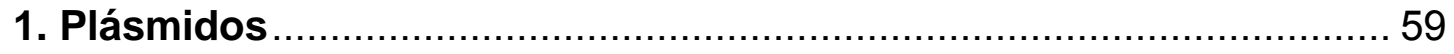

1.1. Plásmidos derivados del pcDNA3 ……………............................. 59

1.2. Plásmidos derivados del vector vírico pHSVpuc ................................ 60

1.3. Plásmidos derivados del pAAV ..................................................... 61 


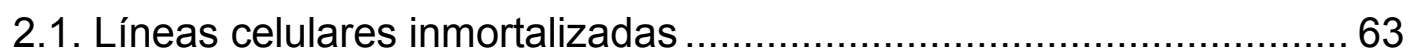

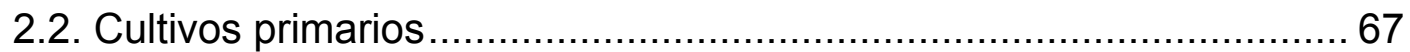

2.2.1. Cultivo puro de astrocitos corticales murinos ........................6 67

2.2.2. Cultivo mixto de astrocitos y neuronas de corteza....................6 69

2.3. Cultivo organotípico......................................................... 69

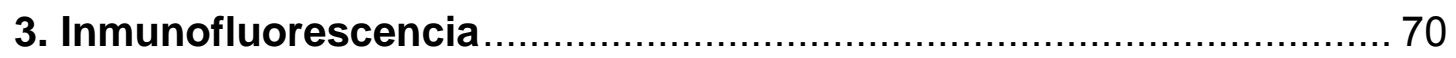

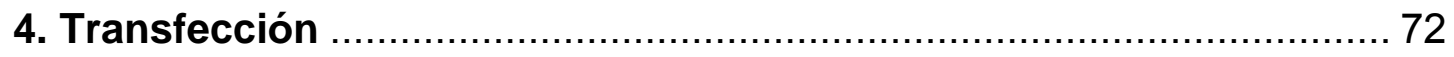

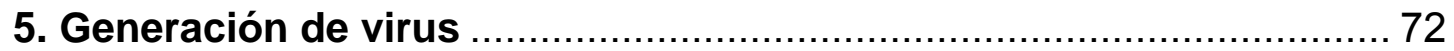

5.1. Vectores derivados del virus herpes simplex tipo 1 (HSV-1) ............. 72

5.2. Vectores derivados del virus adenoasociado (AAV) ........................ 74

5.3. Infección .......................................................................... 76

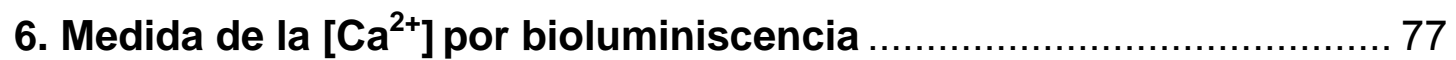

6.1. Sondas: erGA e IgGAP1 ..................................................... 77

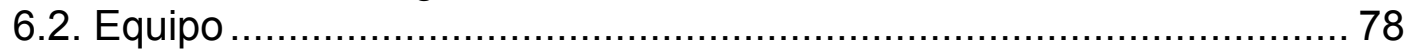

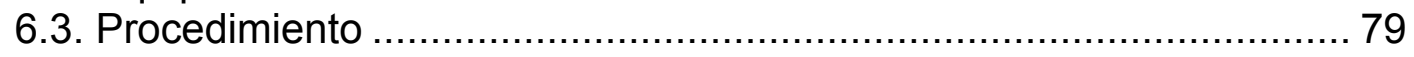

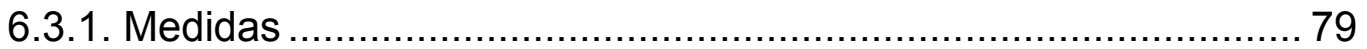

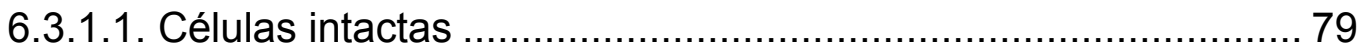

6.3.1.2. Células permeabilizadas.................................................... 80

6.3.2. Calibración de aequorinas ............................................. 81

7. Medida de la $\left[\mathrm{Ca}^{2+}\right]$ por fluorescencia .................................... 82

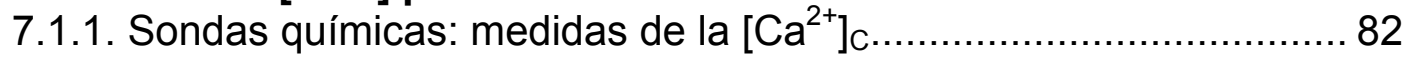

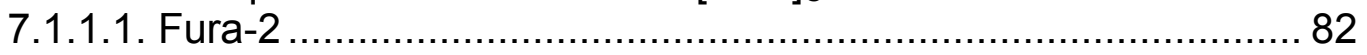

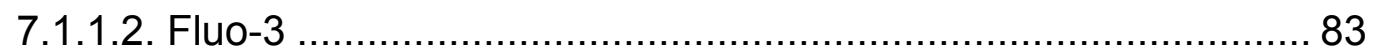

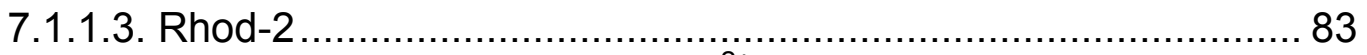

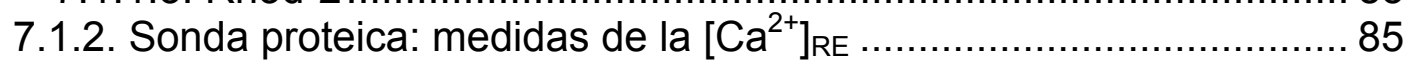

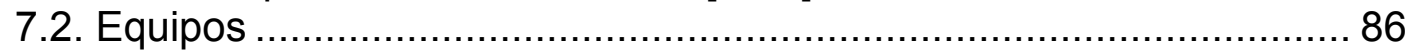

7.2.1. Microscopio de fluorescencia invertido .................................. 86

7.2.2. Microscopio de fluorescencia directo ................................... 88

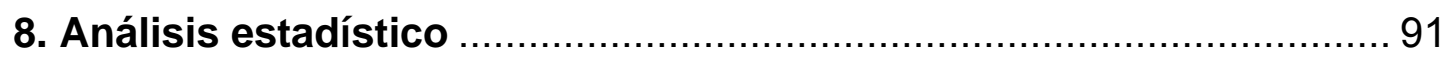

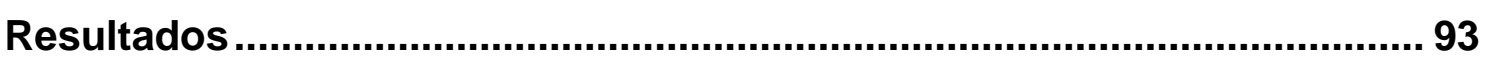

1. Desarrollo de un nuevo sensor luminiscente de baja afinidad por $\mathrm{Ca}^{2+}$

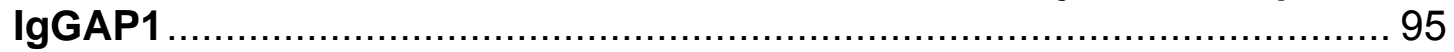

1.1. Diseño y caracterización del sensor ........................................ 95

1.2. Calibración del sensor luminiscente .............................................. 98

1.3. Medidas de la $\left[\mathrm{Ca}^{2+}\right]_{\mathrm{RE}}$ en diferentes tipos celulares ..................... 104

2. Caracterización del cultivo de astrocitos ..................................... 108

2.1. Cultivo primario en monocapa de astrocitos murinos de corteza cerebral 
2.2. Cultivo organotípico de corteza cerebral de ratón 110

2.3. Vectores utilizados para la expresión de sensores GAP en astrocitos

2.3.1. Vector derivado del virus herpes

2.3.2. Vector derivado del virus adenoasociado: sensor fluorescente erGAP3

2.3.3. Expresión de los sensores IgGAP1 y erGAP3 en el RE de astrocitos cultivados en monocapa.

3. Dinámica del $\mathrm{Ca}^{2+}$ en astrocitos corticales murinos ...................... 117

3.1. Cultivo de astrocitos puros .................................................... 117

3.1.1. Funcionalidad de los astrocitos........................................ 117

3.1.2. Activación de los RyR de los astrocitos corticales con cafeína.. 120

3.1.3. Entrada de $\mathrm{Ca}^{2+}$ por despolarización con alto $\mathrm{K}^{+} \ldots \ldots \ldots \ldots \ldots \ldots . . \ldots 125$

3.1.4. Estudio de la $\left[\mathrm{Ca}^{2+}\right]_{\mathrm{RE}}$ en astrocitos permeabilizados .............. 135

3.1.5. Expresión del RyR en astrocitos........................................... 136

3.1.6. Ganancia de función del RyR3 en células HEK 293T............... 137

3.1.7. Medidas de fluorescencia con erGAP3 en astrocitos primarios cultivados en monocapa .

3.2. Monitorización de la $\left[\mathrm{Ca}^{2+}\right]_{\mathrm{RE}}$ (erGAP3) y de la $\left[\mathrm{Ca}^{2+}\right]_{\mathrm{C}}$ (Rhod-2) simultáneamente en astrocitos de rodajas de corteza cerebral .............. 144

4. Oscilaciones y ondas de calcio intracelular en los astrocitos ......... 149

4.1. Oscilaciones de $\mathrm{Ca}^{2+}$ en cultivos primarios de astrocitos ................ 149

4.1.1. Oscilaciones espontáneas ................................................ 149

4.1.2. Oscilaciones inducidas ................................................. 153

4.2 Oscilaciones de $\mathrm{Ca}^{2+}$ de los astrocitos en cultivos organotípicos...... 161

Discusión 165

1. Desarrollo de un nuevo sensor de $\mathrm{Ca}^{2+}$ para medir la $\left[\mathrm{Ca}^{2+}\right]_{\mathrm{RE}}$. 167

2. Desarrollo de nuevas herramientas selectivas para estudiar la señal de $\mathrm{Ca}^{2+}$ en astrocitos

3. Medidas de la $\left[\mathrm{Ca}^{2+}\right]_{\mathrm{RE}}$ en astrocitos ..................................... 172

4. Activación del mecanismo de la liberación de $\mathrm{Ca}^{2+}$ inducida por $\mathrm{Ca}^{2+}$

(CICR) en los astrocitos ............................................................... 174

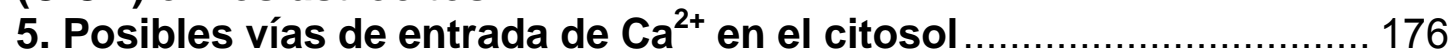

6. Oscilaciones y ondas de $\mathrm{Ca}^{2+}$ en astrocitos ............................ 180

Conclusiones 


\section{Indice de Figuras}

Figura 1. Morfología de los astrocitos.

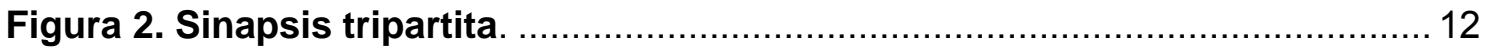

Figura 3. Principios de señalización por $\mathrm{Ca}^{2+}$ en astrocitos. ............................ 14

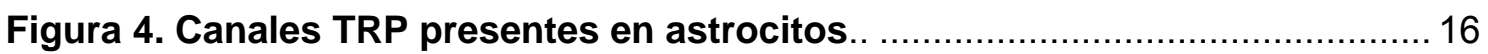

Figura 5. Organización estructural de los receptores ionotrópicos expresados en

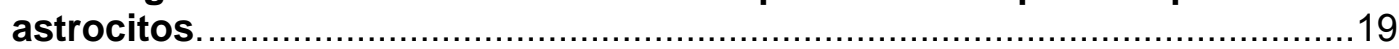

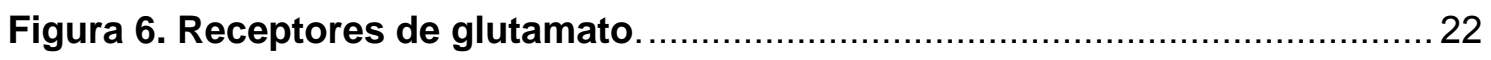

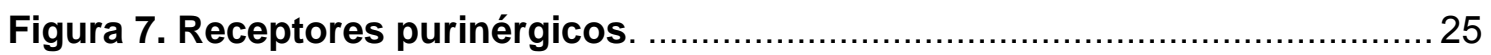

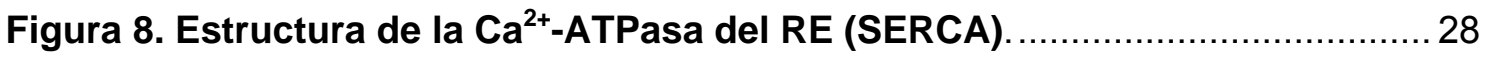

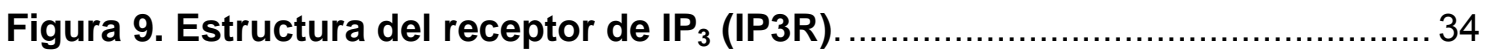

Figura 10. Estructura del receptor de rianodina tipo 2 (RyR2) .......................... 36

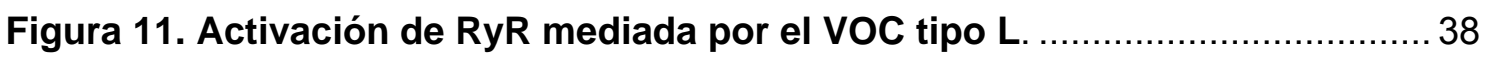

Figura 12. Mecanismos propuestos para la propagación de la onda de $\mathrm{Ca}^{2+}$ intracelular.

Figura 13. Modelos principales que explican las oscilaciones intracelulares. ... 45

Figura 14. La activación de la PKC actúa como en un mecanismo de retroalimentación negativa .................................................................... 46

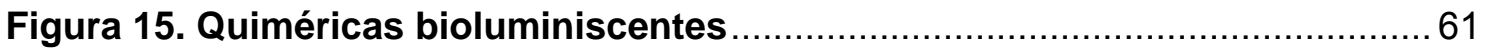

Figura 16. Proteína quimérica fluorescente erGAP3 y de su amplicon pHSV. .....63

Figura 17. Método de empaquetamiento de los virus HSV-1. ............................. 74

Figura 18. Esquema del empaquetamiento de los virus AAV . ........................... 76

Figura 19. Esquema del luminómetro utilizado para medir la $\left[\mathrm{ca}^{2+}\right]$ por bioluminiscencia en poblaciones celulares

Figura 20. Estructura y espectros de fluorescencia de los indicadores de $\mathrm{Ca}^{2+}$ sintéticos utilizados.

Figura 21. Espectro de fluorescencia de GAP con la emisión fijada a 520 nm .... 85

Figura 22. Representación esquemática del sistema de fluorometría en un microscopio invertido

Figura 23. Representación esquemática del sistema de fluorometría del microscopio directo Nikon Zeiss Axioplan 2 
Figura 24. Fotos del equipo directo

Figura 25. Estructura del sensor de $\mathrm{Ca}^{2+}$ GAP y esquema de su funcionamiento dual

Figura 26. Estructura y expresión del indicador bioluminiscente del $\mathrm{Ca}^{2+}$ reticular IgGAP1

Figura 27. Calibración de la bioluminiscencia obtenida a partir de las sondas erGA e IgGAP1 reconstituidas con celenterazina $n$

Figura 28. Comparación de la emisión de fotones y del consumo de la aequorina entre IgGAP1 y erGA

Figura 29. Dinámica de la $\left[\mathrm{Ca}^{2+}\right]_{\mathrm{RE}}$ en células intactas y permeabilizadas 105

Figura 30. Monitorización de la dinámica del $\mathrm{Ca}^{2+}$ del RE en distintos tipos celulares mediante la sonda reticular IgGAP1.

Figura 31. Caracterización del cultivo puro de astrocitos corticales

Figura 32. Marcaje específico de astrocitos en secciones de tejido nervioso de ratón

Figura 33. Transducción del indicador de $\mathrm{Ca}^{2+}$ IgGAP1 mediante el vector viral HSV-IgGAP1

Figura 34. Expresión específica del sensor erGAP3 en astrocitos

Figura 35. Expresión del sensor erGAP3 en astrocitos de una sección de corteza cerebral.

Figura 36. Localización de los sensores IgGAP1 y erGAP3 en el RE de un astrocito

Figura 37. Efecto del ATP en la $\left[\mathrm{Ca}^{2+}\right]_{\mathrm{c}}$ en astrocitos

Figura 38. Dinámica del $\mathrm{Ca}^{2+}$ reticular en astrocitos cultivados monitorizada con la sonda bioluminiscente de $\mathrm{Ca}^{2+}$ IgGAP1.

Figura 39. Efecto de la cafeína en la $\left[\mathrm{Ca}^{2+}\right]_{\mathrm{c}}$ y la $\left[\mathrm{Ca}^{2+}\right]_{\mathrm{RE}}$ de astrocitos.

Figura 40. Efecto del IP 3 y de la cafeína en la $\left[\mathrm{Ca}^{2+}\right]_{\mathrm{RE}}$ de astrocitos

Figura 41. Inhibición del efecto de cafeína en la $\left[\mathrm{Ca}^{2+}\right]_{\mathrm{RE}}$ por rianodina en astrocitos.

Figura 42. Efecto del alto $\mathrm{KCl}$ sobre la $\left[\mathrm{Ca}^{2+}\right]_{\mathrm{c}}$ de astrocitos y su inhibición con EGTA, $\mathrm{NiCl}_{2}$ o furnidipino

Figura 43. Efecto de la estimulación con alto $\mathrm{K}^{+}$sobre la $\left[\mathrm{Ca}^{2+}\right]_{\mathrm{RE}}$ en astrocitos 129

Figura 44. Efecto dosis-respuesta del alto $\mathrm{K}^{+}$en la liberación del $\left[\mathrm{Ca}^{2+}\right]_{\mathrm{RE}}$ en astrocitos 
Figura 45. Inhibición del efecto del alto $\mathrm{K}^{+}$en la $\left[\mathrm{Ca}^{2+}\right]_{\mathrm{RE}}$ medida con IgGAP1 en una población de astrocitos

Figura 46. Efecto del vaciamiento del $\mathrm{Ca}^{2+}$ del RE sobre la respuesta evocada por alto $\mathrm{K}^{+}$en astrocitos

Figura 47. Rellenado o liberación del $\mathrm{Ca}^{2+}$ desde el RE en función de la $\left[\mathrm{Ca}^{2+}\right]_{\mathrm{RE}}$.

Figura 48. Expresión del transcrito de mRNA del RyR3 en astrocitos 137

Figura 49. Efecto de la sobre-expresión del RyR3 sobre la dinámica del $\mathrm{Ca}^{2+}$ reticular en células HEK-293T.

Figura 50. Dinámica de la $\left[\mathrm{Ca}^{2+}\right]_{\mathrm{RE}}$ en célula única con erGAP3 en astrocitos $\ldots 140$

Figura 51. Medidas simultáneas de la $\left[\mathrm{Ca}^{2+}\right]_{\mathrm{RE}}(\operatorname{erGAP3})$ y de la $\left[\mathrm{Ca}^{2+}\right]_{\mathrm{C}}(\mathrm{Rhod}-2)$ por fluorescencia en célula única en astrocitos en cultivo ...

Figura 52. Comparación de la movilización del $\mathrm{Ca}^{2+}$ del RE entre astrocitos y neuronas en un cultivo primario mixto.

Figura 53. Efecto del ATP (2 y $100 \mu \mathrm{M})$ sobre la $\left[\mathrm{Ca}^{2+}\right]_{\mathrm{RE}}$ de un astrocito en una sección de corteza cerebral cultivada medido por fluorescencia con GAP3.

Figura 54. Efecto del agonista metabotrópico DHPG en la $\left[\mathrm{Ca}^{2+}\right]_{\mathrm{C}}$ y la $\left[\mathrm{Ca}^{2+}\right]_{\mathrm{RE}}$ de astrocitos en secciones de corteza cerebral

Figura 55. Efecto del alto $\mathrm{K}^{+}(80 \mathrm{mM})$ sobre la $\left[\mathrm{Ca}^{2+}\right]_{\mathrm{RE}}$ de astrocitos en una sección de corteza cerebral cultivada medida por fluorescencia con GAP3

Figura 56. Oscilaciones espontáneas coordinadas de la $\left[\mathrm{Ca}^{2+}\right]_{\mathrm{RE}}$ y la $\left[\mathrm{Ca}^{2+}\right]_{\mathrm{C}}$ en astocitos primarios

Figura 57. Efecto de la eliminación del $\mathrm{Ca}^{2+}$ extracelular sobre las oscilaciones en astrocitos

Figura 58. El bajo $\mathrm{K}^{+}$provoca oscilaciones coordinadas de la $\left[\mathrm{Ca}^{2+}\right]_{\mathrm{RE}}$ y la $\left[\mathrm{Ca}^{2+}\right]_{\mathrm{C}}$ en astrocitos.

Figura 59. La progresión de una onda intercelular de vaciamiento del RE en un cultivo de astrocitos

Figura 60. Propagación de la liberación de $\mathrm{Ca}^{2+}$ del RE de astrocitos vecinos 158

Figura 61. El glutamato induce oscilaciones coordinadas de la $\left[\mathrm{Ca}^{2+}\right]_{\mathrm{RE}}$ y la $\left[\mathrm{Ca}^{2+}\right]_{\mathrm{c}}$ en astocitos primarios

Figura 62. Oscilaciones del calcio citosólico inducidas por cafeína en astrocitos en cultivo primario.

Figura 63. Oscilaciones de la $\left[\mathrm{Ca}^{2+}\right]_{\mathrm{RE}}$ en astrocitos de secciones de corteza cerebral 


\section{Indice de Tablas}

Tabla 1. Funciones de los astrocitos en condiciones fisiológicas y patológicas... 8

Tabla 2. Lista de plásmidos empleados en esta Tesis. 59

Tabla 3. Líneas celulares utilizadas y sus principales características..................64

Tabla 4. Medio de cultivo de rodajas de corteza de cerebro de ratón.....................70

Tabla 5. Métodos de transducción de las diferentes sondas utilizadas ............... 77

Tabla 6. Composición del medio externo utilizado con células intactas y del medio interno utilizado con células permeabilizadas......................................8 80

Tabla 7. Combinaciones de soluciones valoradas de los quelantes EGTA o EDTA con soluciones de $\mathrm{Ca}^{2+}$ para obtener una $\left[\mathrm{Ca}^{2+}\right]$ final conocida en los medios internos

Tabla 8. Niveles de la $\left[\mathrm{Ca}^{2+}\right]_{E R}$ basal y las velocidades de rellenado del RE en diferentes tipos celulares medidos con IgGAP1 

Abreviaturas 

Abreviaturas más utilizadas

$\left[\mathrm{Ca}^{2+}\right] \quad$ Concentración del $\mathrm{Ca}^{2+}$ iónico

$\left[\mathrm{Ca}^{2+}\right]_{\mathrm{c}} \quad$ Concentración del $\mathrm{Ca}^{2+}$ citosólico

$\left[\mathrm{Ca}^{2+}\right]_{\mathrm{RE}}$ Concentración de $\mathrm{Ca}^{2+}$ en el retículo endoplásmico

ACh Acetilcolina

ACSF fluido cerebro-espinal artificial

AMPA $\quad \alpha$-amino-3-hidroxi-5-metil-4-isoxazolepropiónico

AMPc Adenosín monofosfato cíclico

BRET Trasferencia de energía de resonancia bioluminiscente

BSA Albúmina de suero bovino (Bovine Serum Albumin)

CaMKII Quinasa II dependiente de $\mathrm{Ca}^{2+}$ y Calmodulina

CICR Liberación de $\mathrm{Ca}^{2+}$ inducida por $\mathrm{Ca}^{2+}$ (ㄸalcium Induced Calcium Release)

DHPG Dihidroxifenil-glicina

GECI Indicadores de calcio codificados genéticamente

GFAP Proteína Ácida Fibrilar Glíal (glial fibrillary acidic protein)

GFP Proteína verde fluorescente (green fluorescent protein)

GMPc Guanosín monofosfato cíclico

GPCRs Receptores asociados a proteínas G

HBSS Solución salina balanceada de Hank (Hank's balanced salt solution)

HSV-1 Virus herpes simplex tipo I

iGluR Receptor ionotrópico de glutamato

$\mathbf{I P}_{\mathbf{3}} \quad$ Inositol 1,4,5-trisfosfato

$\mathbf{I P}_{3} \mathbf{R} \quad$ Receptor de 1,4,5-trisfosfato

KA Cainato

mGluR Receptor metabotrópico de glutamato

NCX Intercambiador $\mathrm{Na}^{+} / \mathrm{Ca}^{2+}$

NMDA N-metil-D-aspartato

$\mathbf{P I P}_{2} \quad$ Fosfatidil inositol 4,5 bifosfato

PLC Fosfolipasa C

PKA Proteína quinasa A (dependiente de cAMP)

PKC Proteína quinasa $\mathrm{C}$ (dependiente de $\mathrm{Ca}^{2+}$ ) 
PKG Proteína quinasa $\mathrm{G}$ (dependiente cGMP)

PMCA $\quad \mathrm{Ca}^{2+}$-ATPasa de la membrana plasmática

RE Retículo endoplásmico

RyR Receptor de rianodina

SERCA $\quad \mathrm{Ca}^{2+}$-ATPasa del retículo sarco/endoplásmico

SN Sistema Nervioso

SNC Sistema Nervioso Central

SNP Sistema Nervioso Periférico

SOC Canales de $\mathrm{Ca}^{2+}$ operado por depósitos

SOCE Entrada de $\mathrm{Ca}^{2+}$ operada por depósitos (Store-Operated $\underline{\text { Calcium }}$ Entry)

TBQH 2,5-di-tert-butil-benzo-hidroquinona

TRP Canales receptores de potencial transitorio

vocc Canales de $\mathrm{Ca}^{2+}$ operados por voltaje

4-CmC 4-cloro-m-cresol 
Introducción 



\section{Morfología y función de los astrocitos}

El sistema nervioso (SN) está compuesto por una gran variedad de tipos celulares, que se pueden dividir, en un primer nivel de clasificación, en dos grupos de acuerdo a su excitabilidad. Por un lado, se encuentran las neuronas, que son células eléctricamente excitables; y, por otro, las glías, que se han considerado tradicionalmente como células eléctricamente no excitables. Sin embargo, en los últimos años, se ha demostrado que, aunque no son capaces de conducir impulsos nerviosos como las neuronas, pueden responder a estímulos despolarizantes. Dentro del término glía se agrupa un conjunto muy heterogéneo de células, que pueden dividirse en 3 subgrupos bien diferenciados, tanto fisiológica y funcionalmente, como por su morfología y localización. Por una parte, se encuentran las microglías, que son células fagocíticas con funciones inmunes en el SN, y que participan en la respuesta inflamatoria; por otro lado, los oligodendrocitos y las células de Schwann, que mielinizan el sistema nervioso central (SNC) y el sistema nervioso periférico (SNP) respectivamente; y, finalmente, los astrocitos, en los cuales nos centraremos en este trabajo.

Los términos astrocito y astroglía son usados indistintamente para todas las células macroglíales no mielinizantes del SNC. Estas células, junto a las neuronas, representan los dos tipos celulares mayoritarios en el SNC, y se encuentran a través de todo el cerebro y la medula espinal. Las glías totales representan un número igual o mayor al de las neuronas, y dentro de este grupo, los astrocitos representan alrededor del 20-40\% del total. Sin embargo, existen variaciones en la proporción de astrocitos respecto a la de neuronas en el SNC, que se manifiestan, tanto entre diferentes áreas del cerebro, como entre distintas especies. Por ejemplo, en la corteza cerebral los astrocitos superan en número a las neuronas, variando entre 10.000 a 30.000 por $\mathrm{mm}^{3}$, mientras que en el cerebelo las neuronas superan ampliamente a los astrocitos (Khakh y McCarthy, 2015).

El grupo de células astrogliales está formado por una gran variedad de astrocitos, entre los cuales encontramos la glía radial (común en el desarrollo 
del cerebro), la glía de Bergmann (en el cerebelo), la glía de Muller (en la retina), los astrocitos velados (del cerebelo) y los tanicitos (presentes en órganos periventriculares). Sin embargo, los tipos mayoritarios están representados por 2 grupos principales, distinguibles tanto por su morfología como por su localización: los astrocitos protoplásmicos o de tipo I, y los fibrosos o de tipo II (Fig. 1). Los primeros, poseen procesos cortos, gruesos y muy ramificados, se encuentran en la sustancia gris y están acoplados por uniones de tipo gap. Poseen una morfología típicamente espongiforme, con un diámetro de alrededor de 40-60 $\mu \mathrm{m}$ y un volumen de $6.6 \times 10^{4} \mu \mathrm{m}^{3}$. Están formados por un soma y 4-10 ramificaciones principales, que pueden subdividirse a su vez en cientos de ramificaciones más pequeñas, relacionadas íntimamente con las sinapsis. Alrededor del $90-95 \%$ del área de un astrocito está formada por ramificaciones principales, que se dividen en ramificaciones secundarias, de las cuales sólo el 15\% puede marcarse con la tinción de la proteína acida fibrilar glíal (GFAP). Dichos procesos se caracterizan por exhibir una plasticidad estructural muy rápida, especialmente en los sitios de contacto con las sinapsis, donde los astrocitos extienden estructuras similares a lamelipodios sobre la superficie neuronal (Hirrlinger y col., 2004). Se han utilizado diversos términos para describir los finos procesos de los astrocitos, tales como lamelipodios astrocíticos, hojas astrocíticas, procesos periféricos de astrocitos, procesos presinápticos de astrocitos, y dedos astrocíticos. Estas diminutas ramificaciones fueron observadas mediante microscopía electrónica, ya que no pueden observarse por microscopia óptica convencional, y se han descrito estructuras con dimensiones que se encuentran en el orden de 10-100 nm en los sitios de interacción de los astrocitos con las sinapsis. Los astrocitos protoplasmáticos poseen territorios muy bien delimitados y prácticamente no se solapan con astrocitos vecinos. Cada astrocito de la corteza de roedores puede contactar con 4-8 neuronas, alrededor de 300-600 dendritas, lo que significa que 20.000-150.000 sinapsis se encuentran dentro de sus dominios.

Por otro lado, los astrocitos de tipo II, de aspecto fibroso, exhiben procesos largos, delgados y menos ramificados, se localizan en la sustancia blanca y no están acoplados mediante uniones gap (Sontheimer y col., 1990). Sus procesos pueden tener una longitud mayor de $300 \mu \mathrm{m}$, y son mucho 
menos complejos que los de los astrocitos protoplasmáticos. El soma de los astrocitos fibrosos está localizado entre los grupos de axones y su densidad en la materia blanca es aproximadamente de 200 células por $\mathrm{mm}^{3}$. En contraste con los astrocitos protoplasmáticos, los fibrosos no poseen dominios territoriales separados de sus vecinos y muestran un alto grado de solapamiento.

Por otra parte, los astrocitos presentan una alta densidad de uniones gap, formadas, principalmente, por la conexina $\mathrm{Cx} 43$, y, en menor medida, por las conexinas Cx30, Cx40 y Cx45 (Olivera y col., 1994). Las uniones gap promueven un alto grado de acoplamiento funcional entre astrocitos, que permite la difusión y el intercambio efectivo de iones $\left(\mathrm{Na}^{+}, \mathrm{K}^{+}\right.$y $\left.\mathrm{Ca}^{2+}\right)$, metabolitos (ADP, ATP, glucosa y glutatión), y segundos mensajeros (IP 3 y AMPc) a través del poro hidrofílico del hemicanal (Orellana y Stehberg, 2014). La comunicación es esencial para muchas de las funciones de los astrocitos como son la generación de ondas de metabolitos, de $\mathrm{Ca}^{2+}$ y de $\mathrm{Na}^{+}$, el transporte de agua y el tamponamiento de $\mathrm{K}^{+}$.

Para identificar a los astrocitos se han utilizado numerosas estrategias basadas en marcadores moleculares, tales como la proteína ácida fibrilar glial (GFAP), las proteínas $\mathrm{S} 100 \beta$, la glutamina sintetasa, el transportador de aspartato y glutamato (GLAST), el transportador de glutamato (GLT-1), el transportador de aminoácidos excitatorios (EAAT2), las proteinas de uniones gap conexina 30 (Cx30) y la conexina 43 (Cx43), el canal de potasio Kir4.1, o la 10-formiltetrahidrofolato deshidrogenasa (Aldh1L1). Aunque la proteína GFAP fue uno de los primeros marcadores identificados, su utilización puede ser problemática en algunos casos porque: 1) no todos los tipos de astrocitos expresan GFAP en cantidades detectables por inmunofluorescencia; 2) su expresión génica puede verse modificada en respuesta a una lesión en el SNC; $y, 3)$ los astrocitos de diferentes regiones del cerebro pueden exhibir diferencias en los niveles de expresión de GFAP. Así, por ejemplo, los astrocitos de hipocampo expresan niveles detectables de GFAP, mientras que, en el tálamo, sólo unos pocos astrocitos lo expresan. En la corteza cerebral, los astrocitos de las capas superficiales expresan GFAP, mientras que sólo unos 
pocos de las capas medias lo expresan. Además de los astrocitos, otros tipos celulares, como los progenitores celulares derivados de la glía radial, también expresan GFAP, por lo cual niveles detectables de expresión de GFAP no son suficientes para identificar una célula como un astrocito maduro. Otros marcadores, también muestran diferencias en su expresión en diferentes partes del cerebro. Así, por ejemplo, el GLT-1 se expresa abundantemente en el hipocampo, la corteza y el striatum, mientras que el marcador GLAST muestra una expresión preferencial en el cerebelo. La Cx30 se expresa en los astrocitos de la materia gris, pero no en los de la sustancia blanca. El canal Kir4.1 se expresa a niveles bajos en los astrocitos de la materia blanca, y con niveles variables en la materia gris, con una expresión particularmente alta en el hipocampo y el cerebelo (Khakh y McCarthy, 2015).
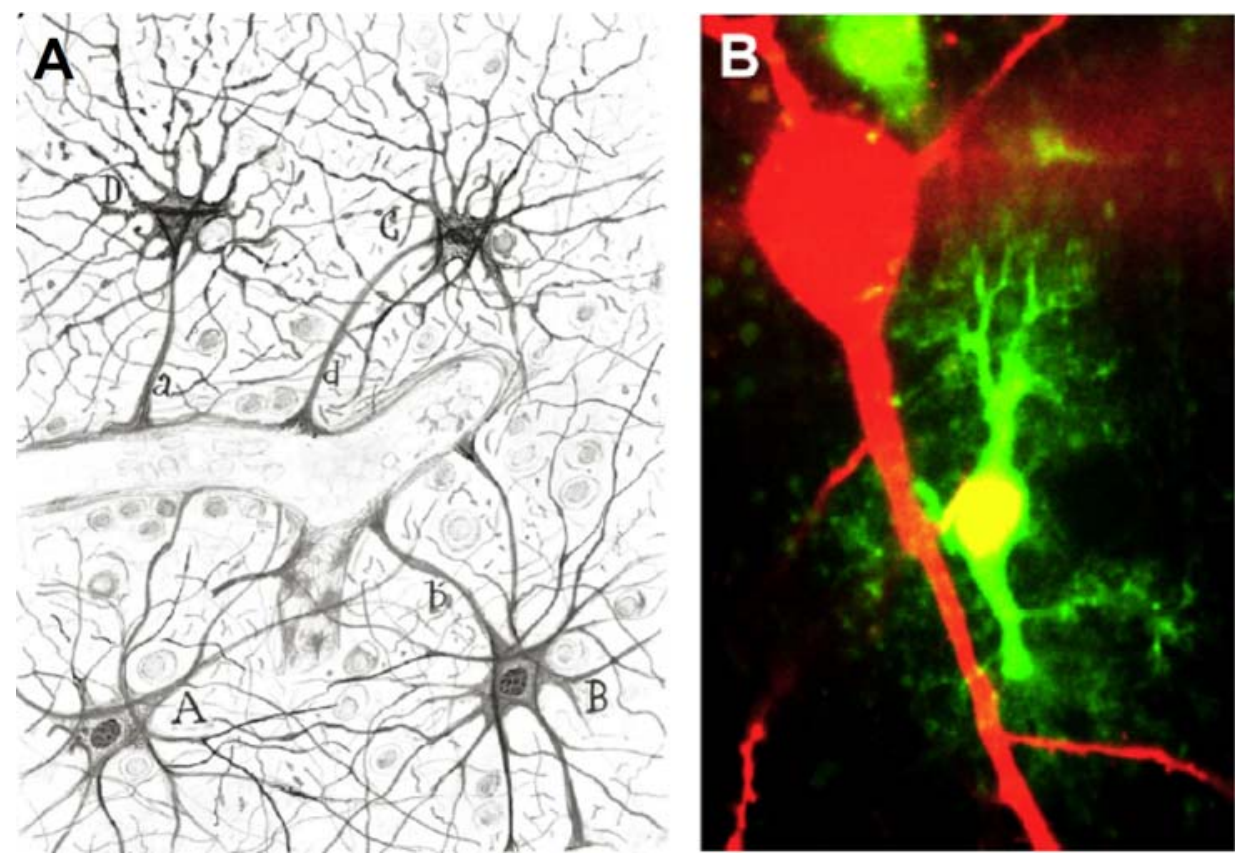

Figura 1. Morfología de los astrocitos. A. llustración de Santiago Ramón y Cajal que muestra astrocitos (A-D) de la sustancia blanca de la corteza cerebral de un cerebro humano adulto, marcados con la tinción de oro. Se observa el aspecto fibrilar de las células astrocíticas y el protoplasma teñido uniformemente no mostrando aspecto de fibras; a, b, d, pies perivasculares contactando con vasos sanguíneos (Navarrete y Araque, 2014). B. Corte de hipocampo donde se observa un astrocito (verde) que extiende sus procesos, muy ramificados, en las proximidades de una dendrita de una neurona piramidal de la región CA1 (rojo) (Fiacco y McCarthy, 2004). 
La astroglía ha sido considerada tradicionalmente como un soporte estructural, metabólico y funcional para las neuronas, aunque este punto de vista está siendo revisado, gracias al descubrimiento de nuevas funciones de la glía, como su participación en la comunicación intercelular del SNC, tanto entre las propias glías como con las neuronas (Codazzi y col., 2001). En la Tabla 1 se han resumido las principales funciones de la glía, en condiciones fisiológicas y patológicas (Heneka y col., 2010).

En primer lugar, a nivel del órgano completo, los astrocitos participan en la formación de la barrera hematoencefálica, regulando el flujo de sangre hacia el cerebro según de las necesidades metabólicas del mismo. También participan en el desarrollo de la morfología del SN, encargándose de definir la migración de las células nerviosas (Kriegstein y Alvarez-Buylla, 2009). A nivel celular y molecular, participan en la regulación de la concentración de iones, neurotransmisores y hormonas en el SNC. Por este motivo, los astrocitos son considerados las principales células quimiorreceptoras del cerebro, y son capaces de detectar variaciones en la concentración del $\mathrm{CO}_{2}$, del $\mathrm{pH}$ y del $\mathrm{Na}^{+}$ (Shimizu y col., 2007; Gourine y Kasparov, 2011).

Un ejemplo notable de la función quimiorreceptora y homeostática de los astrocitos es la regulación de la $\left[\mathrm{K}^{+}\right]$extracelular en el SNC. En condiciones fisiológicas en el SNC, el ión $\mathrm{K}^{+}$se encuentra en torno a $3 \mathrm{mM}$ en el espacio extracelular, mientras que durante la actividad neuronal, la $\left[\mathrm{K}^{+}\right]$extracelular puede aumentar hasta 4-4.2 mM. Esto se debe a que, durante la transmisión del impulso nervioso, las neuronas captan iones $\mathrm{Na}^{+}$y $\mathrm{Ca}^{2+}$ durante la despolarización, y, posteriormente, para recuperar el potencial de reposo de la membrana plasmática, evento conocido como repolarización, se produce una salida de iones $\mathrm{K}^{+}$hacia el medio externo, incrementando la concentración de dicho ión en el espacio extracelular. Este aumento del $\mathrm{K}^{+}$extracelular despolariza la membrana plasmática e incrementa la excitabilidad de las neuronas, ya que mantiene el potencial de membrana de las células más cercano a su umbral, facilitando el disparo de potenciales de acción y la liberación de neurotransmisores. 


\begin{tabular}{|c|c|}
\hline \multicolumn{2}{|r|}{ FUNCIONES DE LA GLÍA } \\
\hline Desarrollo del SNC & $\begin{array}{l}\text { Neurogénesis } \\
\text { Migración de células neurales y formación de capas en la materia } \\
\text { gris } \\
\text { Sinaptogénesis }\end{array}$ \\
\hline Soporte estructural & $\begin{array}{l}\text { Empaquetamiento de la materia gris } \\
\text { Formación de la unidad neuro-vascular }\end{array}$ \\
\hline Función de barrera & $\begin{array}{l}\text { Regulación de la formación y permeabilidad de las barreras } \\
\text { sangre-cerebro y líquido cefalorraquídeo-cerebro }\end{array}$ \\
\hline $\begin{array}{c}\text { Función } \\
\text { homeostática }\end{array}$ & $\begin{array}{l}\text { Control } \mathrm{K}^{+} \text {extracelular } \\
\text { Control } \mathrm{pH} \text { extracelular } \\
\text { Regulación del transporte de agua } \\
\text { Retirada de neurotransmisores del espacio extracelular }\end{array}$ \\
\hline Soporte metabólico & $\begin{array}{l}\text { Captación de glucosa y almacenamiento de glucógeno } \\
\text { Suministro de sustancias energéticas, como el lactato a las } \\
\text { neuronas dependiendo de su actividad }\end{array}$ \\
\hline $\begin{array}{l}\text { Transmisión } \\
\text { sináptica }\end{array}$ & $\begin{array}{l}\text { Regulación y mantenimiento de la sinapsis } \\
\text { Suministro de glutamato para la transmisión sináptica } \\
\text { Regulación de la plasticidad sináptica } \\
\text { Regulación humoral de las redes neuronales a través de la } \\
\text { secreción de neurotransmisores y neuromoduladores }\end{array}$ \\
\hline $\begin{array}{l}\text { Regulación del flujo } \\
\text { sanguíneo }\end{array}$ & $\begin{array}{l}\text { Regulación del flujo sanguíneo local por secreción de sustancias } \\
\text { vasoactivas: vasoconstrictores o vasodilatadores }\end{array}$ \\
\hline $\begin{array}{l}\text { Funciones } \\
\text { cerebrales }\end{array}$ & $\begin{array}{l}\text { Quimiorecepción-regulación de la homeostasis del } \mathrm{Na}^{+} \\
\text {Quimiorecepción-regulación del } \mathrm{CO}_{2} \text { y ventilación } \\
\text { Sueño } \\
\text { Memoria y aprendizaje }\end{array}$ \\
\hline $\begin{array}{l}\text { Funciones de } \\
\text { defensa, } \\
\text { neuroprotección y } \\
\text { remodelado post } \\
\text { lesión cerebral }\end{array}$ & $\begin{array}{l}\text { Astrogliosis reactiva, isomórfica y anisomórfica } \\
\text { Cicatriz glial } \\
\text { Catabolismo del amonio en el cerebro } \\
\text { Respuesta inmune y secreción de factores pro-inflamatorios } \\
\text { (citoquinas, quimoquinas y moduladores inmunes). }\end{array}$ \\
\hline
\end{tabular}

Tabla 1. Funciones de los astrocitos en condiciones fisiológicas y patológicas (Verkhratsky, 2013). 
Los astrocitos, por su parte, perciben incrementos en la $\left[\mathrm{K}^{+}\right]$extracelular, y son los encargados de aclarar el $\mathrm{K}^{+}$acumulado (Olsen y Sontheimer, 2008). El canal rectificador de $\mathrm{K}^{+} \mathrm{Kir} 4.1$, presente en la membrana plasmática de los astrocitos, es uno de los principales componentes encargados de la disipación del $\mathrm{K}^{+}$extracelular. El potencial de reposo de la membrana plasmática de los astrocitos es aproximadamente de $-90 \mathrm{mV}$. Este valor tan próximo al potencial de equilibrio para el $\mathrm{K}^{+}$está determinado por la alta permeabilidad a $\mathrm{K}^{+}$de su membrana. Los iones $\mathrm{K}^{+}$captados en los lugares de alto $\mathrm{K}^{+}$son transferidos a través de una red de astrocitos interconectados entre sí, y finalmente, liberados a los vasos sanguíneos a través de canales Kir4.1 o a través de canales BK de $\mathrm{K}^{+}$, desde los procesos terminales del pie astrocítico (revisado por Berridge, 2014). En condiciones patológicas se produce una alteración de los mecanismos de aclaramiento del $\mathrm{K}^{+}$del medio extracelular. Así, por ejemplo, durante los episodios epilépticos, la concentración de $\mathrm{K}^{+}$extracelular puede aumentar hasta 10-12 mM, y en una isquemia cerebral hasta 50-60 mM (Kofuji y Newman, 2004; Olsen y Sontheimer, 2008).

Otra función de los astrocitos es el acoplamiento neurovascular en respuesta a la actividad neuronal, que permite a la astrogía regular el flujo sanguíneo mediante la secreción de moléculas vasoactivas, ya sea con efecto vasodilatador como el ácido araquidónico, o con efecto vasoconstrictor como la ciclooxigenasa (COX), la prostaglandina F2 (PGF2), el tromboxano A2, las endotelinas o el ácido 20-hidroxieicosatetraenoico (20-HETE), con el objetivo de facilitar la obtención de nutrientes y oxígeno por las neuronas (Haydon y Carmignoto, 2006).

Por último, los astrocitos también participan en la homeostasis metabólica, almacenando glucógeno para proveer de sustratos energéticos a las neuronas mediante la lanzadera lactato-piruvato astrocito-neurona. Las neuronas son responsables de la mayor parte (alrededor del 90\%) de la demanda energética del cerebro, ya que para recuperar su potencial de reposo tras una despolarización de la membrana plasmática realizan un elevado gasto energético. Se ha comprobado que la actividad sináptica neuronal estimula la glucólisis en los astrocitos, generando lactato, que transfiere a las neuronas. El 
metabolismo de la glucosa en los astrocitos se produce a través de la glicólisis aeróbica, mediante la cual la glucosa se convierte en piruvato y luego en lactato. Esta última etapa es catalizada por la enzima lactato deshidrogenasa tipo 5 (LDH5), que se expresa exclusivamente en los astrocitos. El lactato producido se libera al medio extracelular, desde donde es captado por las neuronas mediante los transportadores de carboxilato 1 y 2 (MCT-1 y 2). Una vez en el interior de la neurona, el lactato es convertido a piruvato por acción de la lactato deshidrogenasa tipo 1 (LDH1), para entrar finalmente en el ciclo de los ácidos tricarboxílicos (TCA) y producir energía (17 moléculas de ATP por molécula de lactato) (Pellerin y Magistretti, 1994).

En base a evidencias experimentales tanto en cultivos primarios como en secciones de cerebro, se ha comprobado que los astrocitos actúan como sensores muy sensibles de la actividad neuronal, gracias a que expresan un elevado número de receptores de neurotransmisores. La información recibida es integrada por los astrocitos mediante señales de $\mathrm{Ca}^{2+}$ intracelular, que pueden desencadenar la secreción de una gran variedad de moléculas, como describiremos más adelante. Los procesos de los astrocitos son capaces de contactar hasta con 150.000 sinapsis, y responder mediante oscilaciones y transitorios de $\mathrm{Ca}^{2+}$ cuando detectan actividad neuronal. (Smith, 1994; Pfrieger y Barres, 1996; Codazzi y col., 2001).

Los astrocitos pueden sintetizar y liberar un gran número de moléculas neuroactivas como péptidos, eicosanoides o neurotrofinas (Martin y col., 1992). Precisamente el término "gliotransmisores" se ha acuñado para referirse a las moléculas secretadas por los astrocitos de manera $\mathrm{Ca}^{2+}$ dependiente e implicadas en la comunicación intercelular (Perea y Araque, 2010). La secreción de estas moléculas se produce como consecuencia de la activación de receptores acoplados a las proteínas Gq (GPCR) de los astrocitos (Parpura y col., 1994). Las elevaciones de $\mathrm{Ca}^{2+}$ producidas en la astroglía son necesarias y suficientes para inducir la liberación de los gliotransmisores. Entre los principales gliotransmisores descritos se incluyen el glutamato (Parpura y col., 1994), el ATP (Coco y col., 2003) y la D-serina (Mothet y col., 2005). Estos, a su vez, ejercen un papel paracrino sobre las neuronas tanto pre-como 
post-sinápticas, uniéndose a los receptores específicos de las mismas y modulando su actividad sináptica (Tu y col., 2006). Recíprocamente, como ya hemos mencionado, los astrocitos pueden ser estimulados por neurotransmisores liberados en las terminales pre-sinápticas (Porter y McCarthy, 1996; Navarrete y Araque, 2008).

Numerosos estudios han aportado evidencias acerca de esta comunicación bidireccional entre los astrocitos y las neuronas (Araque y col., 1998). Por ejemplo, se ha demostrado que la liberación sináptica de glutamato en las neuronas puede desencadenar el incremento de la concentración de $\mathrm{Ca}^{2+}$ citosólico $\left(\left[\mathrm{Ca}^{2+}\right] \mathrm{c}\right.$ ) en astrocitos in situ (Porter y McCarthy, 1996; Navarrete y Araque, 2008). Estudios in vivo, en ratas anestesiadas, demostraron que la liberación de neurotransmisores provoca incrementos del $\mathrm{Ca}^{2+}$ citosólico en los astrocitos vecinos. Estos resultados pusieron en evidencia la comunicación neurona-glía en el cerebro intacto. A partir de estas observaciones se acuñó el término "sinapsis tripartita" (Perea y Araque, 2010), para referirse a la comunicación bidireccional entre astrocitos y neuronas. El término deriva del concepto clásico del flujo de información "bipartita" que existe entre las neuronas pre- y post-sinápticas. En la Figura 2 se muestra un esquema de la sinapsis tripartita, donde los astrocitos son capaces de integrar y procesar la información sináptica, controlando de este modo la transmisión sináptica y la plasticidad. Además se han descrito modos de acción de los gliotransmisores que desempeñan un papel activo en la función sináptica neuronal, el procesamiento, la transmisión y el almacenamiento de información en el SN (Perea y Araque, 2010). 


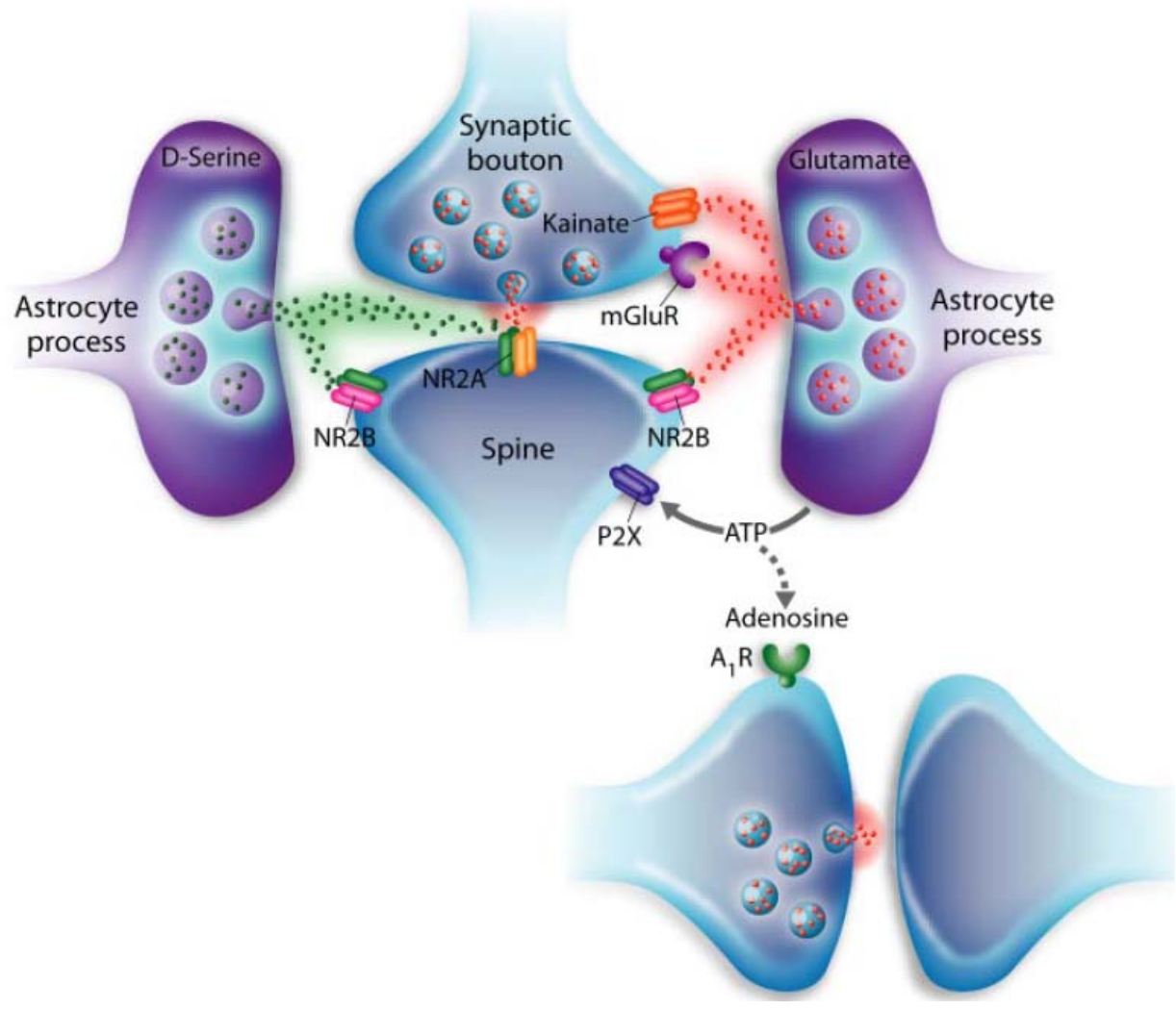

Figura 2. Sinapsis tripartita. Los astrocitos pueden regular la transmisión sináptica actuando tanto a nivel pre- como postsináptico. El glutamato, la D- serina, y el ATP, liberados por los astrocitos, actúan sobre las sinapsis: Presinápticamente, el glutamato puede actuar sobre receptores metabotrópicos de glutamato y sobre receptores de kainato para mejorar la transmisión sináptica. Postsinápticamente, el glutamato puede actuar sobre los receptores de NMDA para despolarizar la membrana neuronal y promover la sincronía neuronal. La D-serina actúa en el sitio de unión de glicina de receptores de NMDA, regulando la plasticidad sináptica. El ATP también puede actuar a nivel postsináptico sobre los receptores P2X para despolarizar la membrana neuronal. Por último, la hidrólisis del ATP por ectonucleotidasas da lugar a la adenosina, que puede tener acción sobre los receptores presinápticos $A 1$ causando una depresión de la transmisión sináptica excitatoria (Figura modificada de Haydon y Carmignoto, 2006).

\section{Principios de la señalización por $\mathrm{Ca}^{2+}$ en astrocitos}

El ión $\mathrm{Ca}^{2+}$ es el mensajero intracelular más ubicuo, y está involucrado en la señalización de diferentes procesos, como por ejemplo, la fertilización, la proliferación, la apoptosis, la contracción muscular y la exocitosis (revisado por Berridge y col., 2003). Dicha versatilidad se debe a que el ión $\mathrm{Ca}^{2+}$ puede unirse a proteínas que ligan $\mathrm{Ca}^{2+}$ y controlar de este modo sus respectivas funciones. Esto es posible debido a sus características: una estructura química de coordinación flexible, una alta afinidad por el oxígeno del carboxilato (el 
motivo más frecuente en los aminoácidos) y una cinética de unión rápida (Jaiswal, 2001). Sin embargo, una acumulación excesiva y mantenida de $\mathrm{Ca}^{2+}$ en el citosol puede ser perniciosa, ya que se produce agregación de proteínas, afecta la integridad de los lípidos de las membranas y puede provocar la precipitación de fosfatos. Por este motivo, la $\left[\mathrm{Ca}^{2+}\right]_{\mathrm{c}}$ se mantiene en niveles extremadamente bajos (típicamente alrededor de $100 \mathrm{nM}$ ) en la mayoría de las células incluidos los astrocitos, cuya $\left[\mathrm{Ca}^{2+}\right]_{\mathrm{c}}$ se encuentra entre $30-300 \mathrm{nM}$ en condiciones de reposo (Verkhratsky y col., 1998). En cambio, en el medio extracelular, la $\left[\mathrm{Ca}^{2+}\right]$ se encuentra en el rango de 1-2 mM, $10^{4}$ veces más concentrado que en el citosol, lo que genera un enorme gradiente de concentración de $\mathrm{Ca}^{2+}$.

\subsection{Canales de $\mathrm{Ca}^{2+}$ de la membrana plasmática}

La entrada de $\mathrm{Ca}^{2+}$ al citosol puede producirse por activación de diferentes vías: los canales de $\mathrm{Ca}^{2+}$ activados por voltaje (VOCs), los canales de potencial transitorio (TRPs), los canales de $\mathrm{Ca}^{2+}$ activados por vaciamiento de los depósitos intracelulares (SOCs) y los canales de $\mathrm{Ca}^{2+} /$ receptores operados por ligando, que pueden subdividirse en canales ionotrópicos y en receptores metabotrópicos (Fig. 3). A continuación describiremos cada uno de ellos con más detalle.

\subsubsection{Canales de $\mathrm{Ca}^{2+}$ operados por voltaje (VOCs)}

Los canales dependientes de voltaje presentes en la membrana plasmática se abren en respuesta a una despolarización capaz de superar su umbral de activación, permitiendo una rápida entrada de iones desde el medio extracelular al citosol a favor de su gradiente electroquímico. Los canales VOCs están formados por diferentes subunidades $(\alpha 1, \beta, \alpha 2 \delta)$. La subunidad $\alpha 1$ es la más grande y está formada por cuatro dominios, cada uno con seis helices $\alpha$ transmembrana que forman el poro del canal selectivo para $\mathrm{Ca}^{2+}$. Las subunidades $\beta$ y $\alpha 2 \delta$ anclan el canal a la membrana plasmática y regulan su actividad. Existen varios subtipos de canales VOCs que se clasifican en 
canales $\mathrm{L}, \mathrm{N}, \mathrm{P}, \mathrm{Q}, \mathrm{R}$ y $\mathrm{T}$, en base a sus propiedades biofísicas y farmacológicas, como su umbral y cinética de apertura, sus propiedades de activación e inactivación, y su sensibilidad a agonistas y antagonistas (Catterall, 2011).

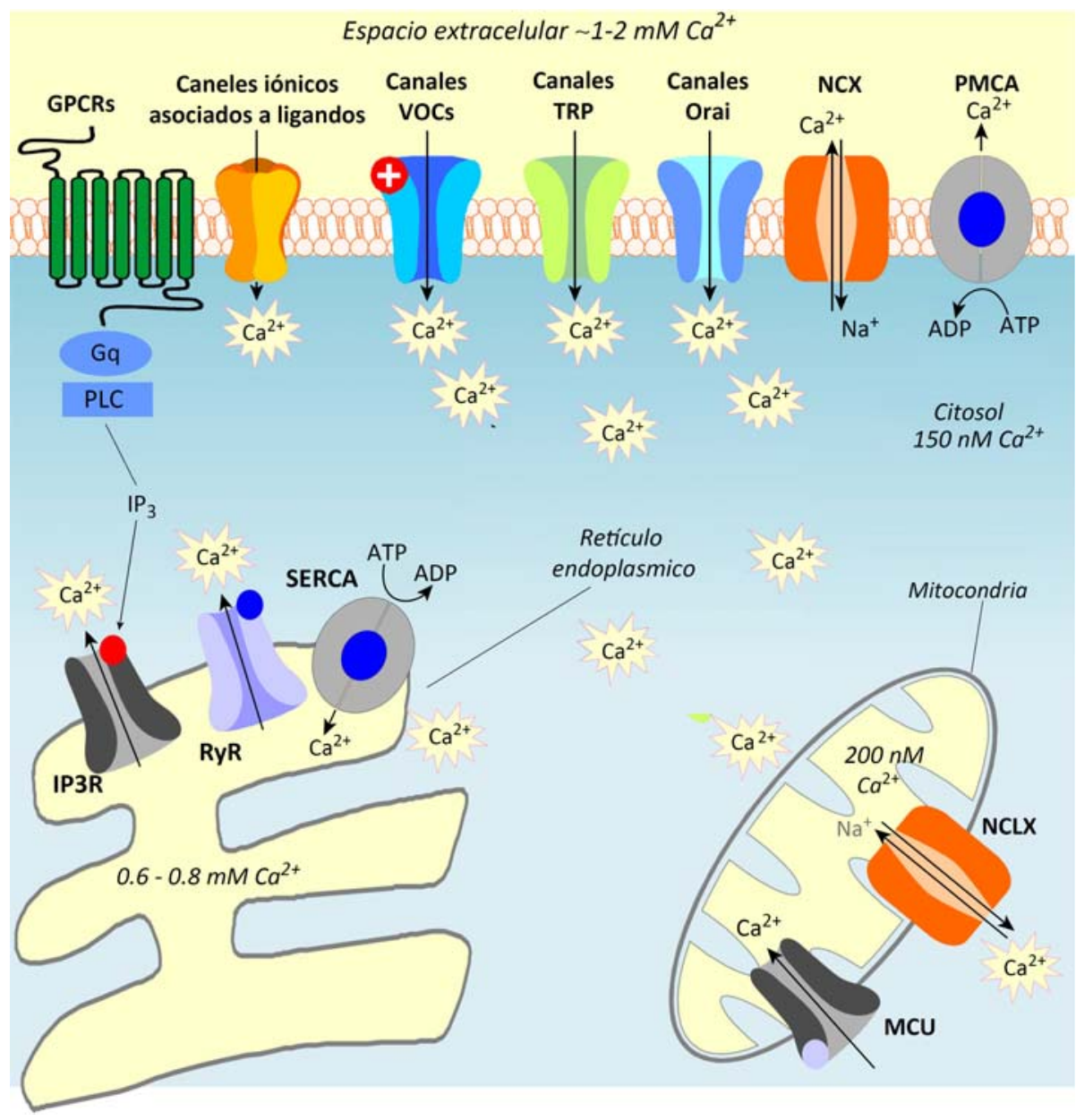

Figura 3. Principios de señalización por $\mathrm{Ca}^{2+}$ en astrocitos. La entrada de $\mathrm{Ca}^{2+}$ extracelular al citosol en astrocitos puede ocurrir a través de canales iónicos asociados a ligandos, de canales de $\mathrm{Ca}^{2+}$ dependientes de voltaje (VOCs), de canales TRPs de la membrana plasmática o de los canales Orai. Los receptores metabotrópicos acoplados a proteínas $\mathrm{G}$ de la membrana plasmática (GPCR), activan a la fosfolipasa $C$ (PLC) que genera inositol tri-fosfato $\left(\mathrm{IP}_{3}\right)$, el cual puede liberar $\mathrm{Ca}^{2+}$ del $\mathrm{RE}$ a través del $I P_{3} R$. Adicionalmente, el receptor de rianodina (RyR) de la membrana del RE también puede liberar $\mathrm{Ca}^{2+}$ del $\mathrm{RE}$, cuando es activado por incrementos de $\mathrm{Ca}^{2+}$ citosólico. Entre los componentes responsables de retirar el $\mathrm{Ca}^{2+}$ del citosol se encuentran, las $\mathrm{Ca}^{2+}$ ATPasas de la membrana plasmática (PMCA) y del RE (SERCA), que bombean el $\mathrm{Ca}^{2+}$ desde citosol hacia el medio extracelular o hacia el lumen del RE respectivamente. El intercambiador $\mathrm{Na}^{+} / \mathrm{Ca}^{2+}(\mathrm{NCX})$ expulsa el $\mathrm{Ca}^{2+}$ hacia el medio externo. La mitocondria puede captar $\mathrm{Ca}^{2+}$ del citosol a través de canales iónicos dependientes de voltaje (VDAC), y mediante el uniportador mitocondrial utilizando el gradiente electroquímico. La liberación de $\mathrm{Ca}^{2+}$ de la mitocondria puede producirse a través del intercambiador mitocondrial $\mathrm{Na}^{+} / \mathrm{Ca}^{2+} \mathrm{O}$ por la apertura del poro de permeabilidad transitoria (MPTP) (Figura modificada de Shigetomi y col., 2016). 
Los VOCs son particularmente importantes en las células eléctricamente excitables como las neuronas, las células musculares y las células secretoras. En el caso de la glía, al no ser consideradas células eléctricamente excitables, durante mucho tiempo se pensó que no respondían a variaciones de voltaje. Sin embargo, en los últimos años se han encontrado evidencias de la expresión de VOCs funcionales en astrocitos (Verkhratsky y Steinhauser, 2000). Concretamente, en astrocitos primarios, se ha descrito la presencia de canales tipo N, L, R y T, pero no de los canales tipo P/Q (Latour y col., 2003). Además, en astrocitos in situ se han encontrado canales de tipo L, que aumentarían su expresión en respuesta a lesiones cerebrales, hipomielización o isquemia (Westenbroek y col., 1998). Estudios funcionales, mostraron que una fuerte despolarización de la membrana plasmática de los astrocitos provocaba un incremento de la $\left[\mathrm{Ca}^{2+}\right]_{\mathrm{c}}$ mediada por los canales VOCs, y, a su vez, que este incremento provocó una liberación de glutamato al medio extracelular (Yaguchi y Nishizaki, 2010). En cortes de tálamo ventrobasal se ha descrito también que la activación de los VOCs de tipo $L$ puede desencadenar oscilaciones de $\mathrm{Ca}^{2+}$ en astrocitos. A pesar de estos datos, el tema es discutible, ya que algunos trabajos afirman que los VOCs no producen incrementos de $\mathrm{Ca}^{2+}$ en astrocitos.

\subsubsection{Canales TRP}

Los canales TRP (Receptores de potencial transitorio), están localizados en la membrana plasmática y no son selectivos para $\mathrm{Ca}^{2+}$, también son permeables a $\mathrm{Na}^{+}$(Owsianik y col., 2006). Están implicados en la detección de estímulos sensoriales como, por ejemplo, cambios de temperatura, equilibrio osmótico, la nocicepción o la quimiorecepción. Están formados por cuatro subunidades, cada una de ellas con seis dominios transmembrana, y sus dominios C- y N-terminales están orientados hacia el lado citosólico (Clapham, 2007b). En vertebrados se conocen 28 miembros de la superfamilia de los TRP, clasificados en 7 familias: TRPC (Canónico), TRPM (Melastina), TRPV (Vaniloide), TRPA (Anquirina), TRPP (Policistina), TRPML (Mucopilina) y TRPN (No mecanoreceptor). En astrocitos se ha confirmado la expresión de TRPA1, TRPC 1/4/5 y TRPV4 (Fig. 4) (revisado por Verkhratsky y col., 2013b). 


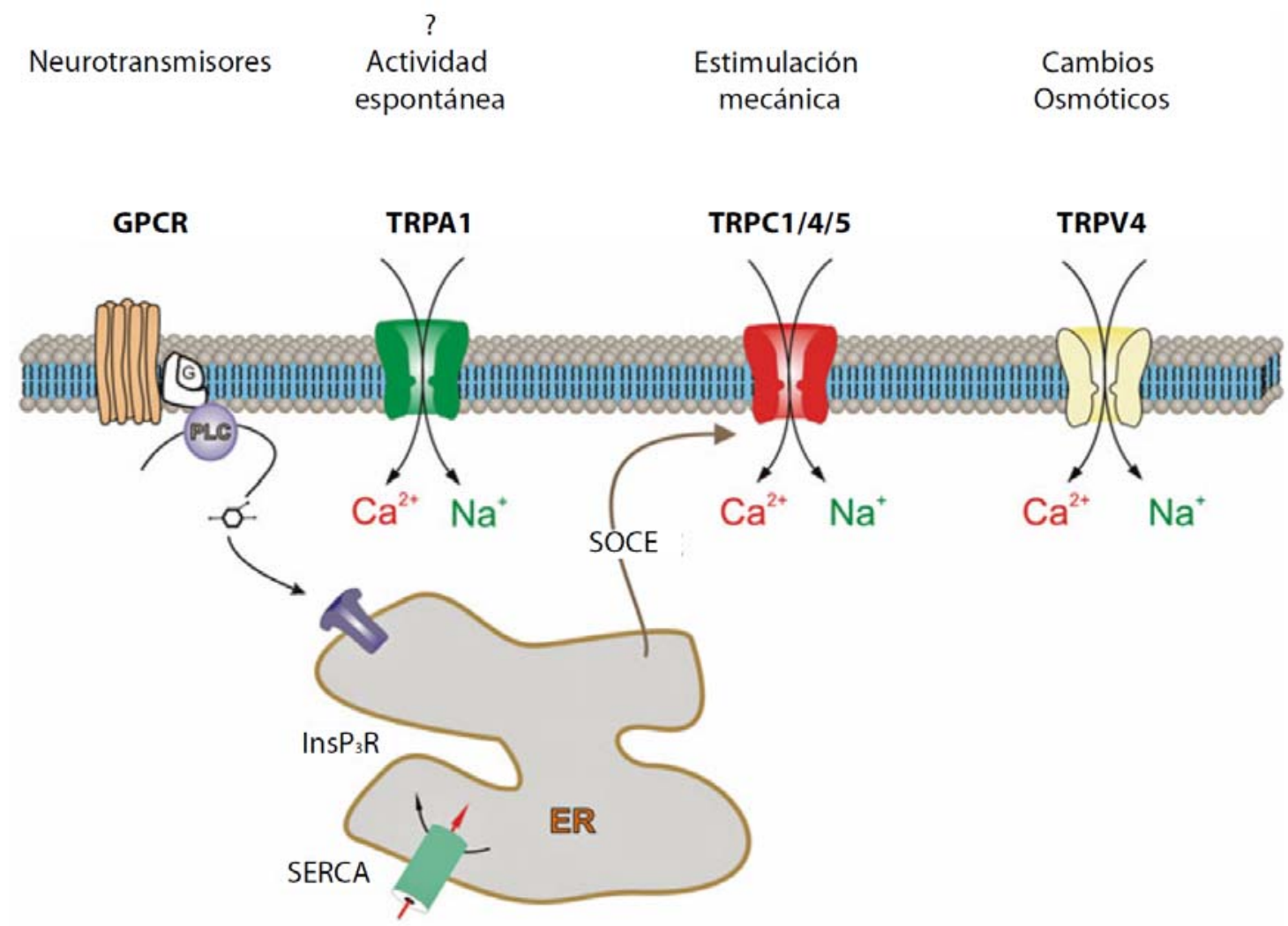

Figura 4. Canales TRP presentes en astrocitos. Se ha propuesto que existe relación entre la estimulación metabotrópica, los canales TRPC y la entrada capacitativa SOCE (se explica con mayor detalle en el texto principal) (Figura modificada de Verkhratsky y col., 2013b).

El TRPA1 está implicado en la regulación de la expresión de los transportadores de GABA. Es un canal de alta conductancia y permeabilidad a $\mathrm{Ca}^{2+}$. Puede ser activado por el frío (por debajo de $17 \mathrm{C}^{\circ}$ ), por sustancias picantes derivadas de plantas, por factores de crecimiento y por factores proinflamatorios. En cultivos de astrocitos se han observado transitorios espontáneos de $\mathrm{Ca}^{2+}$ asociados con la actividad de este canal, que fueron inhibidos por $\mathrm{Gd}^{3+}, \mathrm{La}^{3+}$ y un antagonista de los canales TRP, el HC030031 (Butenko y col., 2012). Los canales TRPC pueden ser activados por la PLC, el DAG y por estimulación mecánica. En astrocitos se han encontrado los TRPC tipo 1, 4 y 5. EI TRPC1 es responsable de la entrada de calcio operada por depósitos en estas células, como se comentará posteriormente. Finalmente, el TRPV4 se ha descrito en astrocitos de corteza y de hipocampo. Se activa por cambios osmóticos y está involucrado en la regulación del volumen celular. 
También se ha descrito que este receptor se sobre-expresa en isquemias (Kwon y col., 2017).

\subsubsection{Canales de $\mathrm{Ca}^{2+}$ activados por vaciamiento de los depósitos intracelulares (SOCE)}

La entrada de $\mathrm{Ca}^{2+}$ operada por depósitos intracelulares (SOCE), también llamada entrada capacitativa, es un fenómeno que conecta el vaciamiento de los depósitos intracelulares de $\mathrm{Ca}^{2+}$ con la activación de canales de $\mathrm{Ca}^{2+}$ de la membrana plasmática para permitir el rellenado del RE. A nivel molecular se forma un complejo proteico llamado STIM1/Orai, donde STIM es una proteína transmembrana del RE que actúa como un sensor del $\mathrm{Ca}^{2+}$ luminal, y se encarga de transmitir la señal de vaciamiento del RE al canal Orai de la membrana plasmática, altamente selectivo para $\mathrm{Ca}^{2+}$, activándolo $\mathrm{y}$ desencadenando un flujo de entrada de $\mathrm{Ca}^{2+}$ desde el medio extracelular. El $\mathrm{Ca}^{2+}$ que entra al citosol será finalmente bombeado al RE por la SERCA para permitir su rellenado. La entrada de $\mathrm{Ca}^{2+}$ a través de SOCE está presente en todos los tipos de glía, aunque la identidad molecular de sus componentes no ha sido aún completamente esclarecida (Verkhratsky y col., 2012).

En astrocitos, resultados in vitro e in situ han demostrado que el mecanismo SOCE está mediado por canales TRP. Como hemos mencionado en el apartado anterior, los astrocitos (tanto aislados frescos como en cultivo) expresan los canales TRP canónicos (TRPC) formados por la proteína TRPC1 combinada con, bien TRPC4 y/o TRPC5 (Malarkey y col., 2008; Parpura y col., 2011). Cuando se produce una depleción del $\mathrm{Ca}^{2+}$ del $\mathrm{RE}$, las moléculas de STIM oligomerizan y pueden contactar con los canales TRPC de la membrana plasmática para activar la entrada de $\mathrm{Ca}^{2+}$ al citosol. El silenciamiento del canal TRPC1, mediante experimentos con oligonucleótidos anti-sentido o la inhibición con anticuerpos específicos contra la región formadora del poro, suprimen significativamente la entrada capacitativa de $\mathrm{Ca}^{2+}$ (Malarkey y col., 2008). En la mayoría de las células no excitables, los canales clásicos de $\mathrm{Ca}^{2+}$ (CRACs) producen corrientes activadas por liberación de $\mathrm{Ca}^{2+}$ (I-CRAC). Sin embargo, estas corrientes no han sido aún detectadas en astrocitos. Se han descrito similitudes entre los perfiles farmacológicos de SOCE de astroglía y de una 
línea celular de leucemia basofílica de rata, que expresa las proteínas STIM1 y Orai, relacionadas con el canal CRAC. Recientemente se ha descrito que los canales Orai1 y Orai3 en combinación con Stim1 son los principales componentes que participan en el mecanismo SOCE en astrocitos cultivados. Se ha descrito la expresión de Stim1 y Stim 2, aunque Stim1 es la isoforma predominante. Además, numerosos trabajos han descrito la participación de Orai 1-3, y de TRPC1 en el SOCE de astrocitos (Kraft, 2015).

\subsubsection{Canales/receptores operados por ligando}

Los receptores ionotrópicos son canales transmembrana que forman un poro permeable a diferentes iones y al ser activados por su ligando específico permiten la entrada directa de $\mathrm{Ca}^{2+}$ desde el medio extracelular al citosol. La fuerza que gobierna el movimiento de estos iones está determinada por un gradiente electroquímico, por lo tanto, depende de la concentración de un determinado ión a cada lado de la membrana plasmática, y del grado de polarización de la misma. El flujo de iones puede modificar frecuentemente el potencial de la membrana plasmática, despolarizandola o hiperpolarizandola.

Los astrocitos expresan un amplio abanico de receptores ionotrópicos, que pueden subdividirse, en base al número de subunidades que conforman el canal, en tres tipos principales (Fig. 5). En primer lugar, el grupo de los receptores pentaméricos, conformado por cinco subunidades transmembrana. Este grupo representa la mayor parte los receptores ionotrópicos, e incluye los de nicotínicos de acetilcolina ( $\mathrm{nACh}$ ), los de $\mathrm{GABA}_{\mathrm{A}}$, y los de glicina. Este tipo de canales pueden ser catiónicos o aniónicos, provocando una despolarización o una hiperpolarización de la membrana, respectivamente. En segundo lugar, encontramos los receptores ionotrópicos tetraméricos, representados por los receptores de glutamato; y, por último, los triméricos que corresponden a los receptores ionotrópicos purinérgicos P2X (Palygin y col., 2010; Verkhratsky y col., 2013a). 


\section{A. Canales/receptores de nACh, $\mathrm{GABA}_{A}, \mathrm{y}$ Glicina \\ B. Canales/receptores de glutamato \\ C. Canales/receptores de ATP}

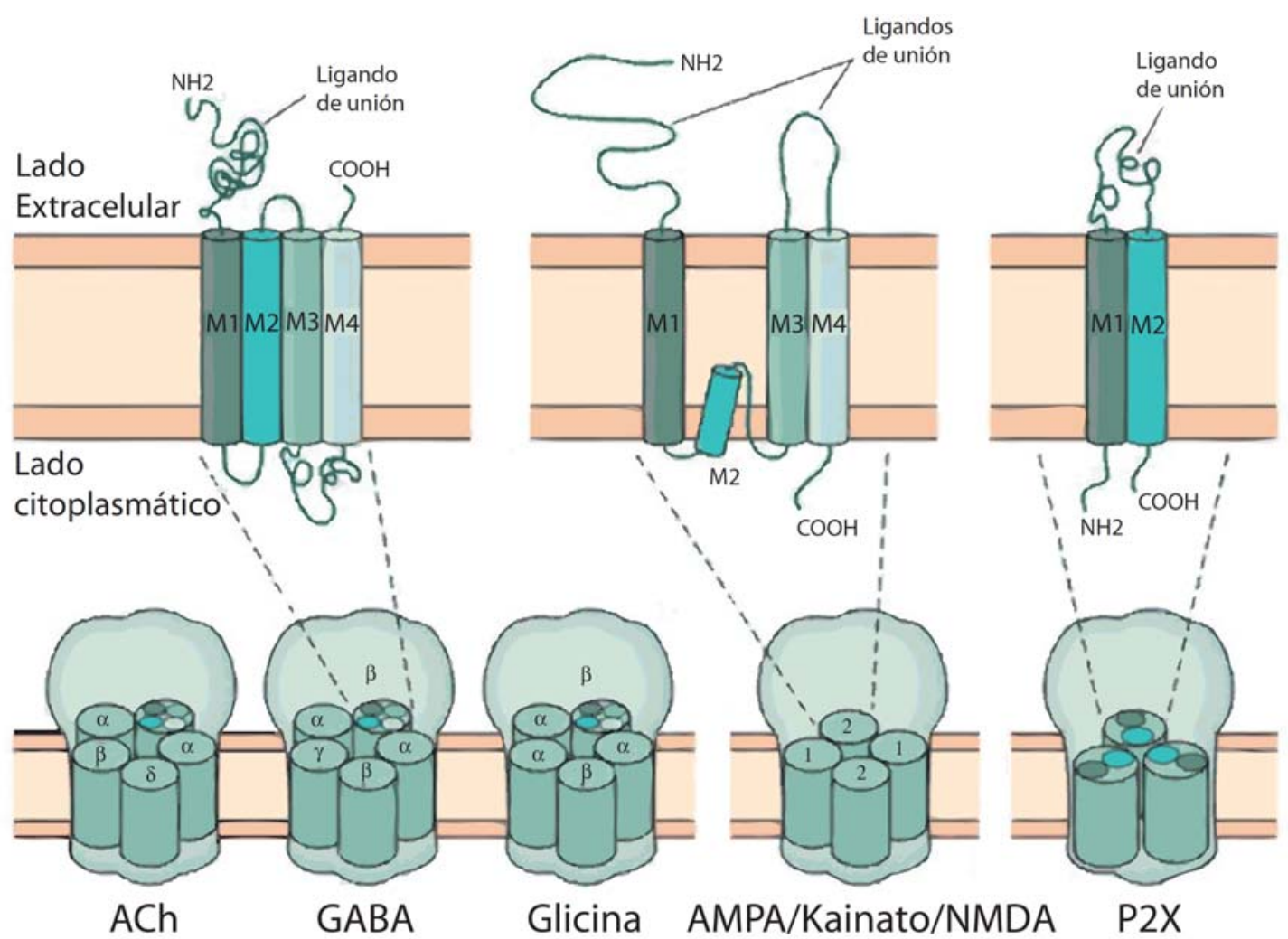

Figura 5. Organización estructural de los receptores ionotrópicos expresados en astrocitos. A. El grupo de los receptores pentaméricos está conformado por cinco subunidades transmembrana, e incluye los receptores de acetilcolina (nACh), los de $\mathrm{GABA}_{\mathrm{B}}$, y los de glicina. B. Los receptores ionotrópicos tetraméricos, representados por los receptores de glutamato. C. Los receptores triméricos que incluyen ionotrópicos purinérgicos P2X (Figura modificada de Kandel, 2000).

Los receptores metabotrópicos son receptores acoplados a proteínas G (GPCRs), proteínas que unen GTP y activan la cascada de señalización del $\mathrm{Ca}^{2+}$ (Fig. 3) (Pin y Duvoisin, 1995). Los GPCRs de astrocitos se asocian principalmente con proteínas Gq (Agulhon y col., 2008), que, a su vez, activan a la fosfolipasa C (PLC). Esta es la enzima resonsable de hidrolizar el fosfatidilinositol 4,5 bisfosfato (PIP2), dando lugar a diacilglicerol (DAG) y al inositol 1, 4, 5-trisfosfato $\left(\mathrm{IP}_{3}\right)$ (Kastritsis y col., 1992; Hamilton y col., 2008; Kirischuk y col., 2012). Este último puede activar, finalmente, al receptor de $\mathrm{IP}_{3}$ $\left(\mathrm{IP}_{3} \mathrm{R}\right)$ presente en la membrana del retículo endoplásmico, y liberar el $\mathrm{Ca}^{2+} \mathrm{de}$ los depósitos intracelulares. La cascada del IP 3 está muy bien caracterizada en astrocitos, ya que estas células expresan una gran cantidad de GPCRs. Por 
ejemplo, en astrocitos del stratum radiatum de la región CA1 del hipocampo, se observaron elevaciones de la $\left[\mathrm{Ca}^{2+}\right]_{\mathrm{c}}$ al activar los receptores purinérgicos $\mathrm{P} 2 \mathrm{Y}$ (Bowser y Khakh, 2007), los adrenérgicos (Duffy y MacVicar, 1995), los muscarínicos de acetilcolina (Fiacco y col., 2007), los glutamatérgicos (Shelton y McCarthy, 1999), los GABAérgicos de tipo B (Serrano y col., 2006), los de endocanabinoides (Navarrete y Araque, 2008), los colinérgicos y los histamínicos (Shelton y McCarthy, 2000). Por otra parte, en la glía de Bergmann del cerebelo, se demostró que la estimulación eléctrica de las neuronas provoca la liberación de neurotransmisores, que, a su vez, activan diferentes receptores en la glía, como los alfa adrenérgicos, los purinérgicos o los de glutamato, provocando incrementos en la $\left[\mathrm{Ca}^{2+}\right]_{\mathrm{c}}$. En tejido aislado de retina de rata, la estimulación de las neuronas con su estímulo fisiológico (luz) produce liberación de ATP que activa los receptores purinérgicos en la glía (Agulhon y col., 2008). A continuación, se describirán los dos tipos principales de receptores estudiados en esta Tesis, el de glutamato y el de ATP.

\subsubsection{Receptores glutamatérgicos}

El glutamato es el principal neurotransmisor excitatorio en el SNC de mamíferos, es capaz de activar los receptores de la membrana plasmática de astrocitos, tanto ionotrópicos (iGluRs) como metabotrópicos (mGluRs) (Verkhratsky y col., 1998) (Fig. 6). Los primeros forman un canal catiónico con diferente selectividad iónica según el tipo de receptor, siendo permeables a $\mathrm{Na}^{+}, \mathrm{K}^{+}$y, en ocasiones, a Ca ${ }^{2+}$ (Nakanishi, 1992; Hollmann y Heinemann, 1994).

Los iGluRs están formados por tetrámeros compuestos por diferentes subunidades (Fig. 5), y dependiendo de la combinación de estas últimas, el canal adquiere diferentes propiedades. Pueden subdividirse en tres clases principales en base a su estructura molecular y sus propiedades biofísicas y farmacológicas, cada clase toma su nombre del ligando específico al que se une. Así se distinguen, el receptor activado por el ácido $\alpha$-amino-3-hidroxi-5metil-4-isoxazolpropiónico (AMPA); el receptor activado por N-metil-D-aspartato 
(NMDA); y, el receptor activado por kainato (KA) (Parpura y col., 2011). Los astrocitos expresan las tres clases de iGluR.

Los receptores de AMPA están formados por cuatro subunidades, GluA1 a GluA4, que pueden ensamblarse en diferentes combinaciones. Además, cada subunidad puede aportar diferentes permeabilidades a $\mathrm{Na}^{+}$y a K $\mathrm{K}^{+}$. En ciertos casos, la permeabilidad a $\mathrm{Na}^{+}$puede provocar una despolarización de la membrana plasmática y activar los canales VOCs, resultando en la entrada de $\mathrm{Ca}^{2+}$ desde el medio extracelular. Asimismo, cuando la subunidad GluA2 está ausente, el canal adquiere también permeabilidad a $\mathrm{Ca}^{2+}$. Los receptores AMPA están presentes en la mayor parte del SNC, desde la corteza cerebral, el hipocampo, el cerebelo, el cuerpo calloso y la retina, hasta la médula espinal (Seifert y Steinhauser, 2001). En los astrocitos se han encontrado las cuatro subunidades que conforman los receptores AMPA, aunque sus combinaciones son diferentes en las distintas regiones del cerebro. En los astrocitos de hipocampo, por ejemplo, predominan los subtipos GluA2 y GluA4, mientras que en los de la medula espinal se expresa tanto los GluA4 como los GluA2/3, y en los astrocitos corticales son más abundantes los receptores GluA1 y los GluA4. Con respecto a su funcionalidad, tanto en astrocitos cultivados como en secciones de tejido se han identificado señales de $\mathrm{Ca}^{2+}$ originadas a partir de flujos resultantes de la estimulación de canales AMPA (Verkhratsky y Kirchhoff, 2007a).

Los receptores de NMDA son permeables a $\mathrm{Ca}^{2+}$ y en la astroglía los tetrámeros están formados por dos subunidades NR1, una NR2 y una NR3 (Lalo y col., 2006). Se activan por glutamato y requieren la presencia de glicina para la apertura del canal. A su vez, son sensibles a la inhibición por $\mathrm{Mg}^{2+}$. La expresión de los receptores NMDA se había restringido exclusivamente a las neuronas, sin embargo, recientemente también ha sido confirmada su presencia en astrocitos, aunque su estructura y función es distinta a la de los receptores neuronales. Los receptores NMDA glíales son sensibles al bloqueo por $\mathrm{Mg}^{2+}$ extracelular. Experimentos electrofisiológicos realizados en astrocitos corticales en cultivo permitieron caracterizar las corrientes de $\mathrm{Ca}^{2+}$ inducidas por NMDA (Lalo y col., 2006; Verkhratsky y Kirchhoff, 2007b). Sin embargo, 
existen dudas acerca de su origen y función, porque estas corrientes se inhibían con tetrodotoxina, lo que sugiere una participación neuronal en la respuesta a NMDA.

Los receptores de kainato son tetrameros formados a partir de las siguientes subunidades: GluR5, GluR6, GluR7, KA1 y KA2. Su permeabilidad a $\mathrm{Ca}^{2+}$ es muy baja, aunque la entrada global de $\mathrm{Ca}^{2+}$ puede verse incrementada de forma secundaria por activación de los canales VOCs mediante despolarización de la membrana plasmática, de manera similar a los receptores NMDA. Los receptores de kainato se encuentran principalmente en el sistema nervioso central, específicamente en neuronas de corteza cerebral, hipocampo y cerebelo. En astrocitos se identificó el receptor de kainato, tanto a nivel de mRNA como de proteína, y su funcionalidad se comprobó en astrocitos cultivados (Bowman y Kimelberg, 1984). Sin embargo, en secciones de cerebro, su actividad funcional no ha sido demostrada aún.

IONOTRÓPICOS

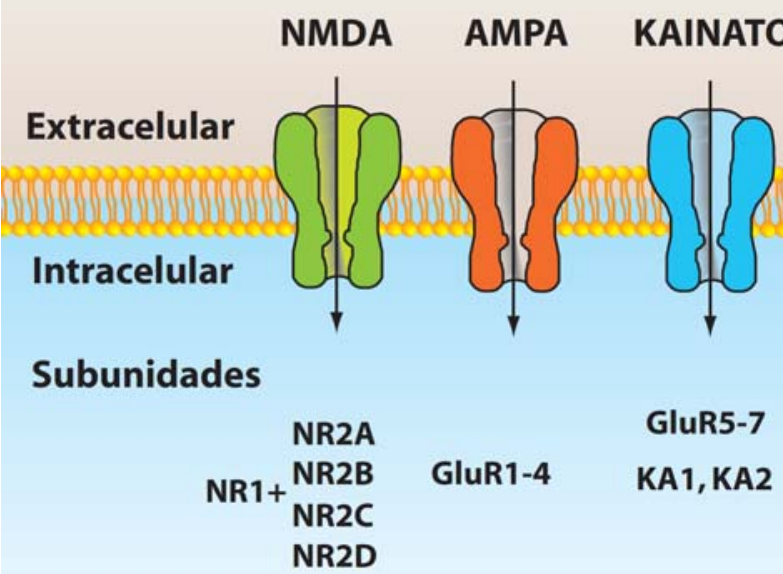

\section{METABOTRÓPICOS}

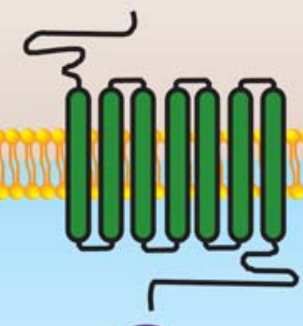

Gq

\section{PLC}

mGluR1-8

Figura 6. Receptores de glutamato. Los receptores de glutamato se dividen en ionotrópicos (canales iónicos) y metabotrópicos (acoplados a proteínas G). Los receptores ionotrópicos se subdividen en NMDA, AMPA y kainato dependiendo de su agonista selectivo. Los receptores metabotrópicos se subdividen en I, II y III dependiendo de su homología de secuencia. En la figura se incluyen los nombres de las subunidades que forman cada receptor. 
Por último, existe una amplia variedad de receptores metabotrópicos de glutamato (mGluR) que se expresan en el sistema nervioso. Los receptores mGluR están formados por siete dominios transmembrana, y se pueden dividir en tres grupos (I, II y III) en base a la cascada de transducción intracelular a la que estén acoplados (adenilato-ciclasa o fosfolipasa $\mathrm{C}$ ), y a sus propiedades farmacológicas (Nakanishi, 1992). Los receptores del grupo I (mGluR1 y mGluR5), están acoplados a la vía de la fosfolipasa $C$, y generan $\mathrm{IP}_{3}$, que provoca la movilización del $\mathrm{Ca}^{2+}$ del RE. Los receptores de los grupos II (mGluR2 y mGluR3) y III (mGluR4 y mGluR6-8), están acoplados a la cascada de la adenilato ciclasa/AMPc. En astrocitos se expresan predominantemente los receptores mGluR1, mGluR3 y mGluR5 (Parpura y col., 2011). En astrocitos cultivados se ha demostrado que la expresión del mGluR5 puede regularse por factores de crecimiento específicos como el factor de crecimiento de fibroblastos (bFGF), el factor de crecimiento epidérmico (EGF) y el factor de crecimiento transformante A (TGF-A) (Miller y col., 1995). La activación de los subtipos mGluR 1 y 5 muestran patrones de señales de $\mathrm{Ca}^{2+}$ distintas, evocando el primero un pico de $\mathrm{Ca}^{2+}$ simple no oscilatorio, mientras que el segundo desencadena oscilaciones del $\mathrm{Ca}^{2+}$ citosólico (Nakajima y col.) (ver más adelante apartado 4.2. Oscilaciones de $\mathrm{Ca}^{2+}$ en astrocitos).

\subsubsection{Receptores purinérgicos}

Según el ligando específico al que se unen y la cascada de transducción que activan, los receptores purinérgicos se clasifican en dos familias: los receptores $\mathrm{P} 1$, que se activan por adenosina y son metabotrópicos; $\mathrm{y}$, los receptores $\mathrm{P} 2$, que se activan por ATP, y pueden ser ionotrópicos (P2X) o metabotrópicos (P2Y) (Fig. 7). Los receptores P2X son canales catiónicos formados por tres subunidades idénticas (homotriméricos) o distintas (heterotriméricos) a partir de las siete diferentes que existen (P2X1-7). Poseen permeabilidad para cationes $\left(\mathrm{Ca}^{2+}, \mathrm{Na}^{+}\right.$y $\left.\mathrm{K}^{+}\right)$y se activan por la unión del ATP extracelular (North, 2002). Estos receptores se expresan tanto en células excitables como no excitables. En astrocitos existe controversia acerca de su expresión funcional. Se ha detectado expresión de los receptores P2X1/5 y 
P2X7 a nivel de mRNA y de proteína en cultivos primarios (Fumagalli y col., 2003; Lalo y col., 2011). Además, también se han medido corrientes iónicas mediadas por receptores P2X en cultivos en monocapa (Walz y col., 1994), aunque no se han detectado en la región CA1 del hipocampo. Por este motivo, algunos autores afirman que los receptores $\mathrm{P} 2 \mathrm{X}$ no son funcionales en astrocitos (Jabs y col., 2007).

Los receptores P2Y pertenecen a la superfamilia de receptores acoplados a proteínas G (GPCR). Estos receptores presentan una estructura típica de los receptores GPCRs, con siete dominios transmembrana hidrofóbicos, unidos por tres bucles extracelulares y tres bucles intracelulares. El extremo N-terminal está orientado hacia el medio extracelular mientras que el dominio C-terminal está localizado en el citosol. En mamíferos se han clonado y caracterizado funcionalmente ocho familias: P2Y1, P2Y2, P2Y4, P2Y6, P2Y11, P2Y12, P2Y13 y P2Y14 (Ralevic y Burnstock, 1998; Abbracchio y col., 2013). Funcionalmente, los receptores P2Y activan a la PLC y liberan $\mathrm{Ca}^{2+}$ del RE mediante la generación de $\mathrm{IP}_{3}$. Por lo tanto, no requieren de $\mathrm{Ca}^{2+}$ extracelular, y son sensibles a inhibidores de las bombas de $\mathrm{Ca}^{2+}$ del $\mathrm{RE}$ (como la tapsigargina y el ácido ciclopiazónico) y a inhibidores de los receptores de $\mathrm{IP}_{3}$ (como la heparina). En astrocitos, la expresión de los receptores P2Y es muy abundante, y se ha demostrado tanto in vitro como in situ (Burnstock y col., 2011). Los tipos más frecuentes en estas células son el P2Y1, el P2Y2 y el P2Y6, siendo el primero de ellos el principal responsable de la respuesta al ATP (Fumagalli y col., 2003). Se han caracterizado transitorios de $\mathrm{Ca}^{2+}$ como consecuencia de la activación de los receptores P2Y en cultivos de astrocitos aislados y en secciones de diversas zonas del cerebro, como el stratum radiatum del hipocampo, el bulbo olfatorio, la glía de Bergmann, o las células de Muller de la retina y del nervio óptico. Además, se ha descrito que los receptores P2Y1 y P2Y2 juegan un papel importante en otras funciones como la generación y la propagación de las ondas de $\mathrm{Ca}^{2+}$, la liberación de gliotransmisores, la movilización del ácido araquidónico, la producción de eicosanoides, la diferenciación o el desarrollo (Verkhratsky y col., 2009). 
En condiciones fisiológicas, el principal agonista purinérgico es el ATP, que puede ser liberado, tanto por las neuronas como por los astrocitos, a través de distintos mecanismos como la exocitosis, la secreción por la vía lisosomal y la difusión a través de canales de la membrana plasmática. En condiciones patológicas, sin embargo, el ATP es masivamente liberado desde las células dañadas, convirtiéndose así en un marcador de riesgo, importante para controlar muchas de las reacciones de defensa asociadas con la activación neuroglíal y, particularmente, con la astrogliosis.

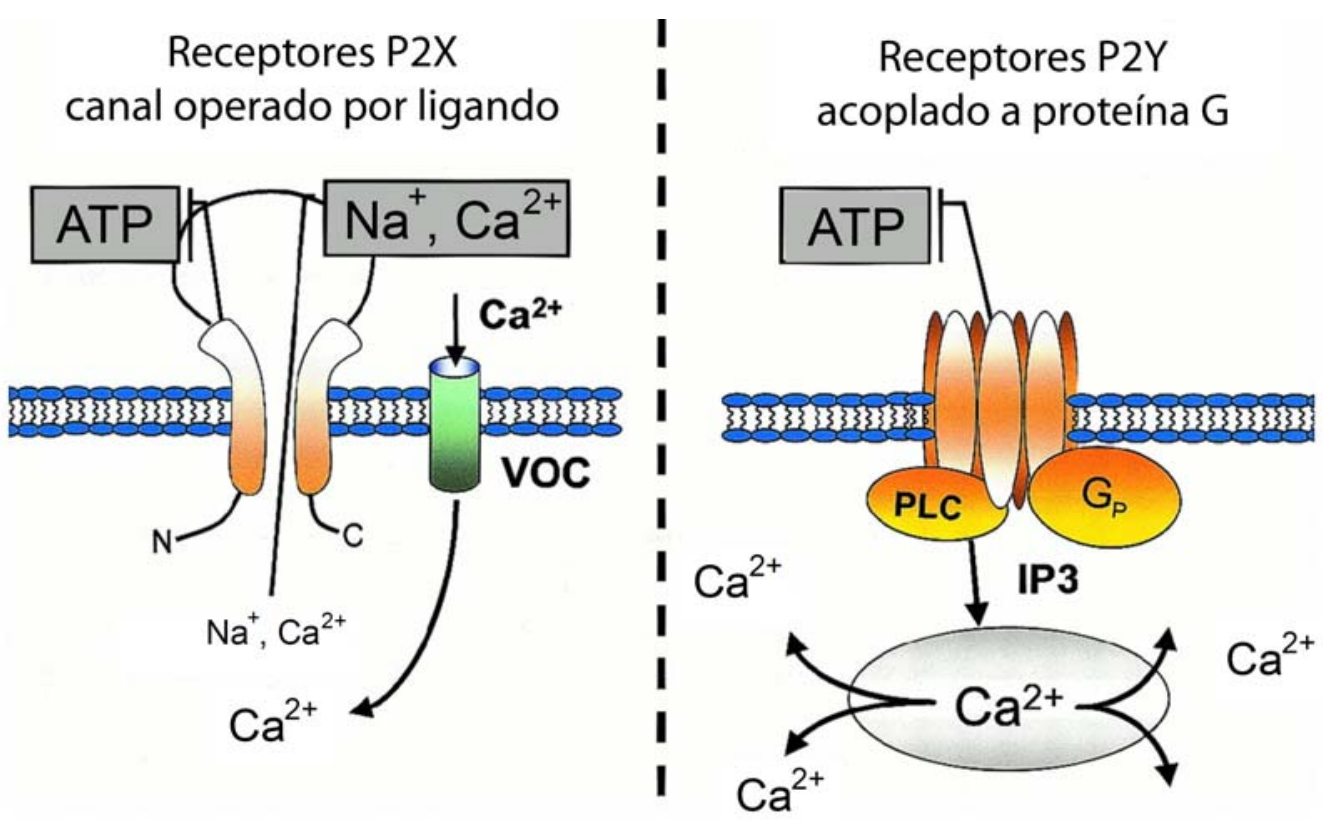

Figura 7. Receptores purinérgicos. Los receptores $P 2$ son activados por ATP o $A D P$, y se clasifican en receptores inonotrópicos $(P 2 X)$ y receptores metabotrópicos (P2Y). Los receptores $\mathrm{P} 2 \mathrm{X}$ son canales catiónicos que poseen permeabilidad para cationes $\left(\mathrm{Ca}^{2+}, \mathrm{Na}^{+}\right.$y K $\left.{ }^{+}\right)$. Los receptores $\mathrm{P} 2 \mathrm{Y}$ son receptores acoplados a proteínas $\mathrm{G}$ (GPCR). Poseen siete dominios transmembrana y activan a una PLC que genera $\mathrm{IP}_{3}$ para liberar $\mathrm{Ca}^{2+}$ del RE (Figura modificada de Inscho, 2001).

\subsection{Bombas e intercambiadores de $\mathrm{Ca}^{2+}$}

Para mantener baja la $\left[\mathrm{Ca}^{2+}\right]_{\mathrm{C}}$, las células utilizan numerosos mecanismos de aclaramiento, como expulsar el $\mathrm{Ca}^{2+}$ hacia el medio extracelular, almacenarlo en diferentes orgánulos intracelulares o tamponarlo con proteínas específicas de unión a $\mathrm{Ca}^{2+}$. El almacenamiento del $\mathrm{Ca}^{2+}$ en los orgánulos intracelulares puede ser de carácter permanente, como es el caso del RE, 
donde se almacenan altas $\left[\mathrm{Ca}^{2+}\right]$, o de carácter transitorio, como es el caso de la mitocondria, que modula la señal de $\left[\mathrm{Ca}^{2+}\right]_{c}$ captando el $\mathrm{Ca}^{2+}$ cuando aumenta su concentración en el citosol y liberándolo posteriormente (Rizzuto y Pozzan, 2006). La maquinaria implicada en el control espacio-temporal de la $\left[\mathrm{Ca}^{2+}\right]$ intracelular se basa en la regulación de canales, bombas e intercambiadores iónicos, que actúan coordinadamente para mantener los niveles de $\mathrm{Ca}^{2+}$ fisiológicos en las células. En la Figura 3 se muestran los principales componentes responsables de la homeostasis del $\mathrm{Ca}^{2+}$ en astrocitos, que se describirán con más detalle a continuación.

\subsubsection{Bombas de $\mathrm{Ca}^{2+}$ PMCA, SERCA y SPCA}

En primer lugar, existen sistemas de extrusión de $\mathrm{Ca}^{2+}$ basados en las ATPasas, bombas de $\mathrm{Ca}^{2+}$ que transportan iones en contra de su gradiente electroquímico con gasto de energía. La energía necesaria la obtienen a partir de la hidrólisis del ATP, generando un intermediario fosforilado durante su ciclo de funcionamiento, $y$, por éste motivo, estas ATPasas se denominan ATPasas de tipo $\mathrm{P}$ (Schatzmann, 1989). Están compuestas por 10 dominios transmembrana y dos bucles citosólicos donde se encuentra el sitio de fosforilación $(\mathrm{P})$ y el de unión a nucleótidos (N) (Fig. 8). Los extremos N- y Cterminales se encuentran hacia el lado citosólico (Carafoli y Stauffer, 1994). Las bombas de $\mathrm{Ca}^{2+}$ se caracterizan por poseer una capacidad de bombeo baja pero una afinidad por $\mathrm{Ca}^{2+}$ alta (entre 0,1-1 $\mu \mathrm{M}$ ), lo que les permite contribuir a un control preciso de la $\left[\mathrm{Ca}^{2+}\right] \mathrm{c}$. Pueden expulsar el $\mathrm{Ca}^{2+}$ fuera del citosol, ya sea hacia el medio extracelular por medio de la bomba $\mathrm{Ca}^{2+}$ ATPasa de la membrana plasmática (PMCA), hacia el lumen del RE por la bomba $\mathrm{Ca}^{2+}$ ATPasa del retículo sarco-endoplásmico (SERCA), o al lumen del aparato de golgi por la ATPasa de $\mathrm{Ca}^{2+}$ de la vía secretora (SPCA).

La bomba PMCA transporta un ión $\mathrm{Ca}^{2+}$ por molécula de ATP hidrolizado (Sarkadi y col., 1980), mientras que la SERCA es capaz de transportar dos iones $\mathrm{Ca}^{2+}$ por molécula de ATP hidrolizado (Yamada y col., 1970). Ambas bombas comparten la característica de requerimiento de $\mathrm{Mg}^{2+}$ en el lado 
citosólico para su correcto funcionamiento, aunque un exceso de este ión puede también ejercer un efecto inhibitorio (Schatzmann y Scheidegger, 1975; Clapham, 1995). La PMCA posee un tamaño de $138 \mathrm{kDa}$ y se han descrito 4 isoformas de la misma codificadas por diferentes genes (pmca 1-4). Las isoformas 1 y 4 se encuentran en la mayoría de los tipos celulares, mientras que la 2 se expresa en células nerviosas y glándula mamaria, y la 3 en células musculares. La PMCA contiene una larga región C-terminal que alberga un sitio de unión para calmodulina, el principal regulador de la actividad de esta bomba. También contiene sitios de unión para otros moduladores, entre ellos fosfolípidos ácidos, quinasas, y numerosas proteínas intracelulares (Brini y col., 2016). En astrocitos corticales de ratón se ha descrito la expresión de las isoformas 1 y 4, mediante análisis de RT-PCR y westernblot (Fresu y col., 1999).

La bomba SERCA se localiza en la membrana del RE (Fig. 8). Posee un tamaño aproximado de $110 \mathrm{kDa}$, y está codificada por tres genes diferentes que dan lugar a tres isoformas (serca 1, 2 y 3). Las SERCAs 1 y 2 se expresan en músculo esquelético, mientras que la 3 se expresa en células no musculares (Pozzan y col., 1994). Mediante tinciones con tapsigargina fluorescente se localizó la SERCA en astrocitos corticales de rata (Simpson y Russell, 1997). Existen varios inhibidores específicos de la bomba SERCA, el RE inhibidor irreversible tapsigargina ( $\mathrm{Tg}$ ), y los dos reversibles, el ácido ciclopiazónico (CPA) y la 2,5-di-tertbutilbenzohidroquinona (TBH). Al inhibir la bomba SERCA, se altera el equilibrio de captación y fuga de $\mathrm{Ca}^{2+}$ desde el $\mathrm{y}$, como consecuencia, se produce una salida pasiva de $\mathrm{Ca}^{2+}$ desde el lumen del $\mathrm{RE}$ al citosol, con el consiguiente incremento de la $\left[\mathrm{Ca}^{2+}\right] \mathrm{c}$.

Por último, la bomba SPCA tiene un tamaño de $104 \mathrm{kDa}$ y se han descrito dos isoformas (SPCA 1 y 2). La SPCA 1 es ubicua y la SPCA 2 es específica de células secretoras (Faddy y col., 2008). 


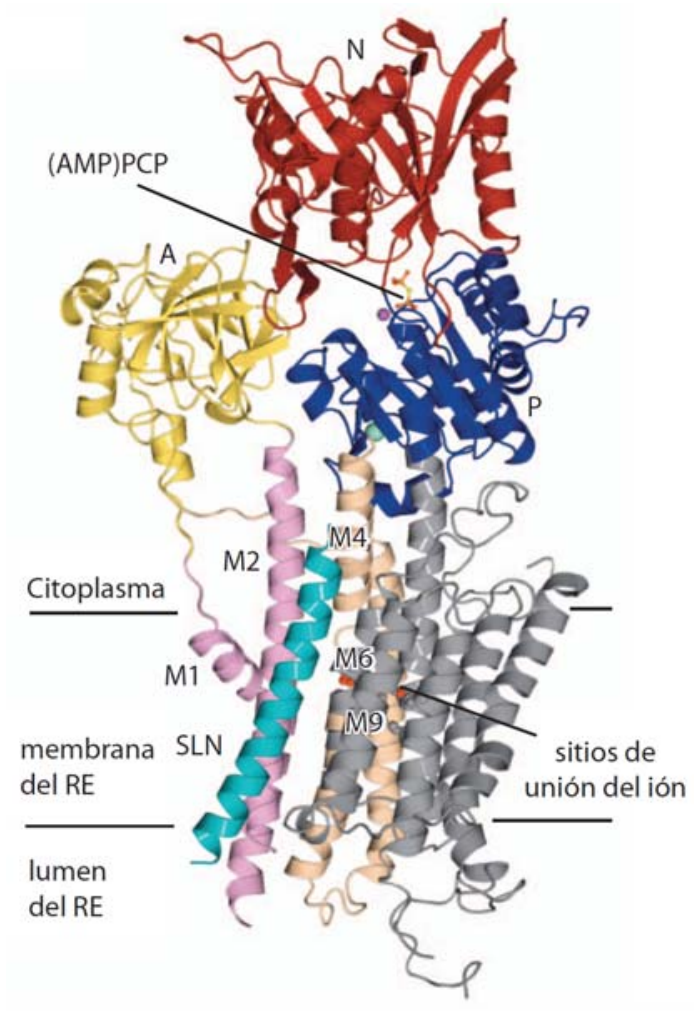

Figura 8. Estructura de la $\mathrm{Ca}^{2+}$-ATPasa del RE (SERCA). Modelo de la bomba SERCA mostrando el sitio de unión a sarcopilina SLN entre las hélices transmembrana M2, M6 y M9 de la SERCA. El $\mathrm{Mg}^{2+}$ se muestra como esferas de color rojo y $\mathrm{K}^{+}$como una esfera verde. Los fosfatos del AMP y los sitios de unión a $\mathrm{Ca}^{2+}$ se muestran como una esfera y una vara (Figura modificada de Winther y col., 2013).

\subsubsection{Intercambiador $\mathrm{Na}^{+} / \mathrm{Ca}^{2+}$ (NCX)}

Otro mecanismo de extrusión de calcio es llevado a cabo por los intercambiadores de $\mathrm{Na}^{+} / \mathrm{Ca}^{2+}$ (NCX) que se encargan de expulsar el calcio del citosol hacia el medio extracelular. Utilizan la energía que obtienen de la disipación del gradiente electroquímico del $\mathrm{Na}^{+}$. La estequiometría del intercambiador $\mathrm{Na}^{+} / \mathrm{Ca}^{2+}$ de la membrana plasmática es de un ión $\mathrm{Ca}^{2+}$ por tres iones $\mathrm{Na}^{+}$. Puede actuar expulsando el $\mathrm{Ca}^{2+}$ al medio extracelular al tiempo que permite la entrada de $\mathrm{Na}^{+}$, o en modo reverso, cuando se produce la entrada de $\mathrm{Ca}^{2+}$, dependiendo de los gradientes iónicos transmembrana y del potencial de la membrana plasmática (Yu y Choi, 1997). EI NCX tiene un tamaño de 110 kDa, posee nueve dominios transmembrana con una región citoplasmática que interviene en su regulación. La región $\mathrm{N}$-terminal se encuentra hacia el espacio extracelular y la C-terminal hacia el lado citoplasmático. El intercambiador 
posee menor afinidad que las ATPasas por el $\mathrm{Ca}^{2+}$, pero una mayor capacidad para expulsar el $\mathrm{Ca}^{2+}$ hacia el medio extracelular. Existen tres isoformas del $\operatorname{NCX}(1,2$ y 3$)$ y las tres se han encontrado en astrocitos corticales y de hipocampo de rata (Minelli y col., 2007).

\subsubsection{Uniportador de $\mathrm{Ca}^{2+}$ mitocondrial (MCU)}

Las mitocondrias cumplen un papel fundamental en la modulación de los patrones espacio-temporales de las señales citosólicas de $\mathrm{Ca}^{2+}$. La captación de $\mathrm{Ca}^{2+}$ por las mitocondrias es muy rápida debido a la baja afinidad de sus mecanismos de transporte. Las mitocondrias in situ forman una red interconectada y dinámica que establece numerosos contactos con otros orgánulos como el RE (Rizzuto y Pozzan, 2006). Pueden estar situadas muy cerca de RE, esta proximidad es necesaria para que las mitocondrias capten el $\mathrm{Ca}^{2+}$ liberado por el RE (Bakowski y col., 2012). En el trabajo de Rizzuto y col., 2012 utilizaron una fotoproteína sensible a $\mathrm{Ca}^{2+}$, dirigida a la cara externa de la membrana interna mitocondrial, y observaron que tras la activación de los receptores $I P_{3} R$ del $R E$, las mitocondrias detectaron una concentración de $\mathrm{Ca}^{2+}$ más alta que la observada en el citosol, y esto se interpretó como que existen puntos de contacto entre el RE y las mitocondrias donde se producen microdominios de alto $\mathrm{Ca}^{2+}$ (Rizzuto y col., 2012).

Para mantener la estrecha asociación entre las mitocondrias y el RE, los dos orgánulos necesitan acoplarse físicamente a través de interacciones proteína-proteína. Las regiones de la membrana del RE que interaccionan con las mitocondrias se denominan membranas asociadas a mitocondrias (MAMs). Las MAMs son ricas en diversos fosfolípidos y enzimas que sintetizan glucoesfingolípidos tales como la ácido graso-CoA ligasa y la fosfatidilserina sintasa-1. La mitofusina 2 (MFN2) es una proteína que se encuentra, tanto en las mitocondrias como en el RE, y se expresa abundantemente en las MAMs, donde forma interacciones homo- y heteroméricas con la mitofusina 1 (MFN1). Se ha descrito que los fibroblastos embrionarios de ratón que carecen de 
MFN2 muestran cambios tanto en la morfología de RE como en las interacciones RE-mitocondria (Bakowski y col., 2012).

La captación del $\mathrm{Ca}^{2+}$ por parte de las mitocondrias se realiza mediante el uniportador mitocondrial (MCU), un complejo oligomérico de proteínas localizado en la membrana interna mitocondrial (De Stefani y col., 2015). El MCU es altamente selectivo para $\mathrm{Ca}^{2+}$ y su afinidad por dicho ión es baja, por lo que necesita concentraciones del orden de $5 \mu \mathrm{M}$ para activarse. El complejo está formado por las proteínas de membrana MCU, MCUb y EMRE, que participan en la conformación del poro. La proteína MCU, es suficiente, por si sola, para formar un canal permeable a $\mathrm{Ca}^{2+}$ en bicapas lipídicas y es esencial para el funcionamiento del canal. Se ha demostrado que las mitocondrias aisladas de un ratón knockout de MCU pierden su capacidad para captar $\mathrm{Ca}^{2+}$. El conocimiento acerca de la complejidad del canal MCU aumentó significativamente con la identificación de los otros dos componentes, MCUb y EMRE. La proteína transmembrana MCUb comparte el $50 \%$ de similitud con MCU y parece regular la formación del poro, mientras que EMRE podría ser esencial para el ensamblaje del complejo MCU. La actividad del canal se inhibe por rojo de rutenio y $\mathrm{Ga}^{3+}$.

$\mathrm{El} \mathrm{Ca}^{2+}$ acumulado en las mitocondrias posteriormente se libera a través del intercambiador mitocondrial $\mathrm{Na}^{+} / \mathrm{Ca}^{2+}$, del intercambiador $\mathrm{Ca}^{2+} / \mathrm{H}^{+}$o a través de una vía alternativa constituida por el poro de permeabilidad transitoria (PTP). La modulación de las señales de $\mathrm{Ca}^{2+}$ por la mitocondria afecta a diversas funciones celulares. En los astrocitos, por ejemplo, se ha descrito que la secreción de glutamato por exocitosis se bloquea al inhibir la liberación del $\mathrm{Ca}^{2+}$ captado por la mitocondria, con CGP37157, un inhibidor del intercambiador $\mathrm{Na}^{+} / \mathrm{Ca}^{2+}$ mitocondrial. Esto demuestra el importante papel que desempeña la mitocondria en la modulación de las señales de $\mathrm{Ca}^{2+}$ en estas células (Reyes y Parpura, 2008). 


\subsubsection{Proteínas amortiguadoras que unen $\mathrm{Ca}^{2+}(\mathrm{CBP})$}

Las proteínas de unión a $\mathrm{Ca}^{2+}$ (CBPs) forman parte de un amplio grupo heterogéneo de proteínas con funciones celulares muy distintas, desde la homeostasis del $\mathrm{Ca}^{2+}$ hasta la señalización celular (Yanez y col., 2012). A pesar de poseer propiedades y estructuras muy diferentes entre sí, la mayoría de las CBP poseen una cinética rápida y se unen de forma específica y reversible al $\mathrm{Ca}^{2+}$ a través de dominios específicos de unión.

Las CBPs cumplen una función tamponadora que mantiene la $\left[\mathrm{Ca}^{2+}\right]$ en un determinado nivel en cada compartimento. Por ejemplo, las CBPs citosólicas se unen rápidamente al $\mathrm{Ca}^{2+}$, limitando su capacidad de difusión en el citosol (menos de $1 \mu \mathrm{M}$ en pocos $\mu \mathrm{s}$ ). Entre las principales CBPs citosólicas se encuentran la calmodulina (CaM), la parvalbumina, la calbindina D-28k y la calretinina (revisado por Berridge, 2014). En el RE se encuentran la calreticulina, la calsecuestrina y la familia de las proteínas S100, entre otras. El lumen del RE es capaz de acumular altas $\left[\mathrm{Ca}^{2+}\right]$ gracias, precisamente, a la existencia de estas proteínas, que además de amortiguar el $\mathrm{Ca}^{2+}$ cumplen funciones especializadas como participar en el plegamiento proteico, actuando como chaperonas (Nakamura y col., 2001).

Uno de los dominios específicos de unión al $\mathrm{Ca}^{2+}$ más extendidos entre las CBPs intracelulares son los dominios de mano-EF. Este dominio caracteriza a una gran subfamilia de CBPs, con más de 66 subfamilias, entre las que se encuentra la calmodulina, la troponina $\mathrm{C}$ o la calcineurina. La mano-EF tiene un motivo hélice-bucle-hélice que se caracteriza por una secuencia de 12 residuos flanqueados por dos hélices alfa posicionadas perpendiculares una de la otra, simulando la disposición espacial entre el pulgar y el dedo índice de una mano humana extendidos. El bucle puede acomodar $\mathrm{Ca}^{2+} \mathrm{O}_{\mathrm{Mg}^{2+}}$ con distintas geometrías y afinidades, dependiendo de la función de la proteína. Por otro lado, existen otras CBPs que carecen de manos-EF, como algunas proteínas de los orgánulos intracelulares (la calsecuestrina y la calreticulina), la gran familia de proteínas llamadas anexinas y algunas proteínas que comparten el dominio de unión a $\mathrm{Ca}^{2+}$ denominado C2 (la PKC o la sinaptotagmina). 


\section{Canales de $\mathrm{Ca}^{2+}$ de endomembranas}

El RE está involucrado en diversas funciones como el metabolismo de fármacos, y la síntesis y el plegamiento de proteínas. Además, es el principal depósito de $\mathrm{Ca}^{2+}$ en las células eucariotas, capaz de acumular concentraciones tan altas como 500-1000 $\mu \mathrm{M}$, a través de la bomba SERCA. Utilizando la sonda fluorescente de baja afinidad por $\mathrm{Ca}^{2+}$ Mag-Fura-2, se realizaron medidas de la $\left[\mathrm{Ca}^{2+}\right]_{\mathrm{RE}}$ en astrocitos (Golovina y Blaustein, 2000) y se compararon con medidas en neuronas aisladas de ganglio de raíz dorsal (Solovyova y col., 2002). En los astrocitos se ha encontrado que la $\left[\mathrm{Ca}^{2+}\right]_{\mathrm{RE}}$ varía entre $100-300$ $\mu \mathrm{M}$, algo menor que la de neuronas, de 300-800 $\mu \mathrm{M}$.

La excitabilidad de los astrocitos se basa en su capacidad de generar y propagar señales de $\mathrm{Ca}^{2+}$ que involucran al RE, que ocupa todo el cuerpo celular. Por este motivo, dicha organela está muy desarrollada en astrocitos, formando una red de microtúbulos y cisternas desde la envoltura nuclear hasta la periferia de la célula, incluyendo los procesos celulares. La activación de los canales de $\mathrm{Ca}^{2+}$ presentes en la membrana del RE en astrocitos, provoca una rápida y localizada liberación del $\mathrm{Ca}^{2+}$. La regulación de estos canales representa la base principal para la generación de complejas señales espaciotemporales. Las dos familias principales de canales iónicos que participan en este proceso son los receptores de $\mathrm{IP}_{3}\left(\mathrm{IP}_{3} \mathrm{Rs}\right)$ y los receptores de rianodina (RyRs), que se describirán a continuación.

\subsection{Receptor de $I P_{3}\left(I P_{3} R\right)$}

El $I_{3} R$ es un canal catiónico, no selectivo, de gran conductancia, localizado en la membrana del $\mathrm{RE}$, que al unirse al $\mathrm{IP}_{3}$ deja salir el $\mathrm{Ca}^{2+}$ acumulado en el RE (Fig. 9) (revisado por Berridge, 2014). Es un tetrámero formado por subunidades iguales o diferentes con un peso aproximado de 1000 kDa (Mikoshiba, 2007). Los dominios C- y N-terminales están orientados hacia el lado citosólico. El gran dominio N-terminal posee el sitio de unión a $\mathrm{IP}_{3}$ y varios sitios reguladores, que sirven para modular e integrar un amplio rango 
de señales. El dominio transmembrana está formado por seis hélices transmembrana, y el poro del canal se encuentra conformado por las hélices 5 y 6 .

La liberación del $\mathrm{Ca}^{2+}$ acumulado en el RE está controlada principalmente por el gradiente químico de concentración mantenido por la bomba SERCA. El $\mathrm{Ca}^{2+}$ es el principal ión que atraviesa los canales de $\mathrm{IP}_{3} \mathrm{R}$, ya que no existe un gradiente de $\mathrm{K}^{+}$a través de la membrana del RE. La activación del canal se regula por el propio $\mathrm{Ca}^{2+}$ y el co-agonista $\mathrm{IP}_{3}$ (Foskett y col., 2007). El IP 3 actúa incrementando la sensibilidad del $\mathrm{IP}_{3} \mathrm{R}$ al calcio, favoreciendo así su apertura. El $\mathrm{IP}_{3} \mathrm{R}$ tiene una sensibilidad bifásica al $\mathrm{Ca}^{2+}$, siendo activado en presencia de $\mathrm{IP}_{3}$ a concentraciones submicromolares de $\mathrm{Ca}^{2+}$ citosólico, e inhibido cuando este alcanza niveles micromolares (Bezprozvanny y col., 1991; Foskett y col., 2007). Además, existe otro nivel de modulación por el $\mathrm{Ca}^{2+}$ luminal, ya que al producirse la liberación del $\mathrm{Ca}^{2+}$ y disminuir su nivel en el RE, se inactiva el receptor, mientras que al rellenarse nuevamente el $R E$ con $\mathrm{Ca}^{2+}$, el $I_{3} R$ recupera su sensibilidad (Missiaen y col., 1992).

En mamíferos se han descrito tres isoformas del $\operatorname{IP}_{3} R(1,2$ y 3$)$, que poseen estructuras primarias y propiedades muy similares. En astrocitos se expresa únicamente la isoforma 2 (Petravicz y col., 2008). El $\mathrm{IP}_{3} \mathrm{R}$ parece expresarse de forma más localizada en los procesos distales de los astrocitos, donde suelen iniciarse las señales de calcio en respuesta a la activación de los receptores metabotrópicos (Parpura y col., 2011; Verkhratsky y col., 2012).

La actividad del $\mathrm{IP}_{3} \mathrm{R}$ se regula por fosforilación a través de la acción de serina/treonina quinasas como la quinasa dependiente de $\mathrm{Ca}^{2+} / \mathrm{CaM}$ (CaMKII), la quinasa dependiente cGMP (PKG), la proteína quinasa C (PKC): la proteína quinasa A (PKA) (revisado por Berridge y col., 2003). 


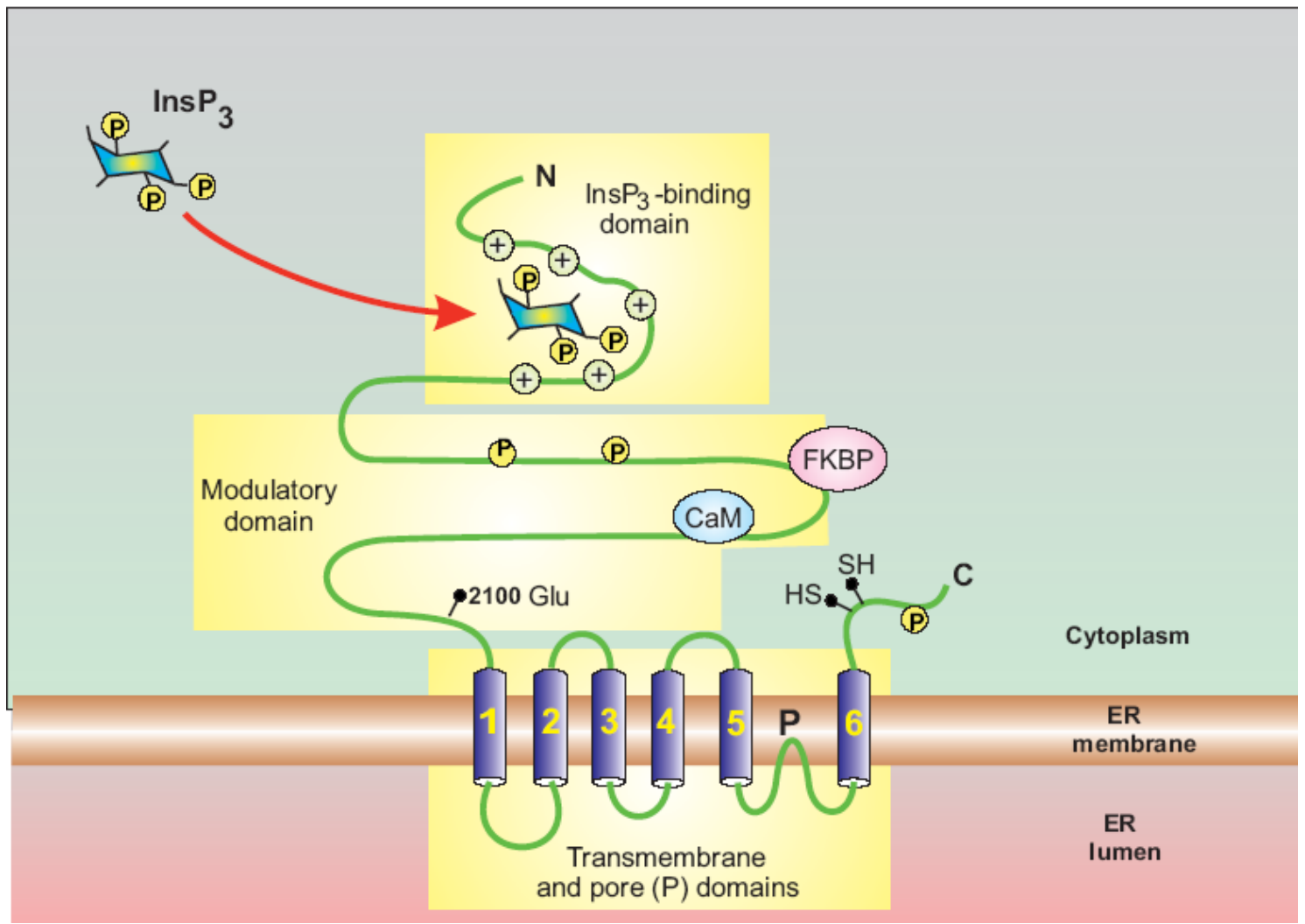

Figura 9. Estructura del receptor de $I P_{3}$ (IP3R) El $I P_{3} R$ puede dividirse en tres dominios funcionales (recuadros amarillos). El dominio transmembrana se compone de seis hélices transmembrana (TM). El poro (P) está localizado entre la TM5 y la TM6. Posee un extremo C-terminal corto del lado citosólico, que contiene dos grupos tiol muy conservados. La gran región $\mathrm{N}$-terminal también está localizada del lado citosólico y contiene el sitio de unión al $\mathrm{IP}_{3}$. Está conectada a TM1 por un dominio modulador, al que pueden unirse la calmodulina (CaM), el factor de trasncripción FKBP y una proteína FK506, que actúa en el plegamiento de proteínas. La interacción entre estas diferentes subunidades conforma un canal funcional capaz de permear $\mathrm{Ca}^{2+}$ (Figura modificada de Berridge, 2014).

Se han generado ratones mutantes nulos para las distintas isoformas de $I P_{3} R$. Mientras que el ratón mutante de $I P_{3} R 1$ es letal en estado embrionario (Matsumoto y col., 1996), el mutante nulo para $\mathrm{IP}_{3} \mathrm{R} 2$ es viable y fértil (Matsumoto y col., 1996), lo que indica que este canal no es esencial para el desarrollo embrionario ni para la supervivencia. Los astrocitos de secciones de hipocampo de éstos ratones mutantes carecen de transitorios de $\mathrm{Ca}^{2+}$ citosólico espontáneos o mediados por agonistas de los receptores acoplados a proteínas $\mathrm{G}$. Esto demuestra que el $\mathrm{IP}_{3} \mathrm{R} 2$ es clave en la transducción de señales de $\mathrm{Ca}^{2+}$ metabotrópicas en astrocitos. Por el contrario, las señales de 
$\mathrm{Ca}^{2+}$ en neuronas piramidales de la región CA1 de secciones de hipocampo no se ven afectadas por la falta del $I_{3} R 2$ (Petravicz y col., 2008).

\subsection{Receptor de rianodina (RyRs)}

El receptor de rianodina (RyR), al igual que el de $\mathrm{IP}_{3} R$, es un canal catiónico no selectivo permeable a $\mathrm{Ca}^{2+}$ presente en la membrana del RE (Imler y Zinsmaier, 2014). Debe su nombre a la alta afinidad que presenta por la rianodina, un alcaloide procedente de la planta Riania speciosa (Meissner, 1986). El RyR está formado por un gran complejo proteico homotetramérico, de un tamaño de aproximadamente $2000 \mathrm{kDa}$. Cada subunidad tiene de cuatro a diez hélices transmembrana, y los dominios transmembrana de las cuatro subunidades conforman el poro. Posee un gran dominio citoplasmático $\mathrm{N}$ terminal regulador, presentando sitios de unión para una gran variedad de proteínas citosólicas que modulan su actividad (Fig 10).

Existen tres isoformas del RyR (1, 2 y 3 ), codificadas por tres genes diferentes, cada una de las cuales posee expresión específica de tejido. El RyR1 y el RyR2 se expresan en músculo esquelético y cardíaco respectivamente, mientras que el RyR3 se encuentra más ampliamente distribuido, expresándose a bajos niveles en un amplio rango de tejidos, incluida la astroglía (Rossi y Sorrentino, 2002). En general, todas las isoformas tienen una conductancia de $1 \mathrm{pA}$, mayor en comparación con los menos de 0.5 pA del $I_{3} R$. Los RyRs pueden ser activados por $\mathrm{Ca}^{2+}$ en el rango de concentraciones de micromolar; ATP y cafeína en concentraciones mM; además de el perclorato, el 4 cloro-m-cresol $(4-\mathrm{CmC})$ y la calmodulina. El agonista ADP ribosa cíclica (CADPR) es capaz de activar el RyR2, pero no activa a las isoformas 1 ni 3 en bicapas lipídicas (Chen y col., 1997). La cafeína, a concentraciones milimolares, es un agonista ampliamente utilizado en el estudio del RyR. Sin embargo, el efecto de la cafeína en astrocitos es discutible, ya que mientras algunos autores han descrito que no produce señales de $\mathrm{Ca}^{2+}$ citosólicas en astrocitos (Verkhratsky y col., 1998), otros por el contrario, han observado transitorios al aplicar dicho agonista. Los primeros sostienen que estas respuestas son probablemente secundarias a la activación 
de las neuronas, que liberarían neurotransmisores que activarían a los astrocitos, y no a un efecto directo de la cafeína sobre los astrocitos.

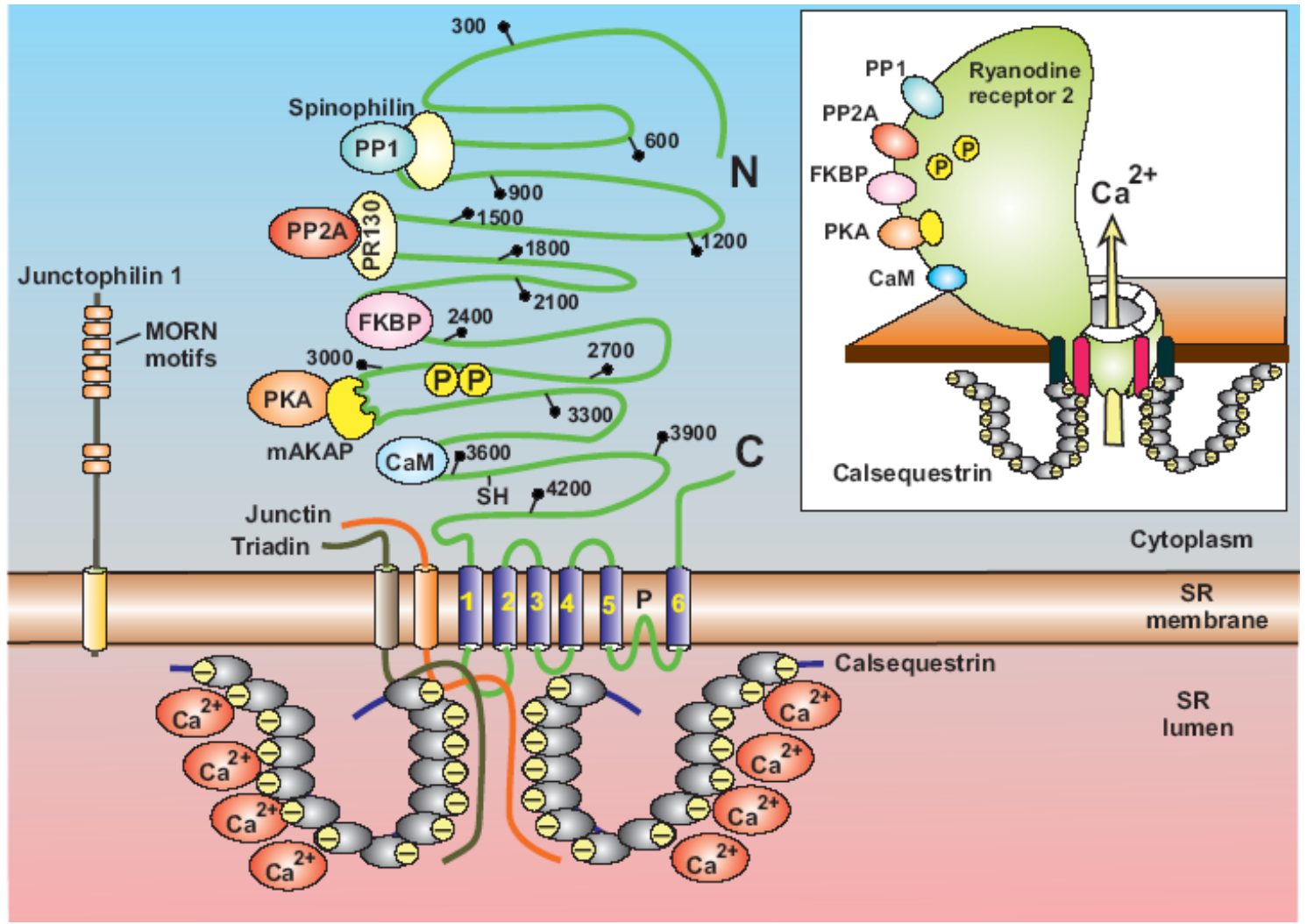

Figura 10. Estructura del receptor de rianodina tipo 2 (RyR2). El RyR2 es un tetrámero. En la región C-terminal de cada subunidad existen seis dominios transmembrana que forman el poro del canal de $\mathrm{Ca}^{2+}$ entre el dominio cinco y seis. La gran región $\mathrm{N}$-terminal posee sitios de unión para diferentes proteínas reguladoras: la calmodulina (CaM); la proteína quinasa $A(P K A)$; la FKBP; la proteína fosfatasa $2 A$ (PP2A) y la proteína fosfatasa 1 (PP1). Los extremos que se proyectan hacia el lumen del RE interactúan con las proteínas junctina y triadina, que a su vez se asocian con la proteína de unión a $\mathrm{Ca}^{2+}$ calsecuestrina (Figura modificada de Berridge, 2014).

La Kd aparente del RyR por $\mathrm{Ca}^{2+}$ se encuentra típicamente entre 0.5 y 5 $\mu \mathrm{M}$ (Fill y Copello, 2002). Los inhibidores del RyR son el $\mathrm{Mg}^{2+}$, el rojo de rutenio o la rianodina a altas concentraciones.

A pesar de que el RyR3 es el subtipo más ampliamente distribuido, es el menos estudiado, ya que la atención se ha centrado principalmente en los receptores RyR1 y RyR2. El mecanismo de activación de estos últimos es esencialmente diferente, y se esquematiza en la Figura 11. El RyR1, presente 
en el músculo esquelético es activado por un mecanismo de acoplamiento conformacional con los canales VOC tipo L, (Cav1.1), de la membrana plasmática. Al despolarizarse esta, los canales $\mathrm{L}$ sufren un cambio conformacional y activan los RyRs por una interacción directa del tipo proteínaproteína. Esto es posible gracias a invaginaciones de la membrana plasmática llamadas túbulos $\mathrm{T}$, que permiten la interacción física de ambas proteínas. Por otro lado, el RyR2, presente en el corazón, es activado directamente por $\mathrm{Ca}^{2+}$, que la entrada a través de los canales VOC tipo $L$, mediante un mecanismo llamado liberación de calcio inducida por calcio o CICR (ㅡalcium Induced Calcium Release). Un pequeño incremento de $\mathrm{Ca}^{2+}$ en el citosol activa al RyR2, que amplifica la señal citosólica mediante la liberación de $\mathrm{Ca}^{2+}$ del RE.

Los RyRs están regulados por una gran variedad de proteínas, entre las que destacan la calmodulina y las proteínas FKBP12, del lado citoplasmático, así como la juntina y la triadina del lado transmembrana, y, la calsecuestrina desde el lumen del RE. Además, la actividad de los RyRs está modulada por su estado de oxidorreducción y de fosforilación, esta última caracterizada principalmente por la proteína quinasa $A(P K A)$ o la calmodulina quinasa IIA (CaMKII) (revisado por Berridge y col., 2003). La sensibilidad del RyR al calcio luminal se debe al trabajo conjunto de tres proteínas: la calreticulina que actúa como sensor del $\mathrm{Ca}^{2+}$ luminal uniéndose al mismo e interaccionando con el dominio C-terminal luminal de las proteínas transmembrana junctina y triadina. Estas últimas proteínas modulan a su vez la apertura del canal RyR, alterando su sensibilidad a $\mathrm{Ca}^{2+}$ en función del nivel de rellenado del RE (revisado por Berridge., 2014).

El RyR3 es activado por incrementos en la concentración de $\mathrm{Ca}^{2+}$ citosólico, en un rango de 1-10 $\mu \mathrm{M}$ de $\mathrm{Ca}^{2+}$ siendo su umbral de activación similar al observado para RyR1, mientras que cada isoforma particular puede tener diferentes afinidades para su inhibición. El RyR1 es completamente inhibido cuando el $\mathrm{Ca}^{2+}$ citosólico alcanza niveles de $1 \mathrm{mM}$, mientras que los otros dos RyRs lo son sólo parcialmente. El RyR3, en particular, posee una sensibilidad diez veces menor a la inactivación por $\mathrm{Ca}^{2+}$. Por este motivo, mientras que RyR1 es inactivado en presencia de entre 1-3 mM de $\mathrm{Ca}^{2+}$, RyR3 
posee actividad hasta con $20 \mathrm{mM}$ (Chen y col., 2002). Los RyRs tipo 1 y 3 comparten numerosas propiedades, sin embargo, también existen algunas diferencias, como su cinética de apertura, ya que el canal RyR3 tiene un tiempo medio de apertura más largo que RyR1, se ha descrito $1.16 \mathrm{~ms}$ en el primer caso y 0.22 ms para el segundo (Chen y col., 1997).

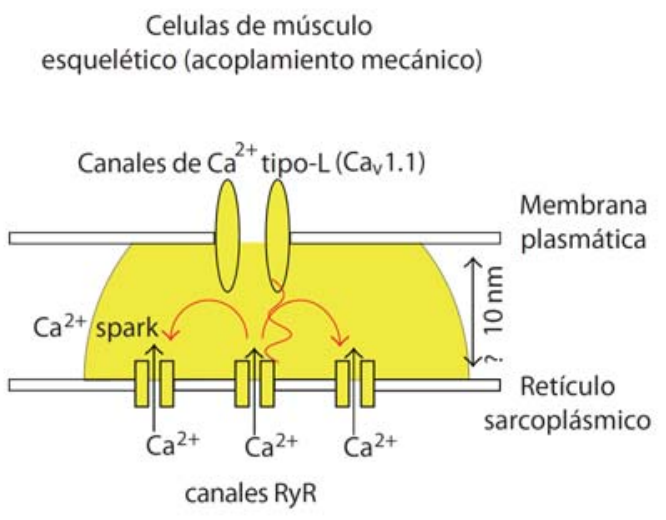

(a)

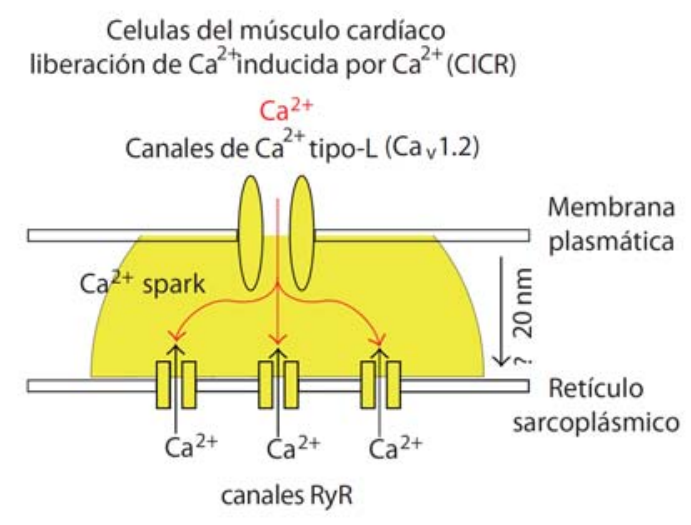

(b)

Músculo liso (a través del $\mathrm{Ca}^{2+}$ luminal) esquelético (acoplamiento mecánico)

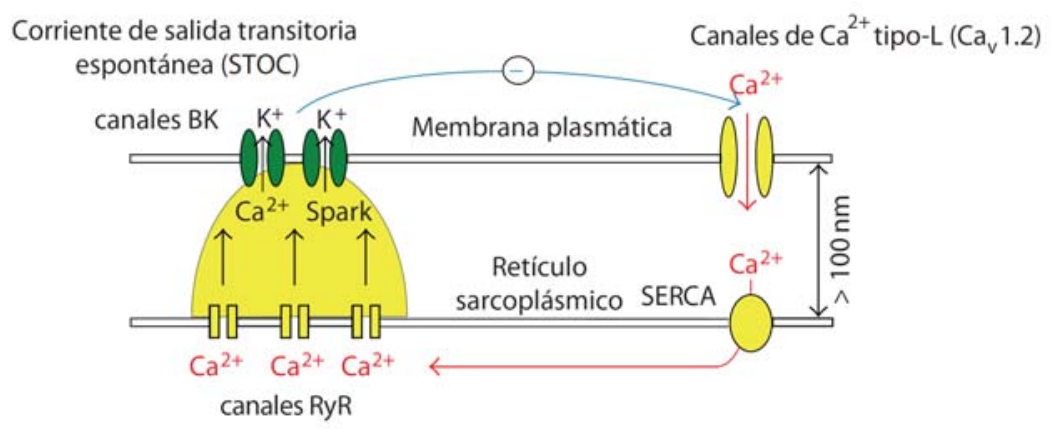

(c)

Figura 11. Activación de RyR mediada por el VoC tipo L. a. En músculo esquelético el canal RyR1 se activa por una interacción física directa con el canal VOC. La liberación de $\mathrm{Ca}^{2+}$ del retículo sarcoplasmico a través del RyR1 activa los RyR vecinos (por ejemplo el RyR3) vía CICR. b. En cardiomiocitos el RyR2 se activa por la entrada de $\mathrm{Ca}^{2+}$ a través de los canales VOCs vía CICR. c. En el músculo liso se ha propuesto que la activación de canales RyR3 se produce como consecuencia de que los VOCs contribuyen a un incremento en el $\mathrm{Ca}^{2+}$ citosólico. El $\mathrm{Ca}^{2+}$ citosólico es captado por la SERCA afectando el nivel de $\mathrm{Ca}^{2+}$ luminal del RE y desencadenando liberación de $\mathrm{Ca}^{2+}$. El incremento de $\mathrm{Ca}^{2+}$ citosólico activa canales BK (Figura modificada de Essin y Gollasch, 2009).

Los ratones mutantes nulos (knockout, KO) para los RyR1 y RyR2 mueren temprano durante el desarrollo embrionario. Mientras que los ratones nulos 
para el RyR3 se desarrollan normalmente, y poseen músculos estriados relativamente normales (Takeshima y col., 1996). Aunque, es interesante destacar que las fibras de músculo esquelético de neonatos del RyR3 KO pierden la capacidad de activación del mecanismo de CICR. Las implicaciones de estas observaciones aún no están claras. En cualquier caso, parece que la función fisiológica que desempaña el canal RyR3 en mamíferos es diferente a la de RyR1 y RyR2. Sin embargo, la función de RyR3 puede ser rápidamente compensada por los otros dos subtipos durante el desarrollo en el adulto (Fill y Copello, 2002).

En astrocitos se ha descrito la expresión de la isoforma RyR3 (Matyash y col., 2002). Se ha encontrado RyR3 en astrocitos aislados de cerebros de ratones, a nivel de RNAm mediante RT-PCR, y se ha comprobado su funcionalidad con 4 cloro-m-cresol $(4-\mathrm{CmC})$, que produjo transitorios de $\mathrm{Ca}^{2+}$ citosólico, sensibles a rianodina.

\subsection{Canales de fuga de $\mathrm{Ca}^{2+}$ (leak channel)}

Los canales de fuga (leak channels) presentes en la membrana del RE permiten que el $\mathrm{Ca}^{2+}$ acumulado salga pasivamente, y en conjunto con la bomba SERCA que bombea el $\mathrm{Ca}^{2+}$ citosólico hacia el RE, logran establecer un equilibrio que determina el nivel basal de $\mathrm{Ca}^{2+}$ en el RE. La identidad molecular de este canal no ha sido confirmada, aunque diferentes proteínas han sido propuestas como canales leak, como las presenilinas (Tu y col., 2006), el complejo Sec 61 (también llamado traslocón) (Lang y col., 2012), el complejo Bcl-2/IP3R (Oakes y col., 2005), el inhibidor de Bax 1 (Bultynck y col., 2012) o los propios canales RyRs (Jiang y col., 2005). Además, algunos canales de tipo TRPs, normalmente presentes en la membrana plasmática pero que también se encuentran en la membrana del RE, pueden ser funcionales y promover la salida del $\mathrm{Ca}^{2+}$ reticular (Gallego-Sandin y col., 2009; Imler y Zinsmaier, 2014). Por último, recientemente se ha identificado una proteína denominada TMCO1 (Transmembrane and coiled-coil domains 1) que actúa previniendo el rellenado excesivo del RE. Esta proteína forma homotetrámeros transmembrana en la 
membrana del RE a través de los cuales permite la salida de $\mathrm{Ca}^{2+}$ del RE, manteniendo los niveles basales de $\mathrm{Ca}^{2+}$ (Wang y col., 2016).

\section{Ondas y oscilaciones de $\mathrm{Ca}^{2+}$ en astrocitos}

\subsection{Ondas de $\mathrm{Ca}^{2+}$}

Las ondas intracelulares de $\mathrm{Ca}^{2+}$ son incrementos en la $\left[\mathrm{Ca}^{2+}\right]_{\mathrm{c}}$ que se propagan a través del citosol de una célula cuando se supera un determinado umbral de $\mathrm{Ca}^{2+}$ citosólico, convirtiendo una respuesta local en una onda de $\mathrm{Ca}^{2+}$ (Scemes y Giaume, 2006). Las ondas de $\mathrm{Ca}^{2+}$ pueden estar restringidas a una sola célula (ondas intracelulares) o transmitirse a las células vecinas (ondas intercelulares). Este mecanismo requiere la apertura de los canales de $\mathrm{Ca}^{2+}$ de las endomembranas, de tal modo que una elevación del $\mathrm{IP}_{3}$ localizada puede producir una liberación local del $\mathrm{Ca}^{2+}$ a través del canal de $\mathrm{IP}_{3}$, que reclutaría otros canales vecinos, amplificando así la liberación inicial, y propagando la señal mediante una onda de liberación de $\mathrm{Ca}^{2+}$ a lo largo de la membrana del RE (Fig. 12). Concretamente, en astrocitos estas ondas son dependientes de los depósitos de $\mathrm{Ca}^{2+}$, ya que se ha demostrado que, tanto una inhibición del $\mathrm{IP}_{3} \mathrm{R}$ (con heparina o 2-APB) como una inhibición de la bomba SERCA (con tapsigargina o ácido ciclopiazónico). Además, la inhibición de la PLC (con el inhibidor específico U73122) evita por completo, la propagación de estas ondas de $\mathrm{Ca}^{2+}$ (Leybaert y Sanderson, 2012).

En astrocitos, las ondas intercelulares de $\mathrm{Ca}^{2+}$ (Verkhratsky, 2013) fueron descritas por primera vez en cultivos primarios confluentes de hipocampo (Cornell-Bell y col., 1990), donde la aplicación localizada de glutamato provocaba un aumento de $\mathrm{Ca}^{2+}$ citosólico en la célula estimulada que se propagaba como una onda a través del citosol de varios cientos de glías. Normalmente, las ondas de $\mathrm{Ca}^{2+}$ se propagan a una velocidad de entre 10-20 $\mu \mathrm{M} / \mathrm{s}$, y pueden involucrar desde decenas a cientos de células contiguas (Leybaert y Sanderson, 2012). Estos datos indicaban que los astrocitos eran capaces de señalizar vía $\mathrm{Ca}^{2+}$ a través de largas distancias, de forma análoga a un potencial de acción neuronal. 


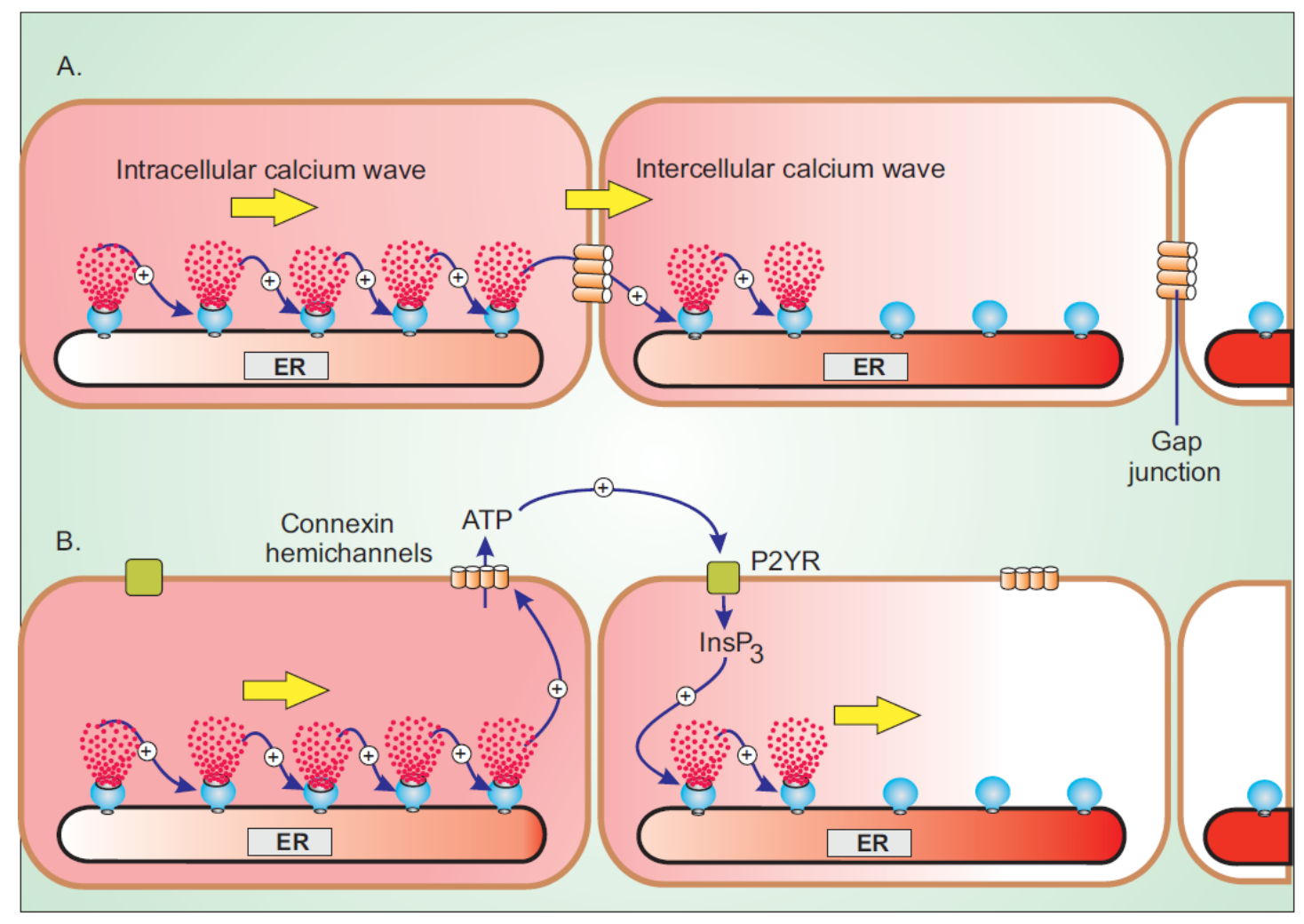

Figura 12. Mecanismos propuestos para la propagación de la onda de $\mathrm{Ca}^{2+}$ intracelular. Existen numerosos ejemplos de ondas de calcio que viajan de una célula a otra, aunque su mecanismo no está totalmente establecido. A. Cuando la onda intracelular de $\mathrm{Ca}^{2+}$ alcanza el límite de la célula, un mediador de baja masa molecular, difundiría a través de las uniones gap hasta la célula vecina. B. Un mecanismo alternativo propone que la onda intracelular en una célula estimula la liberación de ATP a través de hemicanales, que difunde hacia la célula vecina activando los receptores $\mathrm{P} 2 \mathrm{Y}$, y produciendo $\mathrm{IP}_{3}$ (Figura modificada de Berridge 2014).

Se ha propuesto tres hipótesis, no necesariamente excluyentes entre sí, para explicar la propagación de las ondas de $\mathrm{Ca}^{2+}$ entre células vecinas. La primera se basa en que pequeñas moléculas hidrofílicas permean a través de las uniones de tipo gap, formadas por hemicanales hexaméricos, que ponen en contacto los citoplasmas de células contiguas (Fig. 12A). Se ha propuesto que la propagación de la onda de $\mathrm{Ca}^{2+}$ se produciría debido al flujo del propio $\mathrm{Ca}^{2+}$ citosólico, o, alternativamente, del IP 3 (De Bock y col., 2014) a través de las uniones gap (Charles y col., 1992). Sin embargo, la difusión del $\mathrm{Ca}^{2+}$ a lo largo del citosol es lenta (constante de difusión de 13-65 $\mu \mathrm{M} / \mathrm{s}$ ), debido a la presencia de proteínas de unión a $\mathrm{Ca}^{2+}$, que retrasan su propagación. En contraposición, el $\mathrm{IP}_{3}$ es capaz de propagarse más rápidamente (coeficiente de difusión de 283 
$\mu \mathrm{M} / \mathrm{s})$, y por este motivo se suele considerar al $\mathrm{IP}_{3}$ como el principal responsable de la propagación de la onda.

La segunda hipótesis consiste en un mecanismo paracrino basado en la secreción dependiente de $\mathrm{Ca}^{2+}$ de gliotransmisores liberados al medio extracelular (Arcuino y col., 2002). Estos se unirían a los receptores específicos de membrana acoplados a proteínas $\mathrm{G}$ de las células adyacentes, activando así a la PLC, y generando $\mathrm{IP}_{3}$, que finalmente produciría la liberación de $\mathrm{Ca}^{2+}$ del RE en la célula vecina (Fig. 12B). Por último, la tercera hipótesis consiste en una combinación de las dos anteriores, una comunicación de mediadores citoplasmáticos a través de uniones gap y, al mismo tiempo, una señalización paracrina por liberación de gliotransmisores.

Se han observado ondas intercelulares de calcio en distintas preparaciones in vitro de astrocitos, tanto en cultivos en monocapa, como en rodajas agudas o en cultivos organotípicos (Scemes y Giaume, 2006). Pueden iniciarse por aplicación focal de ATP, carbacol, fenilalanina o estimulación mecánica. Actualmente existe cierta controversia acerca de la existencia de las ondas de $\mathrm{Ca}^{2+}$ citosólico in vivo, ya que hay referencias que sugieren que no encuentran ondas de $\mathrm{Ca}^{2+}$ en condiciones fisiológicas in vivo, mientras que otros trabajos sí las han registrado en astroglía de cerebro de roedores. Sin embargo, en este último caso, la propagación de las ondas parece estar restringida a astrocitos individuales o a un limitado número de células adyacentes, sin una gran propagación.

\subsection{Oscilaciones de $\mathrm{Ca}^{2+}$}

Algunos tipos celulares como los oocitos de Xenopus o los hepatocitos presentan oscilaciones del $\left[\mathrm{Ca}^{2+}\right]_{c}, y$ estas tienen una función relevante en la fertilización o la secreción celular respectivamente (Dupont y col., 2011). En astrocitos se han descrito oscilaciones del $\mathrm{Ca}^{2+}$ citosólico en diferentes preparaciones, desde cultivos de astrocitos puros hasta secciones de distintos tejidos. Estas oscilaciones pueden ser inducidas por una amplia gama de agonistas como el glutamato (Cornell-Bell y col., 1990; Morita y col., 2015), el 
NMDA (Parri y col., 2001), la histamina (Morita y col., 2015), el ATP (Jiang y col., 2005), la cafeína (Parri y col., 2001; Tashiro y col., 2002), o bajas concentraciones de $\mathrm{K}^{+}$extracelular (Beck y col., 2004). También se han registrado oscilaciones en astrocitos tras la estimulación neuronal (Porter y McCarthy, 1996; Parri y Crunelli, 2003) y en astrocitos reactivos en modelos de epilepsia (Tashiro y col., 2002).

Aunque el mecanismo responsable de las oscilaciones de la $\left[\mathrm{Ca}^{2+}\right]_{\mathrm{c}}$ aún no se ha esclarecido, se han propuesto dos modelos principales. El primer modelo se basa en los cambios en el potencial de membrana plasmática que conducen a la entrada de $\mathrm{Ca}^{2+}$ desde el medio extracelular. En primer lugar, la apertura de los canales de $\mathrm{K}^{+}$provoca una hiperpolarización de la membrana plasmática, que a su vez, conduce a una despolarización de la misma y a la apertura de canales iónicos de la membrana plasmática que permiten la entrada de $\mathrm{Na}^{+}$y $\mathrm{Ca}^{2+}$ (Fig. 13A). El otro mecanismo se basa en el oscilador citosólico, que depende de la liberación de $\mathrm{Ca}^{2+}$ de los depósitos intracelulares. La estimulación de los $I P_{3} R$ provoca liberaciones periódicas desde el RE (Fig. 13B). A su vez, se ha propuesto dos mecanismos para explicar las oscilaciones inducidas por $\mathrm{IP}_{3}$ : un modelo propone que las oscilaciones se producen por fluctuaciones periódicas en el nivel de $\mathrm{IP}_{3}$ provocadas por la fosfolipasa $\mathrm{C}$ (PLC); y el otro modelo propone que, a niveles constantes de $\mathrm{IP}_{3}$, las oscilaciones se producen por ciclos sucesivos de sensibilización y desensibilización de los canales de $\mathrm{Ca}^{2+}$ del $\mathrm{RE}$, ya sea el $\mathrm{IP}_{3} \mathrm{R}$ o el $\mathrm{RyR}$ (revisado por Berridge, 2014). Se ha demostrado que la inyección de $\mathrm{IP}_{3}$ en el citoplasma celular es capaz de desencadenar un comportamiento oscilatorio de liberación de $\mathrm{Ca}^{2+}$ en varios tipos celulares (Parker y Miledi, 1989).

En astrocitos se han descrito oscilaciones inducidas por glutamato como consecuencia de la activación de receptores metabotrópicos. Es interesante que los subtipos mGluR 1 y 5 muestren respuestas diferentes frente a la aplicación de glutamato, ya que el primero de ellos evoca un pico simple no oscilatorio, mientras que la estimulación del segundo es responsable de desencadenar oscilaciones de $\mathrm{Ca}^{2+}$ intracelular (Nakanishi, 1992). En astrocitos se ha demostrado que el mGluR5, activado por bajas concentraciones de 
agonista $(2-10 \mu \mathrm{M})$ es el responsable de las oscilaciones de $\mathrm{Ca}^{2+}$ tanto en cultivos primarios como in situ (Codazzi y col., 2001; Morita y col., 2015). Además, el glutamato puede ser liberado a partir de las neuronas en sinapsis activas (Cornell-Bell y col., 1990; Smith, 1994; Pasti y col., 1997), o a partir de los propios astrocitos (Parpura y col., 1994; Araque y col., 1998).

Además de las oscilaciones inducidas por agonistas, también se han registrado oscilaciones espontáneas, tanto en astrocitos de cultivos primarios (Fatatis y Russell, 1992), como en astrocitos in situ. Para demostrar la naturaleza espontánea de las oscilaciones se utilizó tetrodotoxina (TTX), y bafilomicina $\mathrm{A} 1$, para inhibir el transporte vesicular y la liberación de neurotransmisores (Nett y col., 2002). Las oscilaciones espontáneas se bloquearon al vaciar los depósitos de $\mathrm{Ca}^{2+}$, (con ácido ciclopiazónico o tapsigargina), o al inhibir el $I_{3} R$ (Nett y col., 2002; Parri y Crunelli, 2003), implicado en la participación de los depósitos intracelulares.

En relación a la regulación de las oscilaciones de $\mathrm{Ca}^{2+}$ inducidas por $\mathrm{IP}_{3}$ se ha involucrado a la proteína quinasa C (PKC). La PKC estaría fosforilando los receptores mGluR5 (Nakahara y col., 1997), que provocarían la fase de caída de $\mathrm{Ca}^{2+}$, es decir, reduce los incrementos de $\mathrm{Ca}^{2+}$ citosólicos provocados por agonistas de mGluR. Se ha demostrado que la inhibición de la PKC elimina las oscilaciones de $\mathrm{Ca}^{2+}$, provocadas tanto con glutamato como con histamina, $y$, en su lugar, se produce un incremento sostenido del $\mathrm{Ca}^{2+}$ citosólico (Codazzi y col., 2001). Un incremento de $\mathrm{Ca}^{2+}$ citosólico activa a la PKC, que, a su vez fosforila, e inhibe a los receptores metabotrópicos, por ejemplo el mGluR5 de glutamato, dando lugar a la fase de caída de la oscilación. A continuación, al disminuir la $\left[\mathrm{Ca}^{2+}\right]_{c}$ se inactiva la PKC, se desfosforila el mGluR5 y puede generarse nuevamente $\mathrm{IP}_{3}$ y liberar $\mathrm{Ca}^{2+}$ de los depósitos provocando otra oscilación (Cuthbertson y Cobbold, 1985; Bird y col., 1993). En la Figura 14 se muestra un esquema del mecanismo propuesto para explicar este comportamiento. 


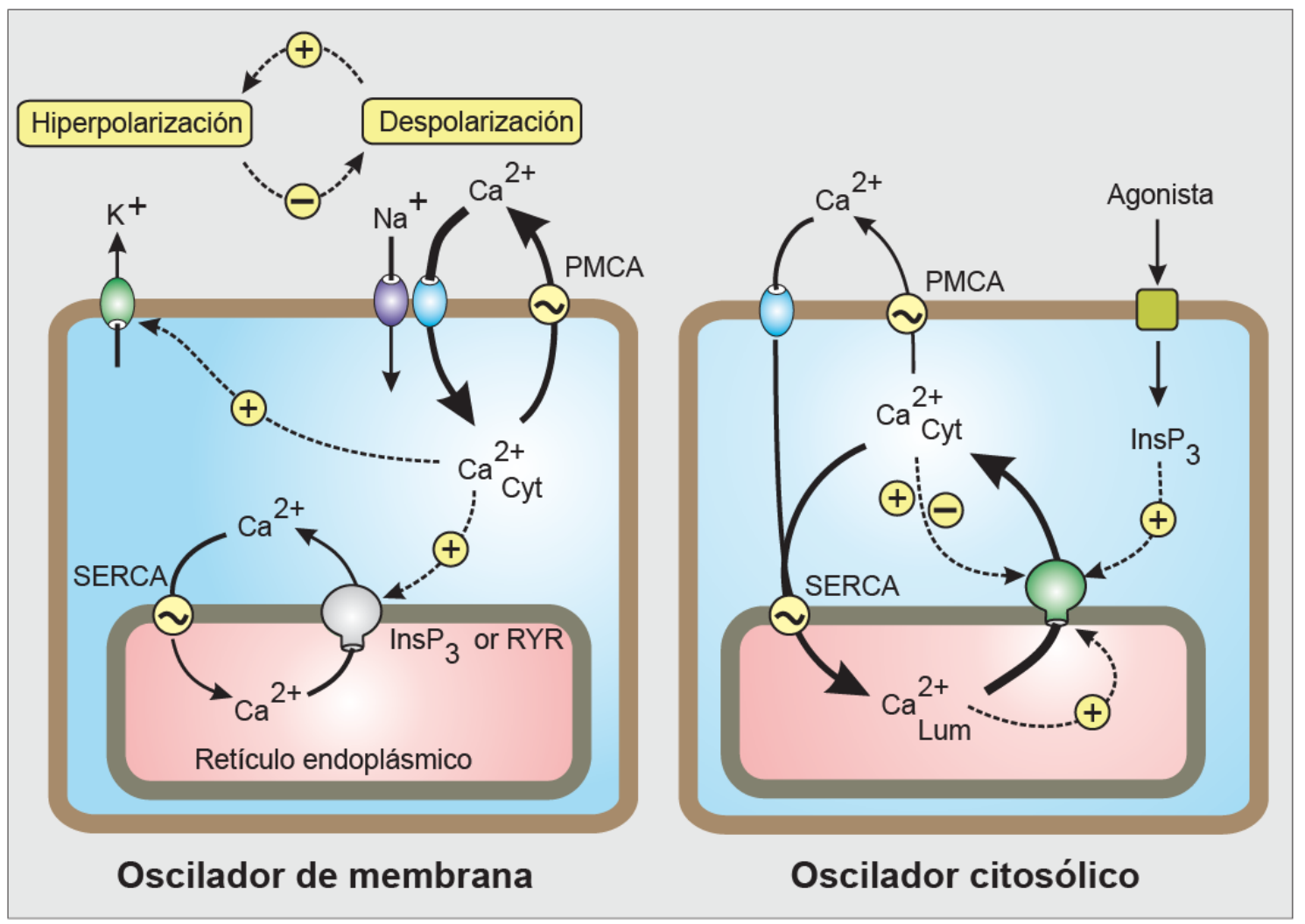

Figura 13. Modelos principales que explican las oscilaciones intracelulares. A. Las oscilaciones de membrana se producen por cambios en el potencial de la membrana plasmática. La apertura periódica de canales de $\mathrm{K}^{+}$produce una hiperpolarización de la membrana que conduce a una despolarización y a la apertura de canales de $\mathrm{Na}^{+}$y $\mathrm{Ca}^{2+}$. B. Por el contrario, las oscilaciones citosólicas se producen por liberaciones periódicas de $\mathrm{Ca}^{2+}$ a partir del $\mathrm{RE}$ a través de los $I \mathrm{P}_{3} \mathrm{R}$ (Figura modificada de Berridge., 2014).

Estos resultados concuerdan con la extensa literatura a cerca de los mecanismos de oscilaciones de $\mathrm{Ca}^{2+}$ en diferentes tipos celulares (revisado por Berridge, 1993, 1998).

Se estudió un modelo de astrocitos sometidos a condiciones epileptiformes (Tashiro y col., 2002), donde el circuito neocortical es hiperexcitable, y, como una consecuencia, el potasio extracelular y la concentración de glutamato están crónicamente elevados. Estas condiciones favorecen un estado de despolarización crónica de los astrocitos y como consecuencia se produce un incremento en la entrada de $\mathrm{Ca}^{2+}$ al citosol a través de los canales de $\mathrm{Ca}^{2+}$ voltaje dependientes (VOCs). El incremento de $\mathrm{Ca}^{2+}$ citosólico sirve para cargar 
los depósitos internos y también, para activar la libración de calcio de los depósitos a través de un mecanismo de CICR.

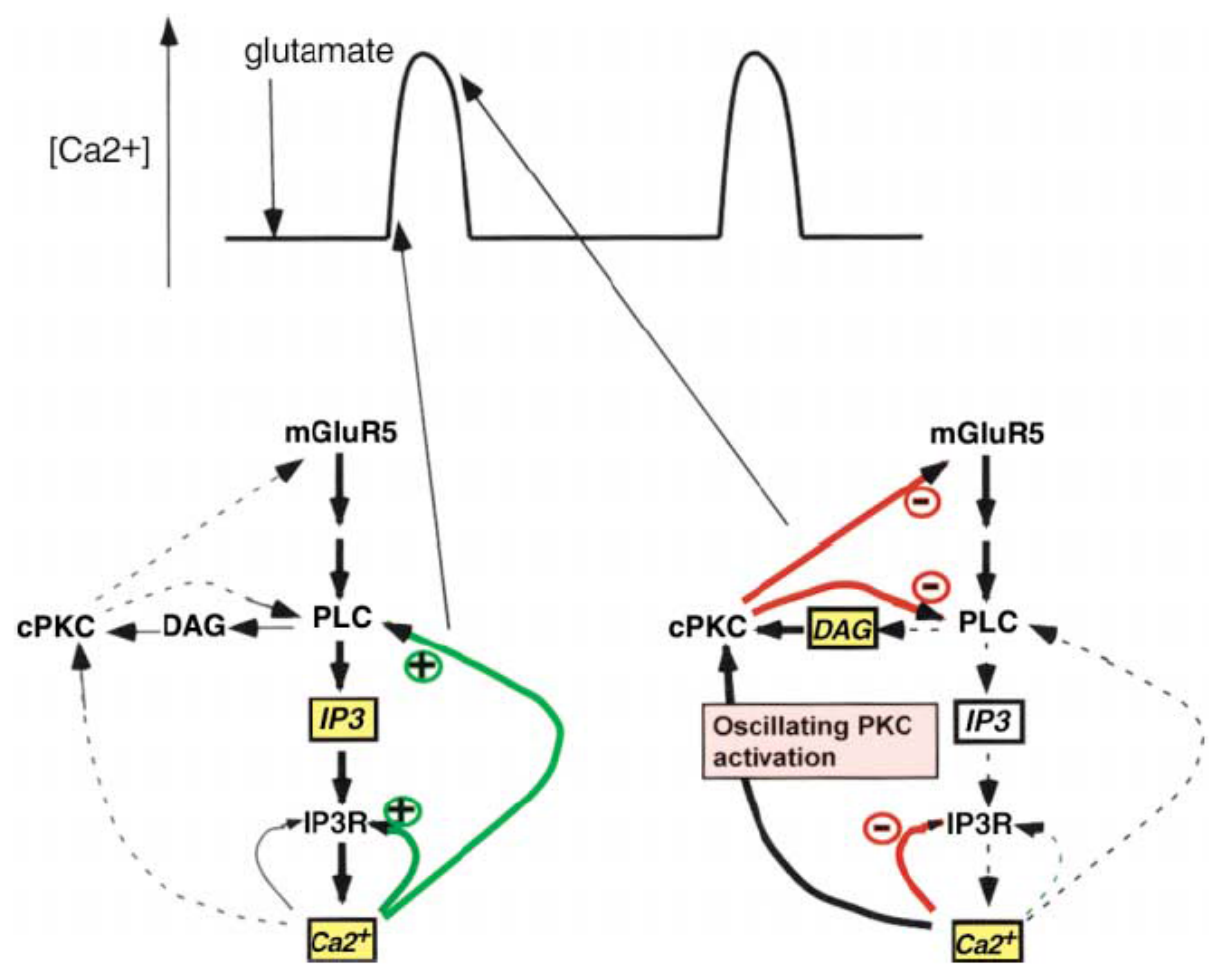

Figura 14. La activación de la PKC actúa como en un mecanismo de retroalimentación negativa involucrado en la generación de oscilaciones y ondas de $\mathrm{Ca}^{2+}$ en astrocitos. El modelo de mecanismo de retroalimentación positiva y negativa se propuso para explicar transitorios, oscilaciones y ondas de $\mathrm{Ca}^{2+}$. La retroalimentación positiva se muestra en la figura de la izquierda. DAG e $\mathrm{IP}_{3}$ conducen a la activación de la PLC y a la liberación de $\mathrm{Ca}^{2+}$ del $\mathrm{RE}$. En el esquema de la derecha se muestra la desensibilización del GPCR y la inhibición de la PLC como resultado de la fosforilación por PKC que termina con el transitorio de $\mathrm{Ca}^{2+}$ (Figura modificada de Codazzi y col., 2001).

Una gran variedad de factores pueden afectar a las oscilaciones de $\mathrm{Ca}^{2+}$ de diferentes maneras, desde incrementar la amplitud o la frecuencia de las mismas hasta inhibirlas. Un factor importante a tener en cuenta es la concentración de agonista, ya que se ha demostrado que la variación en la misma produce variaciones en los niveles de $\mathrm{IP}_{3}$ en las células y como consecuencia se modifican las oscilaciones. Además, la frecuencia de las oscilaciones también es muy sensible a variaciones en las concentraciones de $\mathrm{Ca}^{2+} \circ \mathrm{K}^{+}$extracelulares. Se ha demostrado que un cambio en la concentración 
de $\mathrm{Ca}^{2+}$ citosólico provoca cambios en la frecuencia de las oscilaciones. Éste rápido ajuste implica que las oscilaciones son muy sensibles al influjo de $\mathrm{Ca}^{2+}$ extracelular. Por otro lado, se han descrito que una disminución del $\mathrm{K}^{+}$ extracelular por debajo de $1 \mathrm{mM}$ provoca que se desencadenen oscilaciones citosólicas en células glíales, tanto en cultivos primarios como en secciones de tejido. Las oscilaciones varían desde pequeñas y lentas a grandes y rápidas. Estos transitorios pueden ser consecuencia de una entrada de $\mathrm{Ca}^{2+}$ del medio extracelular a través del canal rectificador de $\mathrm{K}^{+}$, que es permeable a $\mathrm{Ca}^{2+}$ en presencia de concentraciones bajas de $\mathrm{K}^{+}$extracelular (Dallwig y col., 2000). La cafeína puede modular las oscilaciones, ya que se ha demostrado que provoca un incremento en la frecuencia de las oscilaciones citosólicas en astrocitos del neocórtex, a través de la activación del RyRs, (Tashiro y col., 2002).

\section{Patologías relacionadas con la astroglía}

Se han descrito más de 600 enfermedades neurológicas, tanto en el SNC como en el periférico que la glía está involucrada. Entre las más conocidas encontramos enfermedades genéticas como la enfermedad de Huntington; patologías graves del desarrollo, como la espina bífida; enfermedades neurodegenerativas, como la enfermedad de Alzheimer y la de Parkinson; lesiones o traumatismos cerebro-vasculares; tumores cerebrales, como los gliomas; infecciones, como la meningitis; enfermedades mentales y trastornos de la personalidad, como el trastorno bipolar, las alteraciones del sueño y las adicciones; y otras, como la epilepsia. La alteración en la función homeostática de la glía contribuye al desarrollo de enfermedades neurológicas en el SNC, actuando a veces como elemento principal y otras veces, como un agente secundario involucrado en cambios en el entorno de las neuronas. Entre las primeras se encuentran las enfermedades genéticas.

La interrupción del flujo sanguíneo en el cerebro puede causar lesiones irreversibles $\mathrm{y}$, finalmente, la muerte neuronal. Puede estar causada por la rotura de un vaso sanguíneo que provocaría una hemorragia, o por una restricción del suministro de sangre al cerebro, o a parte del mismo, debido a una oclusión vascular o a un fallo cardiaco, produciendo una isquemia cerebral. 
El flujo sanguíneo normal es de unos $8 \mathrm{ml} / \mathrm{min}$, y cuando éste disminuye, se produce una isquemia. Cuando se interrumpe el flujo de sangre al cerebro durante 10-15 segundos se produce la pérdida de la conciencia, mientras que si la interrupción dura unos 30-40 segundos desaparece la actividad neuronal. Finalmente, una isquemia global que dure más de 10 minutos a temperatura fisiológica es letal para los humanos. La muerte neuronal se produce rápidamente, mientras que los astrocitos sobreviven en un primer momento, aunque se convierten en astrocitos reactivos o activados. La astrogliosis reactiva es una respuesta de defensa por parte de los astrocitos frente a una gran variedad de situaciones patológicas que afectan al SNC, tales como un traumatismo, daño isquémico, neuroinflamación o neurodegeneración. Se caracteriza porque los astrocitos poseen una expresión alterada de diversos genes y exhiben cambios morfológicos y funcionales (Pekny y Pekna, 2014).

La astroglía desempeña un papel dual en la isquemia, puede reducir o exacerbar el daño neuronal dependiendo de la magnitud y la duración del daño. Las neuronas localizadas en el centro de la lesión pierden su fuente intracelular de energía en forma de ATP lo que provoca una despolarización del axón, dando como resultado la pérdida de excitabilidad por disipación de los gradientes iónicos transmembrana. Esto conlleva a un flujo de iones $\mathrm{Na}^{+}$y $\mathrm{Ca}^{2+}$ hacia el interior celular, y una salida de iones $\mathrm{K}^{+}$. La concentración de $\mathrm{K}^{+}$en el medio extracelular aumenta hasta alcanzar 40-80 mM. Por otro lado, la entrada masiva de $\mathrm{Ca}^{2+}$ aumenta la $\left[\mathrm{Ca}^{2+}\right]_{\mathrm{C}}$ hasta ordenes en el rango de micromolar, lo que provoca la liberación de glutamato desde las terminales sinápticas. La acumulación de glutamato en el medio extracelular produce una excitotoxicidad glutamatérgica. Además, se produce un descenso del pH extracelular hasta valores de 6.5. Estos eventos culminan con la muerte de las neuronas y de la glía que se encuentran en el centro de la lesión, y afectan también a las células que se encuentran en las zonas de penumbra, que son las regiones contiguas al centro de la lesión.

Los astrocitos son más resistentes a la isquemia y ejercen un efecto protector ante el daño. En primer lugar, son menos sensibles a la excitabilidad por glutamato y son capaces de captarlo del medio extracelular a través de los 
transportadores de glutamato de su membrana. Además, también actúan como elementos protectores de la oxidación, ya que contienen altas concentraciones de antioxidantes como el glutatión y el ascorbato. Las neuronas liberan ascorbato oxidado, que es captado por los astrocitos y convertido nuevamente en ascorbato. Por otro lado, los astrocitos son capaces de realizar un metabolismo anaerobio en condiciones de hipoxia, produciendo sustratos energéticos como el lactato, la alanina y el $\alpha$-cetoglutarato, que pueden ser utilizados por las neuronas en condiciones de privación de glucosa. Como hemos mencionado previamente, los astrocitos están involucrados en el aclaramiento del exceso de $\mathrm{K}^{+}$que se acumula en el medio extracelular, disminuyendo la despolarización neuronal inducida por la acumulación de este ión y la consecuente liberación de glutamato. Los astrocitos también liberan factores neuroprotectores como la eritropoyetina, el factor de crecimiento endotelial vascular (VEGF) y el factor neurotrófico glíal (GDNF), que reducen el daño neuronal y promueve la recuperación funcional.

La epilepsia es otra patología en la que está implicada la glía. Resulta de la sincronización entre distintas redes neuronales, y se caracteriza porque las neuronas comienzan a disparar simultáneamente y presentan una despolarización muy lenta conocida como despolarización paroxística (PDS). El PDS se produce como resultado de un gran potencial excitatorio post-sináptico y dura entre 50-200 ms, y está normalmente mediado por glutamato a través de los receptores NMDA y AMPA. Cuando el PDS falla en terminar y provoca la despolarización sincrónica de varias neuronas, se producen convulsiones, uno de los principales marcadores de la epilepsia. La astrogliosis reactiva y las cicatrices glióticas son marcadores característicos de la epilepsia en humanos. Los astrocitos están involucrados en las etapas tempranas de la enfermedad, se convierten en astrocitos reactivos alterando su morfología, volviéndose hipertróficos, incrementado su número y perdiendo la organización en dominios definidos.

Finalmente, otro ejemplo de patología en la que están involucrados los astrocitos es la migraña. Uno de los mecanismos propuestos para explicar el ataque de migraña es una onda de despolarización cortical, que resulta en la 
acumulación de $\mathrm{K}^{+}$en el medio extracelular, que puede alcanzar concentraciones de hasta $80 \mathrm{mM}$, con las consecuencias antes descritas. En la llamada migraña hemipléjica de tipo 2, existe una mutación en la subunidad $\alpha 2$ de la bomba $\mathrm{Na}^{+} / \mathrm{K}^{+}$ATPasa de astrocitos, que expresa una variante aberrante, y esto conlleva a una alteración en la $\left[\mathrm{K}^{+}\right]$extracelular de los astrocitos que contribuye a una mayor propagación de la despolarización. 


\section{Objetivos}





\section{OBJETIVOS}

La excitabilidad glíal se basa fundamentalmente en el flujo de $\mathrm{Ca}^{2+}$ a través de la membrana de las organelas subcelulares y a la generación de señales de $\mathrm{Ca}^{2+}$ procedente de los depósitos intracelulares. En los astrocitos, como en el resto de células eucariotas de origen animal, el RE ocupa la mayor parte del citoplasma, extendiéndose desde el soma hasta los procesos más finos, y contiene en su interior la mayor reserva de calcio del citoplasma. Numerosos experimentos in vitro, in situ e in vivo en astrocitos han demostrado la expresión de una enorme variedad de receptores metabotrópicos, que, cuando se activan fisiológicamente, desencadenan la producción de $\mathrm{IP}_{3}$ y la consecuente liberación de $\mathrm{Ca}^{2+}$ (Verkhratsky, 2013). En la mayoría de los casos, la monitorización del $\mathrm{Ca}^{2+}$ citosólico sólo refleja vagamente los cambios espaciotemporales que se producen en el RE, y, aunque tengan su origen en dicho orgánulo, estas medidas no puede sustituir a las del $\mathrm{Ca}^{2+}$ luminal. Es decir, para descifrar las señales de $\mathrm{Ca}^{2+}$ procedentes del $\mathrm{RE}$ es esencial registrar directamente el $\mathrm{Ca}^{2+}$ reticular.

Objetivo general: Estudio de la dinámica del $\mathrm{Ca}^{2+}$ y los mecanismos de señalización involucrados en los astrocitos corticales.

\section{Objetivos específicos:}

- Caracterización de una nueva sonda bioluminiscente de baja afinidad por $\mathrm{Ca}^{2+}$ y su aplicación al estudio del $\mathrm{Ca}^{2+}$ en el RE.

- Generación y caracterización de vectores virales para su uso en cultivos primarios. Se probarán tanto vectores de expresión ubicua, como de expresión específica en los astrocitos. Estos vectores se utilizaran para expresar los indicadores de $\mathrm{Ca}^{2+}$ de la familia GAP.

- Realización de medidas en varias preparaciones, más o menos próximas a la situación fisiológica, incluyendo: cultivos de astrocitos (cultivos 
puros en monocapa y cultivos mixtos de neuronas y glías) y, cultivos organotípicos corticales.

- Medidas simultáneas de la $\left[\mathrm{Ca}^{2+}\right]_{\mathrm{RE}}$ y de la $\left[\mathrm{Ca}^{2+}\right]_{\mathrm{C}}$ mediante microfluorimetría con indicadores de la familia GAP dirigidos al RE e indicadores sintéticos de alta afinidad con compatibilidad espectral con los anteriores.

- Estudio del mecanismo de liberación de $\mathrm{Ca}^{2+}$ inducida por $\mathrm{Ca}^{2+}(\mathrm{CICR})$, para estudiar la presencia y el papel de este mecanismo en la modulación de la señal de $\mathrm{Ca}^{2+}$ en los astrocitos.

- Estudio de las oscilaciones de $\mathrm{Ca}^{2+}$ en los astrocitos tanto espontáneas como inducidas por agonistas. 


\section{Materiales y métodos}




\section{Reactivos}

Acetilcolina: Cloruro de Acetilcolina (Sigma, A2661).

AMPA: $\quad \alpha$-amino-3-hidroxi-5-metil-4-isoxazolepropiónico (Sigma, A6816); agonista de los receptores ionotrópicos de glutamato de tipo AMPA.

ATP: Adenosina trifosfato (Sigma, A3377), agonista de receptores purinérgicos ionotrópicos (P2X) y metabotrópicos (P2Y)

Cafeína: (Sigma, C0750), alcaloide del grupo de las xantina, que activa los receptores de rianodina (RyRs).

Carbacol: (Sigma, C4382), agonista colinérgico.

DHPG: (S)-3,5-Dihidroxifenilglicina (Tocris, 0342), agonista del grupo 1 de los receptores metabotrópicos de glutamato; mGluR1 y mGluR5.

EDTA: Ácido elilen-diamino-tetra acético (Sigma, E5134).

EGTA: Ácido etilenglicol-bis-(beta-amino-etil-éter)-N,N'-tetraacético (Molecular Probes, E-1219); quelante de calcio.

Furnidipino: dihidropiridina; bloqueante de los canales de $\mathrm{Ca}^{2+}$ VOCs tipo-L.

Glutamato: Acido L-Glutámico (Sigma, G1626), aminoácido neurotransmisor agonista de receptores glutamatérgicos (kainato, NMDA y AMPA).

HC030031: 2-(1,3-Dimethyl-2,6-dioxo-1,2,3,6-tetrahydro-7H-purin-7-yl)-N-(4isopropylphenyl) acetamide (Tocris, 2896); bloqueante selectivo del canal TRPA1.

Histamina: (Sigma, H7250); activador de receptores de histamina (H1 a 4).

Heparina: (Mayne pharma, 20094-A); inhibidor no permeable del IP ${ }_{3} R$.

IP $_{3}$ : Inositol 1,4,5-Trisfosfato (Sigma, 7012), agonista del receptor $I_{3} R$.

KB-E7943: (Tocris, 1244); inhibidor del intercambiador $\mathrm{Na}^{+} / \mathrm{Ca}^{2+}$

Lantano: cloruro de lantanto; bloqueante de canales de calcio de la membrana plasmática.

LY367385: Ácido (S)-(+)-a-Amino-4-carboxi-2-metilbenzeneacetico (Tocris, 1237); antagonista selectivo del receptor mGlu1a

MCPG: (RS)-a-Metil-4-carboxifenilglicina (Tocris, Cat. 0337); antagonista no selectivo de los receptores de glutamato del grupo I y II.

Níquel: cloruro de níquel (Merck, 106717); inhibidor de los canales de $\mathrm{Ca}^{2+}$ de la membrana plasmática. 
NMDA: N-metil-D-aspartato (Alomone, N-170); agonista del receptor de glutamato de tipo NMDA

Rianodina:

1H-Pyrrole-2-carboxylic

acid,

(3S,4R,4aR,6S,7S,8R,8aS,8bR,9S,9aS)-dodecahydro-4,6,7,8a,

$8 b, 9 a-$

hexahydroxy-3,6a,9-trimethyl-7-(1-methylethyl)-6,9-

methanobenzo[1,2]pentaleno[1,6-bc]furan-8-yl ester (Alomone, R-500), modulador del RyR.

TBH: 2,5-di-(tert-butil)-1,4-benzohidroquinona (Aldrich, 11,297-6); inhibidor reversible de la bomba SERCA.

Tapsigargina: (Calbiochem, 586005) inhibidor irreversible no competitivo de la calcio ATPasa del retículo sacro/endoplasmático (SERCA).

TTX: Citrato de Tetrodotoxina, Octahydro-12-(hydroxymethyl)-2-imino5,9:7,10a-dimethano-10aH-[1,3]dioxocino[6,5-d]pyrimidine-4,7,10,11,12-pentol citrate (Tocris, 18660-81-6); bloqueante reversible selectivo del canal de $\mathrm{Na}^{+}$.

2-APB: 2-aminoetoxidifenil borato (CALBIOCHEM-Bionova, 524-95-8); modulador permeable de $\mathrm{IP}_{3} \mathrm{R}$, inhibe la liberación de $\mathrm{Ca}^{2+}$ sin afectar la unión del $\mathrm{IP}_{3}$ a su receptor. No afecta la liberación de calcio a partir del RyR.

4-CmC: 4-cloro-m-cresol (Sigma, 59-50-7); agonista del RyR. 


\section{Plásmidos}

En esta Tesis se han utilizado los plásmidos que se detallan en la Tabla 2 para expresar diferentes proteínas, como los sensores GAP o la SERCAcherry, en diferentes tipos celulares. Se utilizaron diferentes métodos de trasducción, como transfección o infecciones con vectores virales.

\begin{tabular}{|c|c|c|c|}
\hline Gen & pcDNA3 & pHSVpuc & pAAV \\
\hline erGA & pcDNA3-erGA & pHSV-erGA & - \\
\hline IgGAP1 & pcDNA3-IgGAP1 & pHSV-IgGAP1 & - \\
\hline erGAP3 & - & - & pAAV-erGAP3 \\
\hline SERCA-cherry & pcDNA3-Cherry-SERCA2b & - & - \\
\hline
\end{tabular}

Tabla 2. Lista de plásmidos empleados en esta Tesis.

\subsection{Plásmidos derivados del pcDNA3}

El plásmido pcDNA3 (Invitrogen, V790-20) es un vector de expresión en eucariotas, de 5,4 kb de tamaño, que posee el promotor del citomegalovirus humano (hCMV). Posee los genes de resistencia a la ampicilina para su amplificación en bacterias, y a la neomicina para la selección en células eucariotas. En esta Tesis se utilizaron los vectores del pcDNA3: pcDNA3-erGA (GFP-Aequorin) y el pcDNA3-IgGAP1 (GFP-Aequorin-Protein).

El plásmido pcDNA3-erGA contiene la fusión lg- $\gamma$-2b-EGFP-Aeq ${ }^{\mathrm{D} 119 \mathrm{~A}}$. En esta construcción el $\mathrm{N}$-terminal de la aequorina está fusionado al C-terminal de la EGFP mediante un péptido de 9 residuos con la secuencia SGGSGSGGQ (Baubet et al., 2000). La aequorina está mutada en la posición 119, perteneciente al segundo dominio de unión al calcio, por una sustitución de un aspártico por una alanina. La direccionalidad al RE se obtuvo mediante la fusión a $2.8 \mathrm{~kb}$ de la secuencia de la cadena pesada de la inmunoglobulina G2b (Igy2b) (Chamero y col., 2008; Manjarres y col., 2008). 
El plásmido pcDNA3-IgGAP1, contiene el gen IgGAP1, que consiste en el gen de la aequorina (D117A, D119A y D163A) y la GFPuv, fusionados mediante un péptido de 16 residuos. La direccionalidad y retención en el RE se realizó mediante la fusión al gen de la cadena pesada de la inmunoglobulina al igual que para la fusión erGA (Rodriguez-Prados y col., 2015).

\subsection{Plásmidos derivados del vector vírico pHSVpuc}

Este plásmido se utilizó para generar virus de tipos herpes. Posee un tamaño de $4.8 \mathrm{~kb}$, y contiene secuencias de procariotas, como el origen de replicación bacteriano (ori), y el gen de resistencia a la ampicilina, lo que permite su amplificación en bacterias. Además, contiene secuencias derivadas del virus Herpes simplex tipo 1 (HSV) como el origen de replicación vírico HSVoriS, el promotor IE4/5 (Immediate Early) y la secuencia de empaquetamiento del HSV-1. En este plásmido se clonaron las secuencias erGA e IgGAP1 (Rodríguez-García y col., 2014).

pHSV-erGA. La sonda de baja afinidad dirigida al RE, erGA, estaba disponible en nuestro laboratorio en el vector pHSVpUC dando lugar al pHSV-erGA (Alonso y col., 1998).

pHSV-IgGAP1. El vector pHSV-GA se cortó con la enzima EcoR1 que liberó el inserto GA y el fragmento de $4.8 \mathrm{~kb}$ correspondiente al vector vacío se purificó con el Kit Gel Band Purification Kits (GE Healthcare Life Science). Asimismo, el plásmido pcDNA3-IgGAP1 se digirió con el mismo enzima EcoR1 para aislar el fragmento de $3.8 \mathrm{~kb}$ del gen IgGAP1. Ambos fragmentos se ligaron mediante el enzima ligasa T4 (Thermo Fisher Scientific), comprobando la orientación del inserto mediante digestiones individuales con los enzimas Xbal o Kpnl. La secuencia del plásmido resultante, denominado pHSV-IgGAP1 (Fig. 15), se verificó por secuenciación. 

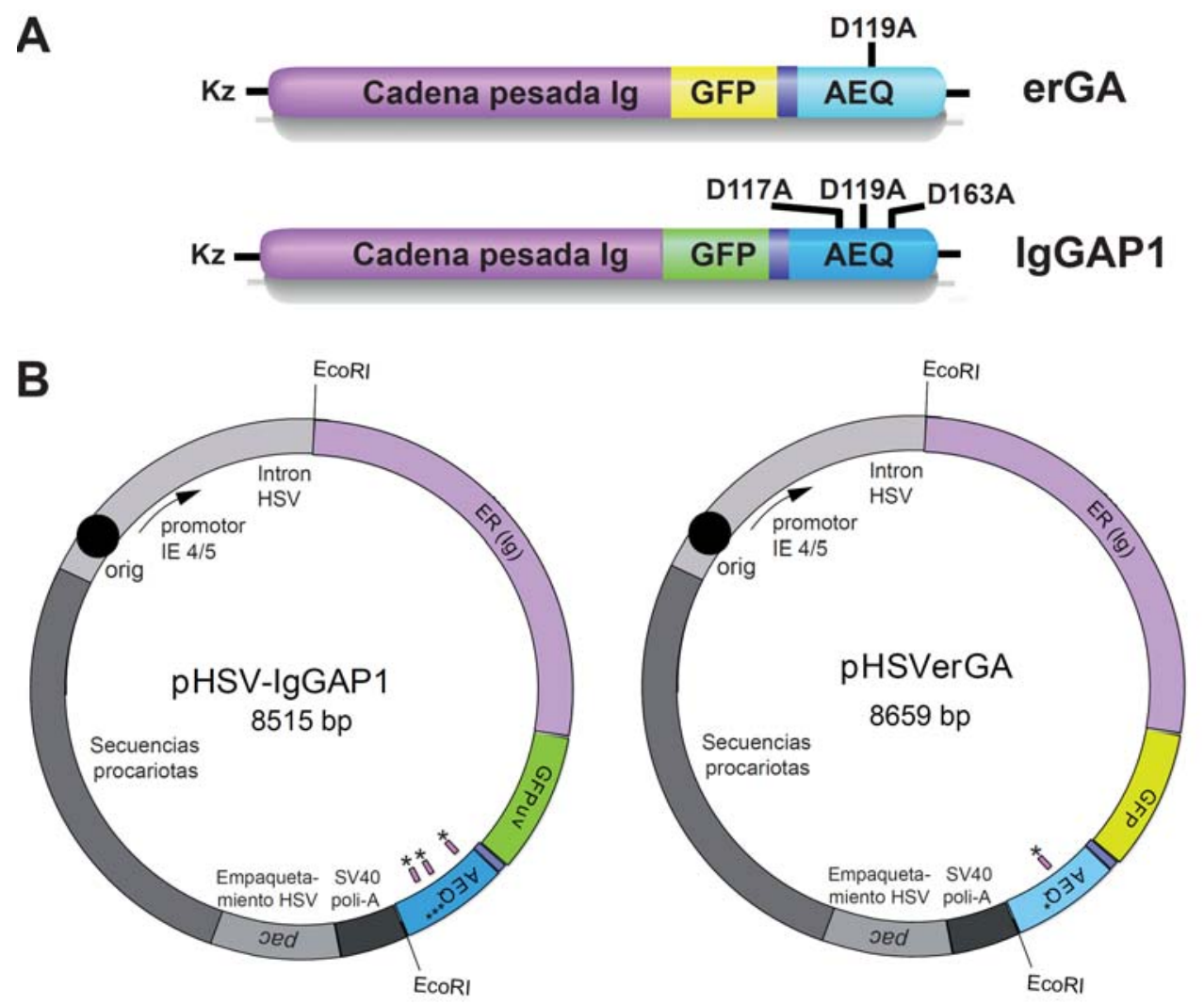

Figura 15. Constructos bioluminiscentes. A. Dominios estructurales de erGA e IgGAP1. Se muestra el constructo erGA conformado por la cadena pesada de la Ig en morado, la GFP en amarillo, el péptido de unión en azul y la aequorina en celeste claro. La mutación D119A en la aequorina está indicada. Inmediatamente debajo, se muestra el constructo correspondiente a la IgGAP1: la cadena pesada de la lg en morado, la GFPuv está representada por una caja verde y se indican las mutaciones en la aequorina D117A, D119A, y D163A. B. Mapas esquemáticos de los vectores pHSV-erGA (Alonso y col., 1998) y pHSV-lgGAP1. Ambos amplicones contienen en común elementos del vector pHSVpuc; la unidad de transcripción contiene el promotor IE 4/5 (representado por una flecha negra), el gen quimérico (erGA o IgGAP1) y una señal de poliadenilación. Dos elementos genéticos de HSV-1, el ori y las secuencias de empaquetamiento HSV, permiten la replicación y empaquetado del amplicón. Secuencias procariotas que contienen un origen de replicación bacteriano y un marcador de selección con ampicilina, permiten la propagación y amplificación en bacterias E.coli.

\subsection{Plásmidos derivados del pAAV}

pAAV-GFAP-erGAP3. El vector plasmídico pAAV-GFAP-hChR2 (H134R)EYFP cedido por el Dr. Deisseroth (Standford, USA), de 7,9 kb de tamaño, contiene el promotor de la proteína ácida fibrilar glial (GFAP) específico de astrocitos (Brenner y col., 1994). El gen erGAP3 (Fig. 16A) se clonó en dicho vector, sustituyendo al fragmento hChR2 (H134R)-EYFP. El gen GAP3 es una 
fusión de la aequorina mutada en los residuos D119A y D24N, y fusionada a la secuencia de la GFPuv, que porta las mutaciones F99S, M153T y V163A, y adicionalmente las mutaciones S175G, D180Y, I167V y L15Q que se introdujeron en un trabajo previo (Navas-Navarro y col., 2016). En este caso, la direccionalidad y retención de GAP3 en el RE (erGAP3) se basa en la fusión de la secuencia de la calreticulina en el extremo N-terminal de la GFPuv, y de KDEL en el extremo C-terminal de la aequorina.

En primer lugar, el plásmido pAAV-GFAP-hChR2(H134R)-EYFP se digirió con las enzimas EcoRl y BamH1 (Fermentas, ER0054) y se purificó un fragmento de $6.2 \mathrm{~kb}$ correspondiente al vector vacío. Por otro lado, el gen erGAP3-kdel de 1,4 kb, se amplificó por PCR a partir del plásmido pcDNA3-erGAP3-kdel, utilizando la enzima DNA polimerasa de alta fidelidad Pfu (Thermo Fisher Scientific), y los siguientes cebadores: ccaggatccccgccaccatgctcctc (directo) y atgaattcctacagttcatcctttggc (reverso), que introducen los sitios de restricción para las enzimas BamH1 y EcoR1, en los extremos 5' y $3^{\prime}$, respectivamente. El producto de PCR resultante de $1.4 \mathrm{~kb}$ se digirió con las enzimas $\mathrm{BamH1}$ y EcoR1. El vector y el fragmento se ligaron con la enzima ligasa T4 para generar el plásmido pAAV-GFAP-erGAP3 (Fig. 16), que se utilizó para producir virus adenoasociados. Los plásmidos utilizados para el empaquetamiento de vectores AAV fueron: pHelper y pAAV-DJ cedidos por el Dr. Miguel Ángel de la Fuente (IBGM). 


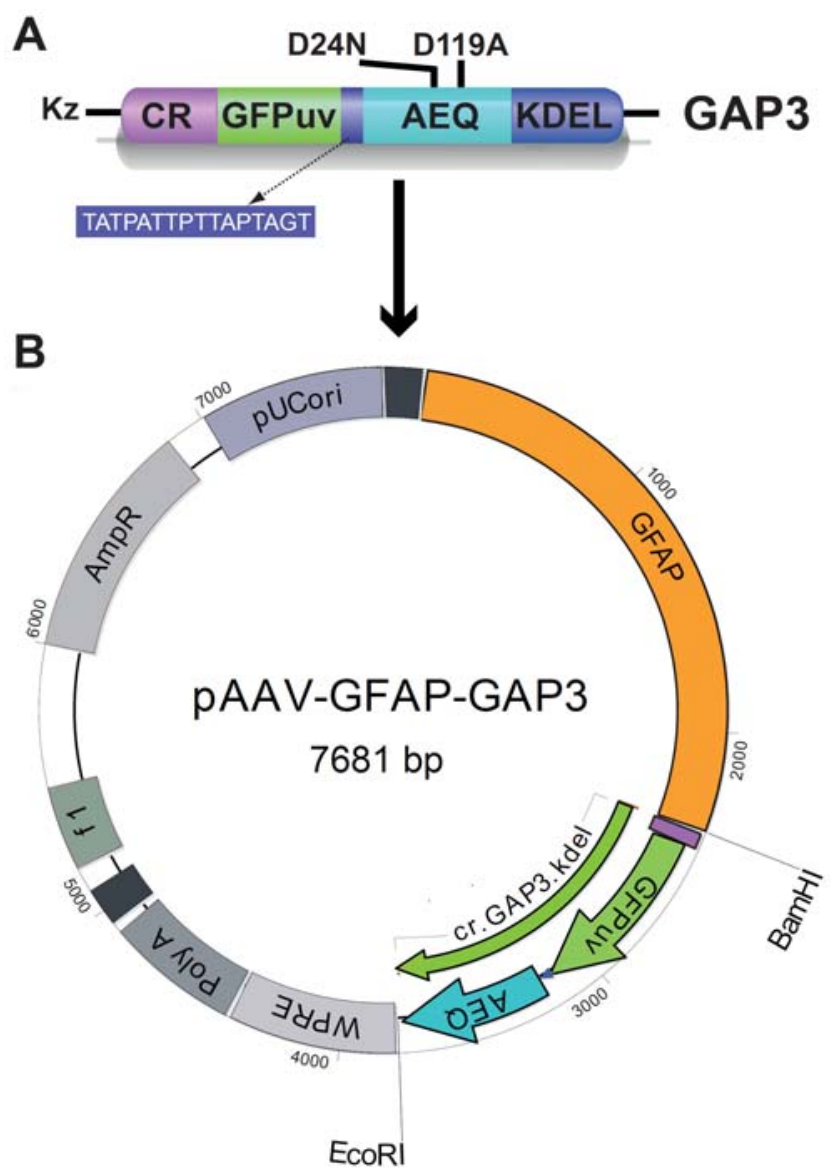

Figura 16. Proteína quimérica fluorescente erGAP3 y de su amplicon pHSV. A. Dominio estructural de erGAP3 (Navas-Navarro y col., 2016): donde se muestra el constructo conformado por aequorina (en celeste claro) mutada en D119A y D24N, unida a la GFPuv mediante un péptido, y flanqueada por la secuencia de direccionalidad al RE calceticulina y la secuencia de retención KDEL. B. Mapa esquemático del vector pAAV-GFAP-erGAP3. La unidad de transcripción contiene el promotor GFAP específico de astrocitos (representado por una caja naranja), y el gen quimérico erGAP3 (representado por la flecha verde). También se muestran los principales elementos del plásmido: WPRE; la señal de poliadenilación (hGH Ploy A); las repeticiones terminales largas ITR, $R$ y $L$; el origen de replicación (f1 origin); el gen de resistencia a ampicilina (AmpR); y el pUCori.

\section{Células}

\subsection{Líneas celulares inmortalizadas}

En esta Tesis se han utilizado las líneas celulares descritas a continuación en la Tabla 3. Además, también se han utilizado líneas estables derivadas de las células HeLa: las líneas HeLa-erGA y HeLa-IgGAP1, esta última se ha generado específicamente para este trabajo de Tesis. 


\begin{tabular}{||c|c|c|c||}
\hline Nombre & Origen & $\begin{array}{c}\text { Características } \\
\text { específicas }\end{array}$ & Procedencia \\
\hline $\begin{array}{c}\text { HeLa } \\
\text { (Henrrieta } \\
\text { Lacks) }\end{array}$ & $\begin{array}{c}\text { Adenocarcinoma } \\
\text { epitelial humano } \\
\text { adulto de cuello de } \\
\text { útero }\end{array}$ & $\begin{array}{c}\text { Morfología epitelial } \\
\text { adherente }\end{array}$ & ATCC (CCL-2) \\
\hline $\begin{array}{c}\text { HEK 293T } \\
\text { (Human } \\
\text { Embrionic } \\
\text { Kidney) }\end{array}$ & $\begin{array}{c}\text { Células embrionarias } \\
\text { de epitelio de riñón } \\
\text { humano }\end{array}$ & $\begin{array}{c}\text { Morfología epitelial } \\
\text { adherente. Resistentes } \\
\text { a geneticina (G418). } \\
\text { Expresan el antígeno } \\
\text { T del SV40 }\end{array}$ & ATCC (CRL- \\
\hline AAV293 & HEK 293T & $\begin{array}{c}\text { Expresan los genes de } \\
\text { los adenovirus (E1a y } \\
\text { E1b) y participan en la } \\
\text { transactivación de } \\
\text { promotores virales. } \\
\text { Esto garantiza una alta } \\
\text { expresión }\end{array}$ & Cell biolabs, Inc \\
(Ref. 240073)
\end{tabular}

Tabla 3. Líneas celulares utilizadas y sus principales características

La línea estable HeLa-erGA se generó mediante electroporación de células HeLa silvestres. En primer lugar se linealizó el plásmido pcDNA3-erGA por digestión con el enzima SCAI, se prepararon $15 \mu \mathrm{g}$ de DNA con $2 \mu \mathrm{l}$ del enzima SCAI y $10 \mu \mathrm{l}$ del buffer SCAI en $73 \mu$ de agua y se incubaron durante 2 horas a $37^{\circ} \mathrm{C}$. El DNA se corrió en un gel de agarosa al $0.8 \%$, se purificó con el Kit Gel Extraction (Qiagen, 28704) y se almacenó a $-20^{\circ} \mathrm{C}$. El día previo a la electroporación se sembró una placa confluente de células HeLa silvestres para obtener $4 \times 10^{6}$ células en medio Dubecco's Modified Eagle's Medium (DMEM), (Lonza, 12-604) suplementado con 10\% (v/v) de suero fetal bovino (FBS, bovine fetal serum, Cambrex, DE-14-801F), $2 \mathrm{mM}$ de L-glutamina (Lonza, BE17-605E), $100 \mathrm{U} / \mathrm{ml}$ de penicilina y $100 \mu \mathrm{g} / \mathrm{ml}$ de estreptomicina (Lonza, DE17-602-E), y se incubaron en una atmosfera de $5 \%$ de $\mathrm{CO}_{2}$, a $37^{\circ} \mathrm{C}$. Al día siguiente, se recogieron las células, se centrifugaron a $200 \mathrm{~g}$ y se 
resuspendieron en $400 \mu \mathrm{l}$ en medio DMEM completo. Se utilizó el electroporador Gene Pulser Xcel ${ }^{\mathrm{TM}}$ Electroporation System (Bio-Rad; \#1652660). Las células se colocaron en una cubeta de electroporación de $4 \mathrm{~mm}$ y se añadieron 3-5 $\mu \mathrm{g}$ de DNA linealizado a la cubeta. Las células se electroporaron con un pulso de 7 milisegundos con un voltaje de $260 \mathrm{~V}$, una capacitancia de 850 uf y una resistencia de 720 Ohms. A continuación, se añadieron $600 \mu \mathrm{l}$ de medio DMEM completo a la cubeta, se recogieron las células y se sembraron en una placa p100. Al día siguiente, se renovó el medio de cultivo DMEM completo y se lo suplementó con $800 \mu \mathrm{g} / \mathrm{ml}$ de G418 (Gibco, 11811-023) para seleccionar las células resistentes que habían incorporado el DNA.

Tras 24 horas de incubación con el antibiótico las colonias se observaron bajo luz UV utilizando un microscopio de fluorescencia invertido Nikon Eclipse (TS 100) con los filtros adecuados para la GFP y se seleccionó una de las colonias verdes. Se retiró el medio de cultivo, se lavó con PBS, ( $\mathrm{NaCl}, 137$ mM; $\mathrm{KCl}, 2.7 \mathrm{mM}$; $\mathrm{Na}_{2} \mathrm{HPO}_{4}, 10 \mathrm{mM} ; \mathrm{KH}_{2} \mathrm{PO}_{4}, 2 \mathrm{mM}$; pH 7.4) para quitar los restos de suero, y se recogió la colonia seleccionada despegándola mediante una resuspensión con $10 \mu \mathrm{l}$ de tripsina-EDTA al 0.05\% (Gibco, 25300) utilizando una pipeta automática p100 en la zona localizada donde se encontraba el clon. Con las células obtenidas de la colonia seleccionada se realizó una dilución límite en una placa de 96 pocillos con medio DMEM completo ( 0.5 células por pocillo). Antes de que las células se adhirieran a la placa se seleccionaron los pocillos que contenían una sola célula. Tras 7 días de incubación, de los pocillos seleccionados se eligieron los que contenían una colonia de células fluorescentes verdes. A continuación, las células se amplificaron progresivamente y los clones obtenidos se almacenaron en viales estériles y en nitrógeno líquido.

La línea estable HeLa-IgGAP1 fue generada mediante la transfección del plásmido pcDNA3-lgGAP1 en células HeLa silvestres. El día anterior a la transfección se sembraron 2 placas de $60 \mathrm{~mm}$ con células HeLa silvestres en medio DMEM completo, a una densidad suficiente para obtener un $80 \%$ de confluencia en 24 horas. Al día siguiente, se transfectaron $2 \mu \mathrm{g}$ del plásmido 
con el método de la LipofectAMINE 2000 (Invitrogen, 11668-019), en una proporción 1:3 siguiendo el procedimiento que se explica más adelante en el punto 4. Transfección. A las 6 horas se reemplaza el medio de transfección por medio DMEM completo. Transcurridas 24 horas tras la transfección se renovó el medio por medio DMEM completo fresco suplementado con $800 \mu \mathrm{g} / \mathrm{l}$ de G418 para seleccionar las células que contenian el plásmido de interés, que les da resistencia a este antibiótico. Una vez obtenidas las diferentes colonias de células fluorescentes verdes, se seleccionaron y se realizó una dilución límite de forma idéntica a la descrita para el clon HeLa-erGA. Los clones obtenidos se amplificaron progresivamente y cuando se obtuvieron suficientes células se realizó una reselección mediante citometría de flujo (citómetro BD FACSaria $^{\mathrm{TM}}$ ) con el láser violeta a una longitud de onda de $403 \mathrm{~nm}$. Las células verdes obtenidas se sembraron en una placa de $100 \mathrm{~mm}$ en medio DMEM completo. Todos los clones generados fueron evaluados funcionalmente y aquellos que ofrecieron mejores características tanto funcionales como de mantenimiento se utilizaron para realizar los experimentos.

Todas las líneas celulares se mantuvieron en cultivo en placas de $100 \mathrm{~mm}$ con $10 \mathrm{ml}$ del medio DMEM completo, en una atmosfera de $5 \%$ de $\mathrm{CO}_{2}$, a $37^{\circ} \mathrm{C}$. Los clones estables HeLa-IgGAP1 y HeLa-erGA se mantuvieron en el mismo medio, suplementado con $0.2 \mathrm{mg} / \mathrm{ml}$ de G-418. Todas las líneas se subcultivaron cada 3 días, a una dilución 1:3, mediante el siguiente protocolo: en primer lugar, las células se lavaron con PBS, para eliminar el suero y las células no adheridas; a continuación, se agregó $1 \mathrm{ml}$ de tripsina-EDTA al 0.25\% $(\mathrm{v} / \mathrm{v})$ y se incuban durante 2 minutos a $37^{\circ} \mathrm{C}$; una vez despegadas, las células se recogieron en $4 \mathrm{ml}$ de DMEM suplementado, con el fin de inactivar la tripsina con el suero. Las células recogidas se centrifugaron a $200 \mathrm{~g}$ durante 5 minutos; $y$, finalmente, se resuspendieron a la densidad deseada en el medio de cultivo completo. Para los experimentos de luminiscencia, las células se sembraron a una densidad de 1000 células $/ \mathrm{mm}^{2}$, bien directamente, en placas de 4 pocillos, o sobre cubreobjetos de $12 \mathrm{~mm}$ de diámetro, previamente tratados con 0.1 $\mathrm{mg} / \mathrm{ml}$ de poli-L-lisina (Sigma, P1274). El tratamiento consiste en incubar los cubreobjetos con una solución de $0.01 \mathrm{mg} / \mathrm{ml}$ de poli-L-lisina (en agua) durante una noche, y posteriormente lavarlos con agua destilada y secarlos. 


\subsection{Cultivos primarios}

\subsubsection{Cultivo puro de astrocitos corticales murinos}

Se decapitaron 2 o 3 ratones en estadio P2 a P4. Las cabezas se colocaron en una placa de Petri con medio HBSS (Hank's Balanced Salt Solution) sin $\mathrm{Ca}^{2+} \mathrm{ni} \mathrm{Mg}^{2+}$ (Gibco, 35050-038), suplementado con $10 \mathrm{mM}$ de glucosa y $0.05 \%(\mathrm{p} / \mathrm{v})$ de albúmina de suero bovino (BSA), a $4{ }^{\circ} \mathrm{C}$. Inmediatamente después se aislaron los cerebros, realizando una incisión medio-sagital bajo la lupa (Zeiss Stemi DV4). Los hemisferios corticales se separaron de otros tejidos cerebrales y de las meninges, y se trocearon en pequeños fragmentos. A continuación, el tejido se transfirió a un tubo que contenía una mezcla de $0.5 \mathrm{mg} / \mathrm{ml}$ de papaina (Worthington, LS003119) y 0.04 $\mathrm{mg} / \mathrm{ml}$ de DNAasa (Roche, 10104159001) disueltas en $5 \mathrm{ml}$ de HBSS completo y se incubaron durante 20 minutos a $37^{\circ} \mathrm{C}$ con agitación. Los fragmentos de tejido se dejaron decantar y se retiró la solución enzimática mediante succión con vacío. El tejido se lavó tres veces agregando $5 \mathrm{ml}$ del mismo medio HBSS frío cada vez, y retirándolo con vacío. Finalmente, se el tejido se resuspendió en $1 \mathrm{ml}$ de medio Neurobasal (Gibco, 21103-049) suplementado con 0.04 $\mathrm{mg} / \mathrm{ml}$ DNAasa y $10 \% \mathrm{FBS}$, para inactivar la papaína. Los trozos de tejido visibles se disgregaron mecánicamente mediante la resuspensión 20-30 veces con una pipeta Pasteur de vidrio estéril con la punta esmerilada. El medio que contenía las células disociadas se trasvasó a otro tubo, se centrifugó a $200 \mathrm{~g}$ durante 5 minutos y se resuspendieron las células en $5 \mathrm{ml}$ de medio Neurobasal suplementado con B27 al 2\% (v/v) (Gibco, 17504-044); penicilina/estreptomicina $100 \mathrm{UI} / \mathrm{ml}$, Glutamax $2 \mathrm{mM}$ (Gibco, 35050-038) y FBS al $2.5 \%(\mathrm{v} / \mathrm{v})$. Las células se sembraron en un frasco de cultivo de $75 \mathrm{~cm}^{2}$ y se mantuvieron a $37^{\circ} \mathrm{C}$ en atmósfera humidificada, con $5 \%$ de $\mathrm{CO}_{2}$.

Con el fin de obtener un cultivo puro de astrocitos, se realizó la separación mecánica de los dos tipos celulares mayoritarios, astrocitos y neuronas. Se siguió un protocolo basado en el descrito por (Kaech y Banker, 2006), que elimina las neuronas debido a que su adherencia a la superficie de la placa es 
menor a la de los astrocitos. El procedimiento consistió en mantener el cultivo en las condiciones descritas previamente durante dos días, para la adhesión de los astrocitos a la superficie del frasco y su proliferación. Al tercer día, el frasco de cultivo se golpeó enérgicamente entre 10 y 15 veces sobre una superficie plana, y se lavó 2 veces con medio HBSS para eliminar las células no adheridas. Se aspiró el medio de cultivo y se agregó medio Neurobasal fresco suplementado, devolviendo el cultivo al incubador en las condiciones previas. Este procedimiento se repitió al quinto día. Al cabo de una semana se tripsinizaron las células con $0.25 \%(\mathrm{v} / \mathrm{v})$ de tripsina-EDTA, recogiéndose alrededor de $5 \times 10^{5}$ células en total. Se sembraron en el mismo medio a una densidad de $2 \times 10^{4}$ células por cubreobjeto de $12 \mathrm{~mm}$ de diámetro tratados con poli-L-lisina (Sigma, P5899). Los experimentos se realizaron a partir del séptimo día tras la siembra cuando los cultivos estaban confluentes, hasta un máximo de 3 semanas, renovándose el medio una vez por semana.

La mayor parte de los experimentos mostrados en esta Tesis se realizaron con cultivos obtenidos a partir de ratones C57/BL6. Los experimentos del apartado 4. (Oscilaciones y ondas de calcio intracelular en los astrocitos) de resultados se realizaron a partir de ratones transgénicos erGAP3 de la línea 10 (NavasNavarro y col., 2016). Este transgénico se ha generado según el procedimiento que se describe a continuación. El gen correspondiente a erGAP3 se clonó en un vector de expresión pCAG para generar el plásmido pCAG.erGAP3 de 5 kb, que contiene todos los elementos necesarios para la correcta expresión del transgen en mamiferos. Se digirió con Sspl/BsaBI para eliminar los elementos procariotas y se purificó en un gel de agarosa al $0.7 \%(p / v)$. El DNA se microinyectó en oocitos de la cepa de ratones B6CBAF2/OlaHsd (Harlan), utilizando técnicas estandarizadas en la Unidad de Transgénesis del Centro Nacional de investigaciones Cardiovasculares (Madrid). El genotipado se realizó por PCR a partir de ADN genómico, obtenido de biopsias de la cola de los ratones. Los ratones erGAP3 exhiben una expresión ubicua del sensor en diversos tejidos y órganos. Se encontró expresión en el cerebro, el músculo esquelético, el músculo cardíaco, el musculo liso, el vaso, el páncreas, el riñon, el hígado, el estómago, el intestino, el organo vomeronasal, el ojo, la piel, las 
gonadas, y los cartílagos entre otros. Los ratones son fértiles y viables, y se desarrollan con normalidad hasta la etapa adulta.

Los animales se mantuvieron y manupuraron de acuerdo a los reglamentos y directrices aprobados por el comité de cuidado de animales de la Universidad de Valladolid.

\subsubsection{Cultivo mixto de astrocitos y neuronas de corteza}

El cultivo mixto se realizó a partir de corteza cerebral de ratón, obtenida mediante el mismo procedimiento descrito en el punto anterior. En este caso, tras la disgregación mecánica del tejido, las células se sembraron directamente en cubreobjetos de $12 \mathrm{~mm}$ de diámetro tratados con poli-L-lisina, a una densidad de $2 \times 10^{4}$ células por cubreobjetos. Se mantuvieron a $37^{\circ} \mathrm{C}$ en atmósfera humidificada, con $5 \%$ de $\mathrm{CO}_{2}$, de 3 a 5 días antes de ser utilizadas.

\subsection{Cultivo organotípico}

El cultivo organotípico de cerebro se realizó según el método descrito por Stoppini (Stoppini y col., 1991). Las rodajas de cerebro se obtuvieron a partir de un ratón neonato C57/BL6, en estadio de P2 a P4. Cada ratón se decapitó y la cabeza se colocó en una placa de Petri con líquido cefalorraquídeo artificial (ACSF) frío. El ACSF tiene la siguiente composición: $\mathrm{KCl}, 4 \mathrm{mM} ; \mathrm{MgCl}_{2} \times 6$ $\mathrm{H}_{2} \mathrm{O}, 5 \mathrm{mM} ; \mathrm{NaHCO}_{3}, 26 \mathrm{mM} ; \mathrm{CaCl}_{2} \times 2 \mathrm{H}_{2} \mathrm{O}, 1 \mathrm{mM}$; glucosa, $10 \mathrm{mM}$; sacarosa, $248 \mathrm{mM}$; ácido quinurénico, $8 \mu \mathrm{M}$. Antes de realizar el cultivo el ACSF se burbujea con $5 \% \mathrm{CO}_{2}$ durante 30 min para estabilizar el pH del medio a 7.4. La disección de la corteza cerebral se realizó en este medio, de manera similar a lo descripto previamente en el apartado 2.2.1. A continuación, la corteza se seccionó con tijeras en tiras de aproximadamente $1 \mathrm{~mm}$ de ancho, que se colocaron en una superficie plana sobre un papel de filtro estéril humedecido con ACSF, y se laminaron transversalmente en rodajas de 350 a $400 \mu \mathrm{m}$, utilizando un cortador Chopper (MclLwain Tissue). Las rodajas se separaron individualmente bajo la lupa con la ayuda una lanceta de wolframio, y se colocaron de 4 a 5 rodajas sobre una membrana estéril, porosa y transparente (Millicell, PICM0RG50) que se insertó en una placa petri de $6 \mathrm{~mm}$ 
con $1 \mathrm{ml}$ de medio MEM (Minimal Essentials Medium), (Gibco, 32360-026) suplementado según se detalla en la Tabla 4. Se obtuvieron habitualmente de 10 a 15 secciones por ratón. Las rodajas se mantuvieron en cultivo hasta un máximo de 10 días a $37^{\circ} \mathrm{C}$ y $5 \%$ de $\mathrm{CO}_{2}$, reemplazando la mitad del medio de cultivo por medio fresco cada 3 días.

\begin{tabular}{|l|c|l|}
\hline \multicolumn{3}{|c|}{ Suplementos del medio MEM } \\
\hline \multicolumn{1}{|c|}{ Componente } & $\begin{array}{c}\text { Concentración } \\
\text { final (en mM) }\end{array}$ & \multicolumn{1}{c|}{ Referencia } \\
\hline Suero de caballo & $20 \%(\mathrm{v} / \mathrm{v})$ & Gibco, 26050-070 \\
\hline Ac. ascórbico & $7 \times 10^{-3}$ & Sigma, A4544 \\
\hline MgSO $_{4}$ & 2 & Panreac, 131404 \\
\hline D-Glucosa & 13 & Merck, 1.08342.1000 \\
\hline Insulina & $1.7 \times 10^{-4}$ & Sigma, 16634 \\
\hline Glutamax & 1 & Gibco, 35050 \\
\hline CaCl 2 & 1 & Merck, 1.02382 .0500 \\
\hline
\end{tabular}

Tabla 4. Medio de cultivo de rodajas de corteza de cerebro de ratón. Se preparó con el medio comercial MEM (Gibco, 32360-026) suplementado con los componentes que se detallan en la Tabla.

\section{Inmunofluorescencia}

Las células sembradas en cubreobjetos se lavaron 2 o 3 veces con PBS y se fijaron con paraformaldehído (PFA) (Fluka, 76240) al 4\% (v/v) en PBS frío durante 20 minutos. A continuación, se retiró el fijador y se lavó tres veces con PBS. El bloqueo de uniones inespecíficas y la permeabilización se hizo incubando con una solución de PBS con suero de cabra (Gibco, 16210064) al $10 \%$ (v/v) y Tritón X-100 al 0.5\% (v/v) (Merck, 1086031000), durante 30 minutos a $22{ }^{\circ} \mathrm{C}$. Luego se añadió el anticuerpo primario correspondiente diluido en una solución de PBS con suero de cabra al 10\% (v/v) y Tritón X-100 al $0.2 \%(\mathrm{v} / \mathrm{v})$, y las células se incubaron toda la noche a $4{ }^{\circ} \mathrm{C}$. En esta Tesis se han empleado los siguientes anticuerpos primarios: el anticuerpo policlonal de conejo anti-GFAP (proteína ácida fibrilar glial; Dako, Z0334) a una dilución de 1:2000, el anticuerpo monoclonal de ratón anti-Tuj1 (tubulina neuronal $\beta$, clase 
III; Covance, MMS-435P) a una dilución de 1:2000 y el anticuerpo anti-SERCA (Santa Cruz, SC-53010).

Al día siguiente, las muestras se lavaron 3 veces con la misma solución utilizada en la permeabilización, y, a continuación, se incubaron durante una hora en la oscuridad con los anticuerpos secundarios correspondientes en cada caso. En esta Tesis se han utilizado: Alexa Fluor 488 (cabra anti-conejo; Molecular Probes, A-11011), Alexa Fluor 568 (cabra anti-ratón; Molecular Probes, A-11031) y Alexa Fluor 405 (cabra anti-conejo; Gibco, A-31556). Los anticuerpos secundarios se prepararon a una dilución 1:200 en una solución idéntica a la utilizada con los anticuerpos primarios, y se mantuvieron durante una hora en la oscuridad a $22{ }^{\circ} \mathrm{C}$. Para marcar los núcleos se añadió a las muestras una solución de PBS con $0.1 \mu \mathrm{g} / \mathrm{ml}$ de DAPI (4',6-diamidino-2fenilindol, Molecular Probes, D-1306) a una dilución 1:200, incubándolo durante 10 min a $22^{\circ} \mathrm{C}$. Finalmente las células se lavaron con PBS una vez, y otra vez más con agua desionizada para eliminar las sales. Los cubreobjetos se montaron sobre una gota de $10 \mu \mathrm{l}$ de la solución de montaje Vectashield (Vector laboratories Inc., H-1000) y se sellaron con laca de uñas. Las muestras se guardaron en oscuridad a $4{ }^{\circ} \mathrm{C}$, hasta su visualización por microscopía de fluorescencia.

Las muestras se visualizaron en un microscopio confocal Leica TCS SP5 equipado con un láser blanco y un objetivo 63X de inmersión en aceite (HCX Plan Apo C5, A.N. 1.4).

El protocolo de inmunofluorescencia en secciones se basa en uno descrito previamente (Yokose y col., 2011). Las secciones, realizadas como se ha descrito previamente, se fijaron con PFA al $4 \%$ a $4{ }^{\circ} \mathrm{C}$, en agitación por balanceo durante 30 minutos. En general, se utilizó un protocolo similar al descrito para células en monocapa, pero con tiempos de incubación más largos, 30 min para cada lavado y 5 a 6 horas para la incubación con el anticuerpo secundario. 


\section{Transfección}

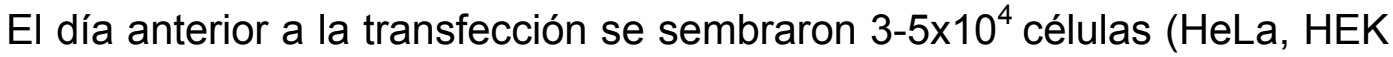
293T, CHO-K1, AAV, 2-2 o astrocitos) por pocillo de una placa de 4, previamente tratadas con $0,1 \mathrm{mg} / \mathrm{ml}$ de poli-L-lisina (Sigma, P-1274). Se retiró el medio de cultivo de las células y se lo sustituyó por $100 \mu \mathrm{l}$ de medio DMEM completo sin suero ni antibióticos. Se preparó un tubo A con 0,05-1 $\mu \mathrm{g}$ de DNA plasmídico en $50 \mu \mathrm{l}$ OptiMEM, y un tubo B con $2 \mu \mathrm{l}$ de LipofectAMINE 2000 en $50 \mu \mathrm{l}$ de OPTI-MEM (medio sin suero y sin antibióticos; Gibco, 51985). Se incubó 5 minutos el tubo $B$, luego se lo mezclo con el tubo $A$ y se incubó nuevamente durante 20 minutos. Tras la incubación, la mezcla se añadió a las células gota a gota. A las 5-6 horas se retiró el medio de transfección y se sustituyó por el medio de cultivo DMEM completo habitual. Tras 24 horas de incubación las células se usaron para las medidas de $\mathrm{Ca}^{2+}$.

\section{Generación de virus}

\subsection{Vectores derivados del virus herpes simplex tipo 1 (HSV-1)}

El empaquetamiento del vector viral Herpes Simplex tipo 1 (HSV1): HSVIgGAP1, se realizó según el protocolo previamente descrito (Alonso y col., 1998) y se esquematiza en la Figura 17. Las células 2-2 (Saeki y col., 2001) se sembraron en una placa de $60 \mathrm{~mm}$ a una densidad de $5 \times 10^{5}$ células, el día anterior a la transfección. Al día siguiente, se preparó un tubo A con $8 \mu \mathrm{g}$ del plásmido pHSV-IgGAP1 en $500 \mu \mathrm{l}$ de OptiMEM, y un tubo B con $20 \mu \mathrm{l}$ de LipofectAMINE 2000 en $500 \mu \mathrm{l}$ de OPTI-MEM. Se mezclaron los contenidos de ambos tubos como se explicó en el apartado anterior (4. Transfección). El medio de cultivo de las células 2-2 se sustituyó por 2,5 $\mathrm{ml}$ de medio DMEM sin suero ni antibióticos. Se añadió $1 \mathrm{ml}$ de la mezcla anterior gota a gota sobre las células y las mismas se incubaron 5 horas. Tras la incubación se sustituyó el medio de transfección por $5 \mathrm{ml}$ de medio DMEM completo (con FBS y antibióticos). 
Transcurridas $24 \mathrm{~h}$ tras la transfección, se reemplazó el medio de cultivo por $3 \mathrm{ml}$ de DMEM fresco con 2\% ( $\mathrm{v} / \mathrm{v})$ de FBS. Inmediatamente después se añadieron $100 \mu \mathrm{l}$ del virus coadyuvante 5dl1.2, a una concentración aproximada de $6 \times 10^{5} \mathrm{pfu}$ (unidades formadoras de placas). El virus coadyuvante $5 d 11.2$. es defectivo en replicación, ya que contiene una deleción parcial en el gen IE2 que se complementa en las células 2-2 (Tabla 2) (McCarthy y col., 1989).

Transcurridas $24 \mathrm{~h}$ desde la infección, se hacen evidentes los primeros signos de citotoxicidad adquiriendo las células una morfología redondeada, sin llegar a despegarse de la placa. En ese momento, las células se recogieron en tubos de polipropileno con la ayuda de un rascador desechable. Las células se lisaron sometiéndolas a 3 ciclos de congelación-descongelación seguidos de 2 minutos de sonicación a intervalos de 30 segundos. Tras una centrifugación de $5 \mathrm{~min}$ a $1800 \mathrm{~g}$ y $4{ }^{\circ} \mathrm{C}$, se recogieron $4 \mathrm{ml}$ del sobrenadante. Con el objetivo de aumentar el virus se realizaron tres ciclos de amplificación, se añadieron los 4 $\mathrm{ml}$ a una placa de $100 \mathrm{~mm}$ con $2 \times 10^{6}$ de células 2-2 que se habían sembrado el día anterior. Al día siguiente se repitió el mismo procedimiento descrito en el ciclo anterior de recogida, lisando, sonicando y centrifugando. Este inóculo se usó para infectar dos placas de $100 \mathrm{~mm}$ de células 2-2 con el sobrenadante obtenido de lisar las células del día anterior repitiendo los pasos antes detallados. Finalmente, a las $24 \mathrm{~h}$ se recogieron las células de las dos placas, juntándolas en un mismo tubo y se procesaron de la misma forma que los ciclos anteriores. El sobrenadante obtenido, compuesto por una mezcla de dos tipos de partículas víricas, (el amplicón portador del gen de interés y del virus co-adyuvante o helper), se alicuotó y se almacenó a $-80{ }^{\circ} \mathrm{C}$. Este virus se nombró como HSV-IgGAP1. 


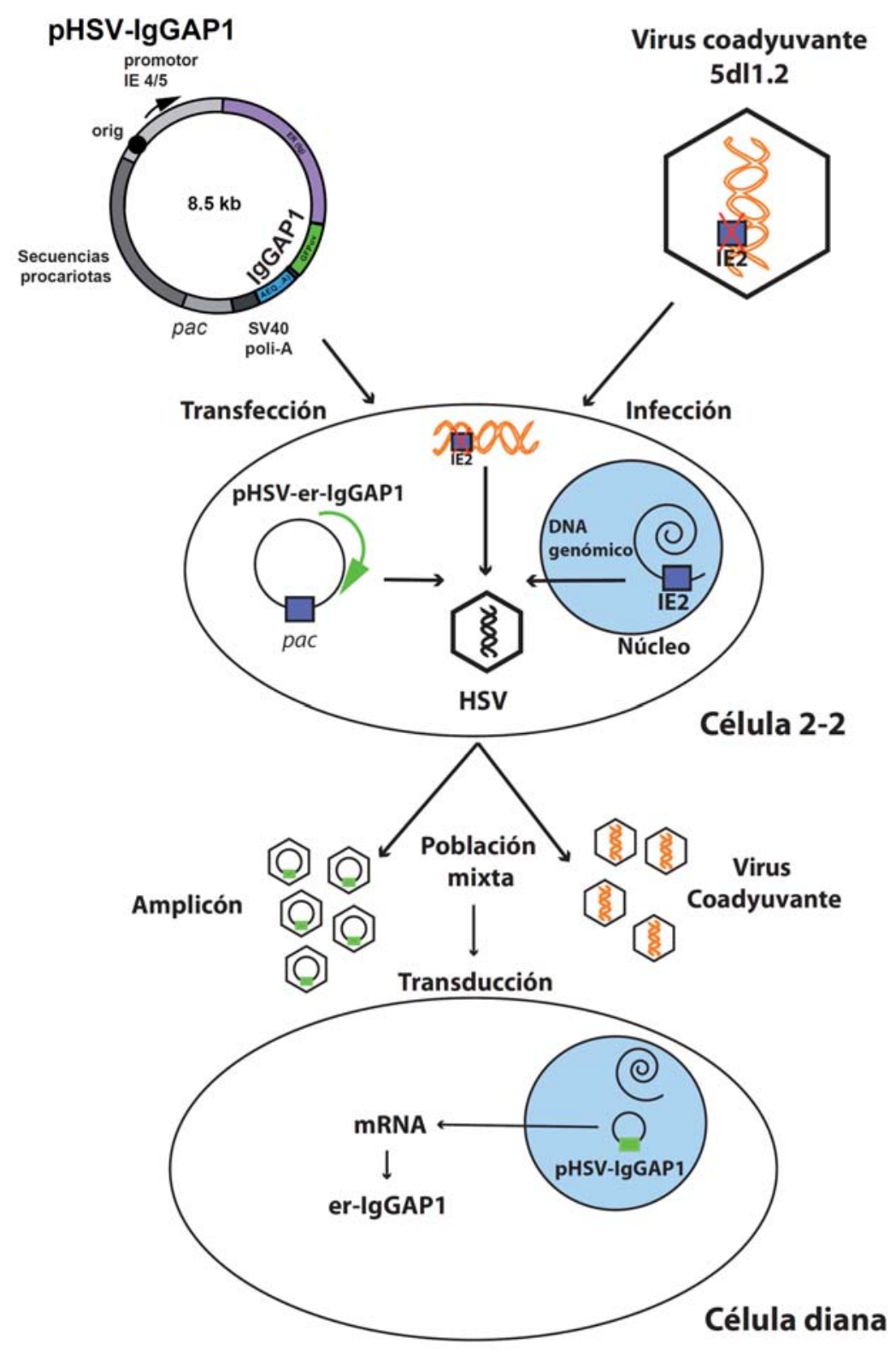

Figura 17. Método de empaquetamiento de los virus HSV-1. Empaquetamiento de virus herpes con coadyuvante. Transfección con el amplicón portador del transgén de interés, y superinfección con el virus coadyuvante 5 dl1.2. Las partículas virales obtenidas son de carácter mixto, contienen partículas de amplicón y coadyuvante.

\subsection{Vectores derivados del virus adenoasociado (AAV)}

El empaquetamiento de los virus AAV se realizó con el kit comercial AAVDJ Helper Free Packaging System (Cell Biolabs Inc., VPK-400-DJ). En la Figura 18 se muestra un esquema del procedimiento seguido. Las células AAV293 se sembraron en una placa de $100 \mathrm{~mm}$ de diámetro, $24 \mathrm{~h}$ antes de la transfección, a una densidad tal que la confluencia el día de la transfección 
fuera del $80-90 \%$. Aproximadamente 30 min antes de la transfección, el medio de cultivo se reemplazó por $10 \mathrm{ml}$ de medio DMEM sin antibióticos. Se cotransfectaron $15 \mu \mathrm{g}$ de cada uno de los 3 plásmidos plásmidos siguientes: pAAV-GFAP-erGAP3, pHelper y pAAV-DJ (Figura 18). Se preparó una mezcla A con $1,5 \mathrm{ml}$ de Opti-MEM y $135 \mu \mathrm{l}$ de lipofectamina 2000; y una mezcla $B$ con los plásmidos en 1,5 ml de Opti-MEM. Después se combinaron y se incubaron 20 minutos para permitir la formación de las micelas de transfección. La mezcla se añadió gota a gota, y agitando suavemente, a la placa con las células que se mantuvieron en cultivo 24 horas. Al día siguiente, se reemplazó el medio de cultivo por el medio DMEM completo y las células se mantuvieron $48 \mathrm{~h}$ más en cultivo. Al tercer día tras la infección las células se recogieron con una espátula desechable, transfiriéndolas a un tubo de polipropileno, y se centrifugaron durante $5 \mathrm{~min}$ a $250 \mathrm{~g} \mathrm{y} 4^{\circ} \mathrm{C}$. Las células se lavaron, se resuspendieron en 1 $\mathrm{ml}$ de PBS y se lisaron mediante 4 ciclos de congelación y descongelación. Finalmente, se centrifugaron durante $5 \mathrm{~min}$, a $400 \mathrm{~g}$, y a una temperatura entre $22-25{ }^{\circ} \mathrm{C}$; el sobrenadante que contenía las partículas víricas, se alicuotó y se almacenó a $-80^{\circ} \mathrm{C}$. Este virus se nombró como AAV-GFAP-erGAP3. 


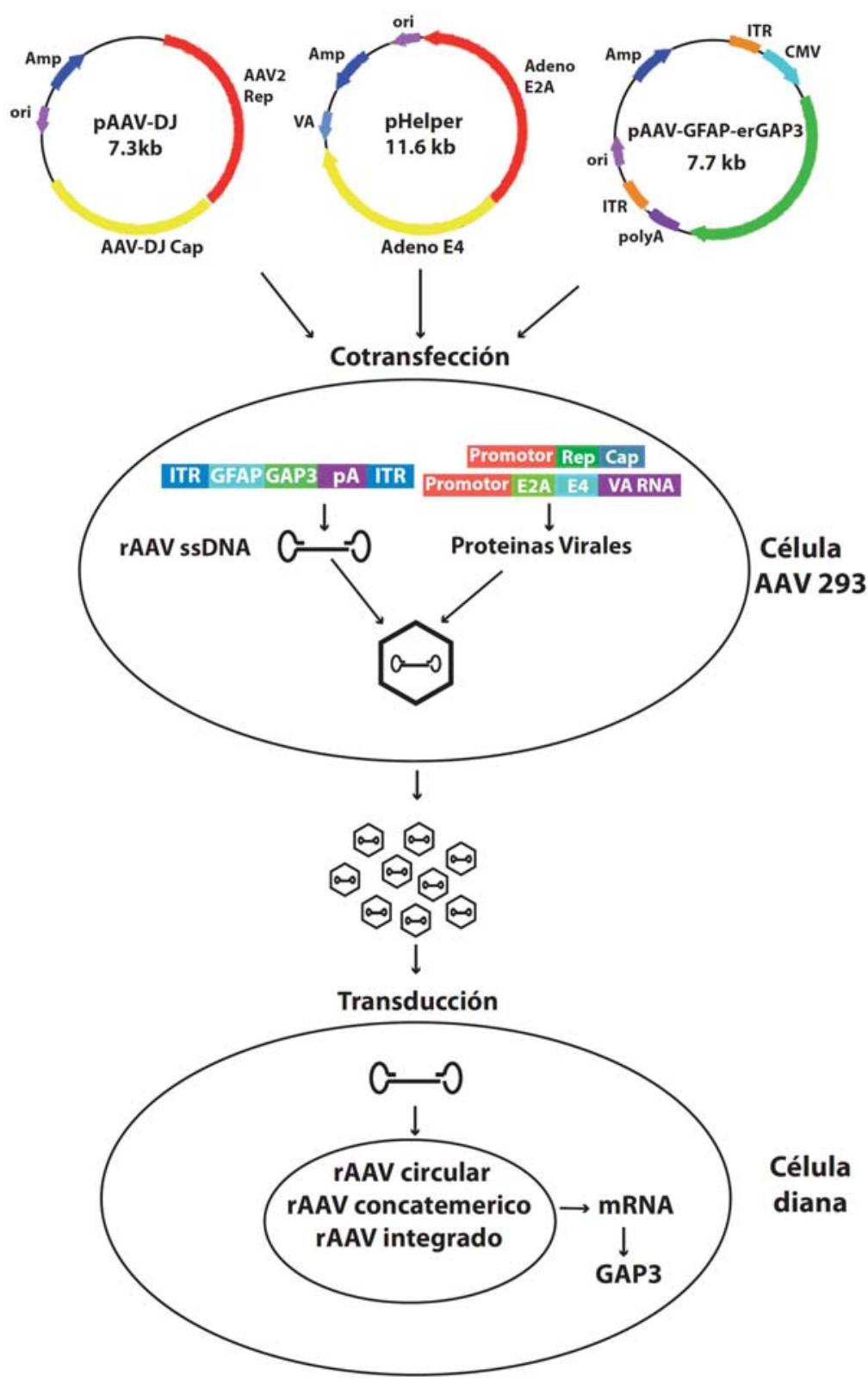

Figura 18. Esquema del empaquetamiento de los virus AAV. Empaquetamiento de virus AAV por cotransfección de células HEK 293 (E1) con tres plásmidos simultáneamente: pAAV-Dj, pHelper y pAAV-GFAP-GAP3.

\subsection{Infección}

La transducción de los sensores de calcio mediante vectores derivados del virus herpes (HSV-1) se realizó en astrocitos de 7 DIV. Las células sembradas en cubreobjetos de $12 \mathrm{~mm}$ se infectaron con 2 o $10 \mu \mathrm{l}$ de los vectores virales HSV-erGA (VAN2.1) o HSV-IgGAP1 (Alonso y col., 1998), en 
un volumen final de $200 \mu \mathrm{l}$. Las células se mantuvieron durante $24-48$ horas antes de realizar los experimentos de medidas de calcio, para permitir una adecuada expresión de los sensores. En el caso del virus derivado del AAV, las células en monocapa adheridas a cubreobjetos de $12 \mathrm{~mm}$ se infectaron con 5$10 \mu \mathrm{l}$ del virus AAV-GFAP-GAP3, y se mantuvieron 4-6 días en cultivo.

En secciones de corteza cerebral de ratón, la infección se realizó con el virus adenoasociado AAV-GFAP-GAP3, tras haber transcurrido 24 horas de la realización del cultivo. Se deslizaron cuidadosamente $2 \mu l$ de inóculo directamente sobre la rodaja, evitando el contacto de la punta de la pipeta con el tejido. Los primeros signos de expresión se obtuvieron a las 48 h, y la misma fue aumentando hasta los 4 días. Los experimentos se realizaron entre los días 4 y 7 posterior a la infección.

\section{Medida de la $\left[\mathrm{Ca}^{2+}\right]$ por bioluminiscencia}

\subsection{Sondas: erGA e IgGAP1}

Se utilizaron tanto clones estables de células HeLa como líneas celulares transfectadas de forma transitoria, así como cultivos primarios infectados con vectores víricos de tipo HSV. Las distintas combinaciones entre el transgen y el método de transducción empleado se detallan a continuación en la Tabla 5.

\begin{tabular}{|c|c|c|c|}
\hline Transducción/indicador & erGA & GAP1 & goGAP1 \\
\hline Trasfección & pcDNA3-erGA & pcDNA3-IgGAP1 & \\
\hline Infección (HSV) & HSV-erGA & HSV-IgGAP1 & \\
\hline Línea estable & HeLa-erGA & HeLa-IgGAP1 & HeLa-goGAP1 \\
\hline
\end{tabular}

Tabla 5. Métodos de transducción de las diferentes sondas utilizadas 


\subsection{Equipo}

Las medidas rutinarias de aequorina se realizaron en un luminómetro construido ad-hoc por Cairn Research Ltd. (Faversham, Reino Unido) y cuyo esquema se muestra en la Figura 19. Las células sembradas en placas de 4 pocillos se colocaron dentro de una cámara oscura en el interior del luminómetro. Este último equipado con un sistema de perfusión de soluciones por gravedad y aspiración por vacío. La perfusión se realizó a un flujo de 6 $\mathrm{ml} / \mathrm{min}$ y a una temperatura de $26{ }^{\circ} \mathrm{C}$. El sistema está equipado con un controlador de válvulas para cambiar la perfusión de una solución a otra. La luz emitida se capturó con un fotomultiplicador (fototubo) situado por debajo de las células, y por encima se colocó un espejo a fin de minimizar la perdida de fotones. La adquisición de luminiscencia se realizó cada 1 segundo utilizando el programa AcquisitionEngine (Modular Data Acquisition, versión 1.1.7, Cairn research) y los datos se procesaron con Origin 7 (OriginLab).

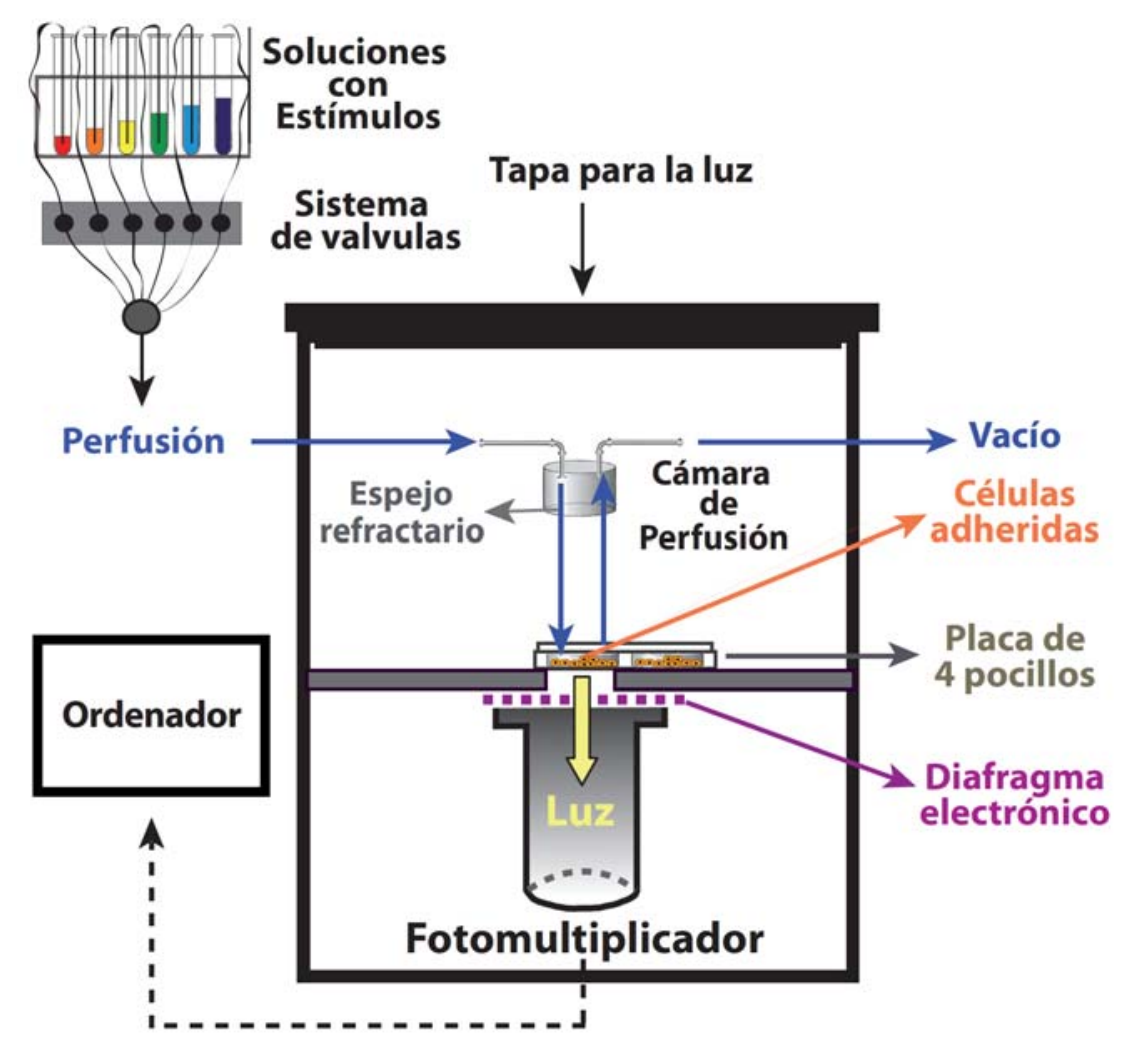

Figura 19. Esquema del luminómetro utilizado para medir la $\left[\mathrm{Ca}^{2+}\right]$ por bioluminiscencia en poblaciones celulares. 


\subsection{Procedimiento}

Los registros de bioluminiscencia en compartimentos intracelulares con alta concentración de calcio, como el RE, se realizaron reconstituyendo la apoaequorina de las sondas GAP1 y GA, con el cofactor celenterazina n (Molecular Probes, C6776). La celenterazina $n$ se disuelve en metanol a una concentración de $0.2 \mathrm{mM}$, se alícuota, se gasea con $\mathrm{N}_{2}$ y almacena a $-80{ }^{\circ} \mathrm{C}$. Antes de realizarse la reconstitución de la apoaequorina los depósitos intracelulares deben depletarse de calcio a fin de evitar el consumo prematuro de la sonda, esto se realiza fuera del aparato (Barrero y cols., 1997). En primer lugar, se retira el medio de cultivo de una placa de 4 pocillos y se añaden 200 $\mu \mathrm{l}$ de medio $\mathrm{ME}$, que contenía: $\mathrm{NaCl}, 145 \mathrm{mM} ; \mathrm{KCl}, 5 \mathrm{mM} ; \mathrm{MgCl}_{2}, 1 \mathrm{mM}$; glucosa, $10 \mathrm{mM}$; hepes, $10 \mathrm{mM}$; pH 7.4, sin calcio (EGTA, $0.5 \mathrm{mM}$ ) y con 0.01 $\mathrm{mM}$ del inhibidor reversible de la bomba SERCA, 2.5-di-tert-butilbenzohidroquinona (TBQ; Aldrich, 11,297-6) (Moore y cols., 1987).

Las células se mantuvieron en dicho medio durante 10 minutos, para permitir el vaciamiento de los depósitos de calcio, luego se adicionó $1 \mu \mathrm{l}$ la celenteracina n a 0.2 mM, (Shimomura y col., 1974; Shimomura y col., 1993) para conseguir una concentración final de $1 \mu \mathrm{M}$. Las células se mantuvieron durante una hora a una temperatura de entre 22 y $25^{\circ} \mathrm{C}$ en oscuridad antes de comenzar las medidas (Alvarez y Montero, 2002).

\subsubsection{Medidas}

\subsubsection{Células intactas}

La placa de 4 pocillos con las células se introdujo dentro del luminómetro y se colocó el sistema de perfusión dentro del pocillo. Se perfundieron las células durante 1-2 minutos con ME (EGTA, $0.5 \mathrm{mM}$ ) para lavar el medio de reconstitución. A continuación, se perfundió $\mathrm{ME}$ con $1 \mathrm{mM} \mathrm{CaCl} 2$ (MEC) durante 5-13 minutos para permitir el rellenado de los depósitos intracelulares. Si no se especifica lo contrario, todos los estímulos se prepararon en un medio 
MEC. La solución de $80 \mathrm{mM}$ de $\mathrm{K}^{+}$se preparó mezclando un 46\% (v/v) de MEC con $54 \%(\mathrm{v} / \mathrm{v})$ de un medio de alto potasio que contenía: $\mathrm{NaCl}, 5 \mathrm{mM} ; \mathrm{KCl}, 145$ $\mathrm{mM} ; \mathrm{MgCl}_{2}, 1 \mathrm{mM}$; glucosa, $10 \mathrm{mM}$; hepes, $10 \mathrm{mM} ; \mathrm{pH}$ 7.4. La duración de cada estímulo fue generalmente de 30 segundos.

Al finalizar cada experimento se perfundió una solución de lisis, con 0.1 $\mathrm{mM}$ de digitonina (Sigma, D141) disuelta en agua y $10 \mathrm{mM}$ de $\mathrm{CaCl}_{2}$, con el fin de obtener la luminiscencia de la aequorina remanente, y poder realizar así la calibración. Todos los experimentos se llevaron a cabo a $22^{\circ} \mathrm{C}$.

\begin{tabular}{|c|c|c|}
\hline & $\begin{array}{c}\text { Medio externo pH } 7.4 \\
\text { (en mM) }\end{array}$ & $\begin{array}{c}\text { Medio interno pH } 7.2 \\
\text { (en } \mathrm{mM} \text { ) }\end{array}$ \\
\hline $\mathrm{NaCl}$ & $145 \mathrm{mM}$ & $10 \mathrm{mM}$ \\
\hline $\mathrm{KCl}$ & $5 \mathrm{mM}$ & $140 \mathrm{mM}$ \\
\hline $\mathrm{MgCl}_{2}$ & $1 \mathrm{mM}$ & $1 \mathrm{mM}$ \\
\hline Hepes-Na & $10 \mathrm{mM}$ & $20 \mathrm{mM}$ \\
\hline Glucosa & $10 \mathrm{mM}$ & - \\
\hline $\mathrm{CaCl}_{2}$ & $1 \mathrm{mM}$ & - \\
\hline Mg-ATP-Mg & - & $1 \mathrm{mM}$ \\
\hline $\mathrm{KH}_{2} \mathrm{PO}_{4}$ & - & $1 \mathrm{mM}$ \\
\hline Succinato & - & $2 \mathrm{mM}$ \\
\hline Piruvato & - & $1 \mathrm{mM}$ \\
\hline $\begin{array}{l}\text { EGTA/EGTA- } \\
\mathrm{CaCl}_{2}\end{array}$ & - & Tabla 7 \\
\hline
\end{tabular}

Tabla 6. Composición del medio externo utilizado en células intactas y del medio interno utilizado en células permeabilizadas.

\subsubsection{Células permeabilizadas}

En los experimentos con células permeabilizadas se utilizó un medio denominado medio interno (MI) similar al medio intracelular y detallado en la Tabla 7. En primer lugar, las células se perfundieron con una solución de 
permeabilización compuesta por MI con digitonina, $0.05 \mathrm{mM}$ y EGTA, $0.5 \mathrm{mM}$, durante 2-3 minutos. A continuación, para permitir el rellenado del RE se perfundió $\mathrm{MI}$ con concentraciones de calcio libre conocidas $(0.1 ; 0.200 .5 \mu \mathrm{M}$ de $\mathrm{Ca}^{2+}$ libre), estas soluciones se prepararon con el tampón EGTA y EGTA$\mathrm{Ca}^{2+}$. Excepcionalmente se utilizó el tampón HEDTA para preparar las soluciones de $\mathrm{Ca}^{2+}$ libre de 20; 30 o $60 \mu \mathrm{M}$ (Fig. 47 de la sección de resultados). En todos los casos se utilizó el programa MaxCHeLator (Bers y col., 1994). En esta preparación las células se estimularon con $\mathrm{IP}_{3}, 5 \mu \mathrm{M}$ o con cafeína, 20-50 mM, y además con concentraciones de calcio libre en el orden de micromolar $(20 ; 30$ y $60 \mu \mathrm{M})$. Al final del protocolo, y al igual que en células intactas, las células se lisaron con una solución con $10 \mathrm{mM} \mathrm{CaCl} \mathrm{Cl}_{2}$ y $0.1 \mathrm{mM}$ digitonina, para obtener las cuentas totales.

\begin{tabular}{|c|c|c|c|c|c|}
\hline \multicolumn{5}{|c|}{$\left[\mathrm{Ca}^{2+}\right.$ final } \\
\hline pH 7.2 & $\mathbf{1 0 0 ~ n M}$ & $\mathbf{2 0 0} \mathbf{n M}$ & $\mathbf{5 0 0} \mathbf{n M}$ & $\mathbf{3 0} \mu \mathrm{M}$ & $\mathbf{6 0} \mu \mathrm{M}$ \\
\hline EGTA & $1,21 \mathrm{mM}$ & $0.89 \mathrm{mM}$ & $0.47 \mathrm{mM}$ & - & - \\
\hline EGTA-Ca & $0.73 \mathrm{mM}$ & $1 \mathrm{mM}$ & $1.5 \mathrm{mM}$ & - & - \\
\hline HEDTA & - & - & - & $1 \mathrm{mM}$ & $1 \mathrm{mM}$ \\
\hline HEDTA-Ca & - & - & - & $0.3 \mathrm{mM}$ & $0.6 \mathrm{mM}$ \\
\hline
\end{tabular}

Tabla 7. Combinaciones de soluciones valoradas de los quelantes EGTA o EDTA con soluciones de $\mathrm{Ca}^{2+}$ para obtener una $\left[\mathrm{Ca}^{2+}\right]$ final conocida en los medios internos. Las $\left[\mathrm{Ca}^{2+}\right]$ libre fueron calculadas con el programa MaxCHeLator en condiciones de $\mathrm{T} 25^{\circ} \mathrm{C}, \mathrm{Mg}^{2+} 1 \mathrm{mM}$, fuerza iónica 0.15 y $\mathrm{pH}$ 7.2. Las soluciones de EGTA $(0.2 \mathrm{M})$ y $\mathrm{EGTA} \mathrm{Ca}^{2+}(0.2 \mathrm{M})$ fueron valoradas previamente. Para las concentraciones en el orden de $\mu \mathrm{M}$ se utilizó una solución de HEDTA (1 mM) y una solución de $\mathrm{Ca}^{2+}$ de $100 \mathrm{mM}$. Las soluciones se llevaron a pH 7.2 con una solución de Tris base $2 \mathrm{M} \mathrm{y} \mathrm{HCl} 30 \%$.

\subsubsection{Calibración de aequorinas}

Las células HEK293T se sembraron a una densidad de $5 \times 10^{4}$ células en cubreobjertos de $9 \mathrm{~mm}$ de diámetro, tratados con poli-L-lisina. Al día siguiente, las células se transfectaron con los plásmidos lgGAP1 o erGA $(0.5 \mu \mathrm{g})$, y se 
mantuvieron en cultivo 24 horas. El día del experimento las células se reconstituyeron de forma idéntica a la descrita en el apartado 6.3.1. El cubreobjeto se insertó en una cubeta de espectrometría de plástico de $1 \mathrm{ml}$, y esta se colocó en la cámara de un luminómetro que posee agitación (Cairn Research Ltd, Reino Unido). Las células se lisaron con una solución con $0.01 \%$ $(\mathrm{v} / \mathrm{v})$ de Triton X-100 en un tampón con la siguiente composición: $\mathrm{KCl}, 140 \mathrm{mM}$; $\mathrm{NaCl}, 10 \mathrm{mM} ; \mathrm{MgCl}_{2}, 1 \mathrm{mM}$; Na-MOPS, $10 \mathrm{mM}$ y pH 7.0. Antes de la adición de $\mathrm{Mg}^{2+}$, las soluciones se trataron con la resina Chelex (Bio-Rad, 142-2832) para eliminar el calcio contaminante. Las adiciones se realizaron en la cubeta con una jeringa Hamilton a partir de una solución de $\mathrm{CaCl}_{2} 0.2 \mathrm{M}$ en un rango de 50 a $1600 \mu \mathrm{M}$ de $\left[\mathrm{Ca}^{2+}\right]$ final. Finalmente, la luminiscencia total (LTOTAL) se obtuvo con una solución con una $\left[\mathrm{Ca}^{2+}\right]$ saturante $(10 \mathrm{mM})$, y sumando todos los valores $L$ de luminiscencia emitidos a lo largo de todo el experimento. Los datos obtenidos se representaron como el cociente entre la luminiscencia en cada punto y la luminiscencia total emitida $\left(\mathrm{L}_{\mathrm{L}} \mathrm{L}_{\mathrm{T}}\right)$. Las concentraciones de calcio de los resultados que se muestran se han estimado interpolando de los valores de $L / L_{\text {Total }}$ en la curva de calibración.

\section{Medida de la $\left[\mathrm{Ca}^{2+}\right]$ por fluorescencia}

\subsubsection{Sondas químicas: medidas de la $\left[\mathrm{Ca}^{2+}\right] \mathrm{c}$}

\subsubsection{Fura-2}

Las medidas de la $\left[\mathrm{Ca}^{2+}\right]_{\mathrm{c}}$ se realizaron con el indicador de $\mathrm{Ca}^{2+}$ fluorescente Fura-2. El Fura-2 es un sensor ratiométrico que tiene una $\mathrm{Kd}$ por $\mathrm{Ca}^{2+}$ de $145 \mathrm{nM}$ a $22{ }^{\circ} \mathrm{C}$, un rango dinámico de 4 , dos picos de excitación a 340 y $380 \mathrm{~nm}$ y una emisión a $530 \mathrm{~nm}$. Las células adheridas a cubreobjetos de 12 $\mathrm{mm}$ se incubaron con $4 \mu \mathrm{M}$ de Fura-2 (acetoximetil éster) (Molecular Probes, F6799), en medio MEC ( $\left.1 \mathrm{mM} \mathrm{Ca}^{2+}\right)$ durante 40 minutos, entre $22-25^{\circ} \mathrm{C}$, con agitación suave (Grynkiewicz y col., 1985). La forma acetoximetil éster del Fura-2 puede atravesar la membrana debido a su naturaleza hidrofóbica, y, una 
vez en el interior de la célula, las esterasas citosólicas hidrolizan el enlace éster, dando como producto la forma ácida del Fura-2 que queda atrapado de esta forma en el citosol.

\subsubsection{Fluo-3}

Otro indicador que hemos utilizado para medir la $\left[\mathrm{Ca}^{2+}\right]_{\mathrm{C}}$ fue indicador de $\mathrm{Ca}^{2+}$ fluorescente Fluo-3. El Fulo-3 es un sensor intensiométrico que tiene una $\mathrm{Kd}$ por $\mathrm{Ca}^{2+}$ de $390 \mathrm{nM}$ a $22^{\circ} \mathrm{C}$, un rango dinámico de 40 , un pico de excitación a 488 y una emisión a $525 \mathrm{~nm}$. Las células adheridas a cubreobjetos de $12 \mathrm{~mm}$ se incubaron con $4 \mu \mathrm{M}$ de Fulo-3 (acetoximetil éster) (Sigma, 121714-22-5), en el mismo medio y en las mismas condiciones que en el caso del Fura-2.

\subsubsection{Rhod-2}

El Rhod-2 es un sensor intensiométrico que tiene una $\mathrm{Kd}$ por $\mathrm{Ca}^{2+}$ de 570 $\mathrm{nM}$ a $22^{\circ} \mathrm{C}$ en ausencia de $\mathrm{Mg}^{2+}$, un rango dinámico de 3.4 y tiene un pico de excitación a $540 \mathrm{~nm}$ y uno de emisión a $580 \mathrm{~nm}$. Este indicador de $\mathrm{Ca}^{2+}$ fluorescente tiene la emisión en el rojo, por esta razón se utilizó para medir la $\left[\mathrm{Ca}^{2+}\right]_{\mathrm{C}}$ de forma simultánea a las medidas de la $\left[\mathrm{Ca}^{2+}\right]_{\mathrm{RE}}$, con la sonda proteica fluorescente verde erGAP3. Las células que expresaban el sensor erGAP3 se cargaron con 2-4 $\mu \mathrm{M}$ de Rhod-2-AM (Molecular Probes, R1245MP), en MEC (1 $\mathrm{mM}$ de $\mathrm{Ca}^{2+}$ ) en el caso de células disociadas y $16 \mu \mathrm{M}$ en el caso de las secciones, incubándose durante $20-30$ minutos a $22-25{ }^{\circ} \mathrm{C}$, con agitación suave. 
A

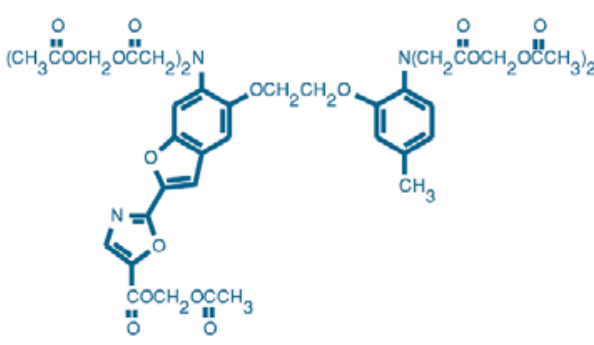

Fura-2

C<smiles>COc1cc(-c2c3ccc(=N)cc-3oc3cc(N(C)C)ccc23)ccc1N(C)CC(=O)O</smiles>

Rhod-2

$\mathbf{E}$

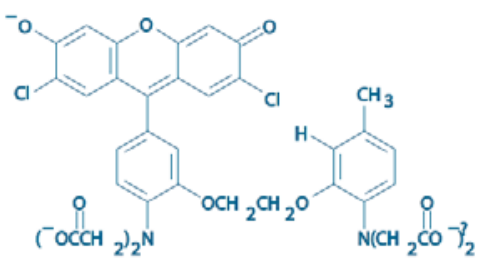

Fluo-3
B

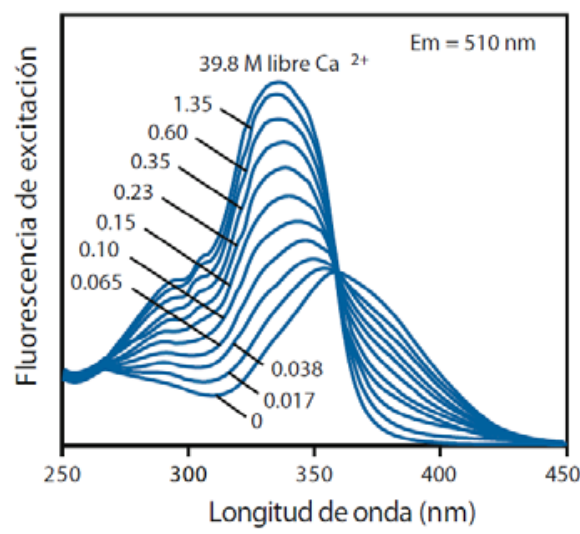

D

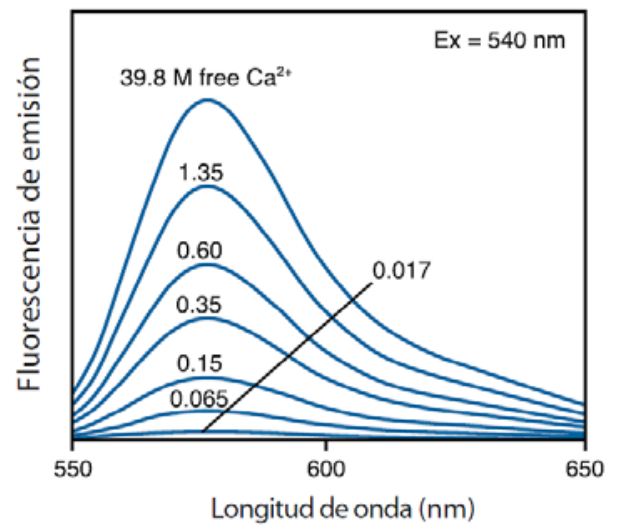

$\mathbf{F}$

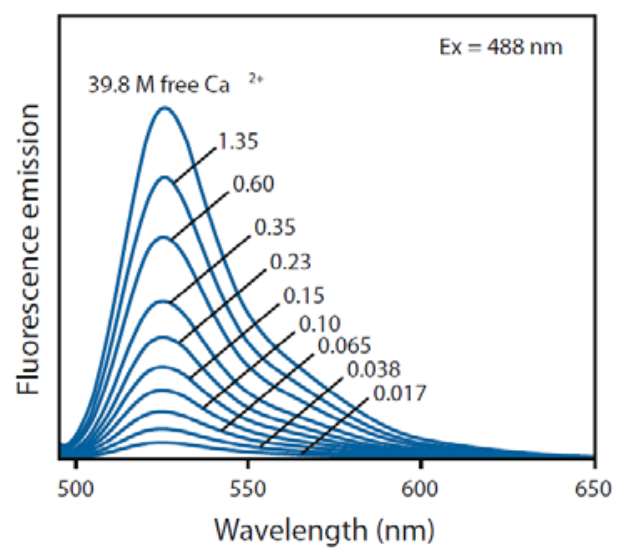

Figura 20. Estructura y espectros de fluorescencia de los indicadores de $\mathrm{Ca}^{2+}$ sintéticos utilizados. (A) Estructura de la sonda fluorescente Fura-2. (B) Espectro de fluorescencia de excitación del Fura-2 en soluciones que contienen desde 0 hasta 39,8 $\mathrm{mM}$ de $\mathrm{Ca}^{2+}$ libre. La longitud de onda de excitación máxima se desplaza hacia el UV al unirse a $\mathrm{Ca}^{2+}$. (C) Estructura de la sonda fluorescente Rhod-2. (D) Espectro de emisión del Rhod-2 en soluciones que contienen desde 0 hasta $39,8 \mathrm{mM}$ de $\mathrm{Ca}^{2+}$ libre. (Figura modificada de Molecular Probes Handbook, capítulo 19, "Indicators for $\mathrm{Ca}^{2+}$, $\mathrm{Mg}^{2+}, \mathrm{Zn}^{2+}$ and other metal ions"). (E) Estructura de la sonda fluorescente Fluo-3. (F) Espectro de fluorescencia de excitación del Fluo-3. 


\subsubsection{Sonda proteica: medidas de la $\left[\mathrm{Ca}^{2+}\right]_{\mathrm{RE}}$}

Las medidas de calcio reticular en célula única se realizaron con el sensor de calcio fluorescente codificado genéticamente, GAP3 dirigido al RE (erGAP3). Este indicador posee dos picos de excitación uno a 403 y otro a 470 , de tal forma que al unirse GAP a $\mathrm{Ca}^{2+}$, el pico a 403 disminuye y el 470 aumenta en fluorescencia, estas características le confieren propiedades ratiométricas (Fig. 21). El espectro de unión tiene un único máximo a $520 \mathrm{~nm}$, que es sensible a $\mathrm{Ca}^{2+}$. La direccionalidad al RE se consiguió mediante la fusión de GAP a la secuencia de la calreticulina en el extremo N-terminal y de la secuencia KDEL en el extremo C-terminal.

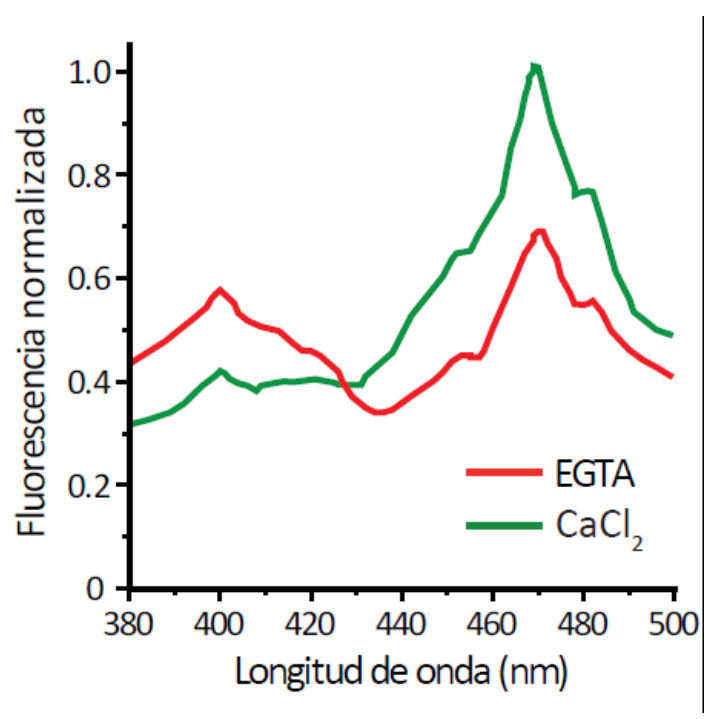

Figura 21. Espectro de fluorescencia de GAP con la emisión fijada a $520 \mathbf{n m}$. Espectro de excitación Medido con $20 \mu \mathrm{g} / \mathrm{ml}$ de la proteína GAP diluida en $1 \mathrm{ml}$ de solución MOPS ( $\mathrm{KCl}, 140 \mathrm{mM} ; \mathrm{MgCl}_{2}, 1 \mathrm{mM}$; MOPS, $20 \mathrm{mM}$; pH 7.2). En verde se muestra la fluorescencia en presencia de $\mathrm{CaCl}_{2}(10 \mathrm{mM})$ y en rojo la fluorescencia en presencia de EGTA (0.1 mM).

Las medidas de la $\left[\mathrm{Ca}^{2+}\right]_{\mathrm{RE}}$ en secciones de cerebro se realizaron exclusivamente en astrocitos. La especificidad de la medida en astrocitos se obtuvo mediante la infección con el virus de tipo AAV (AAV-GFAP-erGAP3), específico de astrocitos, por llevar erGAP3 bajo el promotor específico de astrocitos, GFAP. 
Además, excepcionalmente, en esta memoria se incluyen algunos resultados (Figura 56-58 y 61) realizados a partir de astrocitos aislados de corteza de ratones transgénicos para erGAP3. Estos experimentos se realizan así porque se estaban estudiando las oscilaciones de $\mathrm{Ca}^{2+}$ y los cultivos realizados a partir de ratones transgénicos sufren menos manipulación, y además todas las células del cultivo expresan el transgén GAP a niveles similares.

\subsection{Equipos}

\subsubsection{Microscopio de fluorescencia invertido}

El equipo utilizado para medir la $\left[\mathrm{Ca}^{2+}\right]_{c}$ con Fura-2 (o Fluo-3) se esquematiza en la Figura 22. Se empleó un microscopio de epifluorescencia. Las medidas con el indicador Fura-2 se realizaron en un microscopio de fluorescencia invertido (Nikon Diaphot) con un objetivo 20X (OLYMPUS-DPlanApo $20 \mathrm{UV}$ ) de apertura numérica 0.7. Las imágenes se adquirieron con un binning de $8 \times 8$ y un tiempo de integración de 5-10 segundos para cada par de imágenes. El programa de adquisición utilizado fue el Simple $\mathrm{PCl} 6$ (Hamamatsu). El microscopio está equipado con un sistema de perfusión y aspiración. La cámara de perfusión está compuesta de una pieza de aluminio anodizado encajada en una plataforma del mismo material. El cubreobjeto de $12 \mathrm{~mm}$ con las células adheridas se inserta entre las dos piezas, y se sella con una grasa de silicona (Dow Corning ${ }^{\circledR}$, Z273554-1EA), se perfundieron soluciones por gravedad con un sistema de válvulas. Cada solución se preparó en medio MEC, con $1 \mathrm{mM}$ de $\mathrm{CaCl}_{2}$ o con $0.5 \mathrm{mM}$ de EGTA, a temperatura ambiente (a una velocidad de flujo de $6 \mathrm{ml} / \mathrm{min}$ ).

La fuente de iluminación es una lámpara de xenon de $75 \mathrm{~W}$ (Fig. 22). Las células se iluminaron alternativamente a 340 y $380 \mathrm{~nm}$ para el Fura-2, utilizando un espejo dicroico DM500 y los filtros ET340 (Chroma) y ET380 (Chroma), respectivamente, colocados en una rueda de 6 filtros. Además, se utilizaron filtros de densidad neutra de 0.6 o 1 y filtros de calor para evitar la 
fototoxicidad. La emisión de fluorescencia a partir de $520 \mathrm{~nm}$ se recogió utilizando, el filtro de emisión LP520 y una cámara digital Hamamatsu de 12 bit de resolución (C4742-98). Las imágenes de cada longitud de onda se almacenaron y posteriormente se analizaron mediante el programa de análisis de imagen Image J. Cada imagen de fluorescencia emitida a 340 se dividió pixel a pixel por la correspondiente a $380 \mathrm{~nm}$. Para normalizar las medidas entre dos experimentos, se dividió el cociente entre el promedio de las 5 primeras imágenes (R0), para obtener R/R0. Todos los resultados mostrados se expresaron como el cociente normalizado (R/R0).

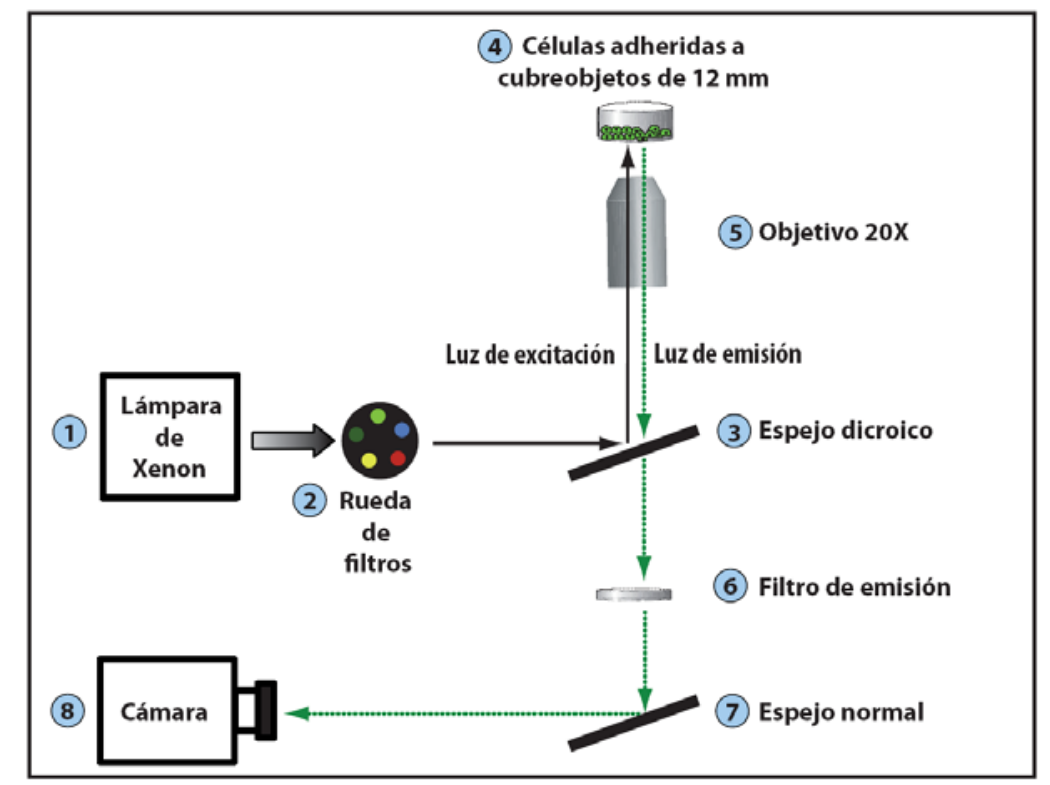

Figura 22. Representación esquemática del sistema de microfluorometría en un microscopio invertido. La fuente de iluminación utilizada es una lámpara de Xenón (1), la luz pasa a través de una rueda de filtros para seleccionar la longitudes de onda de la luz de excitación, 340 y 380 para el Fura-2, 470 y 405 para la GAP3 y 540 para el Rhod-2 (2). El haz de luz se refleja en el espejo dicroico (3) y alcanza las células (4) a través del objetivo del microscopio. La luz emitida por los diferentes indicadores fluorescentes presentes en las células es capturada por el objetivo (5). La luz que atraviesa el espejo dicroico (3), pasa a través de un filtro de emisión (6) y llega por último a la cámara (8). 


\subsubsection{Microscopio de fluorescencia directo}

Los registros de calcio reticular con la sonda GAP3, tanto en células en monocapa como en secciones de tejido, se realizaron en un equipo de imagen esquematizado en la Figura 23.

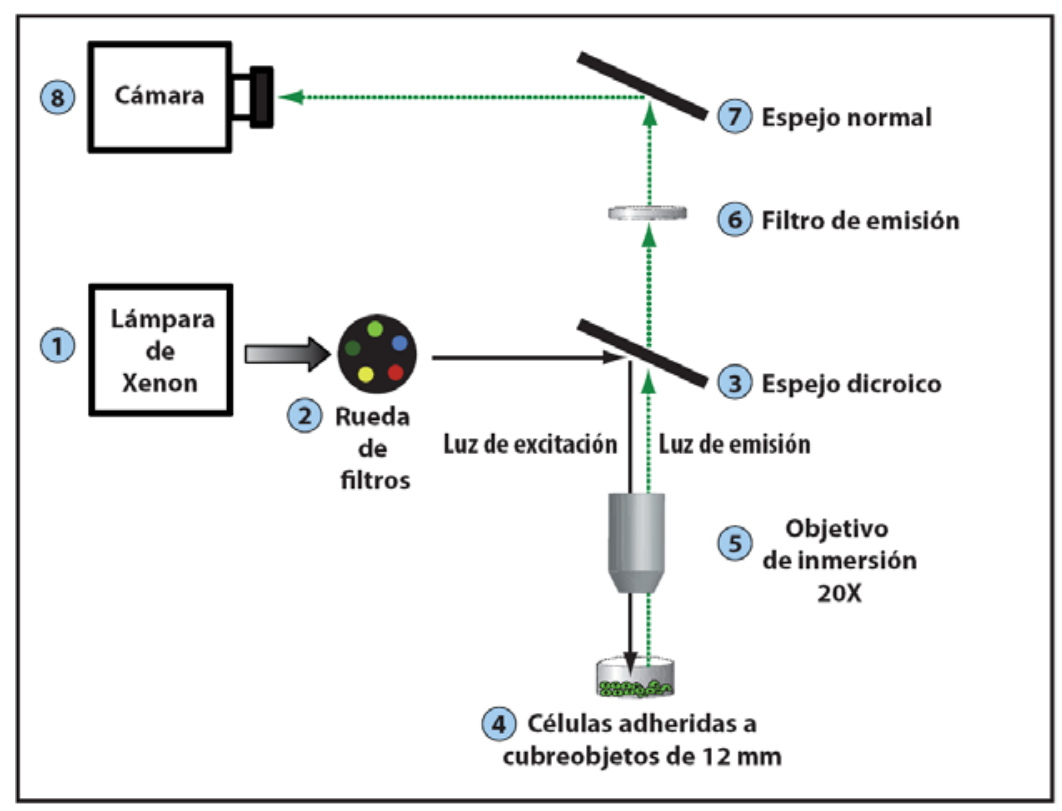

Figura 23. Representación esquemática del sistema de microfluorometría en un microscopio directo. La fuente de iluminación utilizada es una lámpara de Xenón (1), la luz pasa a través de una rueda de filtros para seleccionar las longitudes de onda de la luz de excitación, 340 y 380 para el Fura-2, 470 y 405 para la GAP3 y 540 para el Rhod-2 (2). El haz de luz se refleja en el espejo dicroico (3) y alcanza las células (4) a través del objetivo del microscopio. La luz emitida por los diferentes indicadores fluorescentes presentes en las células es capturada por el objetivo (5). La luz que atraviesa el espejo dicroico (3), pasa a través de un filtro de emisión (6) y llega por último a la cámara (8).

Se utilizó un microscopio de epifluorescencia Nikon Zeiss (Upright Axioplan 2 Imaging), con un objetivo 25X (Zeiss Plan Apochromat, 440544) de apertura numérica 0.8, y de inmersión en agua (Fig. 24). Las imágenes se adquirieron con un binning de 5x5 y un tiempo de integración de 5-10 segundos para cada par de imágenes. El programa de adquisición utilizado fue el AxioVision Rel. 4.6.3. El cubreobjeto con las células o el tejido se colocaron en el microscopio y se perfundieron con diferentes soluciones. En primer lugar, los cubreobjetos de $12 \mathrm{~mm}$ con las células adheridas o las secciones de tejido 
cultivadas se colocan en una cámara de perfusión $(A)$ formada por una base de aluminio donde se inserta el cubreobjeto y se ajustan en centro con una pieza de silgar que encaja perfectamente en el orificio de la cámara y que posee dos ranuras para colocar la entrada de líquido en una y la succión por vacío en la otra (Fig. 24A). En el caso de las secciones de tejido, se recortó la membrana de cultivo con un bisturí bajo una lupa, y se trasladó a la cámara, colocando el tejido en el centro y fijándolo con la cámara de silgar. En segundo lugar, se coloca la cámara en una plataforma acondicionada para colocar la perfusión (Fig. 24B), controlada por válvulas y por gravedad. Por último se coloca la plataforma en el microscopio (Fig. 24C).

La fuente de iluminación fue una lámpara de xenón de 75 W (Osram, XBO75). Las células que expresaban GAP se excitaron a 470 y $405 \mathrm{~nm}$, utilizando un espejo dicroico 505DRPL (XF2031) y los filtros 405IL25 (Comar, T-GQD) y 470DF35 (Omega, XF1013), colocados en una rueda de filtros acoplada. La emisión se registró entre 517 y 552 nm utilizando un filtro de emisión 535DF35 (Omega, XF3007). GAP3 se registra cada 5 a 10 segundos, iluminando las células alternativamente a 470 y $405 \mathrm{~nm}$. El Rhod-2 se excitó usando un espejo dicroico FT580 y un filtro de excitación 545/12 nm (4477148002) y la emisión se registró con un filtro LP590. Además, se usaron filtros de densidad neutra DN 1.0 (Omega Optical, 142588) y DN 0.5 (Omega Optical, 164526). La fluorescencia emitida se recogió con una cámara Zeiss AxioCAM. Los registros simultáneos de la $\left[\mathrm{Ca}^{2+}\right]_{\mathrm{ER}}$ y la $\left[\mathrm{Ca}^{2+}\right]_{\mathrm{C}}$, se realizaron con el sensor GAP3 y el indicador Rhod, las células se excitaron secuencialmente a 405, 470 y $540 \mathrm{~nm}$, y la fluorescencia se registró a >515 (535DF35) nm y >590 (LP590) $\mathrm{nm}$. 


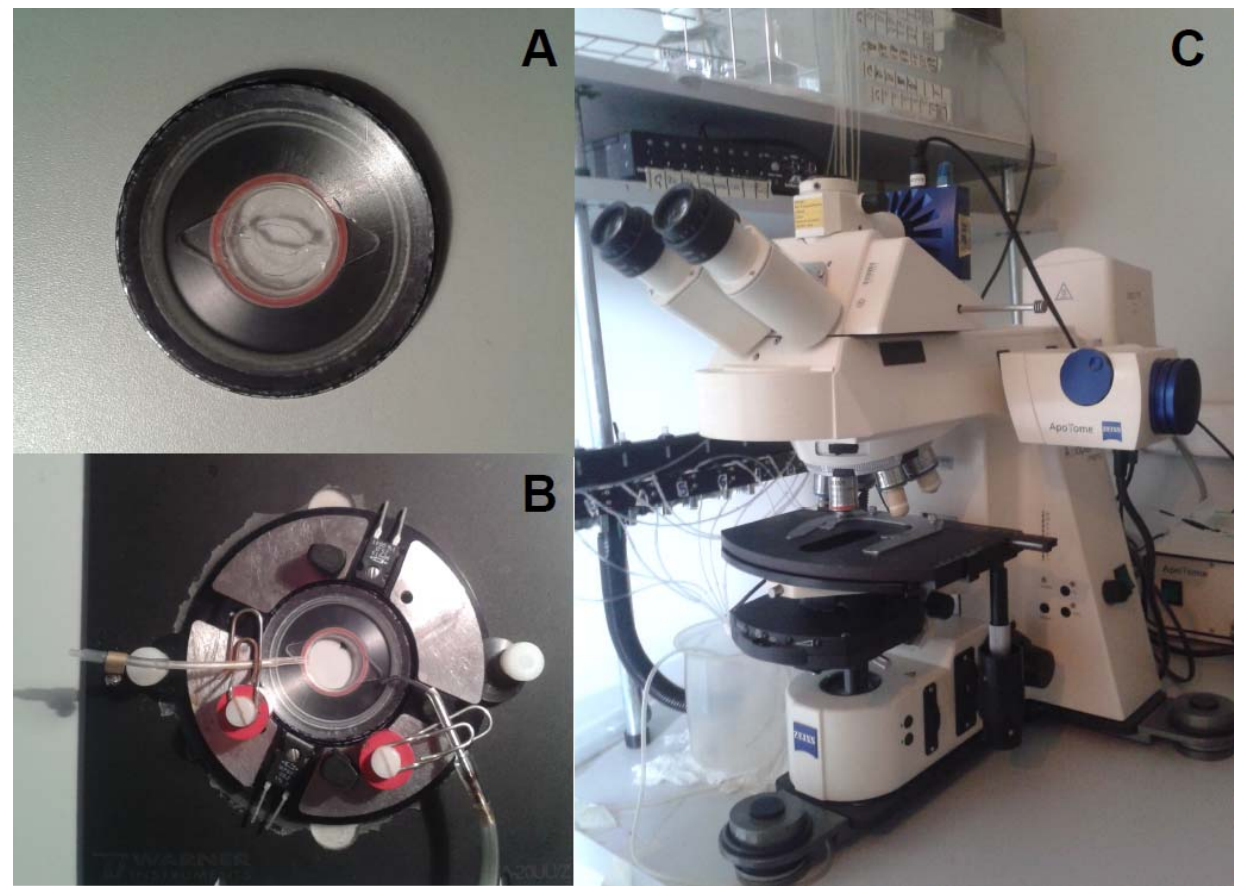

Figura 24. Fotos del equipo directo. A. Cámara de silgar donde se coloca el cristal de $12 \mathrm{~mm}$ con las células. B. Cámara de perfusión. C. Microscopio Nikon Zeiss Axioplan 2.

Finalmente, los datos obtenidos se procesaron utilizando el programa de análisis de imágenes ImageJ. El ruido de fondo de las imágenes obtenidas se restó píxel a píxel y se calculó el cociente entre las fluorescencias a 470 y 405 para GAP.

Los registros se representan como $R / R_{0}$ para GAP3 y Fura-2 (siendo $R_{0}$ el promedio de las primeras 5 imágenes de $R$ en cada experimento) o como $F / F_{0}$ para Rhod-2 y Fluo-3. La calibración de la señal fluorescente de GAP en [ $\left.\mathrm{Ca}^{2+}\right]$ se basó en la ecuación de Hill. Para la normalización se usó la fórmula:

$$
Y=\frac{R-R_{\min }}{R_{\max }-R_{\min }}
$$

donde "Y" es la señal fluorescente normalizada, cuyo valor varía entre 0 y $1, R$ es el cociente $F_{470} / F_{403}$ en un determinado momento del experimento; $R_{\min }$ es el cociente $\mathrm{R}$ en ausencia de $\mathrm{Ca}^{2+}$, y $\mathrm{R}_{\max }$ es el rango dinámico multiplicado por $R_{\text {min. }}$. Una vez obtenido el valor " $Y$ ", se puede calcular la $\left[\mathrm{Ca}^{2+}\right]$ con la ecuación 
de Hill. El valor del rango dinámico utilizado es de 4, que se obtuvo mediante la perfusión de ATP, $100 \mu \mathrm{M}$; TBH, $10 \mu \mathrm{M}$; y EGTA, 0.5 mM en medio externo.

$$
\mathrm{Y}=\frac{\mathrm{V}_{\max } \cdot\left[\mathrm{Ca}^{2+}\right]^{\mathrm{n}}}{\mathrm{K}_{\mathrm{d}}^{\mathrm{n}}+\left[\mathrm{Ca}^{2+}\right]^{\mathrm{n}}}
$$

Al normalizar la señal fluorescente entre 0 y 1 , asumimos que la $V_{\max }=1$. Por lo tanto, igualando las fórmulas 1 y 2 y sustituyendo $V_{\max }$ por 1 , podemos despejar la $\left[\mathrm{Ca}^{2+}\right]$ :

$$
\left[\mathrm{Ca}^{2+}\right]=\frac{\mathrm{K}_{\mathrm{d}}}{\left(\frac{\mathrm{R}_{\max } \mathrm{R}}{\mathrm{R}-\mathrm{R}_{\min }}\right)^{1 / n}}
$$

En la calibración de GAP3 se ha determinado que el valor de n es igual a 1, por lo que se sustituimos este valor en la fórmula y obtenemos una fórmula idéntica a la utilizada para calibrar el Fura-2 (Grynkiewicz y cols., 1985):

$$
\left[\mathrm{Ca}^{2+}\right]=\frac{\mathrm{K}_{\mathrm{d}} \cdot\left(\mathrm{R}-\mathrm{R}_{\min }\right)}{\mathrm{R}_{\max }^{-} \mathrm{R}}
$$

\section{Análisis estadístico}

Los resultados se expresaron como medias \pm desviación (dsm) o medias \pm error estándar de la media (esm). 



\section{Resultados}



En este trabajo nos hemos centrado en el estudio de la dinámica del $\mathrm{Ca}^{2+}$ intracelular en los astrocitos. Con este propósito se utilizaron diversos métodos para registrar las señales del ión en los diferentes modelos de estudio. Entre los métodos empleados destacamos una nueva herramienta basada en la fotoproteína aequorina y generada recientemente en nuestro laboratorio. Es un sensor de $\mathrm{Ca}^{2+}$ codificado genéticamente que permite monitorizar cambios de la $\left[\mathrm{Ca}^{2+}\right]$ en ambientes con altas concentraciones de ese ión. Expondremos los resultados en tres apartados. En primer lugar la descripción y caracterización de la nueva sonda luminiscente de $\mathrm{Ca}^{2+}$, en segundo lugar, estudiaremos la dinámica del $\mathrm{Ca}^{2+}$ en astrocitos corticales de cerebro de ratón en cultivos primarios. $Y$ finalmente, utilizaremos un modelo organotípico para validar el comportamiento del $\mathrm{Ca}^{2+}$ en astrocitos de rodajas de cerebro cultivadas, realizando para ello medidas tanto con indicadores codificados genéticamente como con indicadores químicos.

\section{Desarrollo de un nuevo sensor luminiscente de baja afinidad por $\mathrm{Ca}^{2+}$ IgGAP1}

\subsection{Diseño y caracterización del sensor}

Se ha desarrollado una nueva familia de sensores de $\mathrm{Ca}^{2+}$ denominada GAP (GFP-Aequorina-protein), basada en la fusión de dos proteínas de la medusa Aequorea Victoria, la GFP y la aequorina (Rodriguez-Garcia y col., 2014). A diferencia de la mayor parte de los sensores proteicos de calcio, basados en la calmodulina o la troponina, el elemento responsable de la unión a $\mathrm{Ca}^{2+}$ en el sensor GAP es la fotoproteína aequorina. Esta característica convierte a GAP en un sensor de $\mathrm{Ca}^{2+}$ único, de naturaleza dual: capaz de medir $\mathrm{Ca}^{2+}$, bien como un indicador fluorescente o como uno bioluminiscente, dependiendo de si la aequorina se encuentra en su forma apo-proteica o si está reconstituida con su cofactor lipídico celenterazina, respectivamente (Fig. 25). El modo fluorescente para registros en célula única se ha descrito recientemente, (Rodriguez-Garcia y col., 2014); el modo bioluminiscente, que 
se describe a continuación, se ha desarrollado durante el proyecto de esta Tesis y es más apropiado para poblaciones celulares.

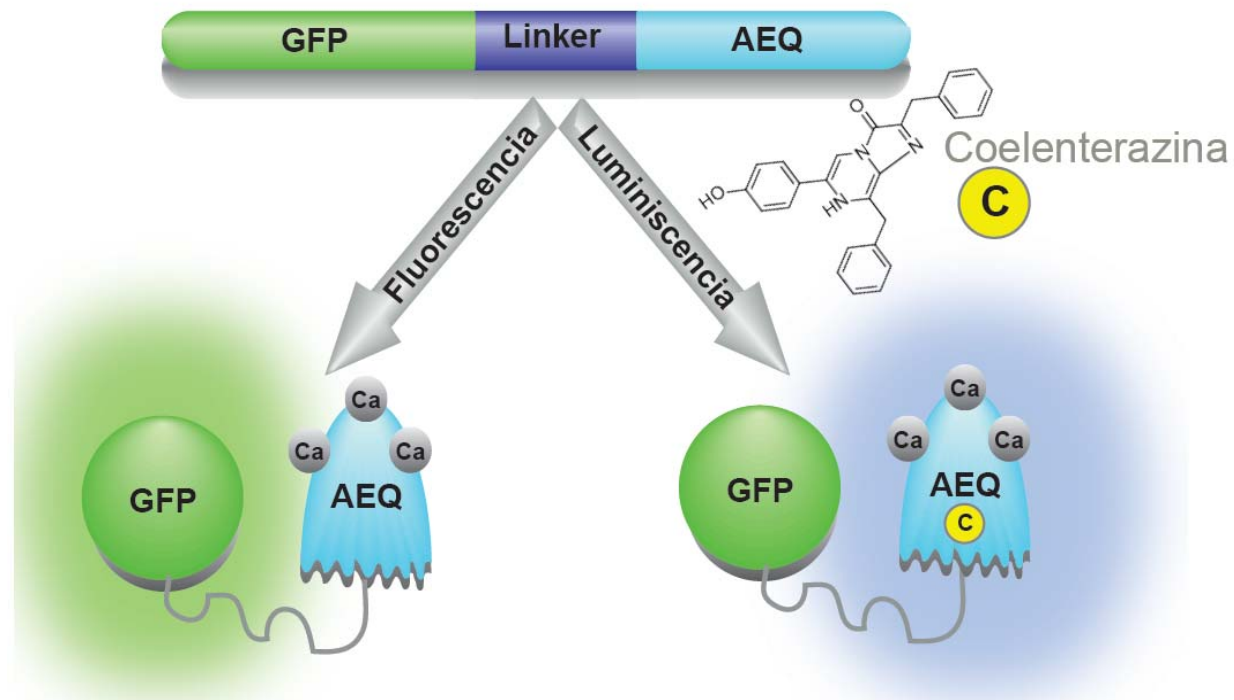

Figura 25. Estructura del sensor de $\mathrm{Ca}^{2+} \mathrm{GAP}$ y esquema de su funcionamiento dual. GAP está compuesta por una proteína fluorescente, una variante de GFP, y una proteína de unión a $\mathrm{Ca}^{2+}$ luminiscente, la aequorina, fusionadas mediante un peptido de 16 residuos. En el modo fluorescente (izquierda), GAP modifica la emisión de su fluorescencia verde cuando el $\mathrm{Ca}^{2+}$ se une a la apoaequorina; este sensor fluorescente se utiliza para medidas de calcio por imagen en célula única. En el modo bioluminiscente (derecha), GAP se reconstituye con el cofactor de la aequorina celenterazina y emite bioluminiscencia azul al unirse a $\mathrm{Ca}^{2+}$, se utiliza para medidas en poblaciones celulares.

Hasta ahora las medidas de la $\left[\mathrm{Ca}^{2+}\right]$ en compartimentos con alto contenido de calcio se habían realizado con la proteína de fusión erGFP-AEQ (erGA). Esta proteína se basa en la fusión de la EGFP (D119A) con una aequorina mutada en el residuo aspartato 119, sustituido por una alanina. Esta mutante (Kendall y col., 1992) disminuye la afinidad de la aequorina unas 20 veces con respecto a la nativa. La combinación de esta mutación con el uso de la celenterazina semisintética " $n$ " reduce todavía más la afinidad por el $\mathrm{Ca}^{2+}$, pero no lo suficiente como para hacer medidas mantenidas en el tiempo en presencia de altas concentraciones de $\mathrm{Ca}^{2+}$. Por este motivo, para medir la $\left[\mathrm{Ca}^{2+}\right]$ en los depósitos con alto contenido de $\mathrm{Ca}^{2+}$, como el RE y el aparato de Golgi, era un requisito indispensable utilizar sensores de menor afinidad que 
los usados hasta el momento. Con dicho objetivo, en un trabajo previo hemos descrito el desarrollo de una variante GAP de baja afinidad, que contiene las mutaciones D117A, D119A y D163A, y que presenta una menor afinidad por calcio que la erGA. En éste trabajo hemos realizado las medidas de calcio con la variante de GAP de baja afinidad denominada IgGAP1 para las medidas de bioluminiscencia. En la Figura 26A se muestran los dominios estructurales correspondientes a los sensores erGA e IgGAP1 y las respectivas mutaciones en la aequorina.

La direccionalidad de IgGAP1 al RE se obtuvo mediante la fusión en fase, en el extremo $\mathrm{N}$-terminal, de GAP1 con el dominio de la cadena pesada de la inmunoglobulina $\gamma 2 \mathrm{~b}$ (Fig. 26A). Esta estrategia permite que la proteína quede localizada y retenida específicamente en el lumen del RE por su interacción con chaperonas residentes en el RE (Montero y col., 1995). Este nuevo sensor se designó como IgGAP1 para diferenciarlo del erGAP1 fluorescente descrito para medidas de $\mathrm{Ca}^{2+}$ en célula única, del que difiere en la señal de direccionalidad al RE. La fusión que se utiliza en modo fluorescente, erGAP3, tiene como direccionalidad al RE el péptido señal de la calreticulina y la señal de retención en el RE KDEL en sus dominios $\mathrm{N}$ - y $\mathrm{C}$ - terminales respectivamente. El erGAP3 no puede ser utilizado para medidas de bioluminiscencia, pues no emite luz. Para que se produzca la emisión de luz al unirse al $\mathrm{Ca}^{2+}$ es esencial que el residuo de prolina del extremo $\mathrm{C}$-terminal de la aequorina se encuentre libre (Watkins y Campbell, 1993).

Para facilitar la caracterización de la sonda lgGAP1 se generaron clones estables en líneas celulares HeLa y HEK 293T Ilamados HeLa-IgGAP1 y HEKIgGAP1 respectivamente, que expresaban de forma estable IgGAP1. La correcta localización intracelular de la proteína IgGAP1 dirigida al RE se comprobó en el clon de células HeLa-lgGAP1 mediante inmunofluorescencia. En la Figura 26B se puede observar la colocalización de la GAP, que emite la fluorescencia verde (GFP), con el marcador del RE SERCA $2 b$, revelado en rojo. Las células de los clones expresaron la sonda correctamente en el RE, con la característica exclusión nuclear (Fig. 26B y 30), como se había observado también en las transfecciones. Además de los experimentos 
realizados con los clones estables de IgGAP1, en este trabajo también se han utilizado diferentes métodos para transducir el sensor, como transfecciones con el plásmido pcDNA3-IgGAP1 o infecciones con el vector viral HSV-IgGAP1.

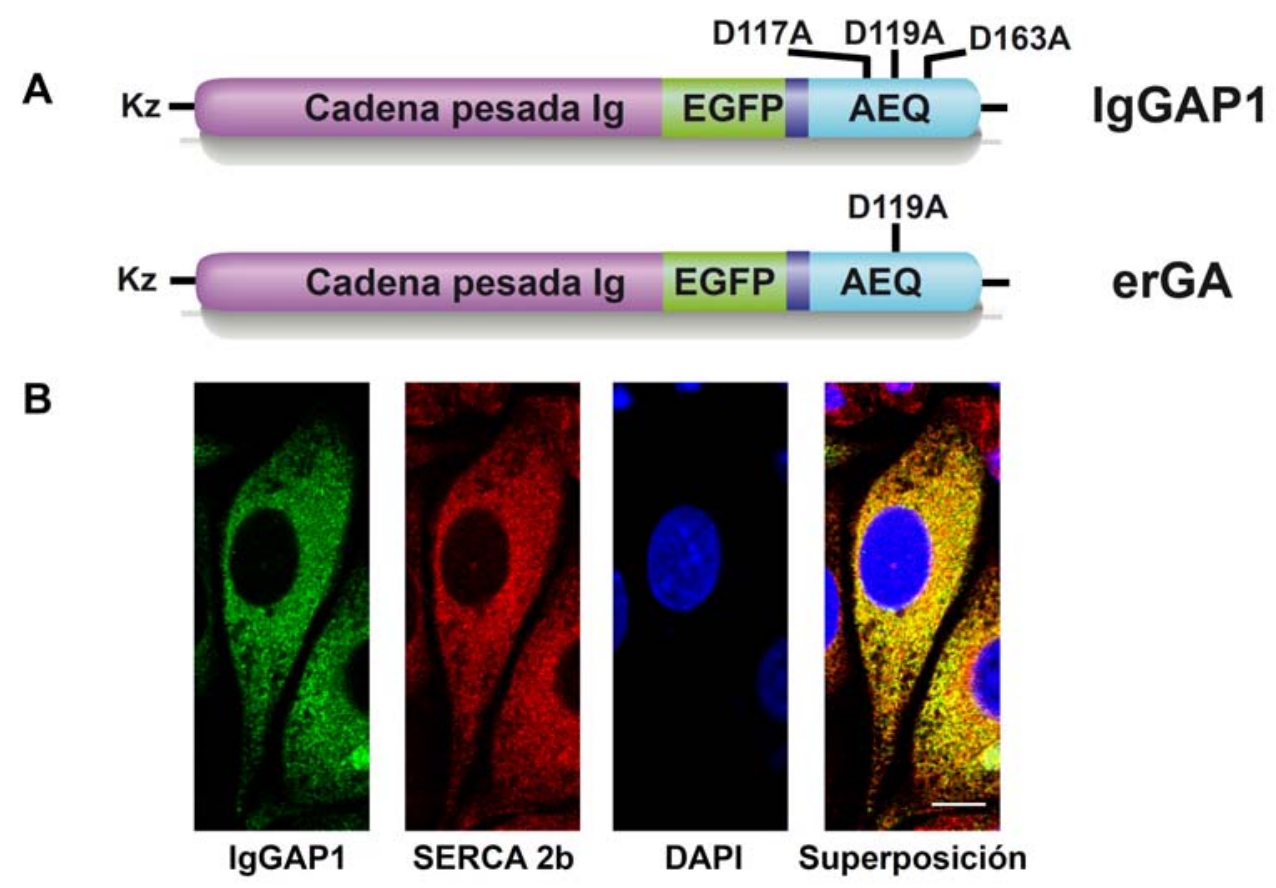

Figura 26. Estructura y expresión del indicador bioluminiscente del $\mathrm{Ca}^{2+}$ reticular IgGAP1. A. Comparación entre los dominios estructurales de IgGAP1 y erGA, indicando en cada caso los residuos mutados en la aequorina. La numeración de los residuos corresponde a la secuencia amioacídica de la aequorina original. Las dos construcciones también difieren en las distintas variantes de GFP empleadas así como en la longitud y composición del péptido espaciador entre la GFP y la aequorina. B. Imágenes de fluorescencia confocal del clon HeLa-IgGAP1 marcadas mediante inmunofluorescencia. Se muestra la expresión endógena de GFP de IgGAP1 en verde, el marcaje con el anticuerpo anti-SERCA $2 b$ en rojo y los núcleos teñidos con DAPI en azul. Barra de escala, $10 \mu \mathrm{m}$.

\subsection{Calibración del sensor luminiscente}

La calibración se realizó en el clon estable de HeLa-lgGAP1, comparando los resultados obtenidos con el clon HeLa-erGA que expresa erGA. Ambas sondas comparten la misma estrategia de direccionalidad al RE descrita previamente (Fig. 26A). Antes de la reconstitución de la aequorina con el cofactor, celenterazina $n$, fue imprescindible vaciar el RE de $\mathrm{Ca}^{2+}$ para evitar el consumo prematuro de la aequorina. El vaciamiento se realizó por inhibición 
reversible de la bomba SERCA con la tert-butilhidroquinona (TBH) (Moore y col., 1990) $(10 \mu \mathrm{M})$ e incubación durante 10 minutos. A continuación, las sondas se reconstituyeron con celenterazina $\mathrm{n}(1 \mu \mathrm{M})$ durante 60 minutos.

La calibración se realizó también in situ. Para ello, las células se permeabilizaron con Tritón X-100 $(0.01 \%)$, en una solución que contenía $\mathrm{KCl}$, $140 \mathrm{mM}$; $\mathrm{NaCl}, 10 \mathrm{mM} ; \mathrm{MgCl}_{2}, 1 \mathrm{mM}$; Na-MOPS, $10 \mathrm{mM}$; $\mathrm{pH}$ 7.2, у а continuación se perfundieron con concentraciones crecientes de $\mathrm{Ca}^{2+}(50,100$, $200,400,800$ y $1600 \mu \mathrm{M})$. Cada punto se midió por triplicado. Para poder realizar las calibraciones es necesario calcular el cociente L/LTOTAL, donde $L$ indica la emisión de luminiscencia (en cps) en un momento dado y LTOTAL representa la suma de todas las cps remanentes en ese momento (Barrero y col., 1997). La estimación de L totAL requiere el consumo completo de la aequorina, y se ha determinado experimentalmente lisando las células con digitonina en presencia de una concentración saturante de $\mathrm{Ca}^{2+}(10 \mathrm{mM})$ al finalizar cada experimento (Fig. 28A y 28C) y esperando a que se consuman todas las cuentas. Los datos se muestran como el cociente entre la luminiscencia/luminiscencia total en cada punto de tiempo (L/L $\left.\mathrm{L}_{\mathrm{TOTAL}}\right)(\mathrm{s}-1)$.

En la Figura 27 se compara la calibración de la nueva sonda, IgGAP1, con la aequorina de baja afinidad, erGA; esta última contiene sólo la mutación D119A y está fusionada a EGFP. El valor máximo de L/LTOTAL fue unas 7 veces menor para IgGAP1 que para la erGA. La combinación de la disminución tanto de la afinidad como del máximo de L/L $\mathrm{L}_{\text {TOTAL }}$, permite un consumo más lento de la aequorina, dando como resultado una emisión de luminiscencia mantenida en el tiempo, aún en presencia de altas concentraciones de $\mathrm{Ca}^{2+}$. Para ejemplificar este fenómeno, podemos estimar que una $\left[\mathrm{Ca}^{2+}\right]$ de $1 \mathrm{mM}$ provocaría un consumo de sólo el $0.1 \%$ por segundo del total de aequorina para la IgGAP1, y esto nos permite realizar registros continuos de luminiscencia durante periodos más largos de tiempo (>1000 s). Como puede observarse en la Figura 27A la curva de calibración de IgGAP1 está desplazada hacia la derecha con respecto a la sonda erGA, lo que demuestra 
una reducción de la afinidad por $\mathrm{Ca}^{2+}$ de aproximadamente un orden de magnitud.

A

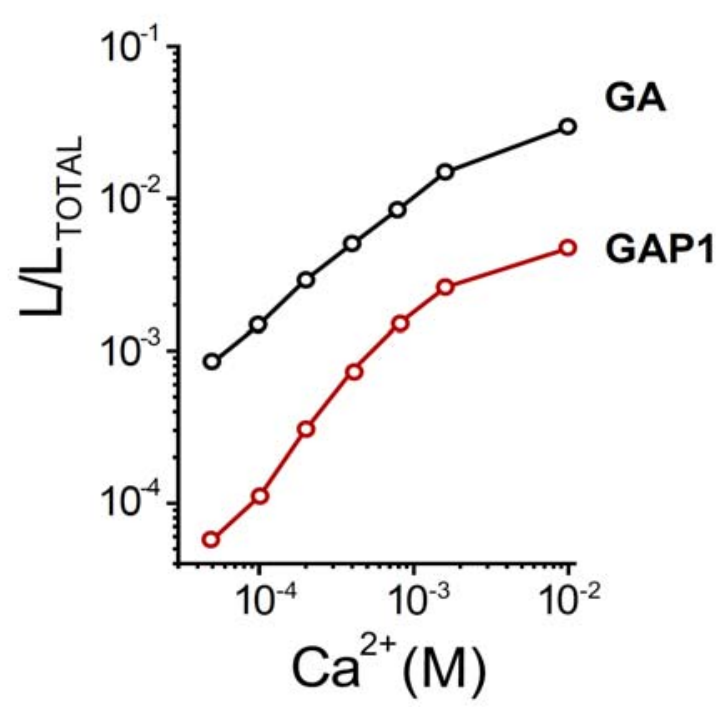

B

\begin{tabular}{||c|c|c||}
\hline \multirow{2}{*}[\mathrm{Ca}^{2+}]{$(\mathrm{M})$} & \multicolumn{2}{|c|}{$\begin{array}{c}\text { LUMINISCENCIA } \\
\text { (CPS) }\end{array}$} \\
\cline { 2 - 3 } & GA & GAP1 \\
\hline $5.00 \mathrm{E}-5$ & $8.41 \mathrm{E}-4$ & $5.75 \mathrm{E}-5$ \\
\hline $1.00 \mathrm{E}-4$ & $1.48 \mathrm{E}-3$ & $1.10 \mathrm{E}-4$ \\
\hline $2.00 \mathrm{E}-4$ & $2.92 \mathrm{E}-3$ & $3.05 \mathrm{E}-4$ \\
\hline $4.00 \mathrm{E}-4$ & $5.02 \mathrm{E}-3$ & $7.40 \mathrm{E}-4$ \\
\hline $8.00 \mathrm{E}-4$ & $8.53 \mathrm{E}-3$ & $1.50 \mathrm{E}-3$ \\
\hline $1.60 \mathrm{E}-3$ & $1.48 \mathrm{E}-2$ & $2.60 \mathrm{E}-3$ \\
\hline $1.00 \mathrm{E}-2$ & $2.96 \mathrm{E}-2$ & $4.70 \mathrm{E}-3$ \\
\hline
\end{tabular}

Figura 27. Calibración de la bioluminiscencia obtenida a partir de las sondas erGA e IgGAP1 reconstituidas con celenterazina $n$. A. Comparación de la calibración en $\mathrm{Ca}^{2+}$ de IgGAP1 y erGA realizada en los clones HeLa-lgGAP1 y HeLaerGA, respectivamente. Se muestran los valores de L/L $\mathrm{L}_{\text {TOTAL }}$ emitidos por cada sonda para una determinada concentración de $\mathrm{Ca}^{2+}$. Las medidas de la calibración se realizaron en un luminómetro que permite realizar adiciones con una pipeta y posee una cámara equipada con un sistema de agitación. Se utilizaron células HEK293T, sembradas a una densidad de $5 \times 10^{4}$ células en cubreobjertos de $9 \mathrm{~mm}$ de diámetro, se transfectaron con el plásmido pcDNA3-IgGAP1 o con el pcDNA3-erGA $(0.5 \mu \mathrm{g}$ en cada caso), y se mantuvieron en cultivo 24 horas. Las células se reconstituyeron con celenterazina $n$ en un medio sin $\mathrm{Ca}^{2+}$ (EGTA) en presencia de TBH $(10 \mu \mathrm{M})$. El cubreobjeto se insertó en una cubeta de espectrometría y esta se colocó en el luminómetro. Las células se lisaron con Triton X-100 $(0.01 \% \mathrm{v} / \mathrm{v})$ para liberar la proteína en un tampón MOPS. Las adiciones de $\mathrm{Ca}^{2+}$ se hicieron con una jeringa Hamilton en un rango de 50 a $1600 \mu \mathrm{M}$. Finalmente, la luminiscencia total ( $\left.\mathrm{L}_{\text {TOTAL }}\right)$ se obtuvo añadiendo una $\left[\mathrm{Ca}^{2+}\right]$ saturante $(10 \mathrm{mM})$, y sumando todos los valores $\mathrm{L}$ de luminiscencia emitidos a lo largo de todo el experimento. Los datos obtenidos se representaron como el cociente entre la luminiscencia en cada punto y la luminiscencia total emitida $\left(\mathrm{L}_{\mathrm{L}} \mathrm{L}\right)$. B. Tabla con los valores representados en la Figura $A$. Cada valor representa la media de tres datos obtenidos en dos experimentos independientes.

A continuación, estudiamos el comportamiento de la nueva sonda en las células intactas de los clones HeLa-IgGAP1 y HeLa-erGA. Las células se reconstituyeron con $1 \mu \mathrm{M}$ de celenterazina $\mathrm{n}$ durante 60 minutos como se explicó previamente. En la Figura 28A se comparan la cinéticas de rellenado del $\mathrm{RE}$ al perfundir $1 \mathrm{mM} \mathrm{Ca}^{2+}$ a las células intactas midiendo la emisión de 
fotones por parte de cada una de las sondas. El registro de bioluminiscencia refleja a la vez la concentración de $\mathrm{Ca}^{2+}$ en el RE (que aumenta durante los primeros minutos) junto con la tasa de consumo, que determina la disminución de la bioluminiscencia. Puede observarse que el pico de erGA consume más del $90 \%$ de la aequorina en los primeros 5 minutos. Al permeabilizar con digitonina hacia el minuto 27 se produce únicamente una liberación de la bioluminiscencia residual. Este hecho se observa mejor en la Figura 28B, donde se muestra el consumo normalizado de cada uno de los sensores, y se calcula el $T 1 / 2$. El $50 \%$ de la erGA se consumió en 1.3 minutos, mientras que IgGAP1 necesitó 11 minutos para alcanzar el mismo porcentaje de consumo. Consecuentemente, más del $90 \%$ de la erGA se consumió en los primeros 5 minutos; en cambio la IgGAP1 tardó 35 minutos antes de alcanzar un valor idéntico de consumo. Estos resultados indican que IgGAP1 es mucho más adecuada para medir la $\left[\mathrm{Ca}^{2+}\right]_{\mathrm{ER}}$ durante tiempos prolongados, permitiendo realizar medidas de hasta 60 minutos de duración. El rendimiento total de bioluminiscencia de la nueva sonda IgGAP1 en células HeLa fue similar al logrado con la antigua erGA de $10^{6}$ a $10^{7} \mathrm{cps}$ por $5 \times 10^{4}$ células.

La emisión de las cps totales se alcanzó en pocos minutos para erGA, mientras que IgGAP1 requirió un tiempo mucho más largo, y esto prolongó marcadamente la duración del experimento, y aún así el consumo no era completo (Fig. 28C). Para acortar este tiempo ideamos un procedimiento simple para estimar la luminiscencia residual al final del experimento, sin la necesidad de registrar el consumo completo de la aequorina remanente. EI procedimiento se ilustra en la Figura $\mathbf{2 8 C}$, y consiste en lisar las células con el procedimiento habitual (Dig./Ca10) y registrar durante unos 10 minutos. Cuando se representa la tasa de consumo en escala logarítmica la disminución es lineal, por lo tanto el consumo puede ser extrapolado en el tiempo (Fig. 28C, línea de puntos). Asumiendo que el consumo sigue la función $L_{t}=L_{0} \cdot e^{-k t}$, donde $k$ es la constante de velocidad de primer orden para el consumo, las cps residuales pueden estimarse multiplicando las últimas cps por el valor $T^{1} 1 / 2$ (en segundos) y por 1.49. Este valor se añadió a la suma de todos los valores previos para calcular el $\mathrm{L}_{\text {TOTAL }}$ (ver el pie de figura para más detalles). El procedimiento para la estimación del T1/2 se muestra en la Figura 28C, donde 
la altura de la caja es equivalente a un incremento x2 (en la escala logarítmica ampliado en las ordenadas). La caja se coloca sobre la gráfica y el T1/2 se calcula de la extrapolación de la caída de la bioluminiscencia (líneas de puntos), como se indica; en este caso, el valor es 5.60 minutos (336 segundos).

La Figura 28D relaciona los cocientes L/LTOTAL con sus correspondientes valores de $\left[\mathrm{Ca}^{2+}\right]_{E R}$ calibrados (escala de la derecha). La $\left[\mathrm{Ca}^{2+}\right]_{E R}$ basal se estimó en $635 \pm 1 \mu \mathrm{M}$ (media \pm sem; $n=4$ ). Valores similares se obtuvieron en las células HeLa, ya sea con transfección estable o con células transducidas transitoriamente con el sensor mediante transfección o infección. Los valores de $\left[\mathrm{Ca}^{2+}\right]_{E R}$ basal fueron muy similares a los descritos previamente usando el sensor erGA con la celenterazina $n$. Una estimulación máxima con ATP/Carbacol produjo una notable disminución de $\left[\mathrm{Ca}^{2+}\right]_{\mathrm{ER}}$ de $93 \pm 1 \%$ (media \pm esm, $n=9$, porcentaje estimado a partir de la disminución de la $\left.\left[\mathrm{Ca}^{2+}\right]_{\mathrm{ER}}\right)$ en 30 segundos, la misma fue rápida, reproductible, y regresó a los niveles basales luego del lavado del estímulo. Es importante destacar que estas medidas no podrían haber sido realizadas con erGA, ya que el $90 \%$ de la aequorina se hubiese consumido en 5 minutos y, como consecuencia, los cálculos de la $\left[\mathrm{Ca}^{2+}\right]_{\mathrm{ER}}$ habrían sido poco exactos (Fig. 28A y 28B). 

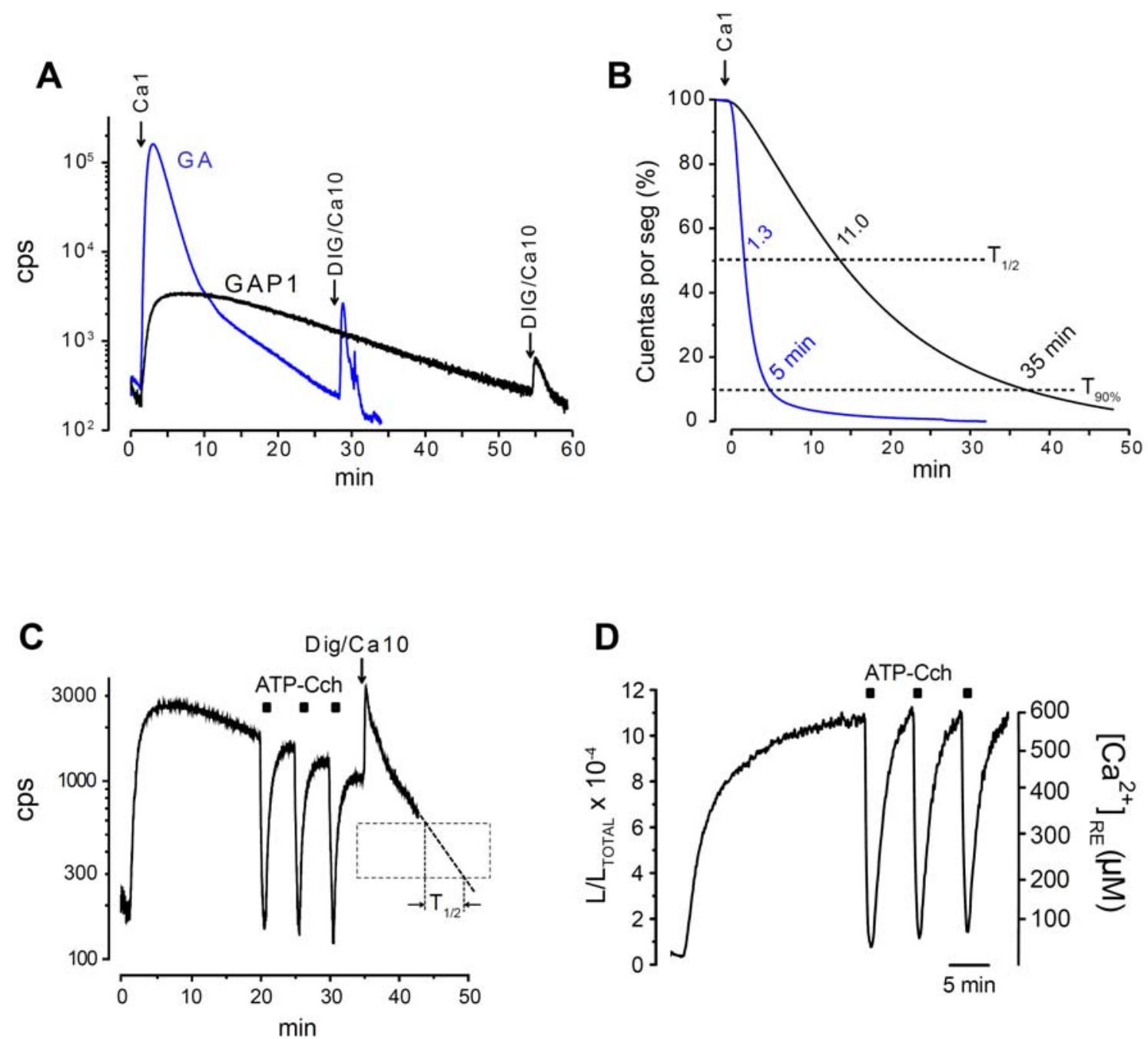

Figura 28. Comparación de la emisión de fotones y del consumo de la aequorina entre IgGAP1 y erGA. A. Rellenado del RE de las células HeLa-erGA y HeLa-IgGAP1 con $1 \mathrm{mM}$ de $\mathrm{Ca}^{2+}$ (Ca1, flecha). Se muestra el curso temporal de la emisión de luminiscencia (en cps) en escala logarítmica y la lisis con digitonina $(100 \mu \mathrm{M})$ en $\mathrm{Ca}^{2+}$ saturante $\left(10 \mathrm{mM}\right.$; Dig/ $/ \mathrm{Ca}^{2+}$ flecha) para liberar el remanente de bioluminiscencia. $\mathbf{B}$. Los resultados de (A) expresados como porcentaje del total de cuentas de bioluminiscencia remanentes en las células, a cada tiempo a lo largo del experimento. Nótese que el consumo es mucho más lento para IgGAP1 que para erGA. Se muestran los valores de $T_{1 / 2}$ y de $T_{90 \%}$. C. Células HeLa-lgGAP1 tratadas como en $(A)$, y estimuladas con 3 pulsos sucesivos de 30 segundos de ATP/Carbacol (ATP-Cch, $100 \mu \mathrm{M}$ cada uno). A los 35 minutos, las cuentas remanentes de la aequorina se liberaron lisando las céluas con digitonina y $\mathrm{Ca}^{2+}$ (Dig/Ca10). La emisión de luminiscencia (cps) está graficada en escala logarítmica. Se muestra el procedimiento de estimación del $T_{1 / 2}$. D. Calibración de los datos obtenidos de $(C)$, se muestra la emisión de luz como L/L total (eje de la izquierda) y la $\left[\mathrm{Ca}^{2+}\right]_{\mathrm{ER}}($ en $\mu \mathrm{M}$ ) (eje de la derecha). 


\subsection{Medidas de la $\left[\mathrm{Ca}^{2+}\right]_{\mathrm{RE}}$ en diferentes tipos celulares}

La funcionalidad de la sonda en el RE se comprobó en células HeLa del clon HeLa-IgGAP1. Se realizaron experimentos tanto en células intactas como en permeabilizadas con digitonina (Fig. 29). Medimos la liberación de $\mathrm{Ca}^{2+}$ del RE inducida por histamina (100 $\mu \mathrm{M}, 30$ segundos) en dichas células (Fig. 29A). La estimulación durante 30 segundos provocó una disminución del $26 \pm 0.5 \%$ del contenido $\mathrm{Ca}^{2+}$ del RE (media \pm esm, $\mathrm{n}=12$ ), la velocidad de liberación fue de $74 \pm 1 \mu \mathrm{M} /$ segundo (media \pm esm, $\mathrm{n}=8$ ). Al retirar el estímulo, la $\left[\mathrm{Ca}^{2+}\right]_{\mathrm{ER}}$ recuperó su nivel basal, demostrando la reproductibilidad de la estimulación. Además, la perfusión del inhibidor reversible de la SERCA TBH, en medio libre de $\mathrm{Ca}^{2+}$ (suplementado con $0.5 \mathrm{mM}$ de EGTA) produjo una depleción completa del $\mathrm{Ca}^{2+}$ del RE en 9 minutos. Al lavar el inhibidor y perfundir nuevamente el medio con $\mathrm{Ca}^{2+}$, el RE recuperó su nivel basal en unos 10 minutos (Fig. 29B). Un segundo estímulo con histamina provocó una respuesta del $\mathrm{Ca}^{2+}$ reticular muy similar al primer estímulo, lo que demuestra el carácter reversible del TBH. El lavado del estímulo provocó una subida en la señal luminiscente hasta recuperarse el nivel anterior al estímulo, indicando la recaptación del $\mathrm{Ca}^{2+}$ por parte del RE. Estos resultados demuestran funcionalmente que la sonda IgGAP1 estaba correctamente localizada en el RE y que permite realizar mediciones muy largas, de hasta 40-60 minutos.

Para tener un control directo de la composición del citosol y poder estimular los receptores de $\mathrm{IP}_{3}\left(\mathrm{IP}_{3} \mathrm{Rs}\right)$ del RE con una concentración conocida del agonista específico $\mathrm{IP}_{3}$, se realizaron experimentos en células permeabilizadas del clon HeLa-lgGAP1. La permeabilización de las células se realizó con el detergente no iónico digitonina. Este detergente actúa solubilizando el colesterol de las membranas biológicas (la membrana plasmática está enriquecida en dicho lípido), creando de esta manera poros en el plasmalema y permitiéndonos así controlar la composición de medio intracelular, y añadir moléculas no permeables como el inositol trifosfato $\left(\mathrm{IP}_{3}\right)$ (Fig. 29C). 

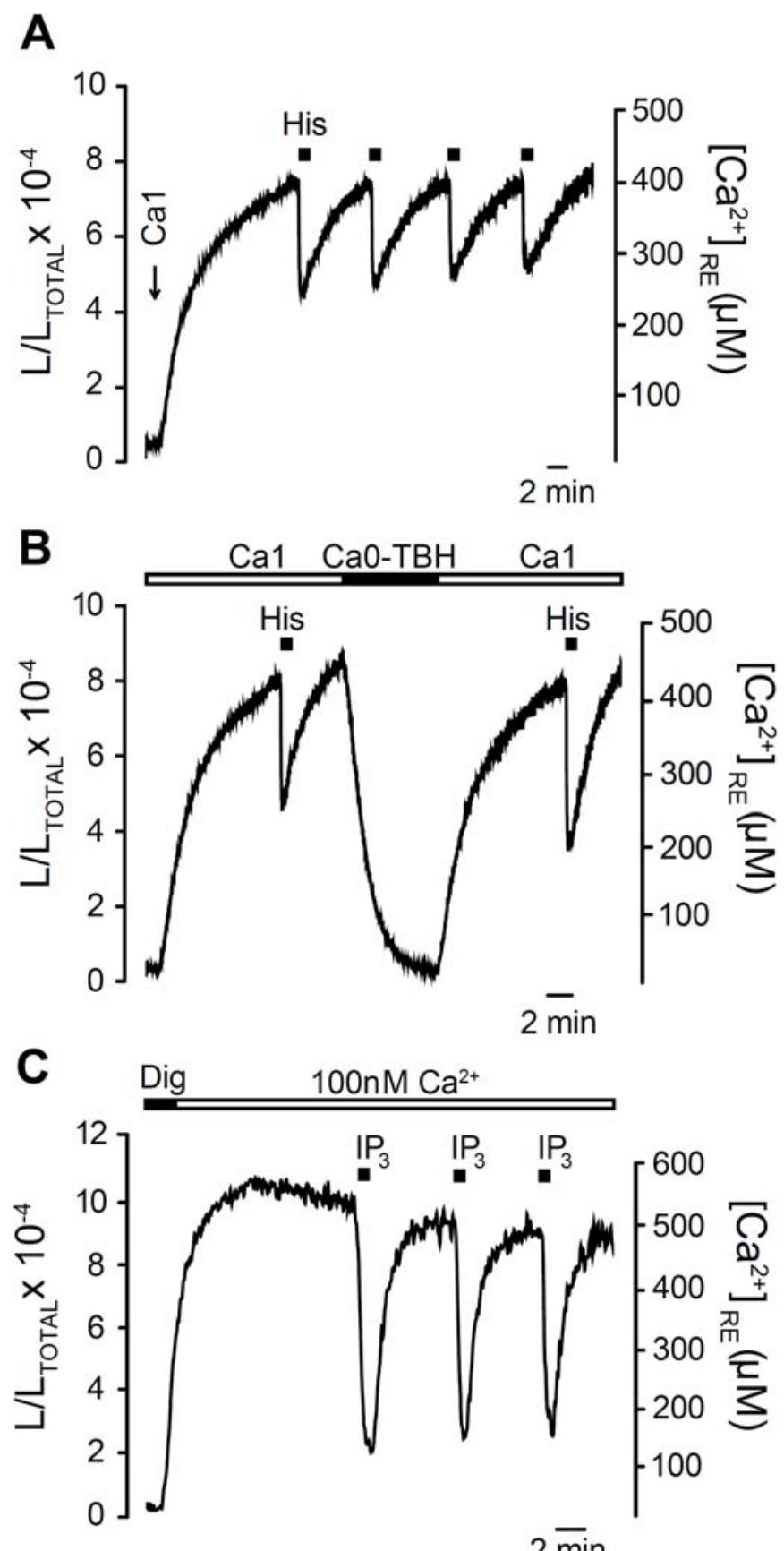

$2 \overline{\min }$

Figura 29. Dinámica de la $\left[\mathrm{Ca}^{2+}\right]_{\mathrm{RE}}$ en células intactas y permeabilizadas. Las HeLa-IgGAP1 se reconstituyeron con celenterazina $n$, depletando previamente el RE de $\mathrm{Ca}^{2+}$ en medio sin $\mathrm{Ca}^{2+}$ (EGTA, $\left.0.5 \mathrm{mM}\right)$ y en presencia de TBH $(0.01 \mathrm{mM})$ A. Células intactas estimuladas con pulsos de 30 segundos de histamina (His, $100 \mu \mathrm{M}$ ). B. Las células se trataron durante 6 minutos en un medio sin $\mathrm{Ca}^{2+}$ (con EGTA, 0.5 mM y $\mathrm{TBH}, 10 \mu \mathrm{M}$ ) para provocar el vaciamiento completo del $\mathrm{Ca}^{2+}$ del RE. C. Las células se permeabilizaron durante 2 minutos con digitonina (Dig, $60 \mu \mathrm{M}$ ) en un medio de composición similar al intracelular en ausencia de $\mathrm{Ca}^{2+}$. A continuación, se perfundieron con $\mathrm{MI}$ con $0.1 \mu \mathrm{M}$ de $\mathrm{Ca}^{2+}$ (tamponado con EGTA) para rellenar el RE y se estimularon con pulsos de $\mathrm{IP}_{3}(5 \mu \mathrm{M})$ de 30 segundos. Los resultados mostrados son trazados representativos de 3-8 experimentos similares. 
Se perfundió con un medio de composición similar al medio intracelular y una $\left[\mathrm{Ca}^{2+}\right]$ cercana a la $\left[\mathrm{Ca}^{2+}\right]_{\mathrm{c}}$ en células en reposo $(0.1 \mu \mathrm{M})$. En estas condiciones el RE se rellenó hasta alcanzar un nivel basal de $533 \pm 17 \mu \mathrm{M}$ (media \pm esm, $n=9$ ), un valor similar al obtenido previamente en células intactas.

En los experimentos donde se utilizaron los protocolos de permeabilización, observamos que la funcionalidad del sensor no había sido afectada. La estimulación con $\mathrm{IP}_{3}(5 \mu \mathrm{M})$ produjo una marcada liberación del contenido de $\mathrm{Ca}^{2+}$ del RE, de $58 \pm 5 \%$ (media \pm sem; $n=9$ ).

A continuación, aplicamos la nueva sonda a 3 tipos celulares distintos, dos líneas celulares ampliamente utilizadas como las células $\mathrm{CHO}$ y HEK293T, y un cultivo primario de neuronas de hipocampo de ratón, para estudiar en todas estas células la dinámica del $\mathrm{Ca}^{2+}$ del RE. En las Figuras $30 \mathrm{~A}$ y $30 \mathrm{~B}$ se muestran los resultados obtenidos en células CHO y HEK293T respectivamente, y en la Figura 30C los de un cultivo neuronal primario de hipocampo de ratón, transducido con el sensor IgGAP1 mediante infección con un vector derivado del herpes simplex. A la izquierda se muestran imágenes de la expresión de la sonda IgGAP1, en cada tipo celular, con el patrón de localización característico del $\mathrm{RE}$ en los 3 tipos celulares, con el núcleo excluido y en el caso de las neuronas las prolongaciones extendiéndose por el cultivo (Fig. 30C). A la derecha, se muestran los registros de la $\left[\mathrm{Ca}^{2+}\right]_{\mathrm{RE}}$ obtenidos en cada caso. Los niveles basales de $\left[\mathrm{Ca}^{2+}\right]_{\mathrm{ER}}$ (media \pm sem) fueron $473 \pm 29 \mu \mathrm{M}(\mathrm{n}=4)$ y $388 \pm 8 \mu \mathrm{M}(\mathrm{n}=3)$ para las células CHO y HEK293T, respectivamente. La estimulación con ATP/Carbacol provocó una liberación de la $\left[\mathrm{Ca}^{2+}\right]_{E R}$ de entre el 44 y el $57 \%$ en ambos tipos celulares. En la Figura 30C se muestra la estimulación de las neuronas con glutamato, que provocó una liberación de $\mathrm{Ca}^{2+}$ del RE de $27 \pm 1.4 \%$ (media \pm esm; $\mathrm{n}=14$ ) a partir de niveles basales de $449 \pm 24 \mu \mathrm{M} ; \mathrm{n}=8$. En la Tabla 8 se resumen los valores de la $\left[\mathrm{Ca}^{2+}\right]_{\mathrm{ER}}$ basales obtenidos en los diferentes tipos celulares, así como las velocidades iniciales de captación de $\mathrm{Ca}^{2+}$ por parte del RE medidas con la sonda IgGAP1. 
A

\section{Células $\mathrm{CHO}$}

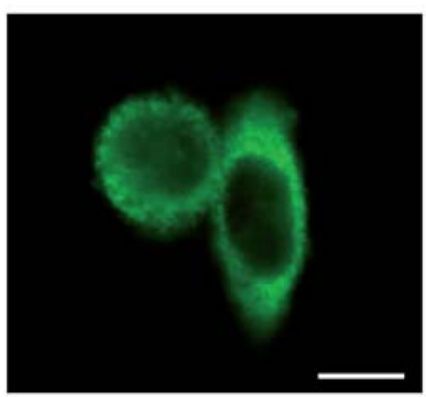

B
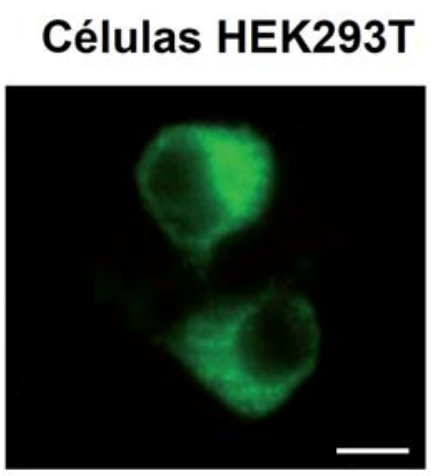

C

\section{Neuronas de hipocampo}

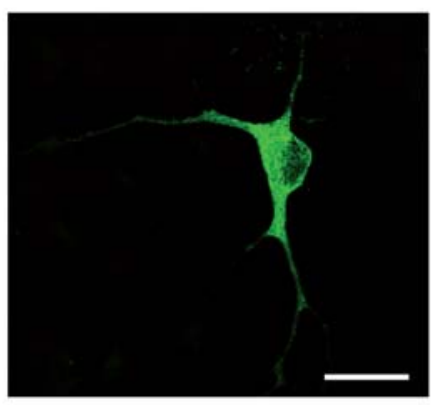

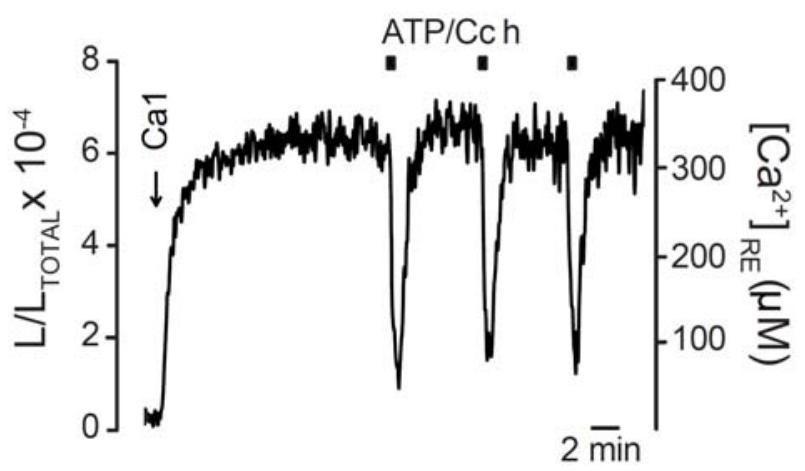
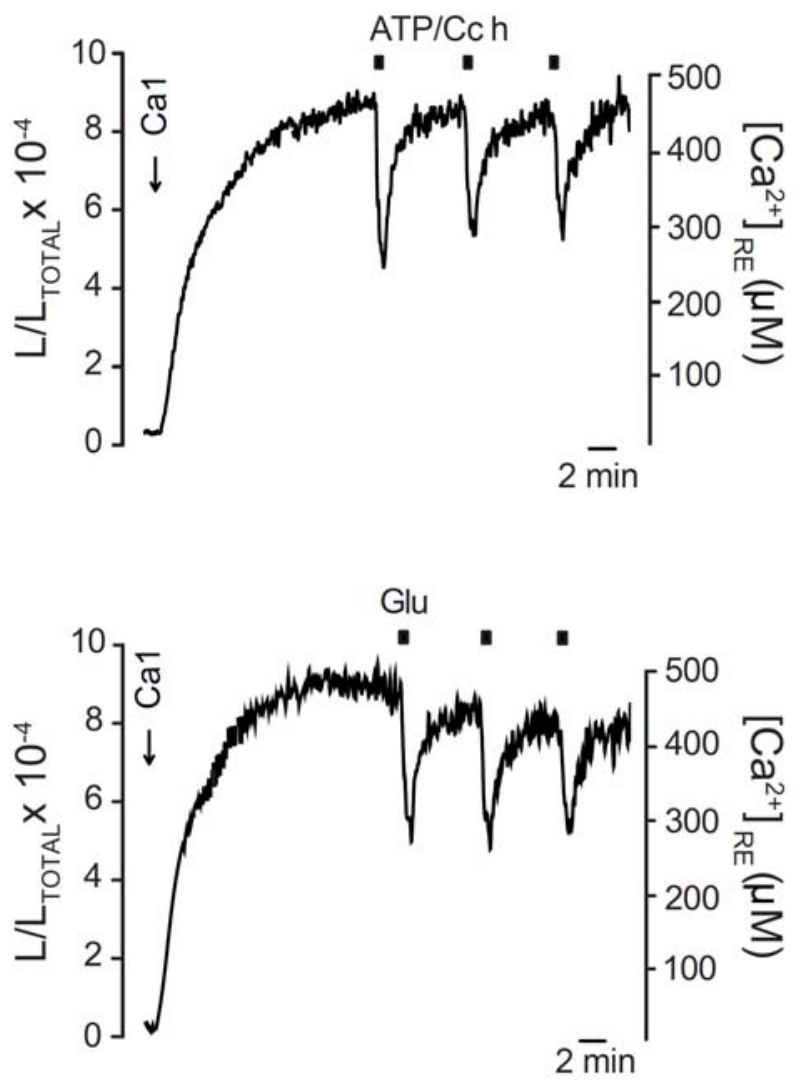

Figura 30. Monitorización de la dinámica del $\mathrm{Ca}^{2+}$ del $\mathrm{RE}$ en distintos tipos celulares mediante la sonda reticular IgGAP1. A. Panel izquierdo (para A, B y C). Imagen de fluorescencia endógena de IgGAP1 que muestra la localización del sensor en verde en el RE. Células $\mathrm{CHO}$ transfectadas transitoriamente y estimuladas con ATP y carbacol (ATP/Cch; $100 \mu \mathrm{M}$ cada uno). Otros detalles experimentales como en la Figura 4. B. Células HEK293T que expresan IgGAP1 y estimuladas como en (A). C. Neuronas de hipocampo de ratón infectadas con el amplicón HSV-lgGAP1, y estimuladas con glutamato $(\mathrm{Glu}, 20 \mu \mathrm{M})$. Cada estímulo fue de una duración de 30 segundos. Barra de escala correspondiente a $10 \mu \mathrm{M}$. Los resultados mostrados son representativos de 4-8 experimentos similares. 


\begin{tabular}{||c|c|c||}
\hline Tipo Celular & Velocidad de Rellenado $(\mu \mathrm{M} / \mathbf{s e g})$ & {$\left[\mathrm{Ca}^{2+}\right]_{\mathrm{ER}}$ basal $(\mu \mathrm{M})$} \\
\hline HeLa infectadas & $3.81 \pm 0.22(\mathrm{n}=4)$ & $523 \pm 14(\mathrm{n}=4)$ \\
\hline HeLa transfectadas & $2.09 \pm 0.12(\mathrm{n}=3)$ & $458 \pm 29(\mathrm{n}=3)$ \\
\hline Clon de HeLa-IgGAP1 & $4.87 \pm 0.65(\mathrm{n}=4)$ & $635 \pm 25(\mathrm{n}=4)$ \\
\hline HEK 293T & $5.73 \pm 1.00(\mathrm{n}=8)$ & $388 \pm 8(\mathrm{n}=8)$ \\
\hline CHO & $4.53 \pm 0.46(\mathrm{n}=3)$ & $473 \pm 29(\mathrm{n}=4)$ \\
\hline Neuronas de hipocampo & $4.20 \pm 0.69(\mathrm{n}=6)$ & $449 \pm 24(\mathrm{n}=8)$ \\
\hline
\end{tabular}

Tabla 8. Niveles de la $\left[\mathrm{Ca}^{2+}\right]_{E R}$ basal y las velocidades de rellenado del $\mathrm{RE}$ en diferentes tipos celulares medidos con IgGAP1. Las medidas se realizaron en el clon estable HeLa-IgGAP1 o en células transducidas mediante infección con un vector viral de tipo HSV (células HeLa y neuronas de hipocampo), o por transfección con el plásmido pcDNA3-IgGAP1 (células HeLa, CHO y HEK293T). La velocidad de rellenado se midió después del vaciamiento del RE durante $1 \mathrm{~h}$ y como velocidad inicial tras la adición de $\mathrm{Ca}^{2+} 1 \mathrm{mM}$.

\section{Caracterización del cultivo de astrocitos}

Se utilizaron 3 tipos de cultivos de astrocitos con un orden creciente de complejidad y de similitud a las condiciones fisiológicas de la corteza de cerebral murina: 1) cultivo de astrocitos puros en monocapa; 2) cultivo mixto de neuronas y glias; y, 3) cultivo organotípico de corteza cerebral. Cada uno de estos cultivos se puso a punto específicamente para esta Tesis.

\subsection{Cultivo primario en monocapa de astrocitos murinos de corteza cerebral}

La pureza del cultivo de astrocitos se comprobó mediante un ensayo de doble inmunofluorescencia utilizando dos anticuerpos específicos, uno frente a la proteína ácida fibrilar glial (GFAP), principal componente de los filamentos intermedios de astrocitos y ampliamente utilizada para el marcaje de éste tipo celular; y, otro frente a la $\beta$-III-tubulina (anti-Tuj1), marcador selectivo neuronal, componente fundamental de los microtúbulos de las neuronas. En el panel superior de la Figura 31 se muestran imágenes representativas de microscopía confocal del cultivo puro de astrocitos, y en el panel inferior las correspondientes a un cultivo mixto de neuronas y glía. En primer lugar, se 
muestra la tinción con GFAP; en segundo lugar el marcaje con $\beta$-III-tubulina; en tercer lugar los núcleos marcados con DAPI, necesario para realizar el contaje de todas las células del campo; y finalmente se muestra la superposición de las 3 imágenes anteriores. Como puede observarse, en el cultivo puro de astrocitos, prácticamente todas las células presentes en el campo son positivas para GFAP y negativas para $\beta$-III-tubulina. Por el contrario, en el cultivo mixto se observan células positivas tanto para GFAP como para $\beta$-III tubulina, demostrando la presencia de neuronas. Podemos considerar que el cultivo obtenido fue prácticamente puro de astrocitos. La morfología poligonal de estas células es otra indicación de su carácter astrocítico, fundamentalmente de tipo I. Las imágenes del cultivo mixto están tomadas en un plano ecuatorial para las neuronas, más alto que el plano de los astrocitos, esto explica que en la imagen de los astrocitos en el cultivo mixto (al contrario que en el cultivo puro de astrocitos) no se observe la exclusión nuclear en las células marcadas con GFAP, ya que los núcleos de los astrocitos quedan en un plano inferior. Las neuronas exhiben una morfología característica con un soma bien definido y largos axones que se prolongan a través de todo el campo.

Estos resultados demostraron la ausencia de neuronas en el cultivo puro de astrocitos. Además, prácticamente todas las células del cultivo puro de astrocitos fueron positivas para GFAP $92 \pm 6 \%$ (media \pm esm, $n=2400$ células, correspondientes a 20 campos de 4 experimentos individuales). El $8 \%$ restante, podría corresponder a otro tipo de glía, como oligodendrocitos, microglía, o alternativamente astrocitos que no se reconocen con el anticuerpo anti-GFAP. 


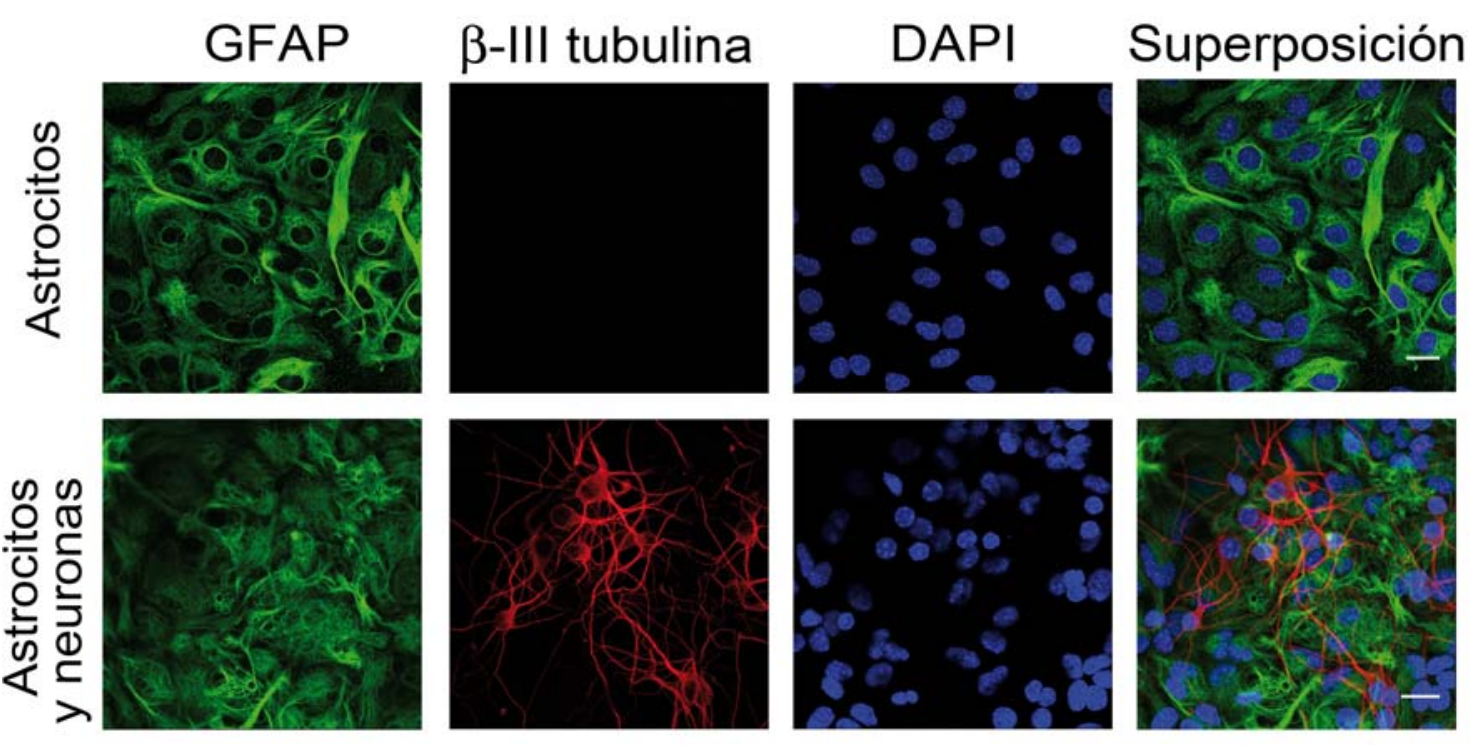

Figura 31. Caracterización del cultivo puro de astrocitos corticales. Imágenes de fluorescencia confocal de un cultivo puro de astrocitos (panel superior) y un cultivo mixto de astrocitos y neuronas (panel inferior). Las células se fijaron y se tiñeron mediante una inmunofluorescencia doble con un anticuerpo específico anti-GFAP (marcador específico glial, en verde) y un anticuerpo anti $\beta$-III tubulina (marcador específico neuronal, en rojo). Los núcleos se tiñeron con DAPI (azul). La barra de escala corresponde a $20 \mu \mathrm{m}$.

\subsection{Cultivo organotípico de corteza cerebral de ratón}

Los resultados obtenidos en los cultivos en monocapa se validaron en un cultivo organotípico de secciones de corteza cerebral, donde las células conservan una organización y estructura tridimensional más parecida a la nativa in vivo. $\mathrm{El} \mathrm{Ca}^{2+}$ del $\mathrm{RE}$ se midió con el sensor fluorescente erGAP3, transducido mediante infección vírica (véase sección siguiente). Los ensayos se realizaron tras 3 a 7 días en cultivo para permitir la expresión del sensor. La morfología de los astrocitos en este cultivo se comprobó mediante inmunofluorescencia con el anticuerpo anti-GFAP. En la Figura 32A se muestra una imagen de microscopía de fluorescencia de una sección de corteza de cerebro (no fijada) e incubada con sulforodamina para marcar a los astrocitos presentes en el tejido. En la Figura 32B se muestra una sección de hipocampo marcado mediante un ensayo inmunofluorescencia, donde se tiñeron los astrocitos con GFAP (verde) y los núcleos con DAPI (azul). El marcaje de los núcleos con DAPI revela una alta densidad celular en el giro 
dentado, correspondiente a la capa de neuronas granulares, y también en el estrato piramidal. Los astrocitos, revelados en verde, se observan distribuidos por todas las zonas de tejido, y en alta densidad en el estrato molecular y lacunosum moleculare, manifestando su típica morfología con un soma pequeño y redondeado $(<15 \mu \mathrm{m})$ y presentando numerosos procesos delgados y ramificados.
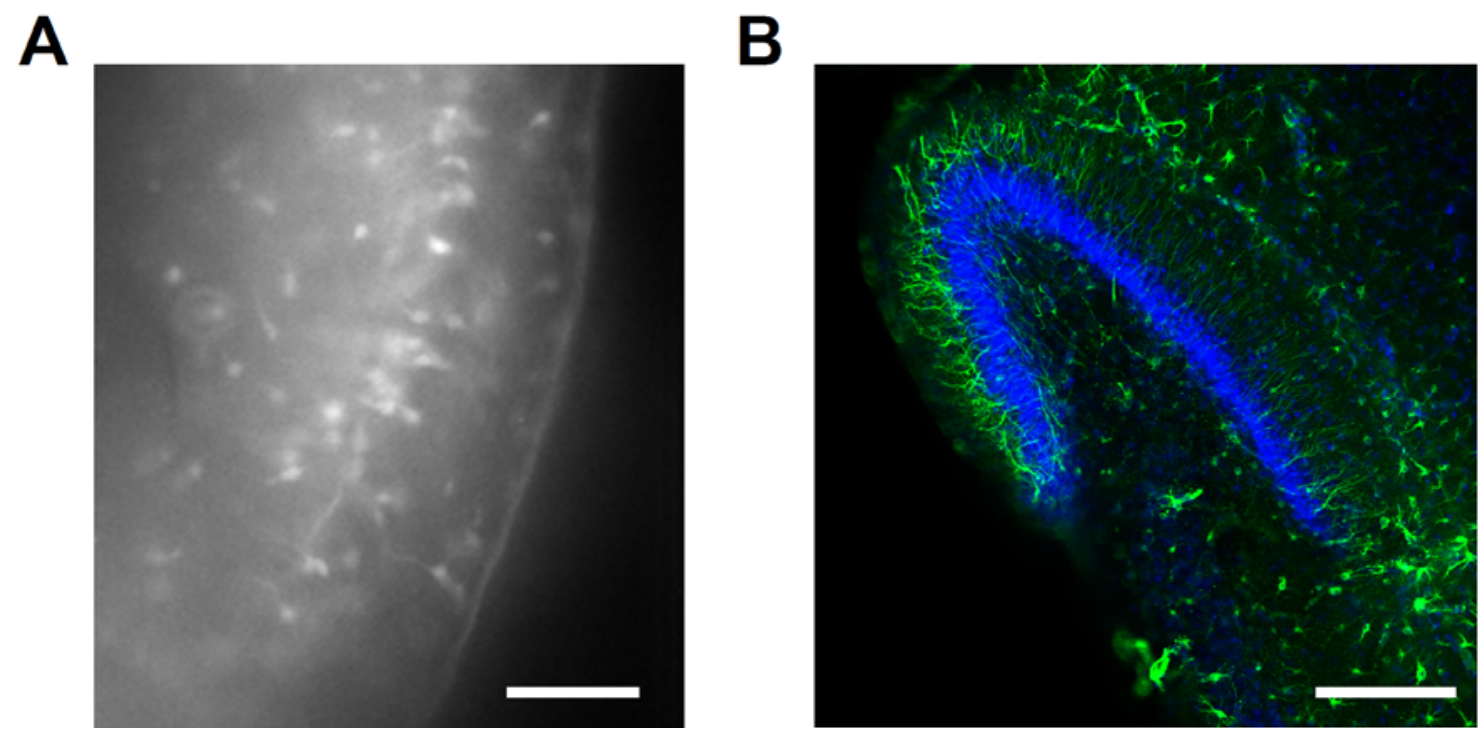

Figura 32. Marcaje específico de astrocitos en secciones de tejido nervioso de ratón. A. Imagen de microscopía confocal adquirida en una sección de corteza cerebral donde se observa el marcaje específico de astrocitos tras 40 minutos de incubación con sulforodamina 101 (SR 101, $1 \mu \mathrm{M}$ ). B. Imagen de microscopía confocal de una sección de hipocampo de ratón fijada y teñida con el anticuerpo específico de astrocitos anti-GFAP (revelado en verde) y los núcleos con DAPI (azul). Barra de escala 100 y $200 \mu \mathrm{M}$ respectivamente.

\subsection{Vectores utilizados para la expresión de sensores GAP en astrocitos}

\subsubsection{Vector derivado del virus herpes}

El vector viral HSV-IgGAP1, derivado del virus herpes simplex tipo 1, se ha utilizado para infectar los astrocitos puros de cultivos primarios y expresar el sensor IgGAP1. Las medidas de la $\left[\mathrm{Ca}^{2+}\right]_{\mathrm{RE}}$ se realizaron por bioluminiscencia en poblaciones celulares. En la Figura 33 se muestran imágenes de fluorescencia de un cultivo puro de astrocitos infectado con el vector HSV- 
IgGAP1. Estos resultados confirmaron que los astrocitos presentan tropismo para el virus herpes simplex tipo I, y que su infección no produce citotoxicidad, como lo demuestra la morfología de los núcleos de las células infectadas verdes (panel B) indistinguible de las células negativas no infectadas (resultados no mostrados).
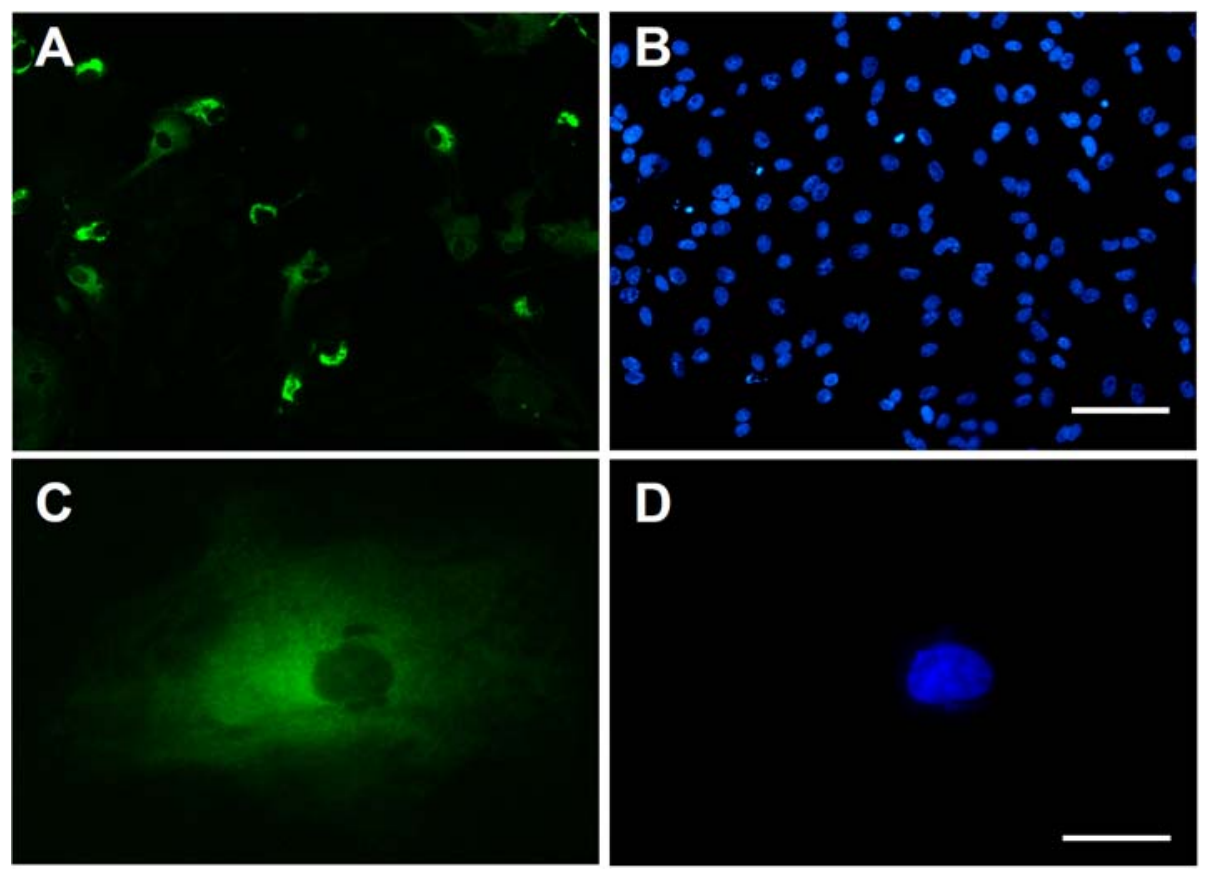

Figura 33. Transducción del indicador de $\mathrm{Ca}^{2+}$ IgGAP1 mediante el vector viral HSV-IgGAP1. Cultivo de astrocitos infectado con HSV-IgGAP1 durante 24 horas. Imágenes de fluorescencia endógena verde de GAP1 localizado en el RE $(A, C)$ y de los núcleos marcados con DAPI (B y C). Barras de escala corresponden a $100 \mu \mathrm{m}$ (A y B) o $10 \mu \mathrm{m}$ (C y D). Imágenes tomadas con un microscopio de fluorescencia.

En nuestros experimentos típicamente tenemos un porcentaje de infección del $19.7 \pm 7.7 \%$ (media \pm esm, $n=2400$ células), cuantificado como células verdes que expresan IgGAP1 del total de células. Aunque éste valor puede parecer modesto nos permitió obtener una expresión y una emisión de luminiscencia suficiente para tener una relación señal/ruido aceptable. El análisis de las células a mayor aumento (Fig. 33C y 33D) permitió determinar que la expresión de la proteína IgGAP1 es compatible con un patrón reticular con exclusión nuclear, más concentrado en la región perinuclear y que se extiende a través de todo el citosol en degradado hasta el borde de la célula. 


\subsubsection{Vector derivado del virus adenoasociado: sensor fluorescente erGAP3}

Hemos utilizado un vector derivado del virus adenoasociado (AAV) que proviene del clon comercial AAV-Dj, desarrollado a partir de diversos serotipos para ampliar el tropismo del virus. Se fusionó el pAAV-GFAP con la sonda erGAP3, para generar el virus AAV-GFAP-erGAP3. Esto nos permitió medir la $\left[\mathrm{Ca}^{2+}\right]_{\mathrm{ER}}$ en célula única mediante fluorescencia específicamente en astrocitos, gracias al promotor GFAP específico de dicho tipo celular. En la Figura 34A se muestran los dominios estructurales del sensor erGAP3 que contiene las mutaciones D24N y D119A en la aequorina (Navas-Navarro y col., 2016), y cuya secuencia de direccionalidad al RE se ha explicado previamente en la sección 1. Además se muestra la fusión con el promotor GFAP específico para astrocitos.

La especificidad del vector se comprobó infectado un cultivo primario mixto de astrocitos y neuronas de corteza cerebral. Tras 4 días desde la infección observamos células verdes positivas para GFP del sensor erGAP3. Se realizó un ensayo de inmunofluorescencia marcando los astrocitos con el anticuerpo primario anti-GFAP revelado en azul y las neuronas con el anticuerpo específico anti- $\beta$-III tubulina revelado en rojo. Todas las células que expresaban el sensor erGAP3 (verde) fueron positivas para GFAP (revelado en azul) confirmando su carácter astrocítico, y ninguna de las células marcadas con $\beta$-III tubulina (revelada en rojo) es positiva para GFP, lo que demuestra que las neuronas no expresan el sensor erGAP3 (Fig. 34B). Estos resultados demuestran la especificidad del promotor GFAP para astrocitos. 
A

\section{Promotor específico} de astrocitos

\section{GFAP}

CR GFPuv

D119A

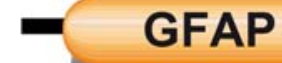

AEQ KDEL

B
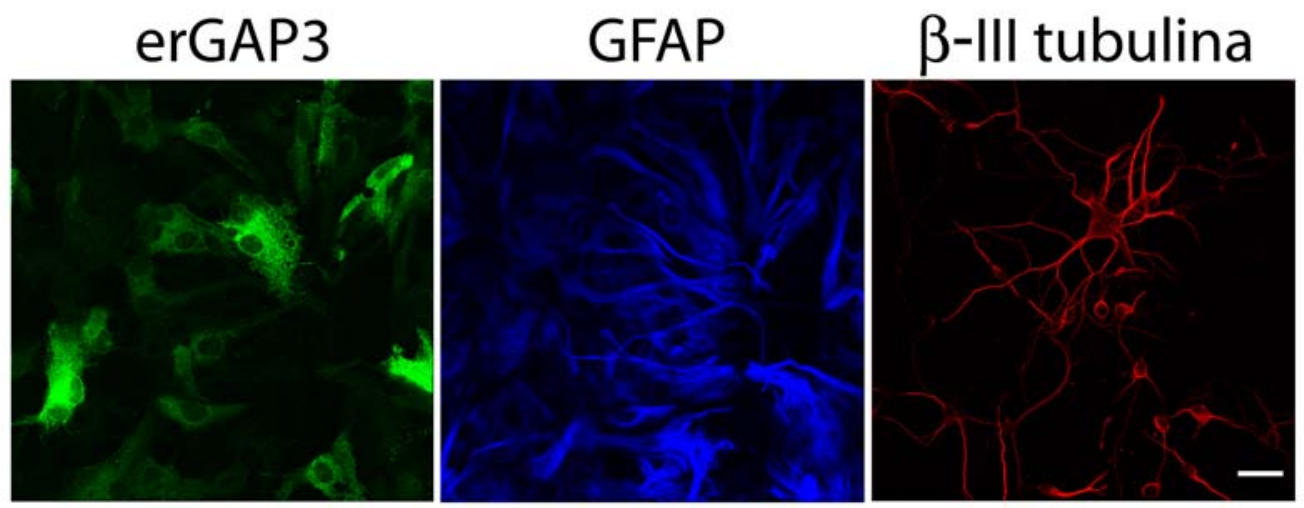

Figura 34. Expresión específica del sensor erGAP3 en astrocitos. A. Representación esquemática de la construcción: el promotor específico de astrocitos humano GFAP; proteína de fusión erGAP3 con sus dominios estructurales (CR, péptido de direccionalidad de la calreticulina; GFP, proteína verde fluorescente uv; $A E Q$, aequorina con las mutaciones D24N y D119A, nomenclatura tomando como aminoácido 1 al primero de la aequorina; KDEL, tetrapéptido de retención en el RE). $\mathbf{B}$. Cultivo mixto de astrocitos y neuronas de corteza cerebral de ratón infectado con el virus adenoasociado AAV-GFAP-erGAP3. Imágenes de fluorescencia confocal mostrando la fluorescencia endógena de erGAP3 (en verde). Las células se fijaron y se tiñeron mediante una inmunofluorescencia doble con el anticuerpo específico antiGFAP (marcador glial, en azul) y un anticuerpo anti $\beta$-III tubulina (marcador específico neuronal, en rojo). Barra de escala, $25 \mu \mathrm{m}$.

Se comprobó la infectividad del vector AAV-GFAP-erGAP3 en secciones de corteza cerebral. Se infectó una sección de cerebro y se la mantuvo en cultivo para permitir la expresión del sensor. La expresión de erGAP3 fue claramente detectable a partir del cuarto día tras la infección, observándose células que expresaban erGAP3 positivas para GFP distribuidas por todo el corte (Fig. 35A). Para comprobar el carácter astrocítico de las células que expresaban el sensor erGAP3 se realizó un ensayo de inmunofluorescencia en la sección de tejido, marcando los astrocitos con anti-GFAP y revelándolo en rojo (Fig. 35D). En las Figuras 35D-G se muestra un astrocito marcado con anti-GFAP rojo y expresando el sensor en verde. Se observó un patrón de expresión típicamente reticular, con exclusión nuclear, y el marcaje de GFP en 
el soma y en las prolongaciones de las células, como sería esperable de una proteína localizada en el RE.
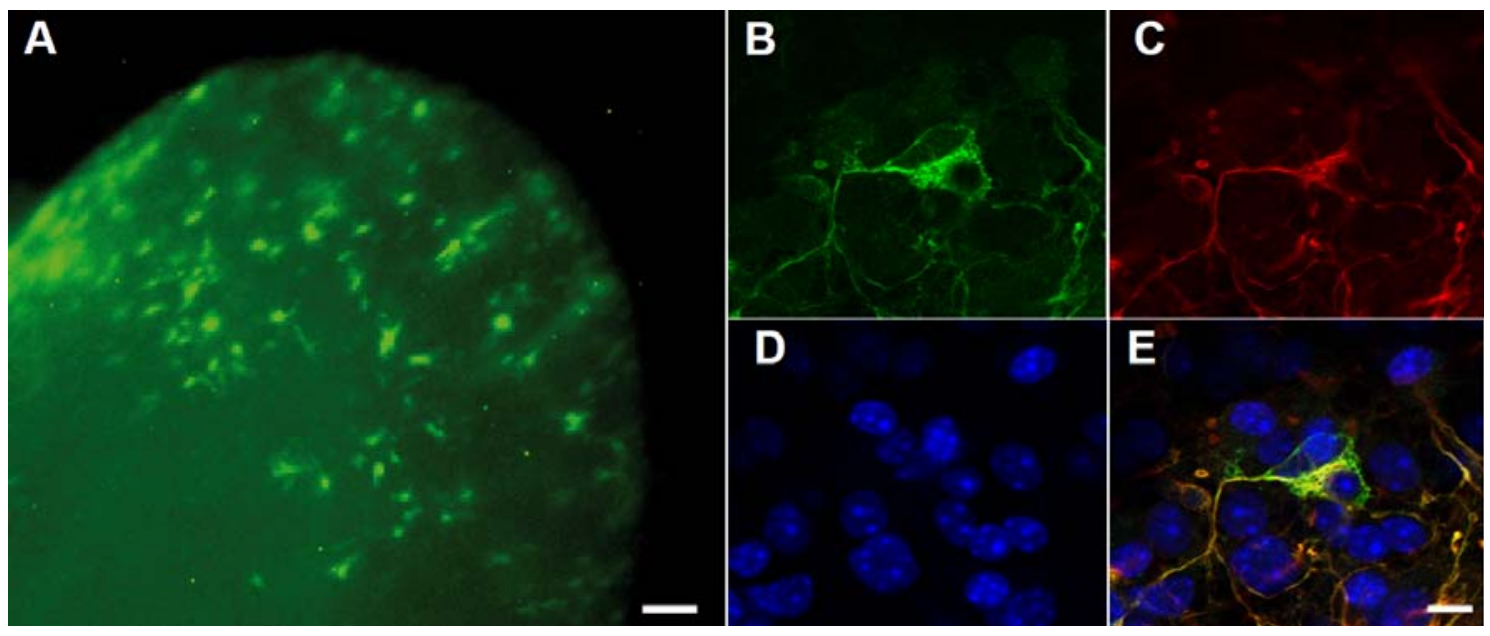

Figura 35. Expresión del sensor erGAP3 en astrocitos de una sección de corteza cerebral. Sección de corteza de cerebro de ratón en cultivo durante 4 días tras su infección con AAV-GFAP-erGAP3. A. Imagen de fluorescencia endógena verde de erGAP3. La barra de escala corresponde a $100 \mu \mathrm{m}$. B-E. Imágenes de fluorescencia confocal. Detalle de un astrocito en una sección de corteza infectada como en $(A)$, con la fluorescencia endógena verde (B) y marcada por inmunofluorescencia con antiGFAP (revelado en rojo) (C), los núcleos marcados con DAPI (D) y la superposición de las tres imágenes anteriores (E). La barra de escala corresponde a $10 \mu \mathrm{m}$.

\subsubsection{Expresión de los sensores IgGAP1 y erGAP3 en el RE de astrocitos cultivados en monocapa}

Los sensores IgGAP1 y erGAP3 se han dirigido al RE con diferentes estrategias de direccionalidad detalladas en el punto 1. Para comprobar la correcta localización de ambas sondas en el RE de astrocitos cultivados en monocapa, se compararon las células que expresaban los sensores GAP de fluorescencia verde característica, con un marcaje de fluorescencia roja de diferentes proteínas del RE. En el caso de IgGAP1 se co-transfectaron los astrocitos con los plasmidos: pcDNA3-IgGAP1 y pcDNA3-cherrySERCA2b. En el panel superior de la Figura 36 se muestran la fluorescencia roja de la SERCA-Cherry, la expresión de IgGAP1 en verde y la correcta co-localización de ambas proteínas en el RE de astrocitos (superposición). En el caso de erGAP3 se super-infectaron los astrocitos con los virus derivados de herpes: pHSV-ERtomato-AEQ y pHSV-erGAP3. En este caso, la fusión ERtomato-AEQ 
muestra fluorescencia roja y se ha dirigido al RE con la secuencia de la cadena pesada de la inmunoglobulina $\gamma 2 b$, al igual que IgGAP1. En el panel inferior de la Figura 36 se muestra la expresión de ERtomato-AEQ roja y la proteína erGAP3 expresando la GFP en verde, ambas proteínas co-localizaron perfectamente en el RE (superposición). Se logró demostrar la correcta localización de las sondas en el RE y la ausencia de citotoxicidad se ha comprobado por la integridad y morfología de las células, similar a células no transducidas (dato no mostrado).

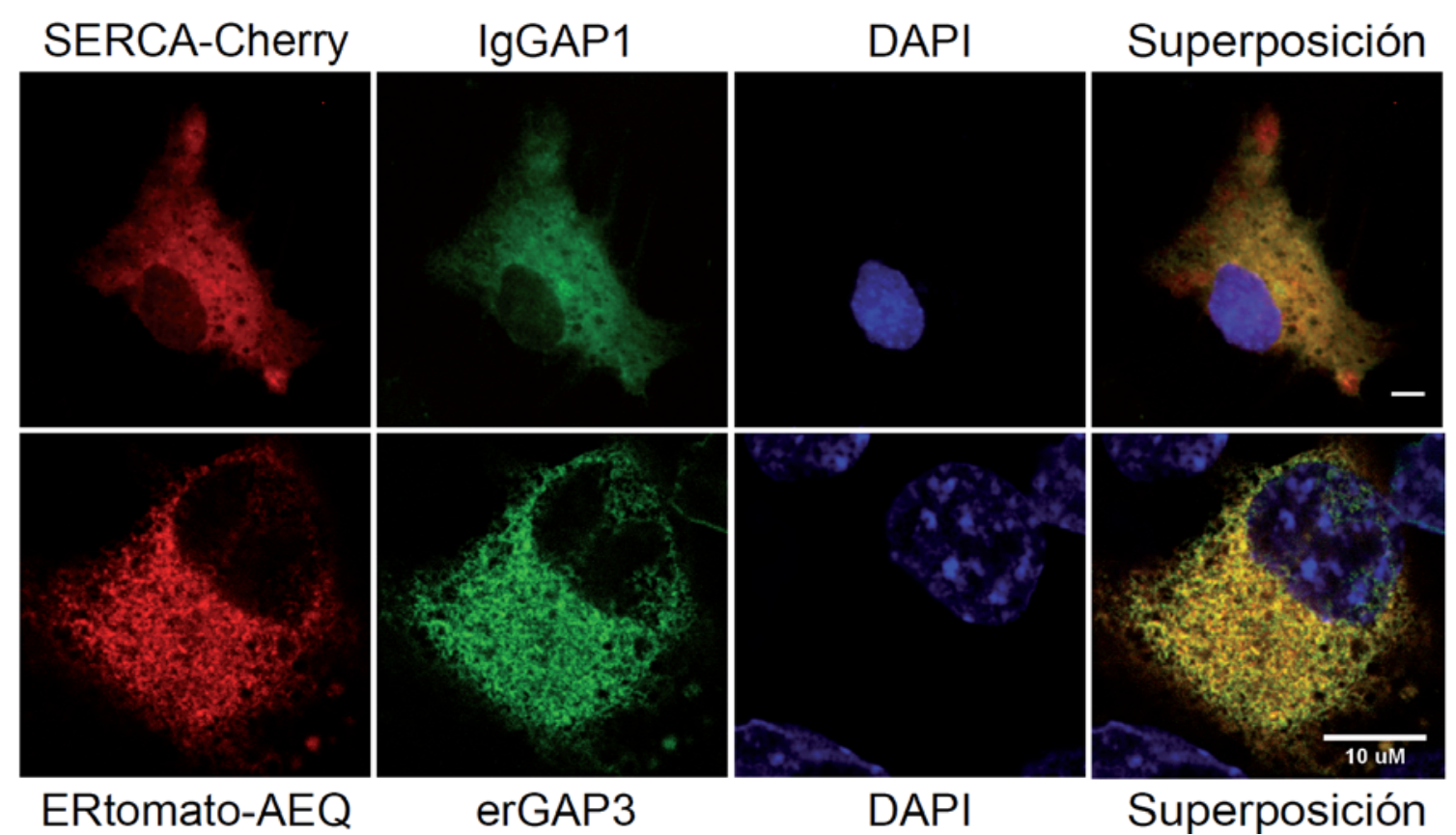

Figura 36. Localización de los sensores IgGAP1 y erGAP3 en el RE de un astrocito. Panel superior. Imágenes de fluorescencia de un astrocito co-transfectado con pcDNA3-SERCA 2b-Cherry (rojo) y pcDNA3-IgGAP1 (verde). Se muestra el marcaje de los núcleos con DAPI (azul) y la superposición de las tres imágenes anteriores. La barra de escala corresponde a $10 \mu \mathrm{M}$. Panel inferior. Imágenes de microscopía confocal de un astrocito co-infectado con HSV-ERtomato-AEQ (marcador del RE; rojo) y HSV-erGAP3 (verde). La barra de escala corresponde a $10 \mu \mathrm{M}$. 


\section{Dinámica del $\mathrm{Ca}^{2+}$ en astrocitos corticales murinos}

\subsection{Cultivo de astrocitos puros}

\subsubsection{Funcionalidad de los astrocitos}

Para comprobar que el cultivo puro de astrocitos era una preparación válida para estudiar la homeostasis del $\mathrm{Ca}^{2+}$ en el RE, estudiamos en primer lugar la señal de $\mathrm{Ca}^{2+}$ citosólico inducida por el agonista ATP. Este agonista estimula los receptores purinérgicos, como el receptor metabotrópico P2Y1, que es el principal responsable de la respuesta a ATP en este tipo celular (Fumagalli y col., 2003), y está acoplado a la cascada del $\mathrm{IP}_{3}$, provocando la liberación de $\mathrm{Ca}^{2+}$ de los depósitos intracelulares. Los cambios en la $\left[\mathrm{Ca}^{2+}\right]_{\mathrm{C}}$ se han medido utilizado el indicador Fura-2. Las células se estimularon con dosis máximas de ATP $(100 \mu \mathrm{M})$ durante 30 segundos, tanto en presencia de $\mathrm{Ca}^{2+}(1$ $\mathrm{mM}$ ), como en su ausencia (EGTA, $0.5 \mathrm{mM}$ ). En la Figura 37 se muestra un ejemplo representativo del calcio citosólico correspondiente a la media de 10 células presentes en el mismo campo, y expresado como el cociente entre las fluorescencias excitadas a 340 y $380 \mathrm{~nm}(\mathrm{R})$ dividido por el cociente al comienzo del experimento $\left(R_{0}\right)$ para normalizar las medidas. En presencia de $\mathrm{Ca}^{2+}$ el ATP produjo un rápido aumento transitorio de un $125 \%$ en la Figura 37 (188 $\pm 20 \%$ media \pm esm; $n=34$ células de 3 experimentos independientes), con un componente doble: un aumento muy rápido seguido de una meseta y una caída de la señal mucho más lenta hasta los niveles basales (2-3 minutos). El primero de los componentes es indicativo de la liberación del $\mathrm{Ca}^{2+}$ de los depósitos intracelulares y el segundo puede ser debido a la entrada capacitativa a través de membrana, secundario al vaciamiento del RE. Para comprobar esta hipótesis, se retiró el $\mathrm{Ca}^{2+}$ extracelular y se aplicaron cuatro estímulos de ATP de idéntica concentración y separados entre si por 1 minuto. El primer pulso provocó un aumento de un 50\% (13.1 $\pm 1.6 \%$ media \pm esm, $n=34$ células de 3 experimentos independientes) del cociente $R / R_{0}$ indicando la activación de la vía metabotrópica; el siguiente pulso provocó un transitorio de menor magnitud y los siguientes dos estímulos aplicados, produjeron transitorios cada vez menores, indicando que el primer estímulo produce un vaciamiento casi completo, por este motivo el último estímulo no produjo 
ninguna respuesta observable. La reposición del $\mathrm{Ca}^{2+}$ externo $(1 \mathrm{mM})$ provocó un rápido aumento del $\mathrm{Ca}^{2+}$ citosólico, que se estabilizó tras 4-5 minutos, en un nivel comparable al del comienzo del experimento. Éste incremento en el $\mathrm{Ca}^{2+}$ citosólico se produce como consecuencia de la activación de la entrada capacitativa de $\mathrm{Ca}^{2+}$ o por Store-operated $\mathrm{Ca}^{2+}$ entry (SOCE), inducida por el vaciamiento de los depósitos intracelulares. El protocolo terminó con dos adiciones sucesivas de ATP en presencia de $\mathrm{Ca}^{2+}$ externo que indujeron aumentos en el cociente de fluorescencias de un $75 \%$ ( $83 \pm 2 \%$ media \pm esm; $\mathrm{n}=35$ células), demostrando la reversibilidad y la reproductibilidad de la respuesta.

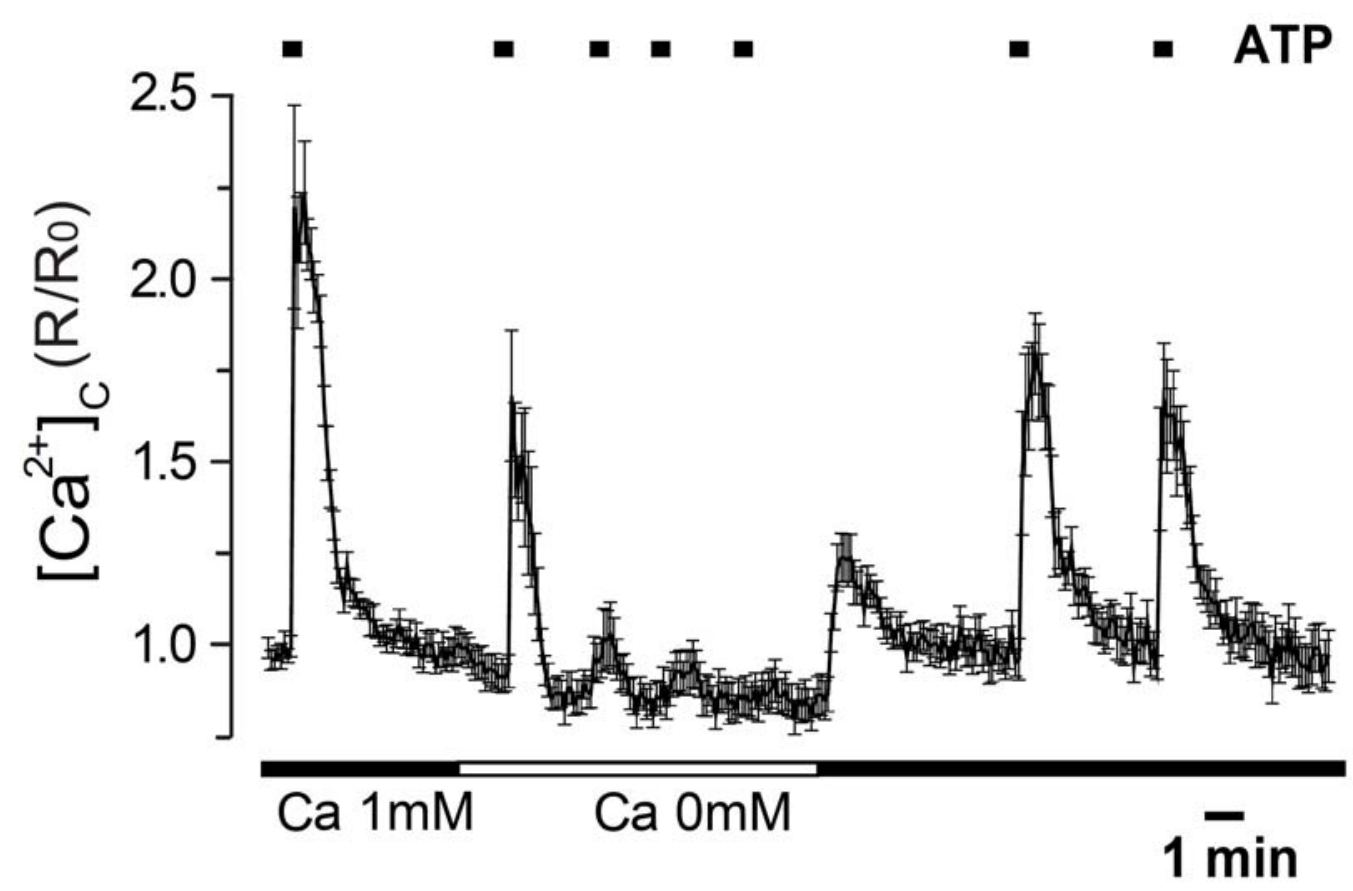

Figura 37. Efecto del ATP en la $\left[\mathrm{Ca}^{2+}\right]_{c}$ en astrocitos. Las células se cargaron con Fura-2 y se estimularon con ATP $\left(100 \mu \mathrm{M}, 30\right.$ segundos), en presencia de $\mathrm{Ca}^{2+}$ extrcelular o en su ausencia (EGTA, $0.5 \mathrm{mM}$ ). Resultado representativo de 5 experimentos individuales. $\mathrm{La}\left[\mathrm{Ca}^{2+}\right]_{\mathrm{C}}$ se representa como el cociente $\mathrm{F}_{340} / F_{380}(R)$, normalizado al dividir por el valor basal $\left(R_{0}\right)$. El trazado corresponde a la media \pm esm obtenida a partir de 10 astrocitos presentes en el mismo campo.

El RE es el principal depósito intracelular de $\mathrm{Ca}^{2+}$, por lo que era bastante esperable que el origen del pico citosólico producido por el ATP fuese el RE. Para confirmarlo se monitorizó la $\left[\mathrm{Ca}^{2+}\right]_{\mathrm{RE}}$ infectando el cultivo de astrocitos puros con el virus HSV-IgGAP1, que nos permitió medir en el lumen del RE con 
el sensor bioluminiscente IgGAP1, que como se ha mostrado en la Figura 27, es capaz de medir $\left[\mathrm{Ca}^{2+}\right]$ entre 0.02 y $1 \mathrm{mM}$.

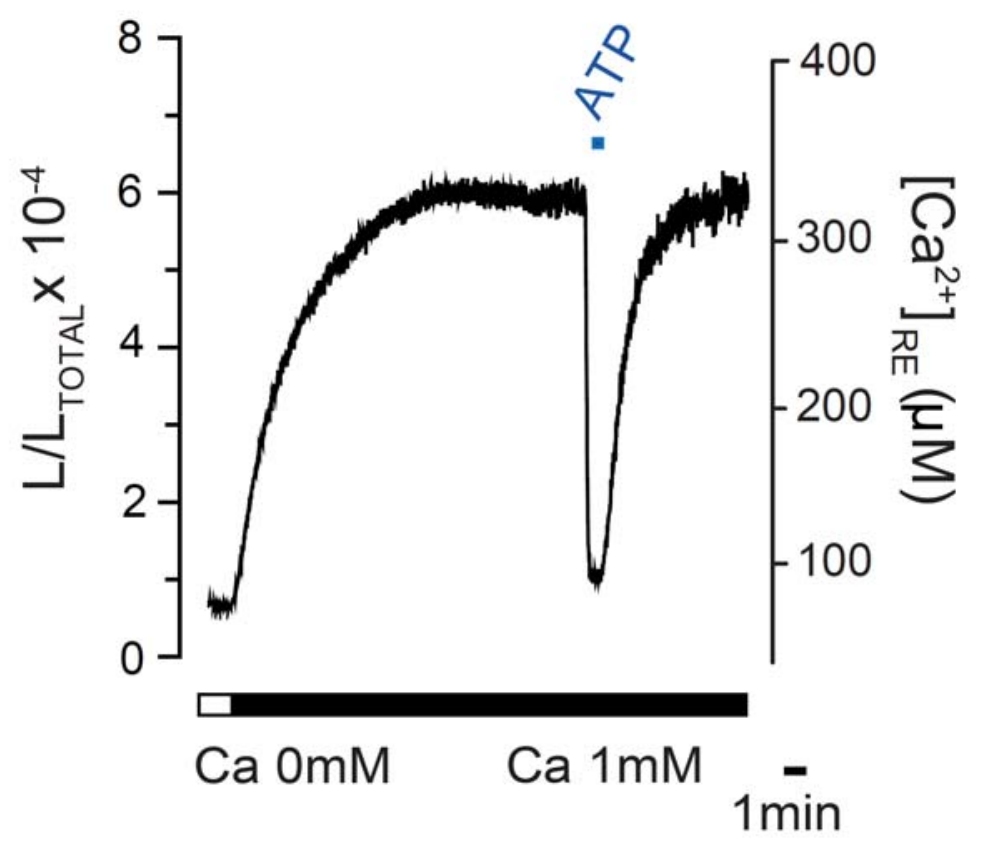

Figura 38. Dinámica del $\mathrm{Ca}^{2+}$ reticular en astrocitos cultivados monitorizada con la sonda bioluminiscente de $\mathrm{Ca}^{2+}$ IgGAP1. Cultivo de astrocitos infectado con HSVIgGAP1. El RE se depletó de $\mathrm{Ca}^{2+}$ incubando las células con $\mathrm{TBH}(0.01 \mathrm{mM})$ en un medio sin $\mathrm{Ca}^{2+}$ (0.5 mM EGTA). La sonda GAP1 se reconstituyó con celenterazina $\mathrm{n}$ durante 1 hora. El experimento comenzó con la adición de $\mathrm{Ca}^{2+}(1 \mathrm{mM})$ para rellenar el RE y se estimuló como se indica con ATP (100 $\mu \mathrm{M}, 30$ segundos). Resultado representativo de 7 experimentos individuales.

Las células se sometieron al mismo procedimiento descrito en la sección 1 (Fig. 27), para reconstituir la aequorina con celenterazina $n$; luego se lavó durante 1 minuto la solución de reconstitución con medio libre de $\mathrm{Ca}^{2+}$, y se perfundió una solución con medio externo con $1 \mathrm{mM}$ de $\mathrm{Ca}^{2+}$. En la Figura 38 se muestra el rellenado del RE al perfundir el $\mathrm{Ca}^{2+}$, que tardó unos 13 minutos en alcanzar el estado estacionario de $340 \mu \mathrm{M}(418 \pm 19 \mu \mathrm{M}$ media \pm esm; $\mathrm{n}=13$ experimentos independientes) con una velocidad de $2 \pm 0.15 \mu \mathrm{M} / \mathrm{seg}$ (media \pm esm; n=7). A los 20 minutos se añadió un pulso de ATP, de 30 segundos, que provocó un rápido vaciamiento casi completo (86 $\pm 1.2 \%$; media \pm esm; $n=10$ ) del contenido de $\mathrm{Ca}^{2+}$ del RE, a una velocidad de $47 \pm 3 \mu \mathrm{M} / \mathrm{seg}$ (media \pm esm; $\mathrm{n}=4)$. Este efecto fue reversible, ya que tras 5 minutos de haber retirado el estímulo, la señal recuperó su nivel basal con una velocidad de captación de 3 $\pm 0.5 \mu \mathrm{M} / \mathrm{seg}$ (media $\pm \mathrm{esm} ; \mathrm{n}=4$ ). Estos resultados demuestran que el 
transitorio de $\mathrm{Ca}^{2+}$ citosólico inducido por ATP, mostrado en la Figura 37, provenía del RE (Fig. 38).

\subsubsection{Activación de los RyR de los astrocitos corticales con cafeína}

El siguiente objetivo que abordamos fue la presencia funcional de los receptores de rianodina (RyRs) en los astrocitos corticales. El papel de los RyRs en la astroglía es objeto de debate. Su expresión se ha estudiado en diferentes tipos de células gliales, incluidos los astrocitos, donde se ha descrito la expresión del RyR3 (Matyash et al., 2002; Simpson et al., 1998). La cafeína es un activador de los RyRs ya que actúa sensibilizando a éste receptor, que se abre en respuesta a incrementos en la $\left[\mathrm{Ca}^{2+}\right]_{c}$.

En primer lugar, estudiamos la respuesta a la cafeína analizando la $\left[\mathrm{Ca}^{2+}\right]_{\mathrm{C}}$ medida con Fura-2 en célula única (Fig. 39A). La cafeína (50 mM) provocó un aumento transitorio del calcio citosólico de un 130\% (178 \pm 10\% media \pm esm; $n=224$ células de tres experimentos independientes). Las células recuperaron su nivel tras un par de minutos de lavado del estímulo. En general, los picos de cafeína son menores que los observados con ATP (160\%), que también se incluye en el protocolo de la Figura 39 para su comparación. En ausencia de $\mathrm{Ca}^{2+}$ externo se produce un pico similar al obtenido en presencia de $\mathrm{Ca}^{2+}$ lo que indica que el aumento del $\mathrm{Ca}^{2+}$ citosólico procede de los depósitos intracelulares, y no del medio extracelular (resultados no mostrados). La cafeína desencadena en algunas células oscilaciones del $\mathrm{Ca}^{2+}$ tras el primer pico citosólico, como se muestra en 3 células seleccionadas en la Figura 39B. Es destacable que las sucesivas adiciones de cafeína aumentan progresivamente tanto la frecuencia como la amplitud de las oscilaciones. Se midió directamente la $\left[\mathrm{Ca}^{2+}\right]_{\mathrm{RE}}$, con la misma metodología descrita en la Figura 14. En la Figura 39C, pulsos consecutivos de cafeína (de 30 segundos cada uno) produjeron vaciamientos rápidos del $\mathrm{Ca}^{2+}$ desde el $\mathrm{RE}$. El efecto fue reversible, ya que tras lavar el estímulo, se produjo nuevamente el rellenado del RE, recuperando así los niveles anteriores a la adición tras 4-5 minutos. El vaciamiento provocado por la cafeína $(25 \mathrm{mM}$ ) fue parcial del $20 \pm 0.6 \%$ (media 
\pm esm; $n=3)$ y tardo entre 1-2 minutos en recuperar su nivel inicial. Una dosis mayor (50 mM) indujo una liberación a su vez mayor, $26 \pm 1 \%$ (media \pm esm; $\mathrm{n}=9$ ), del $\mathrm{Ca}^{2+}$ del RE. Las adiciones de tres pulsos sucesivos de cafeína, de 30 segundos cada uno, produjeron vaciamientos de la misma magnitud lo que demuestra la reproductibilidad del efecto. Estos resultados muestran que la cafeína induce una liberación del $\mathrm{Ca}^{2+}$ del RE coherente con los incrementos observados en la $\left[\mathrm{Ca}^{2+}\right]_{\mathrm{C}}$ (Fig. 39A). Aunque ya se habían descrito previamente incrementos de $\mathrm{Ca}^{2+}$ citosólico con cafeína (Langley y Pearce, 1994; Simpson y col., 1998; Matyash y col., 2002; Hua y col., 2004), esta es la primera vez que se mide la concentración de calcio en el RE de forma directa en astrocitos intactos.

Debido a las altas dosis de cafeína utilizadas (rango 25-50 mM) y al modesto efecto observado (20-26\% de liberación), consideramos esencial comprobar que el efecto de la cafeína era específico de los RyRs, y no estaba afectando a los $\mathrm{IP}_{3}$ Rs como había sido propuesto por algunos autores (Irving y col., 1992). En primer lugar, usamos la heparina, un inhibidor competitivo del $\mathrm{IP}_{3} \mathrm{R}$, no permeable a través de membrana plasmática. Por este motivo, lo siguientes experimentos se realizaron en el modelo de células permeabilizadas. Las células se permeabilizaron con digitonina, y, a continuación, se perfundieron con medio interno conteniendo $0.5 \mu \mathrm{M}$ de $\mathrm{Ca}^{2+}$ durante 5-8 minutos para permitir el rellanado del $\mathrm{RE}$ de $\mathrm{Ca}^{2+}$. Con este protocolo se alcanzó un nivel de $\left[\mathrm{Ca}^{2+}\right]_{\mathrm{RE}}$ de unos $470 \pm 29 \mu \mathrm{M}$ (media \pm esm, $\mathrm{n}=39$ ), un valor similar a lo obtenido en células intactas. 


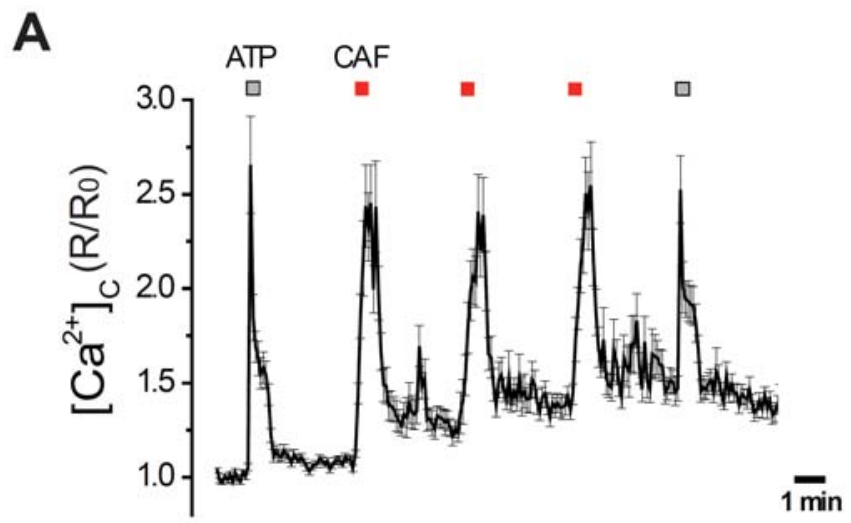

B
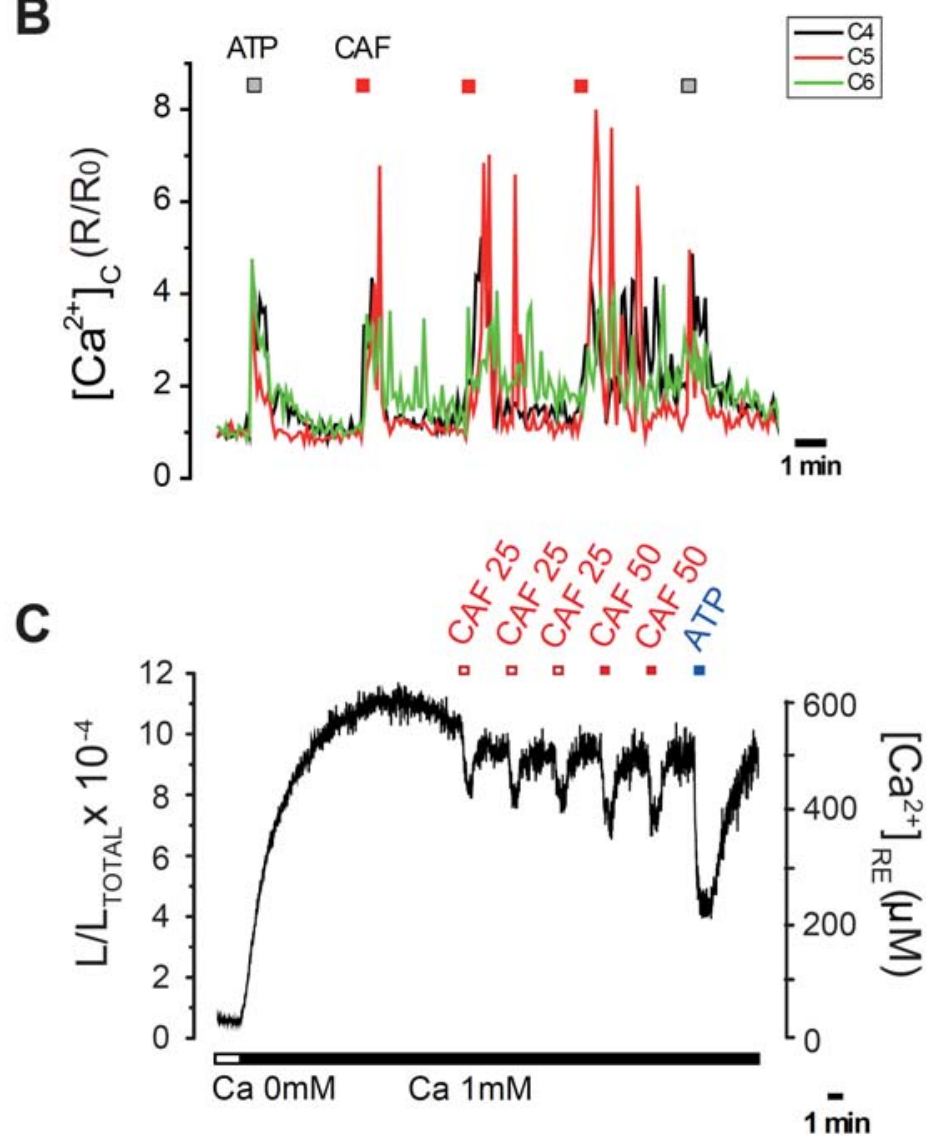

Figura 39. Efecto de la cafeína en la $\left[\mathrm{Ca}^{2+}\right]_{\mathrm{c}}$ y la $\left[\mathrm{Ca}^{2+}\right]_{\mathrm{RE}}$ de astrocitos. A. El trazado representa la media $( \pm \mathrm{esm})$ de la $\left[\mathrm{Ca}^{2+}\right]_{\mathrm{C}}$ obtenida a partir de 42 astrocitos presentes en el mismo campo, cargados con Fura-2 y estimulados con ATP (100 $\mu \mathrm{M})$ o cafeína (CAF, $50 \mathrm{mM}$ ). B. Los trazados son ejemplos de 3 astrocitos individuales de (A) que muestran oscilaciones al aplicar el primer pulso de cafeína. C. El trazado representa la luminiscencia (como $L / L_{\text {TOTAL }}$ ) obtenida a partir de una población de astrocitos que expresaban IgGAP1 y su calibración en $\left[\mathrm{Ca}^{2+}\right]_{\mathrm{RE}}$ (en $\mu \mathrm{M}$, a la derecha). Las células se estimularon con diferentes dosis de cafeína ( 25 y $50 \mathrm{mM})$ y con ATP $(100 \mu \mathrm{M})$. Otros detalles como en la Figura 38. Resultados representativos de, al menos, 3 experimentos individuales. 


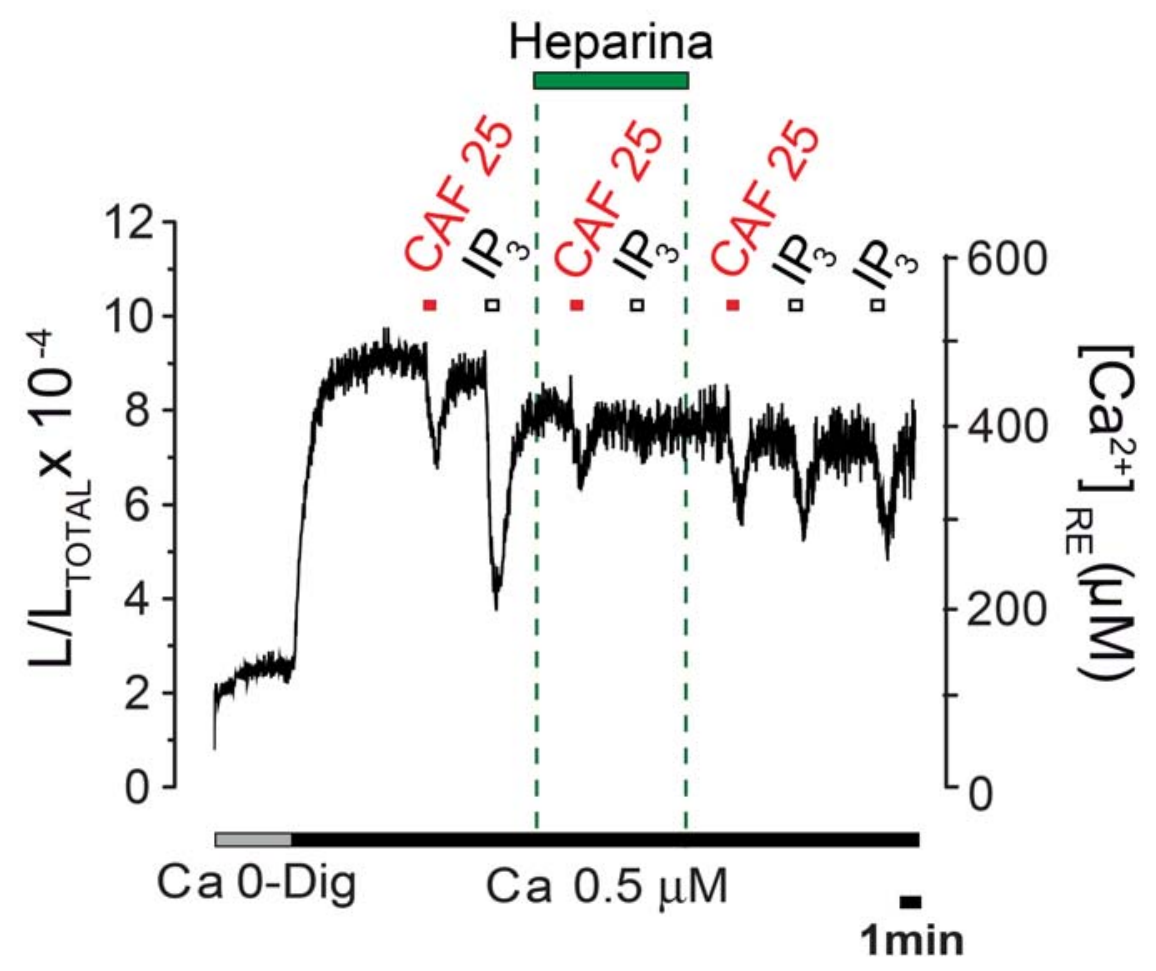

Figura 40. Efecto del IP 3 y de la cafeína en la $\left[\mathrm{Ca}^{2+}\right]_{\mathrm{RE}}$ de astrocitos. Población de astrocitos que expresan GAP1 en el RE por la infección con el vector viral HSVIgGAP1. La sonda se reconstituyó vaciando el RE de forma idéntica a la Figura 38. El experimento comenzó con la permeabilización de la membranan plasmática con digitonina (Dig. $60 \mu \mathrm{M}, 2$ minutos) en medio sin $\mathrm{Ca}^{2+}$ (Ca0; EGTA $0.5 \mathrm{mM}$ ). Las células se perfundieron con $0.5 \mu \mathrm{M}$ de $\mathrm{Ca}^{2+}$ para rellenar el $\mathrm{RE}$ y, se estimularon con cafeína $(25 \mathrm{mM}) \circ \mathrm{IP}_{3}(5 \mu \mathrm{M})$ en un tampón intracelular sin o con heparina $(0.5 \mathrm{mg} / \mathrm{ml})$. Cada estímulo fue de 30 segundos. Resultado representativo de 4 experimentos individuales.

La cafeína a una concentración de $25 \mathrm{mM}$ produjo una liberación del calcio reticular del 25\% en la Figura 40 (20 $\pm 0.7 \%$ media \pm esm, $n=8)$, mientras que una dosis mayor de cafeína $(50 \mathrm{mM})$ provocó una mayor liberación del $30 \pm 1 \%$ (media \pm esm, $n=9$ ) (dato no mostrado). La adición de $\mathrm{IP}_{3}(5 \mu \mathrm{M})$ también indujo una liberación de calcio reticular de $52 \%$ en la Figura 40 (36 $\pm 3.5 \%$ media \pm esm, $n=14$,). Los valores obtenidos fueron comparables a los obtenidos en células intactas. A continuación, se perfundió un medio con heparina $(0.5 \mathrm{mg} / \mathrm{ml})$ durante 2 minutos, y se aplicaron idénticos estímulos, en este caso observamos que la respuesta de la cafeína se mantuvo prácticamente inalterada en presencia del inhibidor, mientras que la respuesta al $\mathrm{IP}_{3}$ fue prácticamente abolida. La naturaleza reversible del inhibidor utilizado nos permitió comprobar que tras su lavado se produce una recuperación de la 
respuesta a $\mathrm{IP}_{3}$, aunque no completa. (Fig. 40). Estos resultados indican que la liberación del $\mathrm{Ca}^{2+}$ del RE por la cafeína es independiente de la activación de los receptores de $\mathrm{IP}_{3}$.

A continuación, se estudió el efecto de la rianodina, un inhibidor irreversible dependiente de uso, que estabiliza a los RyRs en la forma "abierta" (Lee y col., 1991; Alonso y col., 1999). En la Figura 41A se muestra cómo la adición de pulsos sucesivos de cafeína $25 \mathrm{mM}$ a los astrocitos permeabilizados produjeron descensos comparables de la $\left[\mathrm{Ca}^{2+}\right]_{\mathrm{RE}}$, dejando intervalos de 2.5 minutos entre dos pulsos consecutivos para permitir el rellenado del RE con $\mathrm{Ca}^{2+}$ hasta su nivel inicial. El grado de vaciamiento fue aproximadamente de $30 \%$, un valor similar al obtenido en células intactas. La adición al final de un pulso de $\mathrm{IP}_{3}(5 \mu \mathrm{M})$ produjo una liberación de $30 \%$ del $\mathrm{Ca}^{2+}$ del $\mathrm{RE}$, indicando que las células tenían receptores de $\mathrm{IP}_{3}$ funcionales. En la Figura $41 \mathrm{~B}$ se muestra el efecto de la rianodina añadida junto a la cafeína. El primer pulso produjo una liberación de $\mathrm{Ca}^{2+}$ del $\mathrm{RE}$, que no recuperó el nivel de $\mathrm{Ca}^{2+}$ inicial tras el lavado del estímulo. Varios estímulos sucesivos no produjeron liberaciones claras, sino más bien una aceleración de la salida de $\mathrm{Ca}^{2+}$ del RE. Después de tres adiciones el nivel de la $\left[\mathrm{Ca}^{2+}\right]_{\mathrm{RE}}$ era de aproximadamente la mitad, y la adición de $\mathrm{IP}_{3}$ produjo una clara liberación del $\mathrm{Ca}^{2+}$ reticular, que tampoco se rellenó tras su lavado. Se obtuvieron resultados similares usando concentraciones de rianodina de 5, 10, 20 y $100 \mu \mathrm{M}$ (datos no mostrados). Todos estos resultados son compatibles con que la rianodina mantiene el canal abierto de manera irreversible tras su activación inicial por la cafeína, y esto conduciría a un vaciamiento lento y completo del RE. En la Figura 41C y D se muestra una amplificación de L/Lt y de la escala temporal de la respuesta a cafeína $(50 \mathrm{mM})$ en ausencia 0 en presencia de rianodina (20 mM) respectivamente. Nótese el cambio de pendiente que se produce en presencia de rianodina, relacionado con una disminución de la velocidad de liberación de $\mathrm{Ca}^{2+}$ del RE. 
A

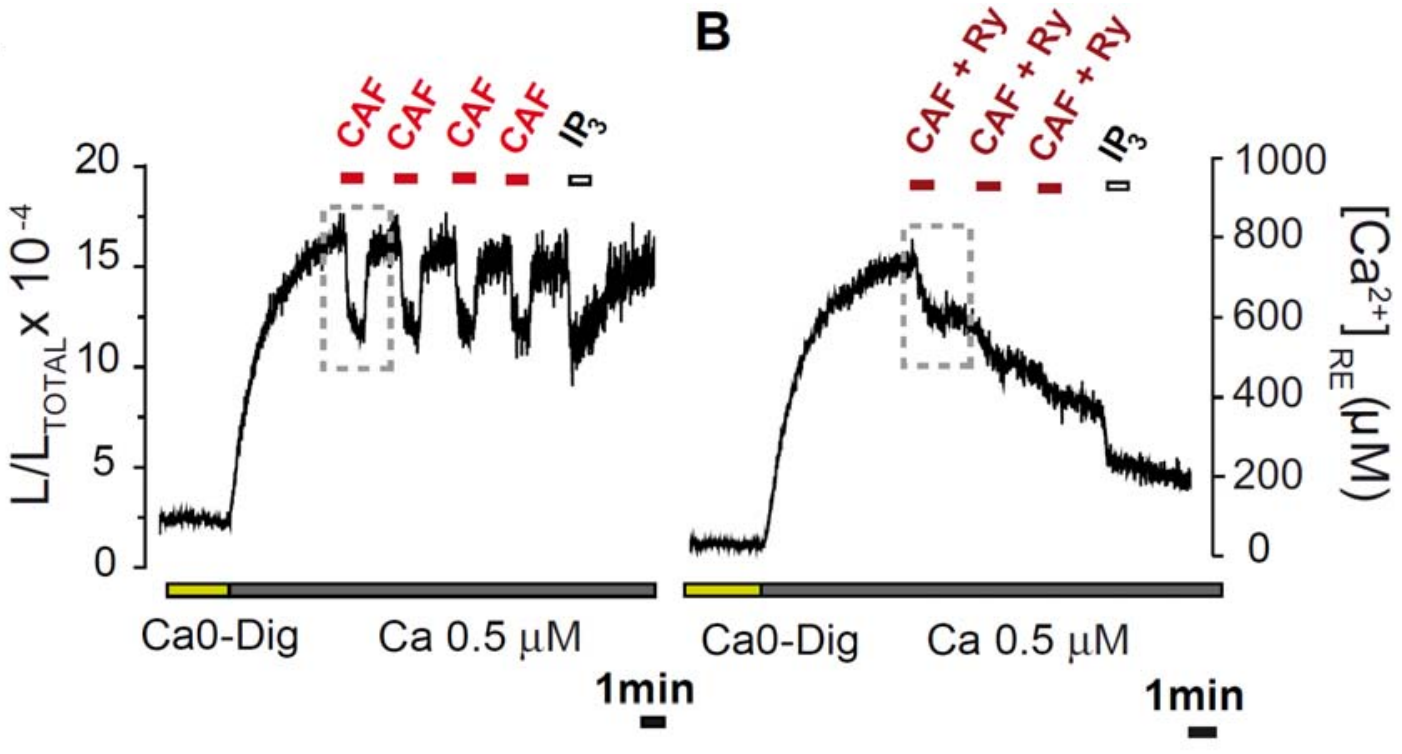

C

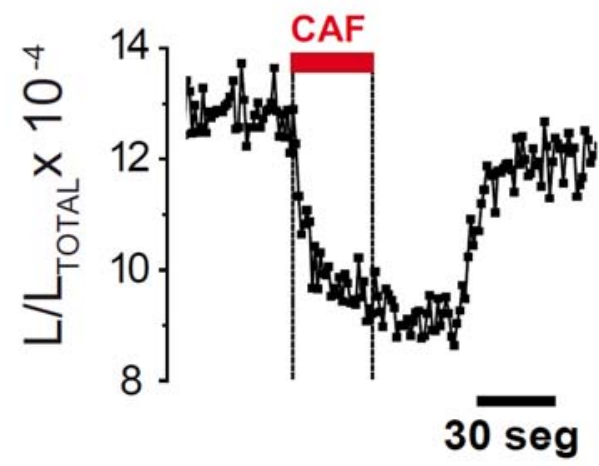

D

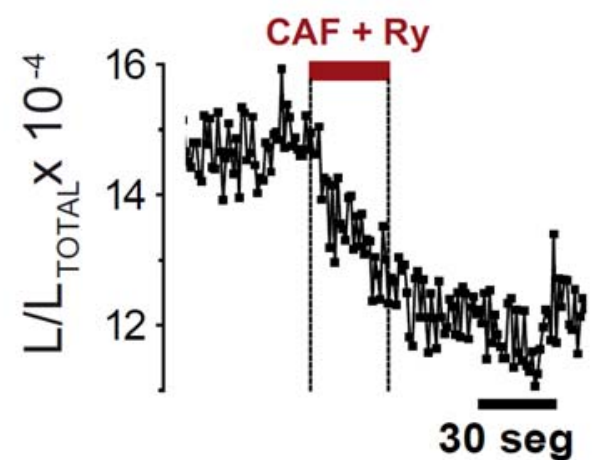

Figura 41. Inhibición del efecto de cafeína en la $\left[\mathrm{Ca}^{2+}\right]_{\mathrm{RE}}$ por rianodina en astrocitos. Las células que expresaban IgGAP1 se rellenaron como en la Figura 40. A. El trazado representa la $\left[\mathrm{Ca}^{2+}\right]_{\mathrm{RE}}$ de los astrocitos permeabilizados estimulados con 4 pulsos sucesivos de cafeína $(50 \mathrm{mM})$ y un pulso de $\mathrm{IP}_{3}(5 \mu \mathrm{M})$. B. Igual que en $(\mathrm{A})$ pero la cafeína se añadió junto con rianodina $(20 \mu \mathrm{M})$. C. Detalle de la respuesta de cafeína mostrada en A (recuadro en A). D. Detalle de la respuesta a cafeína y rianodina mostrada en $B$ (recuadro en $B$ ). Amplificación de la escala de L/Lt y de la escala temporal del primer estímulo en A y B respectivamente.

\subsubsection{Entrada de $\mathrm{Ca}^{2+}$ por despolarización con alto $\mathrm{K}^{+}$}

A continuación, decidimos investigar si podíamos activar los canales de RyRs de forma más directa activando la entrada de $\mathrm{Ca}^{2+}$ a través de la membrana plasmática. El mecanismo de $\mathrm{CICR}\left(\mathrm{Ca}^{2+}\right.$ induced $\mathrm{Ca}^{2+}$ release) es más propio de las células excitables. Aunque los astrocitos se clasifican como 
no excitables, cada vez hay más referencias en la literatura que describen la expresión de canales voltaje-dependientes en estas células (Yaguchi y Nishizaki, 2010).

En primer lugar, decidimos comprobar si la despolarización con un medio que contenía alto $\mathrm{K}^{+}$producía incrementos de $\mathrm{Ca}^{2+}$ citosólico, y si podríamos utilizarlo como herramienta para la activación de los RyRs por calcio. Para ello utilizamos astrocitos cargados con Fura-2 y como estímulo se perfundió medio externo que contenía $\mathrm{KCl}(80 \mathrm{mM}$, durante 30 segundos).

En la Figura 42 se muestra el efecto de tres pulsos despolarizantes de 80 $\mathrm{mM}$ de $\mathrm{K}^{+}$sobre la $\left[\mathrm{Ca}^{2+}\right]_{\mathrm{c}}$. En la Figura $42 \mathrm{~A}$ el alto $\mathrm{K}^{+}$produce rápidos incrementos en la $\left[\mathrm{Ca}^{2+}\right]_{\mathrm{c}}$ de un $80 \%(110 \pm 2 \%$ media \pm esm; $\mathrm{n}=304$ pulsos a partir de 4 experimentos independientes) un $40 \%$ menor al evocado por el ATP (200\%). Estos aumentos transitorios están provocados por la entrada de $\mathrm{Ca}^{2+} \mathrm{a}$ través de la membrana plasmática, ya que la despolarización en ausencia de $\mathrm{Ca}^{2+}$ externo (en presencia de EGTA, $0.5 \mathrm{mM}$ ) no produjo transitorios en la $\left[\mathrm{Ca}^{2+}\right]_{\mathrm{C}}$ (Fig. 42B). Al quitar el $\mathrm{Ca}^{2+}$ del medio extracelular puede observarse como la $\left[\mathrm{Ca}^{2+}\right]_{\mathrm{c}}$ disminuyó hasta alcanzar un nuevo nivel basal más reducido. La estimulación con alto $\mathrm{K}^{+}$no produjo transitorios citosólicos en ausencia de $\mathrm{Ca}^{2+}$ externo. Tras 7 minutos de perfusión con medio sin $\mathrm{Ca}^{2+}$, los depósitos intracelulares no se habían vaciado ya que un nuevo pulso de ATP provocó un pico en la $\left[\mathrm{Ca}^{2+}\right]_{\mathrm{c}}$, por lo tanto la falta de respuesta al alto $\mathrm{K}^{+}$observada no se debía a que los depósitos estuvieran vacíos. Al reintroducir el calcio externo se produjo un incremento transitorio de la $\left[\mathrm{Ca}^{2+}\right]_{\mathrm{c}}$, como resultado de la activación de la entrada capacitativa. Pulsos despolarizantes en estas condiciones provocaron incrementos de $\mathrm{Ca}^{2+}$ reproductibles y de una magnitud similar a los observados al principio del experimento, demostrando la recuperación del efecto. Estos resultados sugieren que los incrementos de $\mathrm{Ca}^{2+}$ citosólico observados se producen por la activación de algún mecanismo que requiere, en primera instancia, la entrada de $\mathrm{Ca}^{2+}$ desde el medio extracelular.

La eliminación del $\mathrm{Ca}^{2+}$ extracelular en las células excitables puede alterar la excitabilidad celular, y así provocar efectos distintos a los que se pretende 
estudiar. Como por ejemplo, con la condición utilizada en la Figura 42B, ya que en algunos experimentos en EGTA se producía un primer pico con el alto $\mathrm{K}^{+}$ (no mostrado), que no volvía a reproducirse y que no podemos explicar. Como alternativa, utilizamos los cationes níquel (Figura 42C) y lantano (resultados no mostrados) en el rango de $\mathrm{mM}$, que bloquean de forma inespecífica los canales de $\mathrm{Ca}^{2+}$ de la membrana plasmática, y comprobamos que bloqueaban completamente los picos producidos por el alto $\mathrm{K}^{+}$. Todos estos resultados indican que el alto $\mathrm{K}^{+}$provoca entrada de $\mathrm{Ca}^{2+}$ a través de canales de la membrana plasmática.

Se ha descrito la expresión de diversos canales dependientes de voltaje en los astrocitos, principalmente los de tipo $L$ (VOC-L), y también los tipo $P / Q$ y $\mathrm{N}$. Las dihidropiridinas, furnidipina y nifedipina, han sido utilizadas como antagonistas de los VOC tipo-L. Los experimentos mostrados en la Figura 42B hacen pensar en conjunto en que la vía de entrada del $\mathrm{Ca}^{2+}$ desde el medio extracelular al estimular las células con alto $\mathrm{K}^{+}$podían ser canales dependientes de voltaje. En la Figura 42D la dihidropiridina furnidipina (10 $\mu \mathrm{M})$, produjo una inhibición del pico de alto $\mathrm{K}^{+}$de solamente un $33 \%(19 \pm 7 \%$ media \pm esm, $n=3$ experimentos 51 células).

Así pues, parece que los VOCs tipo L están involucrados en el efecto observado, pero hay un importante componente, mayoritario, que no había sido inhibido por las dihidropiridinas, lo que sugiere que existen otras vías de entradas de $\mathrm{Ca}^{2+}$ al despolarizar las células con alto $\mathrm{K}^{+}$. 
A

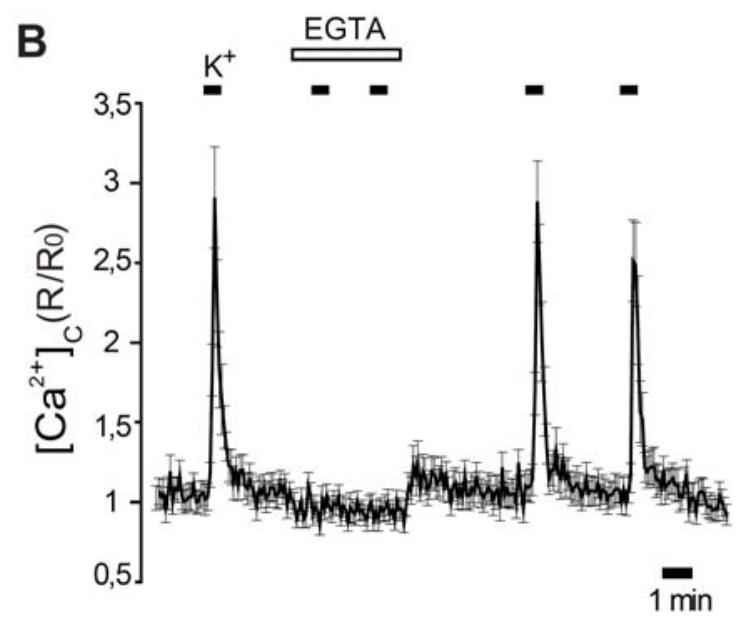

C

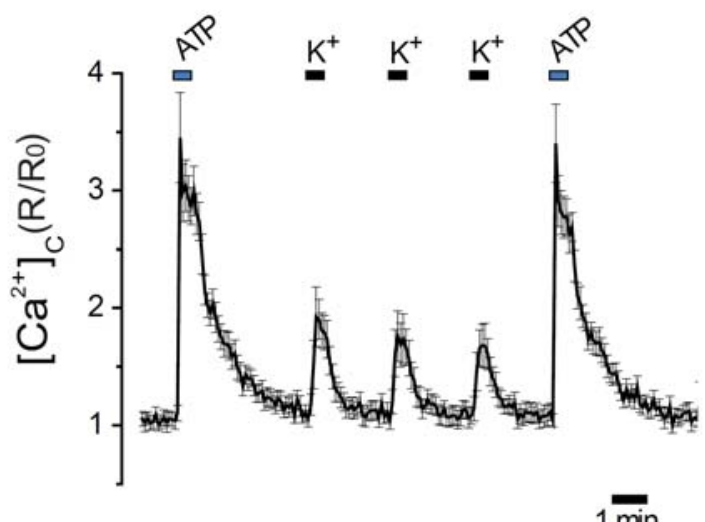

D
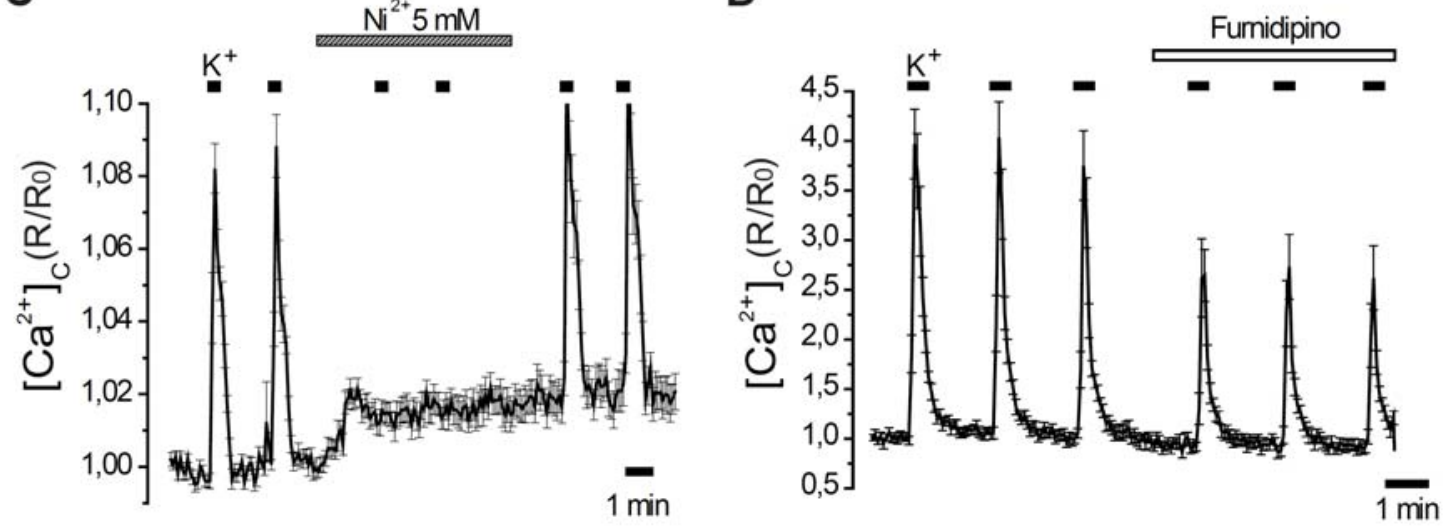

Figura 42. Efecto del alto $\mathrm{KCl}$ sobre la $\left[\mathrm{Ca}^{2+}\right]_{\mathrm{C}}$ de astrocitos y su inhibición con EGTA, NiCl ${ }_{2}$ o furnidipino. Los trazados representan la $\left[\mathrm{Ca}^{2+}\right]_{\mathrm{c}}$ medida con Fura-2 y expresada como $\left(R / R_{0}\right)$. A. Estimulación de 7 astrocitos con ATP $(100 \mu \mathrm{M})$ o alto $\mathrm{K}^{+}$ $(80 \mathrm{mM})$. B. Respuesta del alto $\mathrm{K}^{+}(80 \mathrm{mM})$ en presencia de $\mathrm{Ca}^{2+}$ externo $\left(1 \mathrm{mM} \mathrm{Ca}^{2+}\right)$ o en su ausencia (EGTA, $0.5 \mathrm{mM}$ ) en 10 astrocitos. C. Efecto del $\mathrm{NiCl}_{2}(5 \mathrm{mM})$ sobre la respuesta del alto $\mathrm{K}^{+}$en 13 astrocitos. D. Efecto de furnidipina ( $10 \mu \mathrm{M}, 8$ minutos) sobre la respuesta provocada por el alto $\mathrm{K}^{+}$en 19 astrocitos. Otros detalles técnicos como en la Figura 37.

A continuación, medimos la $\left[\mathrm{Ca}^{2+}\right]_{R E}$ en una población de astrocitos estimulados con alto $\mathrm{K}^{+}$, utilizando la sonda IgGAP1. La Figura 43A muestra un registro representativo donde pulsos sucesivos de alto $\mathrm{K}^{+}$producen sendas liberaciones reversibles de $\mathrm{Ca}^{2+}$ del RE. La liberación fue del $35 \%$ del $\mathrm{Ca}^{2+}$ del RE (50 $\pm 2 \%$ media \pm esm; $n=28$ de 11 experimentos independientes), $y$ corresponde aproximadamente a la mitad de la liberación evocada por el ATP, $86 \pm 1 \%$, media \pm esm; $n=10$ ( $T 1 / 2=0.06$ minutos). La recuperación del nivel basal de la $\left[\mathrm{Ca}^{2+}\right]_{R E}$ fue rápida, antes incluso de lavar el estímulo (Fig. 43B y C). Estos resultados indican que la entrada de $\mathrm{Ca}^{2+}$ provocada por el alto $\mathrm{K}^{+}$ 
activa un mecanismo que libera el $\mathrm{Ca}^{2+}$ del $\mathrm{RE}$ de los astrocitos. Este mecanismo se llama liberación de calcio inducida por calcio o CICR (calcium induced calcium release).

A

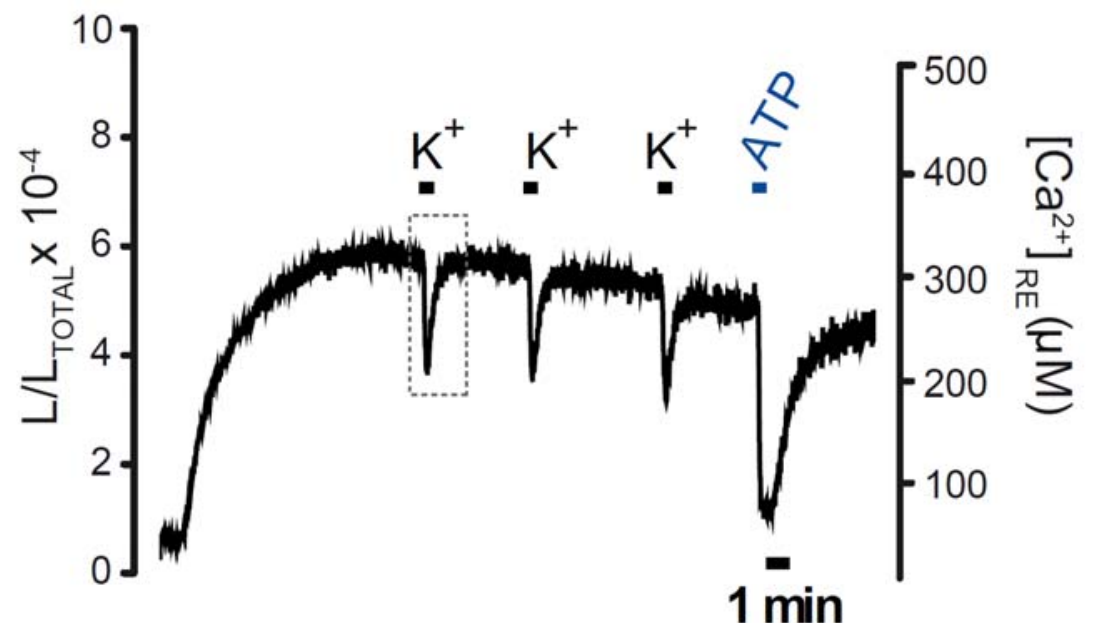

B

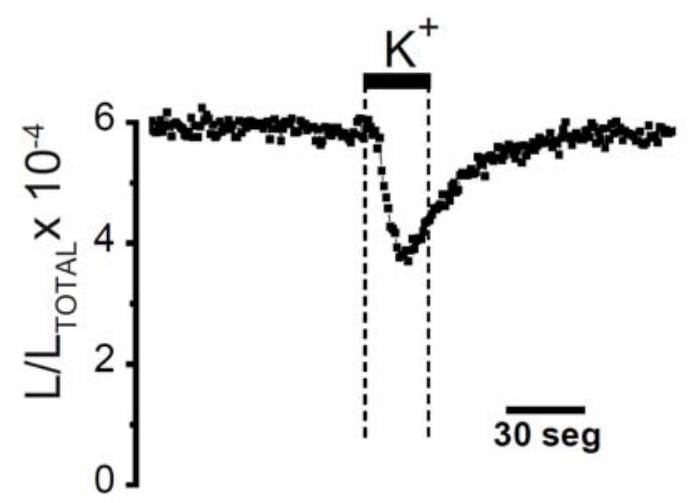

C

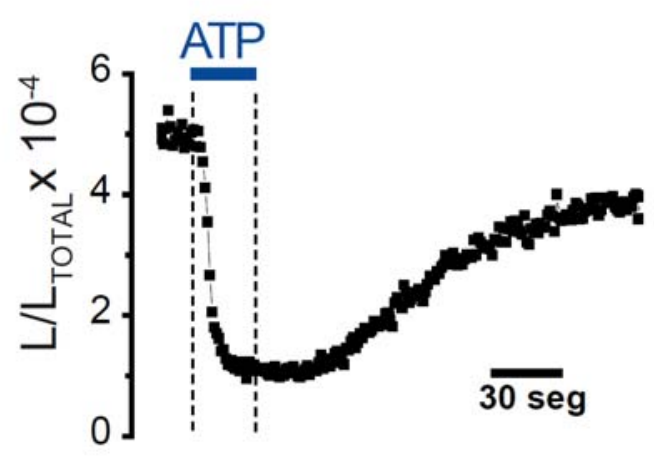

Figura 43. Efecto de la estimulación con alto $\mathrm{K}^{+}$sobre la $\left[\mathrm{Ca}^{2+}\right]_{\mathrm{RE}}$ en astrocitos. Los trazados representan $\left[\mathrm{Ca}^{2+}\right]_{R E}$ de astrocitos cultivados. A. Se compara la respuesta del alto $\mathrm{K}^{+}(80 \mathrm{mM})$ y la del ATP $(100 \mu \mathrm{M})$ en la $\left[\mathrm{Ca}^{2+}\right]_{\mathrm{RE}}$. B y C. Detalle de los resultados del alto $\mathrm{K}^{+}$(recuadro punteado en gris) y del ATP mostrados en A. Se amplificaron las escalas de L/Lt y temporal del primer estímulo de alto $\mathrm{K}^{+}$y el último correspondiente al ATP de (A) para comparar sus cinéticas de liberación y rellenado. Otros detalles técnicos como en la Figura 38.

Para ver si había una correlación entre la magnitud del estímulo y la liberación del $\mathrm{Ca}^{2+}$ reticular se aplicaron pulsos con concentraciones crecientes del estímulo despolarizante de alto $\mathrm{K}^{+}$en el rango desde $10 \mathrm{mM}$ hasta $120 \mathrm{mM}$ 
de $\mathrm{KCl}$. Se observó que efectivamente, a mayores concentraciones de $\mathrm{K}^{+}$, el pico citosólico era mayor (resultados no mostrados). En la Figura 44, se muestran los cambios en la $\left[\mathrm{Ca}^{2+}\right]_{\mathrm{RE}}$ (con IgGAP1), al añadir diferentes concentraciones del estímulo despolarizante: 40, 80 y $120 \mathrm{mM} \mathrm{K}^{+}$. Así pues, hay una relación de proporcionalidad directa entre la despolarización, la entrada de $\mathrm{Ca}^{2+}$ y la liberación de $\mathrm{Ca}^{2+}$ del $\mathrm{RE}$, siendo la reproductibilidad excelente.

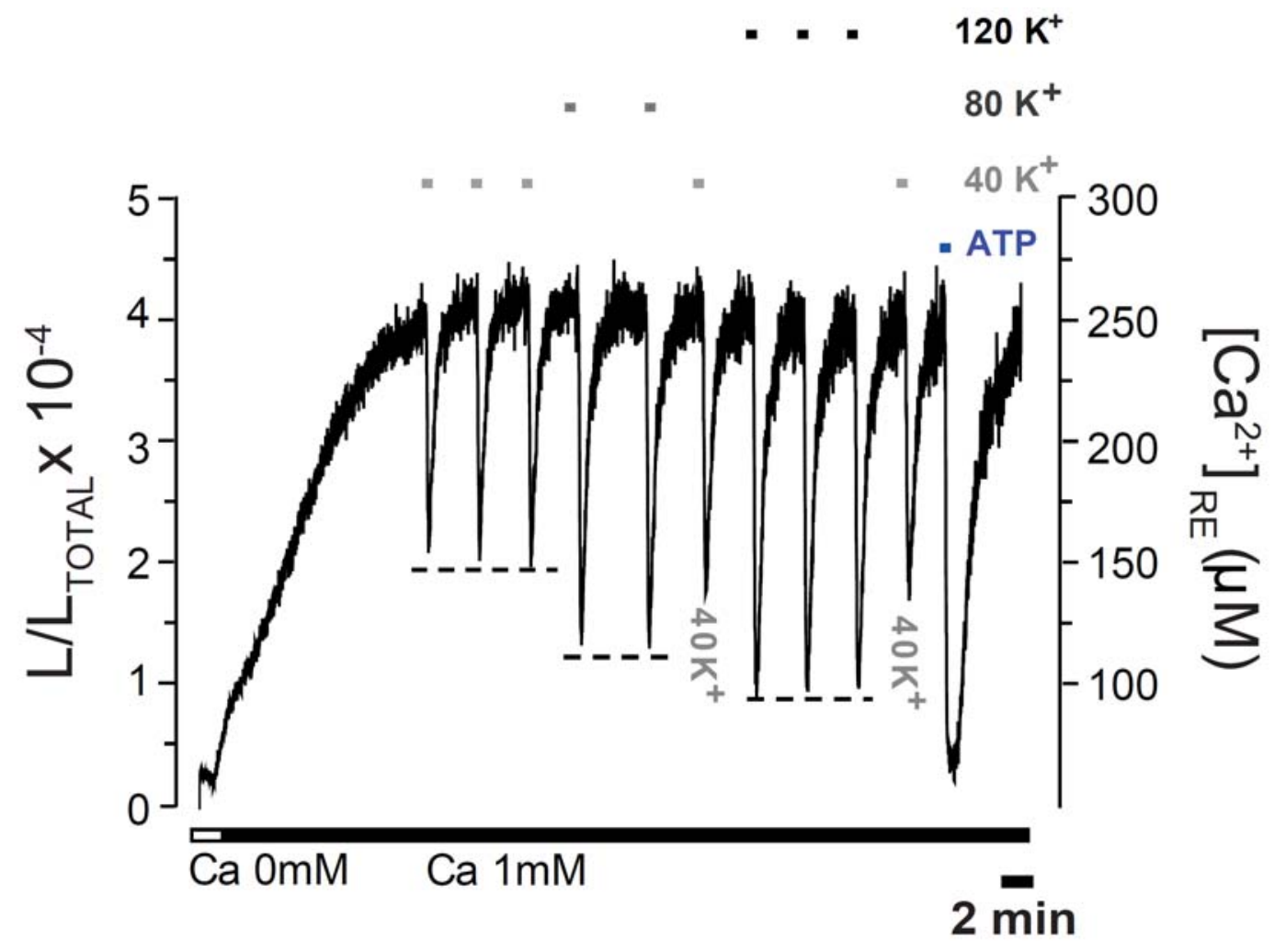

Figura 44. Efecto dosis-respuesta del alto $\mathrm{K}^{+}$en la liberación del $\left[\mathrm{Ca}^{2+}\right]_{\mathrm{RE}}$ en astrocitos. El trazado corresponde a la $\left[\mathrm{Ca}^{2+}\right]_{\mathrm{RE}}$ de una población de astrocitos que expresaban el sensor IgGAP1 y estimulados con pulsos consecutivos de concentraciones crecientes de alto $\mathrm{K}^{+}(40,80$ y $120 \mathrm{mM})$ y un pulso final de ATP (100 $\mu \mathrm{M})$. Otros detalles metodológicos como en la Figura 38. Resultados representativos de 3 experimentos independientes.

En la Figura 45A se estimularon los astrocitos con alto $\mathrm{K}^{+}(80 \mathrm{mM})$, en presencia de $\mathrm{Ca}^{2+}(1 \mathrm{mM})$ y en su ausencia (EGTA, $\left.0.5 \mathrm{mM}\right)$ y se registraron los cambios en la $\left[\mathrm{Ca}^{2+}\right]_{\mathrm{RE}}$ con el sensor IgGAP1. La ausencia de respuesta en 
EGTA confirmó que la liberación de calcio del $\mathrm{RE}$ inducida por alto $\mathrm{K}^{+}$era dependiente de la entrada de $\mathrm{Ca}^{2+}$ extracelular. En la Figura 45A puede observarse cómo la retirada del $\mathrm{Ca}^{2+}$ extracelular produjo un vaciamiento lento del calcio reticular a una tasa de unos $0.30 \mu \mathrm{M} / \mathrm{seg}$, posiblemente por la salida del mismo a través de un mecanismo de fuga de $\mathrm{Ca}^{2+}$; "Leak". La respuesta a ATP en estas condiciones no se vio afectada, como era de esperar de un agonista acoplado a la cascada del $\mathrm{IP}_{3}$, que produjo un vaciamiento casi completo del contenido de $\mathrm{Ca}^{2+}$ del RE. El nivel de $\mathrm{Ca}^{2+}$ reticular no se recuperó hasta que no se reintrodujo el $\mathrm{Ca}^{2+}$ en el medio extracelular, que rápidamente activó la potente entrada capacitativa característica de estas células (como se puede observar en el calcio citosólico en la Fig. 42B), que rellenó el $\mathrm{RE}$ en pocos minutos alcanzando un nivel de $\left[\mathrm{Ca}^{2+}\right]_{\mathrm{RE}}$ incluso más alto que el inicial.

Para evitar los artefactos causados por la eliminación del $\mathrm{Ca}^{2+}$ extracelular, se utilizó el $\mathrm{Ni}^{2+}$ a una concentración de $5 \mathrm{mM}$, que bloqueó de forma notable (aunque no totalmente) la liberación de $\mathrm{Ca}^{2+}$ reticular inducida por alto $\mathrm{K}^{+}$. Esta inhibición fue reversible, de tal forma que al lavar el $\mathrm{Ni}^{2+}$ se recuperó la respuesta (Fig. 45B).

Por último, estudiamos el efecto de la rianodina sobre la liberación de $\mathrm{Ca}^{2+}$ inducida por alto $\mathrm{K}^{+}$. En la Figura $45 \mathrm{C}$ se observa que la adición de alto $\mathrm{K}^{+} \mathrm{con}$ rianodina $(10 \mu \mathrm{M})$ durante 30 segundos, provocó un vaciamiento del RE. En otro protocolo experimental no mostrado, se incubó con rianodina, combinando diferentes concentraciones $(10,20,50$ y $100 \mu \mathrm{M})$ y tiempos (entre 10 y 60 minutos). Después se lavó la rianodina y se reconstituyó la aequorina. En todas las condiciones la adición de $\mathrm{Ca}^{2+}$ apenas rellenó el RE. La rianodina estaría uniéndose de forma irreversible al RyR, que estaría parcialmente abierto. En otros tipos celulares, se ha descrito que la rianodina inhibe los canales de RyR de forma dependiente de uso (Lee y col., 1991; Alonso y col., 1999). 

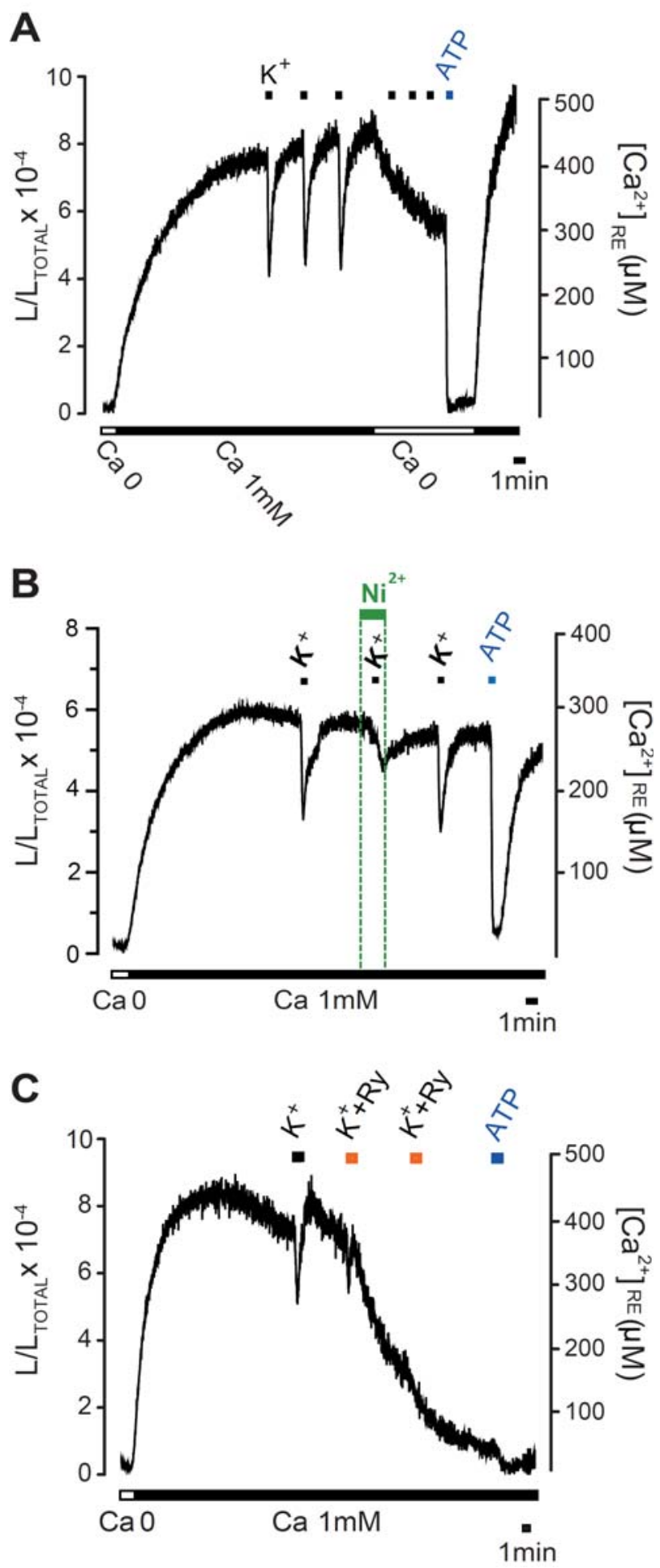

Figura 45. Inhibición del efecto del alto $\mathrm{K}^{+}$en la $\left[\mathrm{Ca}^{2+}\right]_{\mathrm{RE}}$ medida con IgGAP1 en una población de astrocitos. A. Estimulación con alto $\mathrm{K}^{+}(80 \mathrm{mM})$ en astrocitos primarios en monocapa en presencia de $\mathrm{Ca}^{2+}(1 \mathrm{mM})$ o en su ausencia $(0.5 \mathrm{mM}$ EGTA) de $\mathrm{Ca}^{2+}$ en el medio extracelular. B. Efecto del $\mathrm{NiCl}_{2}(5 \mathrm{mM})$ sobre la respuesta del alto $\mathrm{K}^{+}$. C. Efecto de la rianodina $(10 \mu \mathrm{M})$. ATP $(100 \mu \mathrm{M})$. 
Con el objetivo de estudiar si se puede producir una potenciación del efecto del alto $\mathrm{K}^{+}$a través de los RyRs, el alto $\mathrm{K}^{+}$se añadió con cafeína ( $5 \mathrm{mM}$ ), pero no se observaron diferencias con los pulsos de $\mathrm{K}^{+}$controles (resultados no mostrados).

Estos resultados indican que el alto $\mathrm{K}^{+}$produce una entrada de $\mathrm{Ca}^{2+}$ a través de canales dependientes de voltaje de tipo $L y$, probablemente otras vías. El $\mathrm{Ca}^{2+}$ que entra activa la liberación del $\mathrm{Ca}^{2+}$ desde el $\mathrm{RE}$ a través de un mecanismo de CICR. Esto implica que los picos citosólicos mostrados en la Figura 42 tienen un doble componente, uno de entrada desde el medio extracelular y otro de liberación del RE. Como era de esperar, esta liberación de $\mathrm{Ca}^{2+}$ del RE con alto $\mathrm{K}^{+}$es dependiente del $\mathrm{Ca}^{2+}$ extracelular, ya que tanto la eliminación del $\mathrm{Ca}^{2+}$ extracelular mediante la adición de EGTA (0.5 mM) (Fig. 45A) o como el bloqueo de los canales de $\mathrm{Ca}^{2+}$ con níquel (5 mM) (Fig. 45B) inhibieron el efecto del alto $\mathrm{K}^{+}$.

Quisimos disecar la contribución de cada componente, e, intentamos abolir completamente la contribución del RE vaciando los depósitos con inhibidores específicos de la bomba SERCA. En un caso los experimentos se realizaron con Fura-2 y en el otro con Fluo-3 para amplificar más los picos observados con alto $\mathrm{K}^{+}$, debido al mayor rango dinámico de este último.

En primer lugar, se incubaron los astrocitos, previamente cargados de Fluo-3, con el inhibidor irreversible de la SERCA tapsigargina $(0.2 \mu \mathrm{M}, 10$ minutos), en un medio con $\mathrm{Ca}^{2+} 1 \mathrm{mM}$. En la Figura 46B se muestra como el tratamiento con el inhibidor tapsigargina en medio con $\mathrm{Ca}^{2+} 1 \mathrm{mM}$ produjo una inhibición del $90 \%$ del pico de $\left[\mathrm{Ca}^{2+}\right]_{\mathrm{c}}$ provocado por el alto $\mathrm{K}^{+}$respecto al control (Fig. 46A). Los pequeños picos que se observaron en presencia de tapsigargina corresponderían a la entrada de $\mathrm{Ca}^{2+}$ del medio extracelular. Como comprobación del vaciamiento del RE se añadió un pulso de ATP que en estas condiciones no produjo ningún efecto. Se obtuvieron resultados similares usando el inhibidor reversible tertbutilhidroquinona (TBH), que además permitió demostrar la reversibilidad del efecto y asegurar que las células no habían sido afectadas por el protocolo utilizado. 
A

B
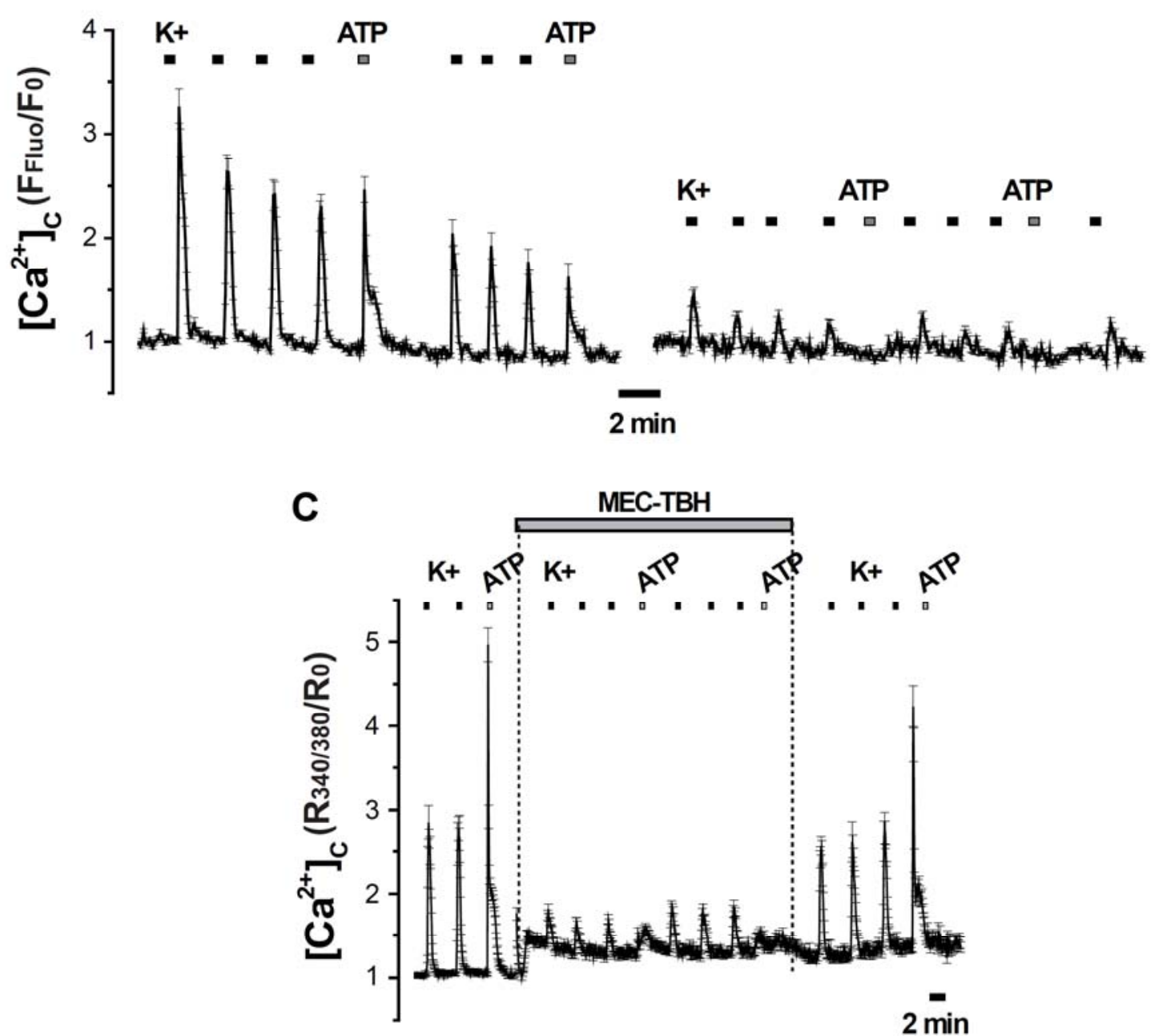

Figura 46. Efecto del vaciamiento del $\mathrm{Ca}^{2+}$ del RE sobre la respuesta evocada por alto $\mathrm{K}^{+}$en astrocitos. A. Las células se cargaron con Fluo- 3 y se estimularon con alto $\mathrm{K}^{+}(80 \mathrm{mM})$ y ATP $(100 \mu \mathrm{M})$. El trazado representa la media \pm esm de la $\left[\mathrm{Ca}^{2+}\right]_{\mathrm{C}}$ de 49 células presentes en el mismo campo. B. Las células se incubaron con tapsigargina $0.2 \mu \mathrm{M}$ durante 10 minutos y se estimularon como en (A). El trazado representa la media \pm esm de la $\left[\mathrm{Ca}^{2+}\right]_{\mathrm{C}}$ de 14 células presentes en el mismo campo. C. Las células se cargaron con Fura- 2 y se estimularon con $\mathrm{K}^{+}(80 \mathrm{mM})$ y ATP $(100 \mu \mathrm{M})$ en presencia o ausencia de TBH $(10 \mu \mathrm{M})$. El trazado representa la media \pm esm de la $\left[\mathrm{Ca}^{2+}\right]_{\mathrm{C}}$ de 30 células presentes en el mismo campo.

En la Figura 46C se observa cómo la adición de TBH en presencia de $\mathrm{Ca}^{2+}$ externo produce un aumento del nivel de $\left[\mathrm{Ca}^{2+}\right]_{\mathrm{C}}$ que se mantiene elevado hasta que se elimina el inhibidor. Los pulsos de alto $\mathrm{K}^{+}$se vieron notablemente inhibidos respecto a los controles, reflejando la contribución de entrada de $\mathrm{Ca}^{2+}$ del medio extracelular. Este resultado confirma los resultados obtenidos con tapsigargina. El alto $\mathrm{K}^{+}$provocó elevaciones transitorias de un $180 \%$ (153 $\pm 7 \%$ 
media \pm esm; $n=149$ ) en el control, mientras que en presencia de TBH se midieron incrementos de un $33 \pm 3 \%$ (media \pm esm; $n=147$ ), una inhibición del $78 \%$ del pico total. Al lavar el TBH se recuperaron los niveles basales de calcio anteriores al tratamiento, así como la magnitud de los picos evocados por el alto $\mathrm{K}^{+}$. El transitorio producido por el ATP final demostró que los depósitos intracelulares se habían rellenado. Estos resultados demuestran que los picos citosólicos producidos por el alto $\mathrm{K}^{+}$provienen en gran medida de la liberación de $\mathrm{Ca}^{2+}$ del RE (en un $80 \%$ ), y que la entrada representa alrededor de un $20 \%$.

\subsubsection{Estudio de la $\left[\mathrm{Ca}^{2+}\right]_{\mathrm{RE}}$ en astrocitos permeabilizados}

Por último, nos planteamos demostrar el mecanismo de CICR en astrocitos de forma directa, es decir, monitorizar la liberación de $\mathrm{Ca}^{2+}$ inducida por $\mathrm{Ca}^{2+}$ desde el RE. Para ello diseñamos el experimento que se muestra en la Figura 47, donde las células se permeabilizaron con digitonina, de forma similar a lo mostrado en la Figura 40, y se perfundieron con un medio que contenía $0.1 \mu \mathrm{M}$ de $\mathrm{Ca}^{2+}$ (tamponado con EGTA) (Fig. 47A). La cinética de rellenado fue similar a la de las células intactas, alcanzándose el estado estacionario en 10-15 minutos y un valor de $\left[\mathrm{Ca}^{2+}\right]_{\mathrm{RE}}$ basal de $330 \pm 44 \mu \mathrm{M}$ (media \pm esm, $n=8$ ), algo menor que el obtenido con células intactas. En estas condiciones un pulso de $30 \mu \mathrm{M}$ de $\mathrm{Ca}^{2+}$ indujo un aumento en la $\left[\mathrm{Ca}^{2+}\right]_{\mathrm{RE}}$. Este resultado fue muy reproductible cuando se añadieron 2 pulsos consecutivos, observándose en todos los casos un rellenado del RE. Sin embargo, al rellenar el RE con una mayor concentración de $\mathrm{Ca}^{2+}, 0.5 \mu \mathrm{M}$, obtuvimos un nivel de $\left[\mathrm{Ca}^{2+}\right]_{\mathrm{RE}}$ basal de alrededor de $500 \mu \mathrm{M}(470 \pm 29 \mu \mathrm{M}$, esm, $\mathrm{n}=39)$ que tardó en alcanzarse entre 5-8 minutos (Fig. 47B). En estas condiciones el pulso de alto $\mathrm{Ca}^{2+}$ provocó una clara liberación del $\mathrm{Ca}^{2+}$ reticular de $14 \pm 1.7 \%$ (media \pm esm, $n=11$ ) y este resultado se reprodujo en los dos pulsos siguientes, aunque el efecto fue menor. Además, con este último nivel de rellenado se probó un estímulo de $60 \mu \mathrm{M}$ de $\mathrm{Ca}^{2+}$ y también se observó una liberación de $\mathrm{Ca}^{2+}$ del $\mathrm{RE}$, representada por una reducción del $22 \pm 1.9 \%$ (media \pm esm, $n=17$ ) del nivel de $\mathrm{Ca}^{2+}$ reticular (resultados no mostrados). 


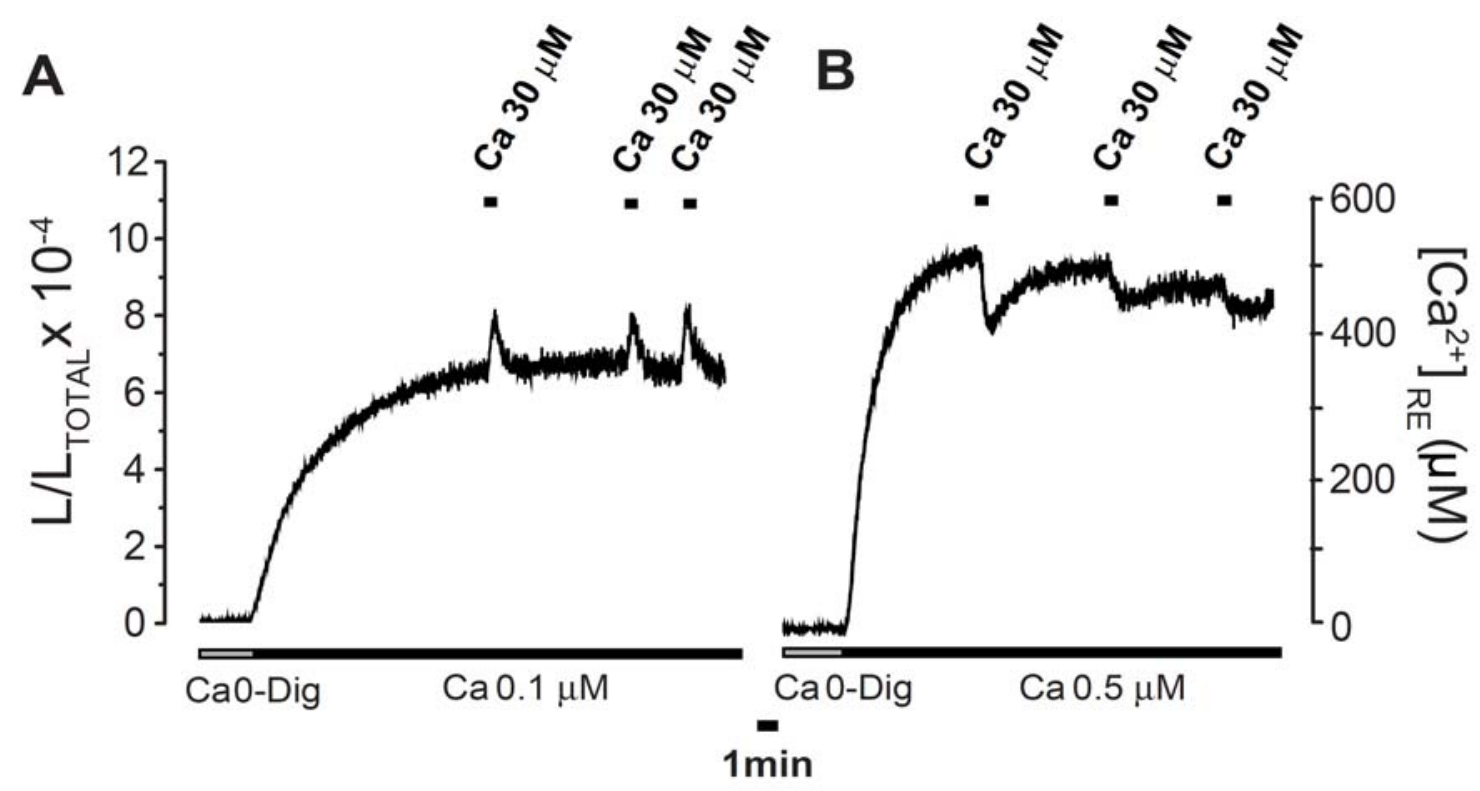

Figura 47. Rellenado o liberación del $\mathrm{Ca}^{2+}$ desde el RE en función de la $\left[\mathrm{Ca}^{2+}\right]_{\mathrm{RE}}$. Los astrocitos que expresaban la sonda IgGAP1 en el RE se permeabilizaron como se ha descrito. El RE se rellenó con un medio interno que contenía $0.1 \mu \mathrm{M} \mathrm{Ca}^{2+}$ o B. 0.5 $\mu \mathrm{M} \mathrm{Ca}^{2+}$. Una vez alcanzado un nivel estable en la $\left[\mathrm{Ca}^{2+}\right]_{\mathrm{RE}}$, en ambos casos se estimuló con pulsos de $30 \mu \mathrm{M} \mathrm{CaCl}_{2}$ durante 30 segundos.

Estos resultados indican que el $\mathrm{RE}$ de astrocitos puede funcionar simultáneamente como un reservorio o como una fuente de $\mathrm{Ca}^{2+}$. El rellenado del RE facilita el CICR. Además, a veces los astrocitos poseen el mecanismo de CICR, probablemente a través de los RyR, y que la activación del mecanismo de CICR requiere una concentración umbral mínima de $\mathrm{Ca}^{2+}$ en el RE.

\subsubsection{Expresión del RyR en astrocitos}

Con el objeto de comprobar la expresión del RyR3 en astrocitos realizamos un ensayo de RT-PCR utilizando cebadores específicos para el receptor RyR3, que es el subtipo descrito previamente en este tipo celular (Matyash y col., 2002). En la Figura 48 se muestra la amplificación de una banda del tamaño esperado, 300 pb, únicamente en el carril de los astrocitos (carril 7), y no en el control de fibroblastos (carril 6). En ambas muestras se amplificaron la banda del gen y se utilizó GAPDH como control. 


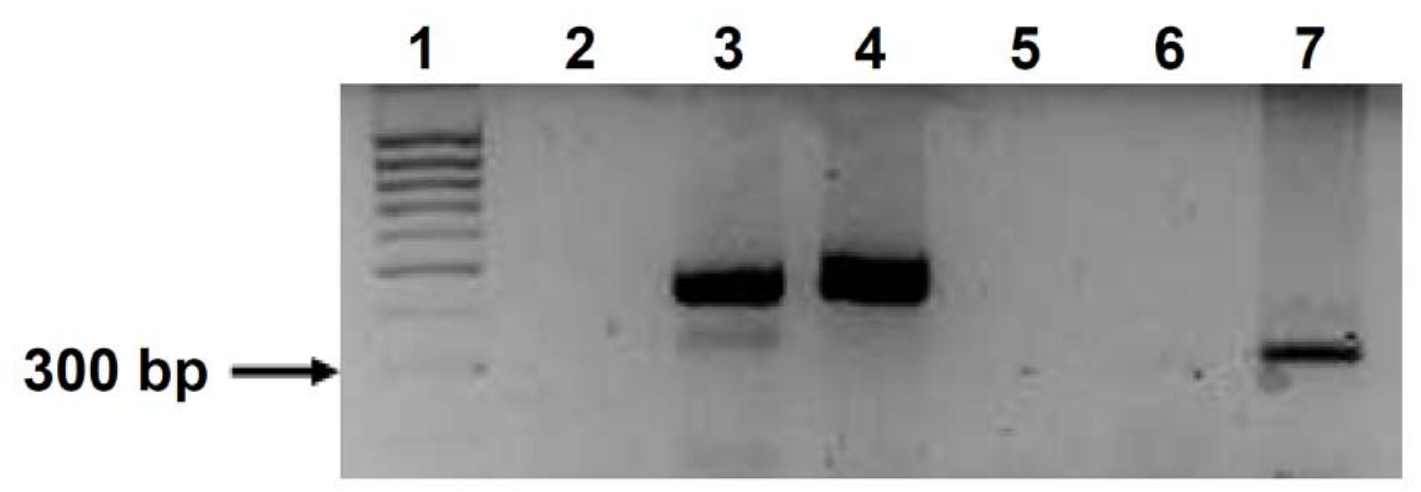

Figura 48. Expresión del transcrito de mRNA del RyR3 en astrocitos. En el gel de agarosa se muestran los productos RT-PCR obtenidos a partir de extractos de RNA de fibroblastos de ratón (calles 3 y 6 ) y de cultivos de astrocitos (carriles 4 y 7 ). Se utilizaron cebadores específicos para GAPDH (carriles 2-4) y para RyR3 (carriles 5-7). Carril 1, marcador de tamaño molecular; carril 2 y 5 , agua, control negativo de la reacción de PCR.

\subsubsection{Ganancia de función del RyR3 en células HEK 293T}

Con el objetivo de confirmar que el efecto del CICR observado se producía a través del RyR se transfectó el gen de RyR3 en células HEK 293T, modelo celular muy utilizado por sus bajos niveles de expresión de las proteínas RyR endógenas (Tong y col., 1999). Se midió la $\left[\mathrm{Ca}^{2+}\right]_{\mathrm{RE}}$ en células que expresaban el receptor RyR3, tanto en células intactas como en permeabilizadas, midiendo la liberación de $\mathrm{Ca}^{2+}$ inducida por cafeína en células intactas y la provocada por $\mathrm{Ca}^{2+}$ en permeabilizadas. En el caso de las células que expresan RyR3 la liberación de calcio del RE por cafeína (25 mM) fue del $69 \pm 4 \%$ (media \pm esm, $n=4$ de dos experimentos independientes). Esta cifra es tres veces mayor que en las células control transfectadas con el mismo plásmido vacío, donde se produjo una liberación de $24 \pm 1.5 \%$ (media \pm DS, $\mathrm{n}=4$ de dos experimentos independientes). En las células que expresaban el RyR3 la liberación con cafeína fue incluso mayor que la liberación evocada por ATP $(100 \mu \mathrm{M})$, en las mismas células. En el caso de las células que expresaban RyR3 la liberación con ATP fue $53 \pm 4.5 \%$ (media \pm esm, n=4) y en las células control $52 \pm 4 \%$ (media \pm esm, $n=4$ ), no se observaron diferencias significativas con éste estímulo entre ambas condiciones. 
A

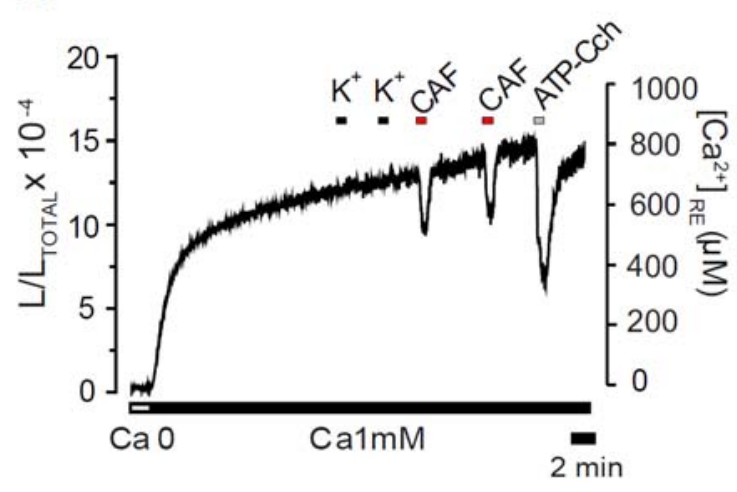

C

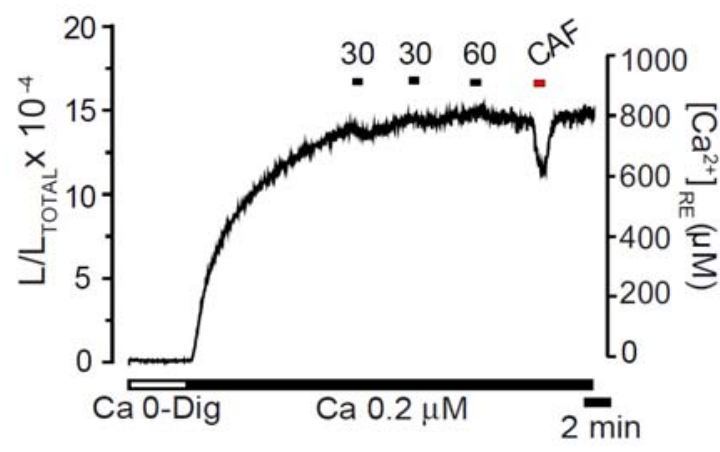

B

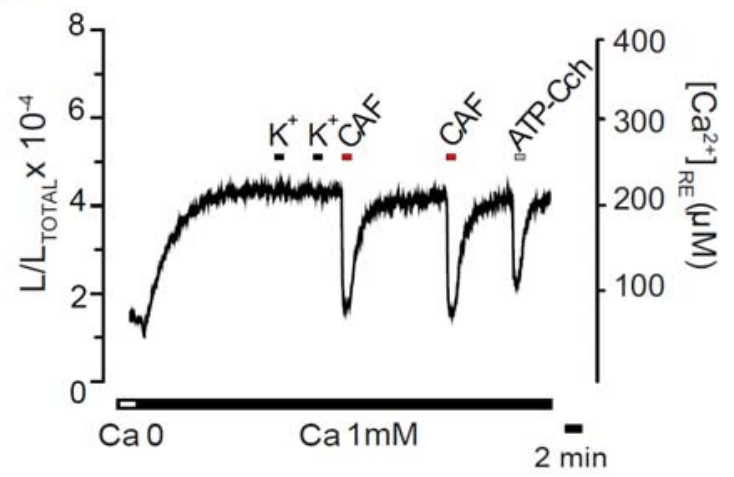

D

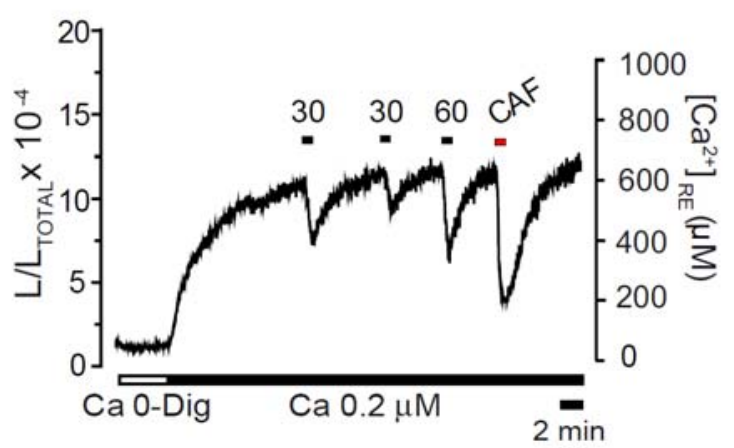

Figura 49. Efecto de la sobre-expresión del RyR3 sobre la dinámica del $\mathrm{Ca}^{2+}$ reticular en células HEK-293T. Las células HEK-293T se co-transfectaron con pcDNA3-IgGAP1 y con pcDNA3 vacío (A y C) o con pcDNA3-IgGAP1 y pcDNA3-RyR (B y D). A, B. Las células intactas se estimularon con alto $\mathrm{K}^{+}(80 \mathrm{mM})$, cafeína $(25$ $\mathrm{mM}$ ) y con la mezcla ATP/Carbacol (ATP-Cch, $100 \mu \mathrm{M}$ cada uno). C, D. Las células se permeabilizaron como en la Figura 40 y se perfundieron con un medio con $0.2 \mu \mathrm{M}$ de $\mathrm{Ca}^{2+}$ para rellenar el $\mathrm{RE}$, se estimularon con pulsos de medio con $\mathrm{CaCl}_{2}(30 \mu \mathrm{M})$ y cafeína (25 mM).

Los experimentos con células permeabilizadas se muestran en la Figura 49. Tras la permeabilización, realizada como se ha explicado previamente, se perfundió un medio de composición similar al medio interno con $0.2 \mu \mathrm{M}$ de $\mathrm{Ca}^{2+}$ hasta que se rellenó el RE. Al estimular las células con pulsos de alto $\mathrm{Ca}^{2+}(30$ y $60 \mu \mathrm{M})$, en las células trasfectadas con el RyR3 se produjo una liberación de $\mathrm{Ca}^{2+}$ del RE: con $30 \mu \mathrm{M}$ se liberó alrededor de $21 \pm 2 \%$ (media \pm esm, $\mathrm{n}=4$ de dos experimentos independientes) y con $60 \mu \mathrm{M} 38 \pm 9.5 \%$ (media \pm esm, $\mathrm{n}=4$ de tres experimentos independientes). La cafeína (25 mM) produjo una liberación del $48 \pm 0.5 \%$ (media \pm esm, $n=4$ de dos experimentos independientes) a partir del RE de las células transfectadas. En el caso de 
células control, no se observó liberación del calcio del RE con los estímulos de alto $\mathrm{Ca}^{2+}$ y la cafeína produjo una liberación de $21 \pm 2.3 \%$ (media $\pm \mathrm{esm}, \mathrm{n}=3$ de tres experimentos independientes). Nótese que en las células permeabilizadas la cafeína también produjo una liberación mayor en las células transfectadas con RyR3 que en las células control.

\subsubsection{Medidas de fluorescencia con erGAP3 en astrocitos primarios cultivados en monocapa}

Todos los resultados mostrados hasta aquí se realizaron en poblaciones celulares de astrocitos puros en monocapa. El siguiente paso fue demostrar que el efecto del alto $\mathrm{K}^{+}$también se producía en un modelo más fisiológico, como es el cultivo neuronal. Debido al carácter mixto del cultivo, compuesto de neuronas y astrocitos, los registros se realizaron en célula única, mediante imagen de la $\left[\mathrm{Ca}^{2+}\right]$.

Como se mostró en la Figura 1, una de las ventajas de las proteínas GAP es que son indicadores duales, que pueden usarse como indicadores luminiscentes, cuando la apo-GAP está reconstituida con celenterazina, o fluorescentes en ausencia del cofactor. El sensor erGAP3 (Kd; $466 \mu \mathrm{M})$ es una sonda dirigida al lumen del RE, que permite realizar medidas ratiométricas de fluorescencia en célula única. La proteína GAP3 se expresó mediante infección con un vector viral derivado de adenoasociados 0 a partir de ratones transgénicos para GAP3. En la Figura 50A se muestran los cambios de fluorescencia de cultivos de astrocitos a cada longitud de onda de GAP3. Como se esperaría, la estimulación con ATP (2 o $100 \mu \mathrm{M})$ produjo un incremento en la señal a 405 y una disminución a $470 \mathrm{~nm}$. En la Figura 50B se muestran los valores del cociente $(R)$ entre las dos longitudes de onda, normalizado con respecto a la señal basal $\left(R / R_{0}\right)$, y a la derecha la $\left[\mathrm{Ca}^{2+}\right]_{E R}$ calibrada en $\mathrm{Ca}^{2+}$. 

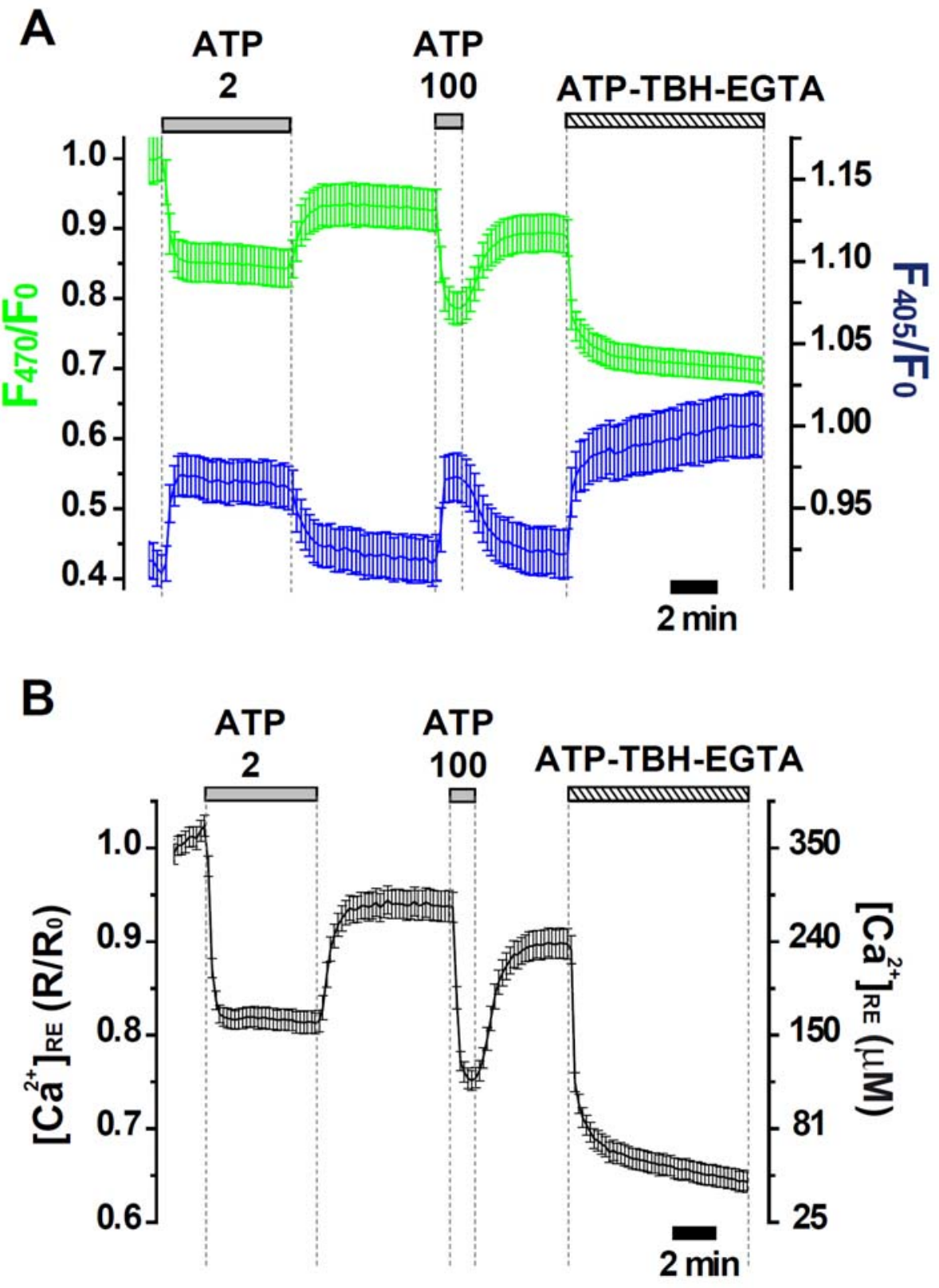

Figura 50. Dinámica de la $\left[\mathrm{Ca}^{2+}\right]_{\mathrm{RE}}$ en célula única con erGAP3 en astrocitos. Los astrocitos se obtuvieron a partir de cultivos de cortezas cerebrales de ratones transgénicos para erGAP3 (línea 10). A. Cada trazado corresponde a la media $( \pm$ esm,) de 28 células individuales, de la fluorescencia $(F)$ registrada a las dos longitudes de onda de la sonda GAP3 dirigida al RE y normalizadas con respecto a la fluorescencia inicial $\left(F_{0}\right), F_{470} / F_{0}$ (trazado verde) y $F_{405} / F_{0}$ (trazado azul). Las células se estimularon con ATP (2 y $100 \mu \mathrm{M})$ seguido de un vaciamiento completo del RE con ATP $(100 \mu \mathrm{M})$ en medio sin calcio con TBH $(10 \mu \mathrm{M})$. B. El trazado corresponde a la $\left[\mathrm{Ca}^{2+}\right]_{R E}$ expresada como la media \pm esm, $n=28$ células individuales, del cociente entre $\mathrm{F}_{470} / \mathrm{F}_{405}$ obtenidas a partir de (A). El cociente $(\mathrm{R})$ está normalizado dividiéndolo en $\mathrm{R}_{0}$ (trazado negro). Resultado representativo de, al menos, otros 5 experimentos. 
La $\left[\mathrm{Ca}^{2+}\right]_{E R}$ basal se estimó en $350 \mu \mathrm{M}(375 \pm 13 \mu \mathrm{M}$ media \pm sem; $\mathrm{n}=384$ células de 12 experimentos diferentes). La estimulación con $2 \mu \mathrm{M}$ de ATP produjo una liberación con un descenso en la $\left[\mathrm{Ca}^{2+}\right]_{E R}$ mantenida en un nivel inferior al basal mientras estuvo presente el estímulo. Tras permitir la recuperación de los niveles basales cuando se lavó el ATP, se realizó un vaciamiento completo del RE con una mezcla compuesta por ATP $(100 \mu \mathrm{M})$ y TBH $(10 \mu \mathrm{M})$ en medio sin $\mathrm{Ca}^{2+}$ (EGTA, $\left.0.5 \mathrm{mM}\right)$. En estas condiciones se observó una disminución mantenida de la señal de alrededor de un $50 \%$ con respecto al nivel basal.

El sensor erGAP3 puede combinarse con indicadores sintéticos para realizar registros simultáneos, pudiéndose así monitorizar a la vez la $\left[\mathrm{Ca}^{2+}\right]$ en el RE y el citosol. Los espectros del sensor GAP (excitación azul y emisión verde) no solapan con los del Rhod-2 (excitación verde, 560 nm; y emisión roja, 580-630 nm) lo que permite la medida simultánea. Las células que expresaban constitutivamente erGAP3 se cargaron con Rhod-2 y se iluminaron alternativamente a 405, $470 \mathrm{~nm}$ (para erGAP3) y a $540 \mathrm{~nm}$ (para Rhod-2). En la Figura 51A se muestran las imágenes de fluorescencia individuales obtenidas a 405 y 470 (GAP3) y a 545 (Rhod-2) al principio del experimento. En la Figura 51B se muestran los cambios especulares que se producen en cada longitud de onda de GAP3 al estimular las células y provocar una liberación de $\mathrm{Ca}^{2+}$ del $\mathrm{RE}$, de manera similar a lo explicado en la Figura 51A. Finalmente, en la Figura $51 \mathrm{C}$ se muestran simultáneamente los cambios en la $\left[\mathrm{Ca}^{2+}\right]_{\mathrm{RE}}$ (expresado como en la Fig. 50B) y la $\left[\mathrm{Ca}^{2+}\right]_{\mathrm{c}}$ (expresado como la emisión de fluorescencia de Rhod-2 dividida por la fluorescencia inicial, $F / F_{0}$ ). 
A

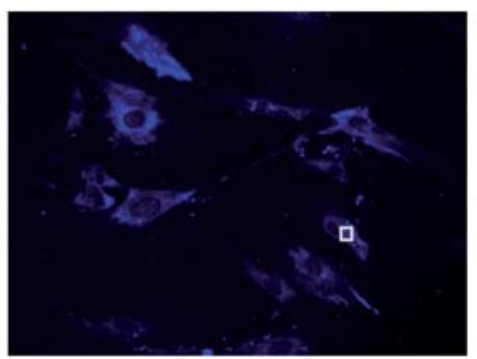

F405

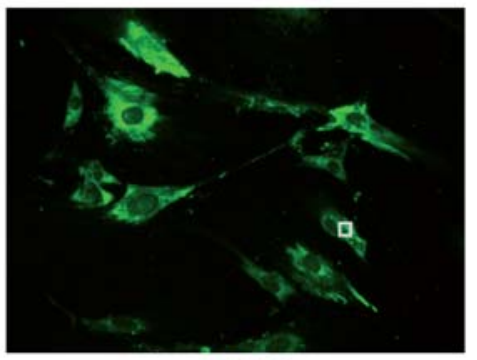

F470

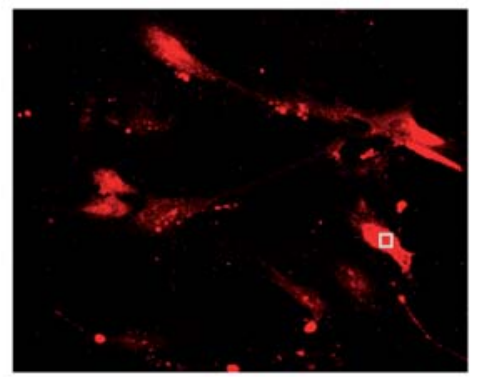

F545
B

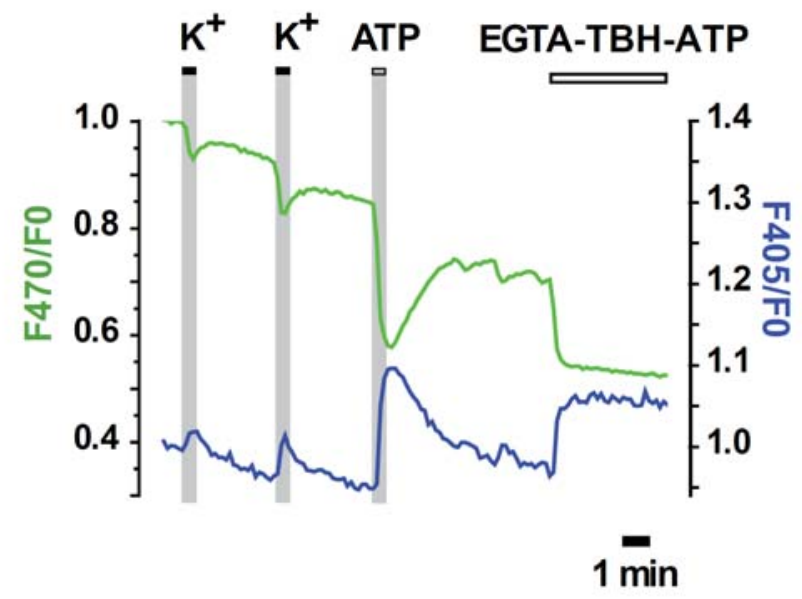

C

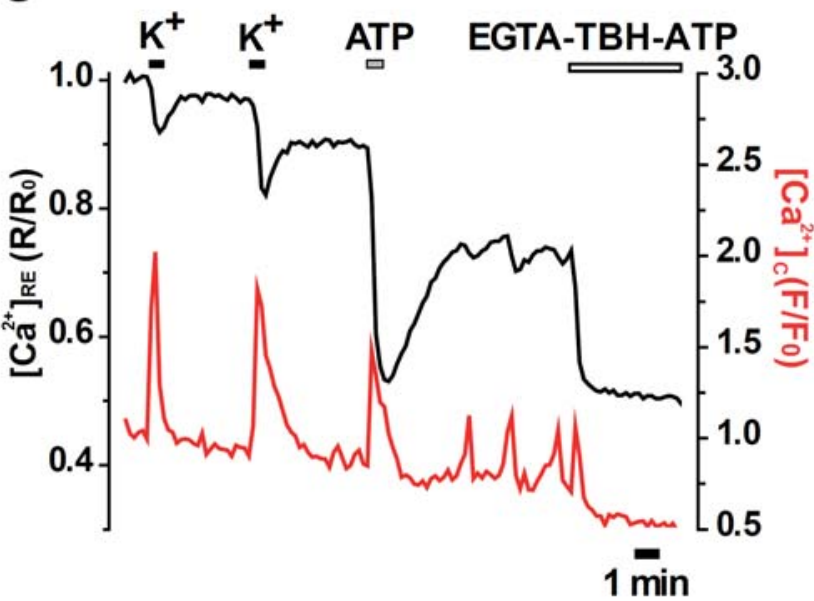

Figura 51. Medidas simultáneas de la $\left[\mathrm{Ca}^{2+}\right]_{\mathrm{RE}}(\operatorname{erGAP3})$ y de la $\left[\mathrm{Ca}^{2+}\right]_{\mathrm{C}}(\mathrm{Rhod}-2)$ por fluorescencia en célula única en astrocitos en cultivo. A. Cultivo de astrocitos que expresaban erGAP3 mediante la infección con AAV-erGAP3 y cargadas con Rhod-2. Imágenes de fluorescencia individuales de células no estimuladas, $F_{470}$ y $F_{405}$ de GAP3, y $F_{545}$ para Rhod-2. B. Los trazados corresponden a los cursos temporales de las fluorescencias de las dos longitudes de onda de la sonda GAP3 normalizadas con respecto a la fluorescencia inicial $\left(F_{0}\right), F_{470} / F_{0}$ (trazado verde) y $F_{405} / F_{0}$ (trazado azul), obtenidas a partir de una única célula (marcada en $A$ ). C. Los registros corresponden a la misma célula que en $(A)$ expresado como el cociente entre $F_{470} / F_{405}$ (R) normalizado dividiéndolo en $\mathrm{R}_{0}$ (trazado negro) y la $\left[\mathrm{Ca}^{2+}\right]_{\mathrm{C}}$ medida con Rhod-2 y expresada como $F_{545}$ dividido en $F_{0}$ para normalizarla (trazado rojo). Se registró la respuesta a la estimulación con alto $\mathrm{K}^{+}(80 \mathrm{mM})$ y ATP $(100 \mu \mathrm{M})$ seguida de un vaciamiento completo del RE con ATP $(100 \mu \mathrm{M})$ en medio sin calcio (EGTA, $0.5 \mathrm{mM})$ con $\mathrm{TBH}(10 \mu \mathrm{M})$. Resultados representativos de otros 5 experimentos independientes.

La adición de alto $\mathrm{K}^{+}$provocó un incremento transitorio en la $\left[\mathrm{Ca}^{2+}\right]_{\mathrm{c}}$ y una liberación parcial del $\mathrm{Ca}^{2+}$ del $\mathrm{RE}$, en la Figura 51 se muestra descenso del valor basal del $22 \%$ ( $33 \pm 1.4 \%$, media \pm esm, $n=102$; de 5 experimentos independientes). Un segundo pulso de alto $\mathrm{K}^{+}$, reprodujo la respuesta. EI ATP aumentó la $\left[\mathrm{Ca}^{2+}\right]_{\mathrm{C}}$ a un pico transitorio menor que el evocado por el alto $\mathrm{K}^{+}$; sin 
embargo, la liberación por ATP fue mayor, en la Figura 51 95\% (80 \pm $1.5 \%$ media \pm esm, $n=72$ de tres experimentos independientes). Esto se debe a que el aumento de la $\left[\mathrm{Ca}^{2+}\right]_{c}$ provocado por el ATP proviene principalmente de la liberación de $\mathrm{Ca}^{2+}$ del RE. Por el contrario, el transitorio evocado por el alto $\mathrm{K}^{+}$, tiene un componente de entrada de $\mathrm{Ca}^{2+}$ desde el medio extracelular, como se mostró en la Figura 46 (aún cuando se refuerza por CICR). Al lavar el ATP, el vaciamiento del RE activa la entrada capacitativa, y se rellena el RE. Esto desencadena a veces un comportamiento oscilatorio que se analizará con mayor detalle en la siguiente sección de este trabajo. Al final del experimento se añadió la mezcla de vaciamiento (EGTA+TBH+ATP) para obtener el valor de $R_{\min }$.

En la Figura 52 se comparan los cambios de $\left[\mathrm{Ca}^{2+}\right]_{\mathrm{RE}}$ inducidos por varios agonistas en neuronas y glías. El alto $\mathrm{K}^{+}$produjo liberación de calcio del RE, tanto en las neuronas como en los astrocitos pero generalmente de mayor intensidad en estos últimos. La aplicación de cafeína (50 mM) provocó una rápida bajada de la señal en ambos tipos celulares, que posteriormente recuperó su nivel basal al lavar los estímulos. Otros estímulos fueron capaces de desencadenar liberación del calcio, aunque de menor intensidad y en menos células. Por ejemplo, el glutamato (Glu, $100 \mu \mathrm{M}$ ), la acetilcolina (ACh, $100 \mu \mathrm{M})$, y la cafeína tuvieron efecto tanto en neuronas como en glias, mientras que el ATP $(100 \mu \mathrm{M})$ sólo provocó liberación de $\mathrm{Ca}^{2+}$ del RE de astrocitos. 


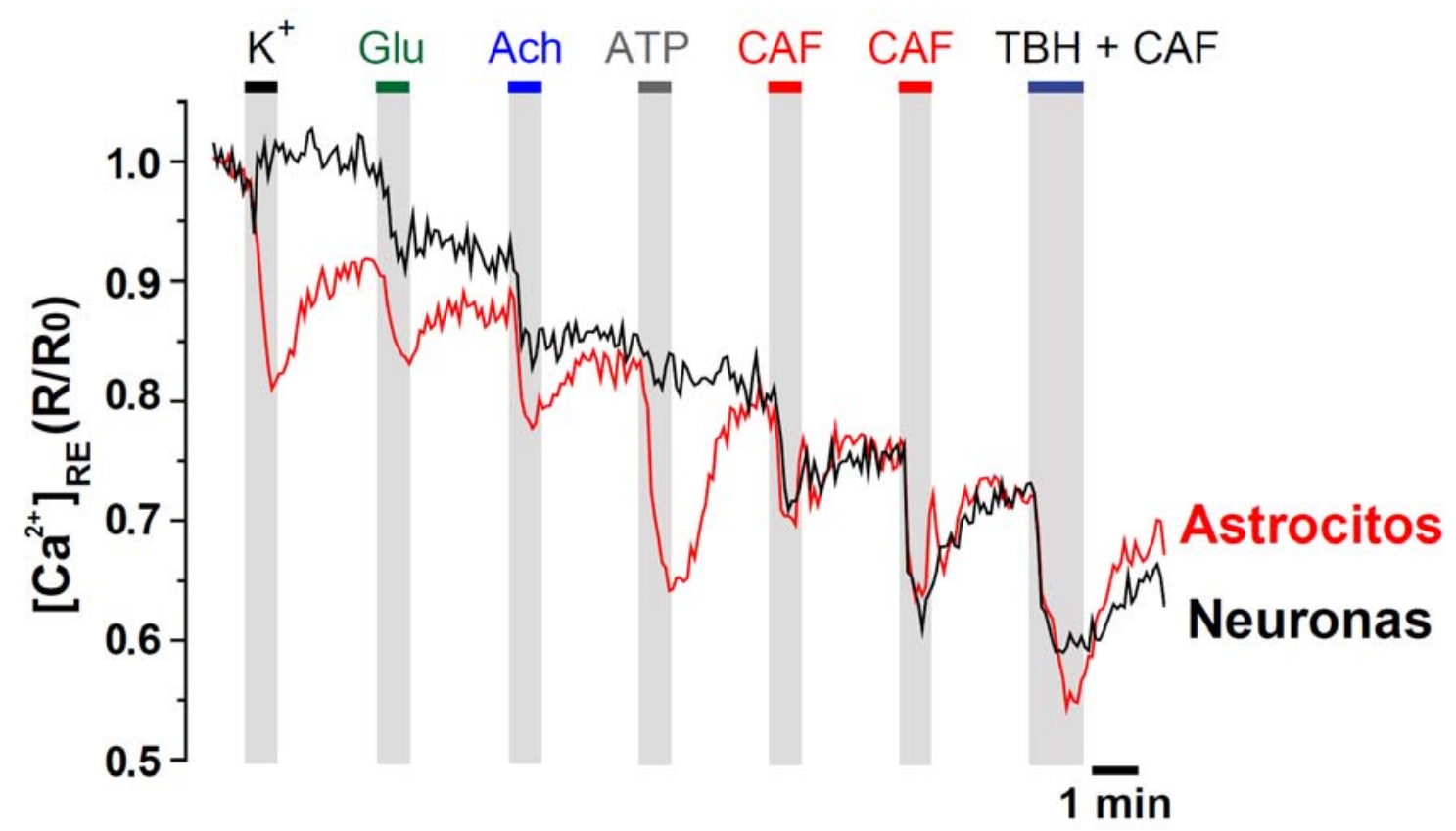

Figura 52. Comparación de la movilización del $\mathrm{Ca}^{2+}$ del $\mathrm{RE}$ entre astrocitos y neuronas en un cultivo primario mixto. Los trazados representan la $\left[\mathrm{Ca}^{2+}\right]_{\mathrm{RE}}$, expresada como $\left(R / R_{0}\right)$, de 6 neuronas (media \pm esm, trazo negro) y de 7 astrocitos (media \pm esm, trazo rojo) de un cultivo mixto de 4 DIV aislado de corteza cerebral de ratones transgénicos de la línea erGAP3. Las células se estimularon con alto $\mathrm{K}^{+}(80$ $\mathrm{mM}$ ), glutamato (Glu, $100 \mu \mathrm{M}$ ), acetilcolina (Ach, $100 \mu \mathrm{M}$ ), cafeína (Caf, $50 \mathrm{mM}$ ) y ATP $(100 \mu \mathrm{M})$. Resultados representativos de, al menos, otros 3 experimentos independientes.

\subsection{Monitorización de la $\left[\mathrm{Ca}^{2+}\right]_{\mathrm{RE}}$ (erGAP3) y de la $\left[\mathrm{Ca}^{2+}\right]_{\mathrm{C}}(\mathrm{Rhod}-2)$ simultáneamente en astrocitos de rodajas de corteza cerebral}

Las medidas en secciones de corteza cerebral presentan numerosas ventajas con respecto al tejido disociado; los astrocitos conservan su arquitectura, su posición en el tejido y su morfología astroglial, lo cual permite preservar los contactos con el resto de tipos celulares, y por tanto se aproximan más a la situación fisiológica. El principal inconveniente es la dificultad para diferenciar a los astrocitos del resto de tipos celulares. Para solventar este inconveniente hemos desarrollado el vector adenoasociado, mostrado en la Figura 34, AAV-GFAP-erGAP3, que posee el promotor específico GFAP, con el fin de expresar erGAP3 exclusivamente en los astrocitos. Este vector viral se utilizó en todos los experimentos de medidas de la $\left[\mathrm{Ca}^{2+}\right]_{\mathrm{RE}}$ en astrocitos de secciones de corteza cerebral. Las rodajas se mantuvieron en cultivo durante 24 horas y se infectaron. Tras la infección el cultivo se prolonga durante al 
menos 4 días para permitir la expresión del sensor en los astrocitos antes de realizar las medidas.

Para comprobar que la sonda GAP se comportaba adecuadamente en los astrocitos tras la expresión con el virus adenoasociado, se estudió la movilización del $\mathrm{Ca}^{2+}$ del RE por adición de una dosis máxima de ATP durante 30 segundos. Este estímulo provocó, como se esperaba, cambios especulares en las fluorescencias de las dos longitudes de onda de GAP, un aumento a 405 y un descenso a $470 \mathrm{~nm}$ (Figura 53A), con una rápida y marcada caída del cociente (R/R0, Fig. 53B, comparar con Fig. 50), que evidencia un gran vaciamiento del RE en pocos segundos. A continuación, se perfundió una dosis submáxina de ATP (2 $\mu \mathrm{M})$, lo que permitió el semirellenado del RE hasta alcanzar una meseta en la $\left[\mathrm{Ca}^{2+}\right]_{\mathrm{RE}}$ que se mantuvo constante hasta que se lavó el estímulo (Fig. 53B). En este momento el RE se llenó completamente acercándose al nivel de reposo previo al primer estímulo. La figura muestra también el protocolo de calibración del experimento, que es especialmente importante en esta preparación. La adición de la mezcla de ATP (100 $\mu \mathrm{M})$ y $\mathrm{TBH}(10 \mu \mathrm{M})$ en ausencia de $\mathrm{Ca}^{2+}$ (EGTA, $\left.0.5 \mathrm{mM}\right)$ provocó un rápido descenso de la señal hasta un mínimo correspondiente al vaciamiento completo del RE. Con estos datos se puede calcular un valor de la $\left[\mathrm{Ca}^{2+}\right]_{\mathrm{RE}}$ de reposo en astrocitos "in situ" de alrededor de $350 \mu \mathrm{M}$. Al promediar otros experimentos calibrados se obtuvo una media de $270 \pm 150 \mu \mathrm{M}(\mathrm{n}=254$ células, 11 experimentos). Este valor algo menor al obtenido en cultivos de células disociadas (de $375 \mu \mathrm{M} \pm 13 \mu \mathrm{M}$ media \pm sem; $\mathrm{n}=384$ células de 12 experimentos, Figura 50). 

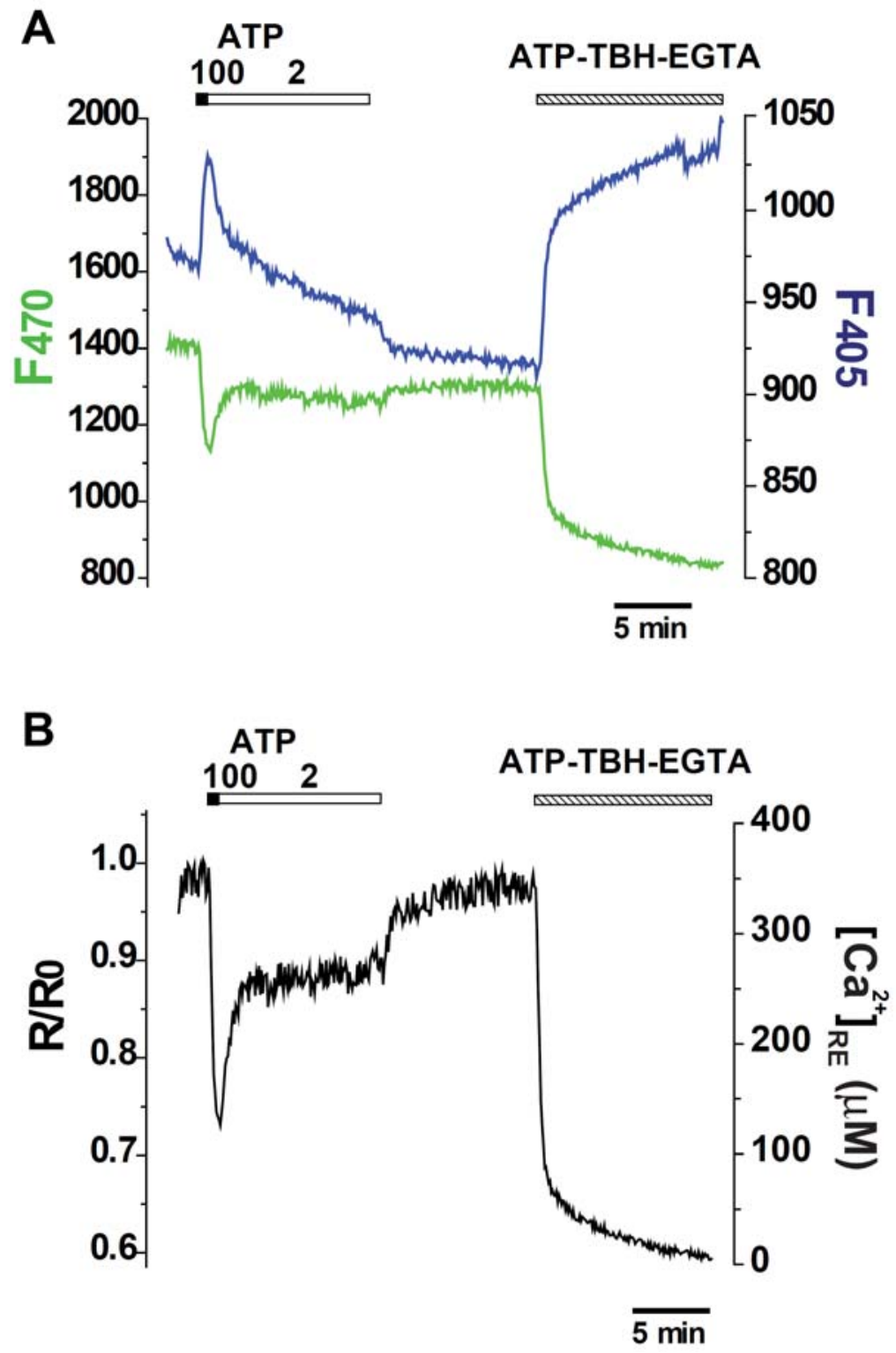

Figura 53. Efecto del ATP ( 2 y $100 \mu \mathrm{M})$ sobre la $\left[\mathrm{Ca}^{2+}\right]_{\mathrm{RE}}$ de un astrocito en una sección de corteza cerebral cultivada medido por fluorescencia con GAP3. La sección de tejido se infectó con AAV-GFAP-erGAP3. A. Los trazados representan las medias de las fluorescencias correspondientes a cada longitud de onda de la sonda GAP3 normalizadas con respecto a la fluorescencia inicial $\left(F_{0}\right), F_{470} / F_{0}$ (trazado verde) y $F_{405} / F_{0}$ (trazado azul), y obtenidas a partir de 23 astrocitos presentes en la sección de tejido. Las células de la sección se estimularon con alto $\mathrm{K}^{+}(80 \mathrm{mM})$, cafeína $(25$ $\mathrm{mM})$ y $\operatorname{ATP}(100 \mu \mathrm{M})$. B. El trazado representa la media de la $\left[\mathrm{Ca}^{2+}\right]_{\mathrm{RE}}$, expresada como $R / R_{0}$ (donde $R$ representa el cociente entre $F_{470} / F_{403}$ ), con los valores obtenidos a partir de $(A)$.

Además del ATP, probamos el efecto la dihidroxifenil-glicina (DHPG), un agonista selectivo de los receptores metabotrópicos de glutamato. En la Figura 54A se muestra el efecto de tres concentraciones de DHPG (10, 50 y $100 \mu \mathrm{M})$, 
que tuvieron efectos crecientes, con $100 \mu \mathrm{M}$ el efecto es máximo y comparable al obtenido con el ATP (Fig. 54A). La parte B de la Figura muestra un registro simultáneo de la $\left[\mathrm{Ca}^{2+}\right]_{\mathrm{C}}$ y la $\left[\mathrm{Ca}^{2+}\right]_{\mathrm{RE}}$ que confirman los resultados.
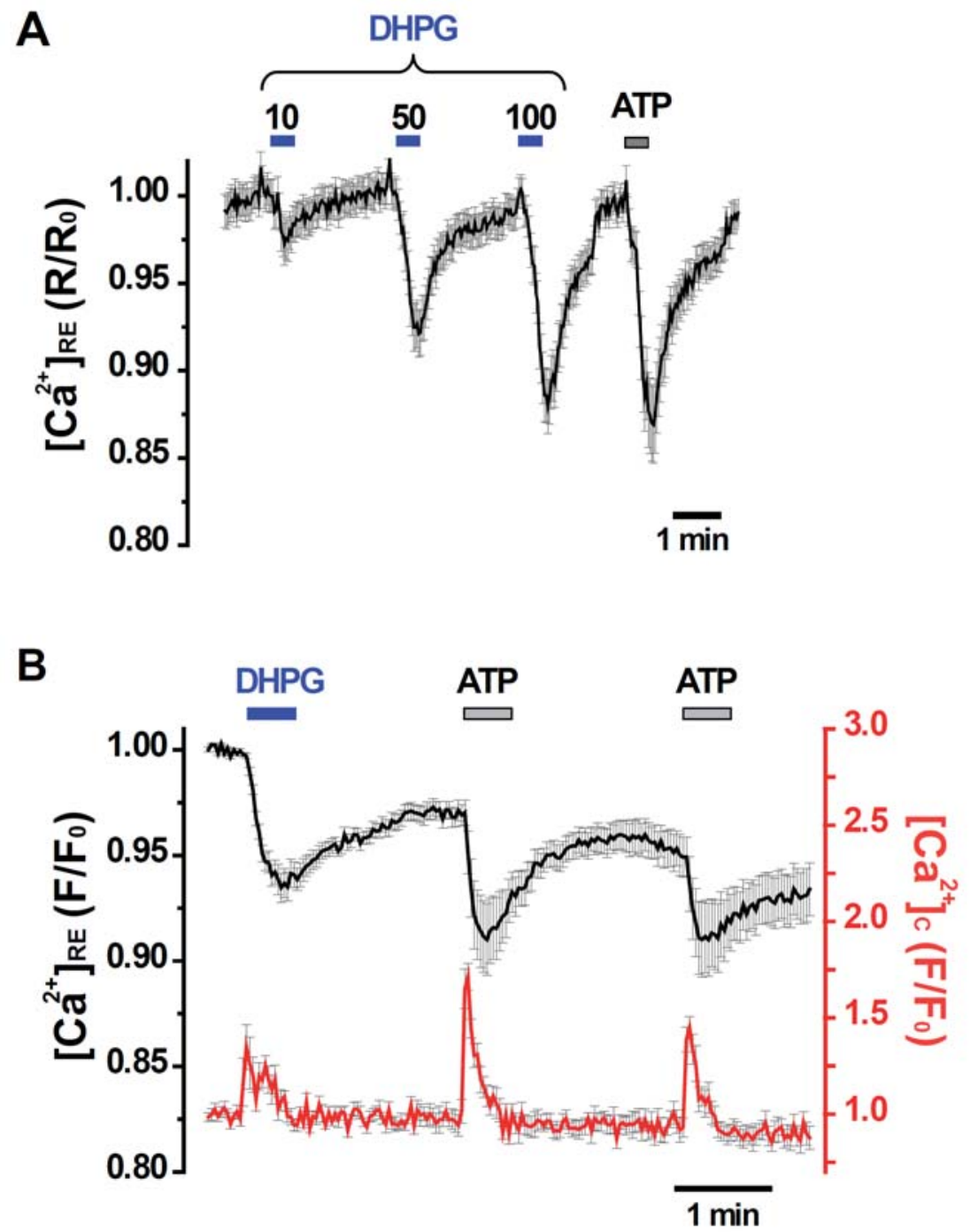

Figura 54. Efecto del agonista metabotrópico DHPG en la $\left[\mathrm{Ca}^{2+}\right]_{\mathrm{c}}$ y la $\left[\mathrm{Ca}^{2+}\right]_{\mathrm{RE}}$ de astrocitos en secciones de corteza cerebral. Las secciones de corteza de ratones neonatos se infectaron con el vector viral AAV-GFAP-GAP3 y se mantuvieron 4 DIV antes de realizar las medias. A. El registro representa la media \pm sem de la $\left[\mathrm{Ca}^{2+}\right]_{\mathrm{RE}}$, expresada como $R / R_{0}$ (donde $R$ es $F_{470} / F_{403}$ ), obtenida a partir de 31 astrocitos del mismo campo estimulados con DHPG $(10,50$ y $100 \mu \mathrm{M})$ o con ATP $(100 \mu \mathrm{M})$. B. Medidas simultáneas de la $\left[\mathrm{Ca}^{2+}\right]_{\mathrm{RE}}$ (erGAP3, trazo negro) y de la $\left[\mathrm{Ca}^{2+}\right]_{\mathrm{C}}$ (Rhod-2, trazo rojo) de 9 astrocitos. Resultados representativos de, al menos, otros 3 experimentos independientes.

La estimulación con alto $\mathrm{K}^{+}$también indujo liberación de $\mathrm{Ca}^{2+}$ del $\mathrm{RE}$ (Fig. 55A y B). La respuesta fue modesta, (un $20-30 \%$ de la respuesta del ATP), 
pero reproductible, observándose los tres pulsos consecutivos en el 95\% de los astrocitos. Nótese como la medida ratiométrica (Fig. 55B) corrige la deriva de las fluorescencias individuales. La cafeína, también provocó un vaciamiento parcial del RE con su correspondiente transitorio de la $\left[\mathrm{Ca}^{2+}\right]_{\mathrm{C}}$.

A

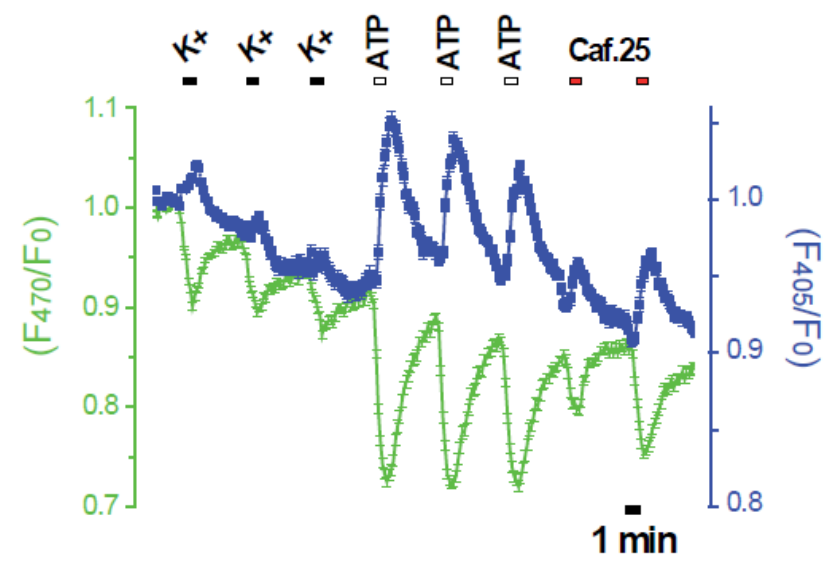

B

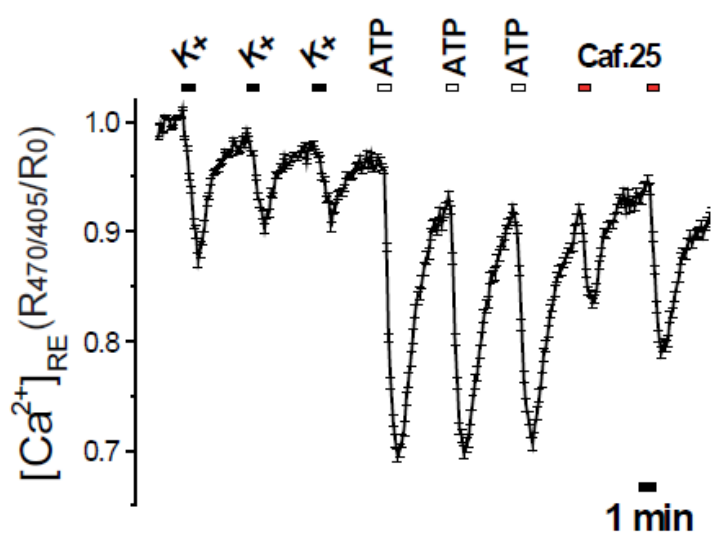

Figura 55. Efecto del alto $\mathrm{K}^{+}(80 \mathrm{mM})$ sobre la $\left[\mathrm{Ca}^{2+}\right]_{\mathrm{RE}}$ de astrocitos en una sección de corteza cerebral cultivada medida por fluorescencia con GAP3. Las secciones de tejido se infectaron con AAV-GFAP-erGAP3 A. Los trazados representan las medias \pm sem de las fluorescencias correspondientes a cada longitud de onda de la sonda GAP3 normalizadas con respecto a la fluorescencia inicial $\left(F_{0}\right), F_{470} / F_{0}$ (trazado verde) y $\mathrm{F}_{405} / \mathrm{F}_{0}$ (trazado azul), y obtenidas a partir de 39 astrocitos presentes en la sección de tejido. Las células de la sección se estimularon con alto $\mathrm{K}^{+}(80 \mathrm{mM})$, cafeína $(25 \mathrm{mM})$ y con ATP $(100 \mu \mathrm{M})$. B. El trazado representa la media \pm sem de la $\left[\mathrm{Ca}^{2+}\right]_{\mathrm{RE}}$, expresada como $R / R_{0}$ (donde $R$ representa el cociente entre $F_{470} / F_{403}$ ), con los valores obtenidos a partir de $(A)$. 
En conclusión, en el modelo de rodajas se reproducen las mismas repuestas que en los cultivos de astrocitos puros en monocapa, por lo que lo válida para estudiar muchas de las respuestas características de las glias en este escenario simplificado.

\section{Oscilaciones y ondas de calcio intracelular en los astrocitos}

\subsection{Oscilaciones de $\mathrm{Ca}^{2+}$ en cultivos primarios de astrocitos}

Las oscilaciones del $\mathrm{Ca}^{2+}$ citosólico observadas en los cultivos primarios son elevaciones transitorias repetitivas, separadas entre sí por periodos en los que la $\left[\mathrm{Ca}^{2+}\right]_{\mathrm{c}}$ regresa al nivel basal. Los astrocitos muestran oscilaciones de $\mathrm{Ca}^{2+}$ citosólico en muchas circunstancias, y son un excelente modelo celular para estudiarlas. En todos los estudios realizados hasta la fecha se ha monitorizado únicamente el calcio citosólico. En esta Tesis estudiamos directamente la contribución del RE por registro simultáneo del calcio citosólico y reticular.

\subsubsection{Oscilaciones espontáneas}

En los cultivos de astrocitos puros registramos con frecuencia oscilaciones espontáneas que ocurren de forma coordinada en el citosol y en el RE (Fig. 56). Como puede observarse en el panel $A$, el inicio de la liberación del calcio del RE coincide con el inicio del pico citosólico, en cada oscilación. En los cultivos confluentes, estas oscilaciones se observaron en un $24 \%$ de los astrocitos ( $n=41$ de 168 astrocitos estudiados en 4 experimentos). La amplitud inicial se mantenía por al menos 10 minutos, que fue el máximo de tiempo de observación utilizado. La amplitud de las oscilaciones reticulares se cuantificó como la fracción de la fluorescencia inicial $\left(R / R_{0}\right)$. Las variaciones de célula a célula, se movieron entre el 9 y $46 \%$ de liberación. De forma análoga, la amplitud de las oscilaciones del calcio citosólico varió entre aumentos del 40 al $468 \%$ de la fluorescencia normalizada $\left(R / R_{0}\right)$. No todas las células que oscilaban lo hacían con la misma frecuencia. El periodo variaba entre 30 a 120 
segundos (la media 67 segundos; $n=28$ células procedentes de 4 experimentos).

El vaciamiento previo del RE con TBH, bloqueó completamente las oscilaciones, tanto en el RE como en el citosol (Figura 56B). Este resultado sugiere que el $\mathrm{Ca}^{2+}$ reticular es esencial para el mantenimiento de las oscilaciones citosólicas, pero no excluye la participación adicional del $\mathrm{Ca}^{2+}$ extracelular.

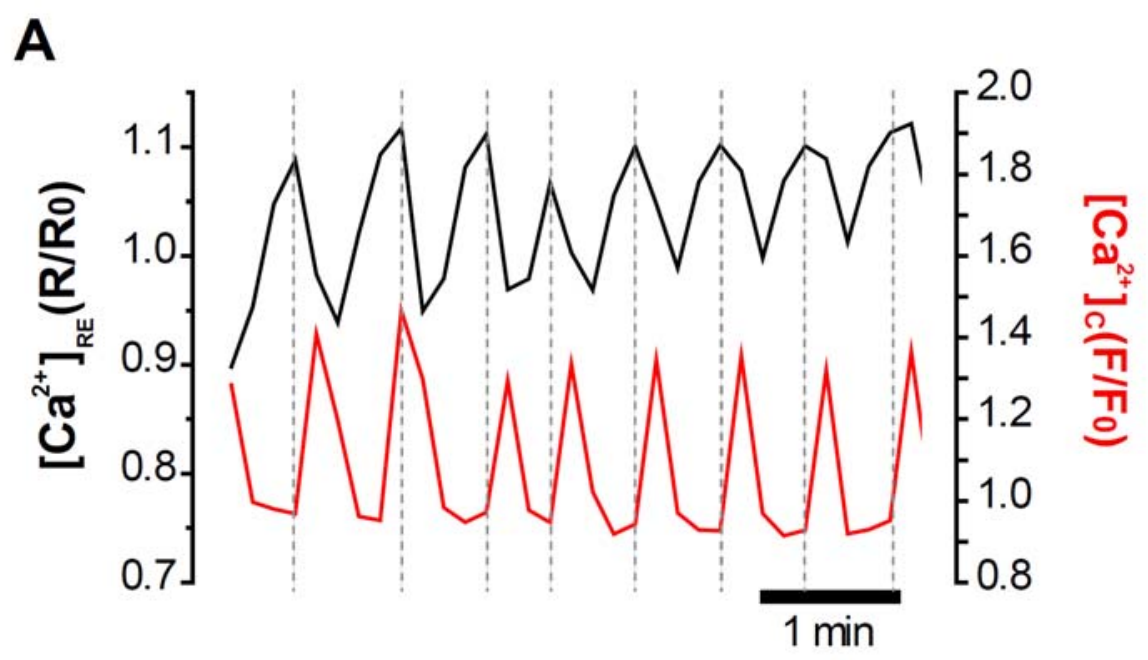

B

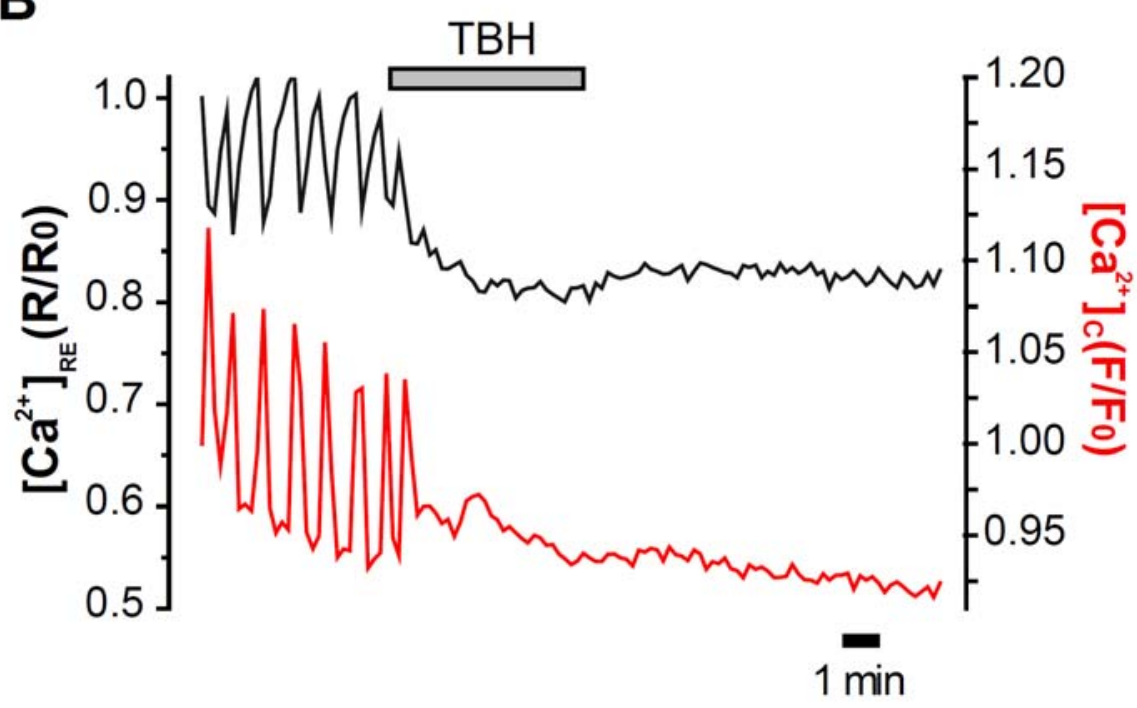

Figura 56. Oscilaciones espontáneas coordinadas de la $\left[\mathrm{Ca}^{2+}\right]_{\mathrm{RE}}$ y la $\left[\mathrm{Ca}^{2+}\right]_{\mathrm{c}}$ en astocitos primarios. A. Los trazados representan la dinámica de la $\left[\mathrm{Ca}^{2+}\right]$ en el RE y en el citosol de un único astrocito de un cultivo primario en monocapa realizado a partir de ratones neonatos de la línea transgénica erGAP3. Las células se cargaron con Rhod-2. Las medidas se realizaron simultáneamente con GAP3 (trazado negro, R/R ${ }_{0}$ ) y Rhod-2 (trazado rojo, $F / F_{0}$ ). B. Inhibición de las oscilaciones espontáneas con TBH $(10 \mu \mathrm{M})$ en un medio con $\mathrm{Ca}^{2+} 1 \mathrm{mM}$. 
La retirada del $\mathrm{Ca}^{2+}$ extracelular (EGTA, $0.5 \mathrm{mM}$ ) detuvo las oscilaciones en todas las células observadas ( $n=41$ en 4 experimentos), registradas paralelamente en el RE y en el citosol (Fig. 57). En cuanto al comportamiento de $\left[\mathrm{Ca}^{2+}\right]_{\mathrm{RE}}$, se observaron dos tipos de respuesta: en algunas células se observó un vaciamiento brusco del RE inmediatamente después de eliminar el $\mathrm{Ca}^{2+}$ externo, seguido de un vaciamiento regular y progresivo (Fig. 57A). Pero en la mayoría de las células, las oscilaciones se inhibieron sin alterarse bruscamente los niveles luminales del $\mathrm{Ca}^{2+}$ (Fig. 57B y 57C, primer minuto tras la retirada del $\mathrm{Ca}^{2+}$ extracelular). En un análisis célula a célula pudimos observar que de las 41 células que oscilaban, 28 (68\%) detuvieron las oscilaciones en el RE y en el citosol con EGTA, seguido de un vaciamiento lento y paulatino del RE (Fig. 57A), mientras que en 13 (32\%) de las células restantes se observaron rápidas y bruscas liberaciones de $\mathrm{Ca}^{2+}$ del $\mathrm{RE}$ en ausencia de $\mathrm{Ca}^{2+}$ extracelular (Fig. 57 B y C). En todos los casos, los picos de $\left[\mathrm{Ca}^{2+}\right]_{\mathrm{C}}$ tuvieron el correlato de bajadas "quantales" de $\left[\mathrm{Ca}^{2+}\right]_{\mathrm{RE}}$. En algunas células que no estaban oscilando la retirada del $\mathrm{Ca}^{2+}$ indujo oscilaciones sincrónicas de $\left[\mathrm{Ca}^{2+}\right]_{C}$ y $\left[\mathrm{Ca}^{2+}\right]_{R E}$ con un vaciamiento progresivo del RE (Fig. 57C).

En la segunda mitad del experimento de la Fig. 57 se muestra que al restituir el $\mathrm{Ca}^{2+}$ en el medio extracelular se produjo una brusca entrada (capacitativa) de $\mathrm{Ca}^{2+}$ hacia el citosol (registro de Rhod-2), seguida de una gran liberación del $\mathrm{Ca}^{2+}$ del RE. Este comportamiento, observado en 17 de 168 $(10 \%)$ células estudiadas, sugiere que la brusca entrada de $\mathrm{Ca}^{2+}$ activa el CICR del RE. En general, este comportamiento fue seguido por la aparición de oscilaciones sincronizadas en citosol y RE (Fig. 57A y B).

En conjunto, nuestros resultados indican que el RE participa en las oscilaciones espontáneas del $\mathrm{Ca}^{2+}$ citosólico, pero que dichas oscilaciones requieren, además, la entrada de $\mathrm{Ca}^{2+}$, o al menos su presencia en el medio extracelular. Como ya se ha mostrado (Fig. 45A) la eliminación del $\mathrm{Ca}^{2+}$ extracelular provoca un vaciamiento paulatino del $\mathrm{Ca}^{2+}$ del $\mathrm{RE}$; parece probable, por tanto, que el cese de las oscilaciones citosólicas no sea debido al vaciamiento de los depósitos, que no es instantáneo, sino a la necesidad de la 
entrada de $\mathrm{Ca}^{2+}$ para facilitar la liberación desde el RE por el mecanismo de CICR.
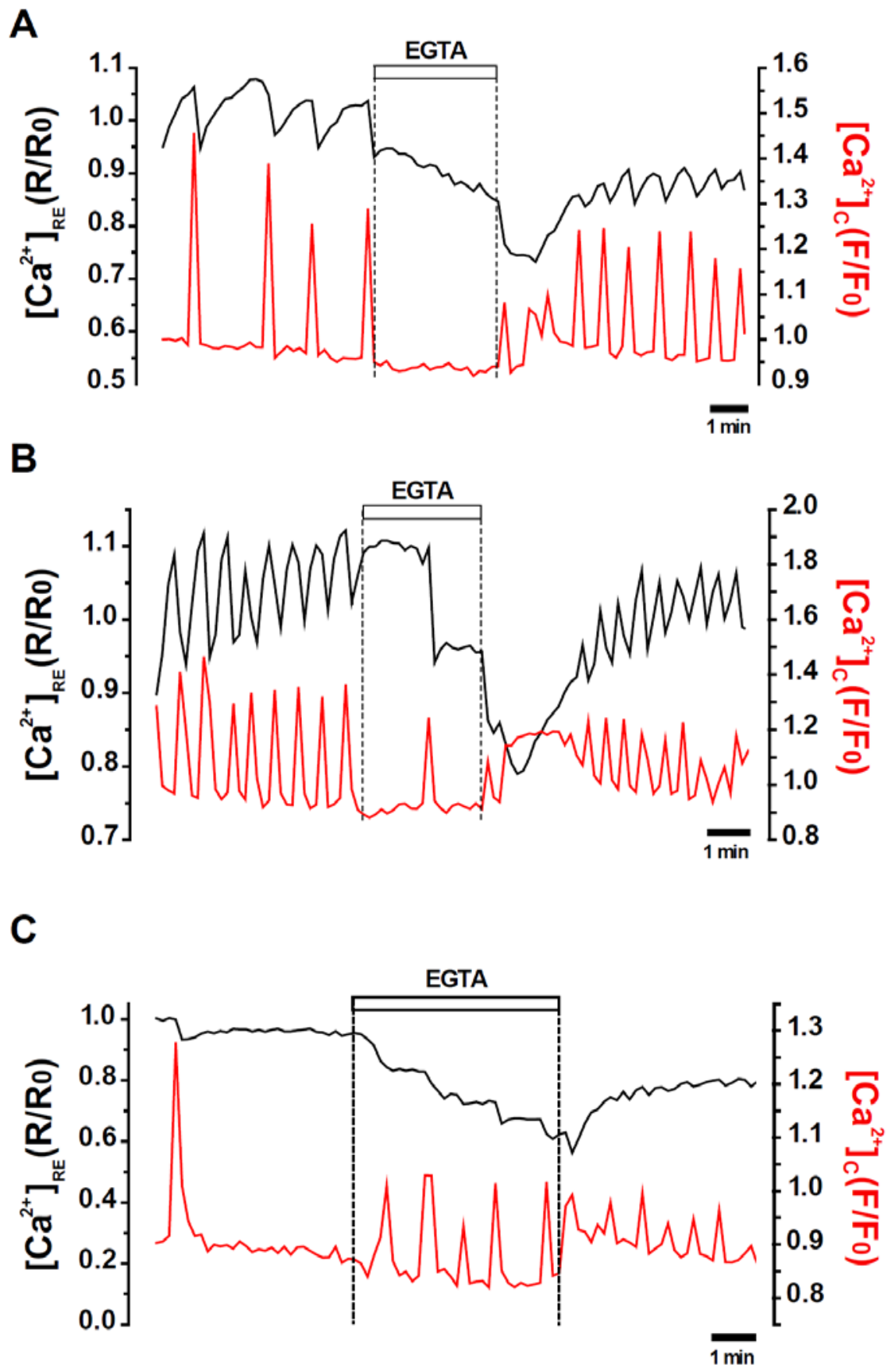

Figura 57. Efecto de la eliminación del $\mathrm{Ca}^{2+}$ extracelular sobre las oscilaciones en astrocitos. Ejemplos representativos de tres tipos de respuestas del $\mathrm{Ca}^{2+}$ reticular (trazos negros) y citosólico (trazos rojos) de tres astrocitos individuales de un cultivo primario realizado a partir de ratones transgénicos de la línea erGAP3. Las medidas se realizaron como en la Figura 55A. Los astrocitos se perfundieron con un medio sin $\mathrm{Ca}^{2+}$ (EGTA, $0.5 \mathrm{mM}$ ) durante 6 minutos y después se repuso el $\mathrm{Ca}^{2+} 1 \mathrm{mM}$. Se muestran dos astrocitos que oscilan espontáneamente (A y $\mathbf{B})$. Los trazados representan las medidas simultáneas de la $\left[\mathrm{Ca}^{2+}\right]_{\mathrm{RE}}$ con erGAP3 (en negro) y la $\left[\mathrm{Ca}^{2+}\right]_{\mathrm{C}}$ con Rhod-2 (en rojo). C. Ejemplo de un astrocito en el cual se producen liberaciones de $\mathrm{Ca}^{2+}$ del $\mathrm{RE}$ e incrementos en el $\mathrm{Ca}^{2+}$ citosólico en ausencia de $\mathrm{Ca}^{2+}$ extracelular. 


\subsubsection{Oscilaciones inducidas}

\section{Oscilaciones inducidas por bajo $\mathrm{K}^{+}$}

Para desencadenar las oscilaciones se emplearon diversos protocolos con estímulos ionotrópicos que aumentan la entrada de $\mathrm{Ca}^{2+}$ extracelular. En primer lugar, se estimuló la entrada de $\mathrm{Ca}^{2+}$ disminuyendo el $\mathrm{K}^{+}$extracelular. Este procedimiento se basa en que al disminuir la concentración de $\mathrm{K}^{+}$aumenta la permeabilidad aparente para el $\mathrm{Ca}^{2+}$ de los canales de $\mathrm{K}^{+}$, lo que conlleva entrada de $\mathrm{Ca}^{2+}$ siguiendo su gradiente electroquímico (Dallwig y col., 2000). Frecuentemente, el sistema oscila y se producen picos repetitivos de $\mathrm{Ca}^{2+}$ citosólico. En efecto, al perfundir un medio externo que contiene solamente 0.2 $\mathrm{mM}$ de $\mathrm{KCl}$ (25 veces menos de lo normal) se observa un gran aumento transitorio del $\mathrm{Ca}^{2+}$ citosólico, que está asociado a una liberación del $\mathrm{Ca}^{2+}$ del RE (Fig. 58A). Tras la liberación aparecen oscilaciones sincrónicas de la $\left[\mathrm{Ca}^{2+}\right]_{\mathrm{RE}}$ y la $\left[\mathrm{Ca}^{2+}\right]_{\mathrm{C}}$ en los astrocitos, como se ilustra en una célula representativa en la Fig. 58A. En la Figura 58B se muestran las oscilaciones de la $\left[\mathrm{Ca}^{2+}\right]_{\mathrm{RE}}$ de los astrocitos presentes en el mismo campo. En muchas células las oscilaciones persisten mientras se mantiene la hipopotasemia y se detienen al retirar el estímulo. En otros astrocitos las oscilaciones continúan durante varios minutos después de retirar el estímulo. En la mayor parte de las células se produce una disminución inicial en el nivel de $\left[\mathrm{Ca}^{2+}\right]_{\mathrm{RE}}$ al perfundir con el bajo $\mathrm{K}^{+}$extracelular. Este nivel reducido de $\left[\mathrm{Ca}^{2+}\right]_{\mathrm{RE}}$ se mantiene durante las oscilaciones mientras está presente el estímulo (Fig. 58B). Como se muestra en la figura, las oscilaciones de la segunda mitad del experimento fueron visibles en el trazado promedio de las 10 células estudiadas y la frecuencia fue similar (4-6 oscilaciones durante este periodo), lo que indica que existe cierto grado de sincronización. 
A

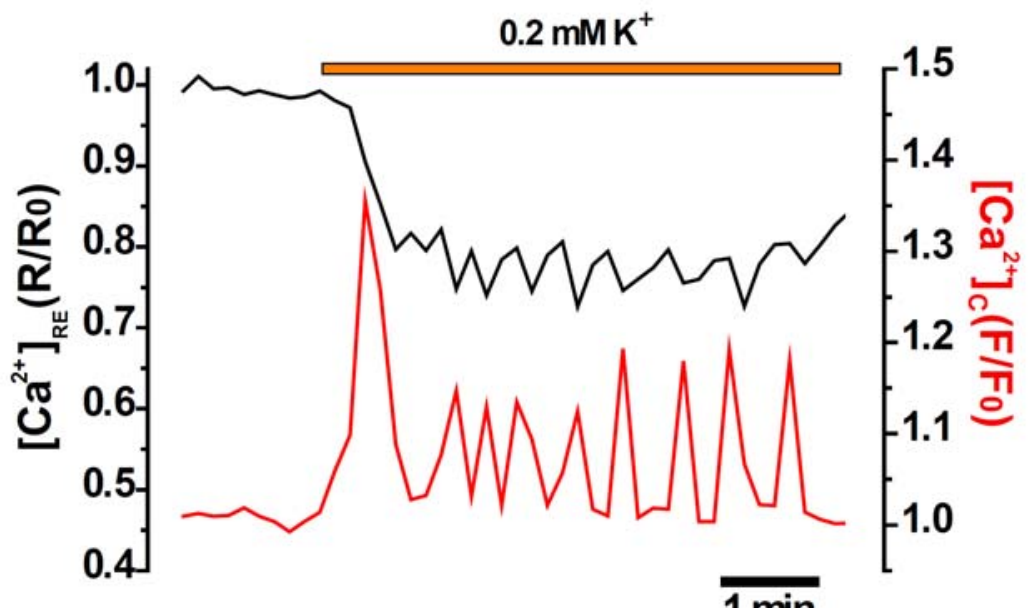

B

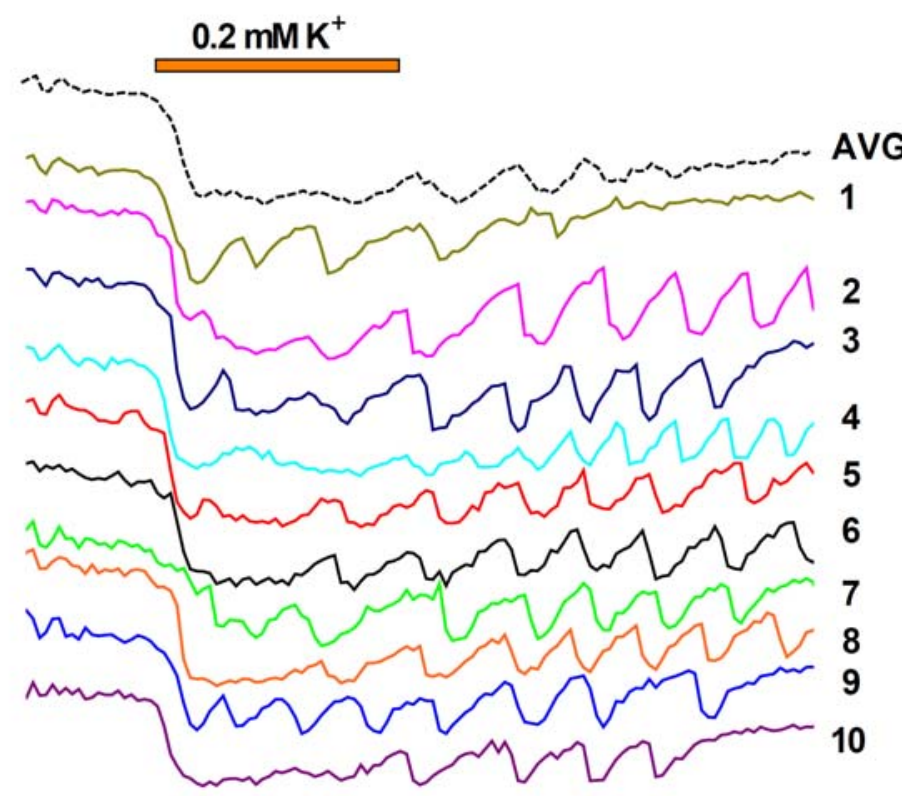

$\left[\mathrm{Ca}^{2+}\right]_{\mathrm{RE}}(\mathrm{R} / \mathrm{R} 0) 0.1$

$1 \mathrm{~min}$

Figura 58. El bajo $\mathrm{K}^{+}$provoca oscilaciones coordinadas de la $\left[\mathrm{Ca}^{2+}\right]_{\mathrm{RE}}$ y la $\left[\mathrm{Ca}^{2+}\right]_{\mathrm{C}}$ en astrocitos. A. Oscilaciones de $\mathrm{Ca}^{2+}$ inducidas por bajo $\mathrm{K}^{+}$extracelular y medidas simultáneamente en el RE y en el citosol de un astrocito procedente de la línea transgénica erGAP3 y cargado con Rhod-2. B. Comparación de las respuestas oscilatorias de la $\left[\mathrm{Ca}^{2+}\right]_{\mathrm{RE}}$, medida como R/R , de GAP3 en 10 astrocitos del campo. 


\section{Propagación intra- e inter-celular del vaciamiento del retículo endoplásmico.}

Un incremento de $\mathrm{Ca}^{2+}$ localizado puede propagarse a través de la célula sensibilizando y reclutando los canales asociados a los RyR o los $I P_{3} R$ vecinos, generando así una onda de $\mathrm{Ca}^{2+}$ citosólico. Este mecanismo de propagación de señales de $\mathrm{Ca}^{2+}$ se ha demostrado en astrocitos mediante la monitorización de la $\left[\mathrm{Ca}^{2+}\right]_{\mathrm{c}}$. Se ha descrito además la propagación la señal a células vecinas, que genera ondas intercelulares de $\mathrm{Ca}^{2+}$. En este caso lo que se propaga no es el $\mathrm{Ca}^{2+}$ sino el estado de excitación, que provoca la entrada de $\mathrm{Ca}^{2+}$ o la liberación de los depósitos intracelulares. Esta propagación intercelular se ha observado en cultivos confluentes de astrocitos tras la estimulación mecánica o química (por ejemplo con glutamato). Estas observaciones han sido confirmadas por varios grupos de investigación, aunque siempre se han estudiado registrando la $\left[\mathrm{Ca}^{2+}\right]_{c}$. En este trabajo hemos explorado las ondas de $\mathrm{Ca}^{2+}$ midiendo tanto la propagación de $\left[\mathrm{Ca}^{2+}\right]_{\mathrm{C}}$ como la de $\left[\mathrm{Ca}^{2+}\right]_{\mathrm{ER}}$ en células que expresan la sonda fluorescente erGAP3.

En la Figura 59A se muestra la imagen de fluorescencia (F470) de 4 astrocitos en la que se distinguen los vacíos que dejan los núcleos de las células (n1-n4). En la imagen siguiente se indican los contornos de las 4 células. También, se muestran las imágenes de fluorescencia de las células en estado basal (BL; $\left[\mathrm{Ca}^{2+}\right]_{\mathrm{RE}}$, expresado como cociente $\mathrm{R}_{470 / 405}$ ) y tras 30 segundos de estimulación máxima con ATP. La estimulación con el agonista provoca un vaciamiento prácticamente completo del RE, que se evidencia por el cambio del pseudocolor a azul. Al lavar el ATP el RE tardó en rellenarse alrededor de unos 3 minutos (gráfica en parte $B$ ). Las células se incubaron entonces con baja concentración de $\mathrm{K}^{+}(0.2 \mathrm{mM})$ durante 5 minutos. Este tratamiento provoca, como ya se mostró en la Figura 58, oscilaciones citosólicas y reticulares, cuyo curso temporal se muestra en la Figura 59B. 


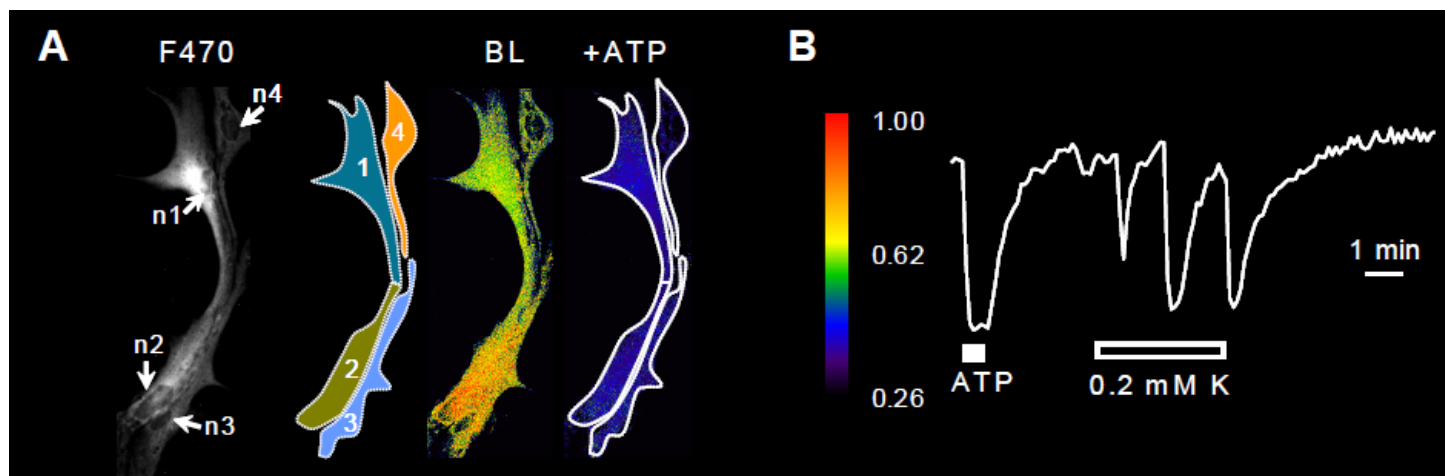

C

Oscilación \#1. Imágenes 1-14 (90 s)

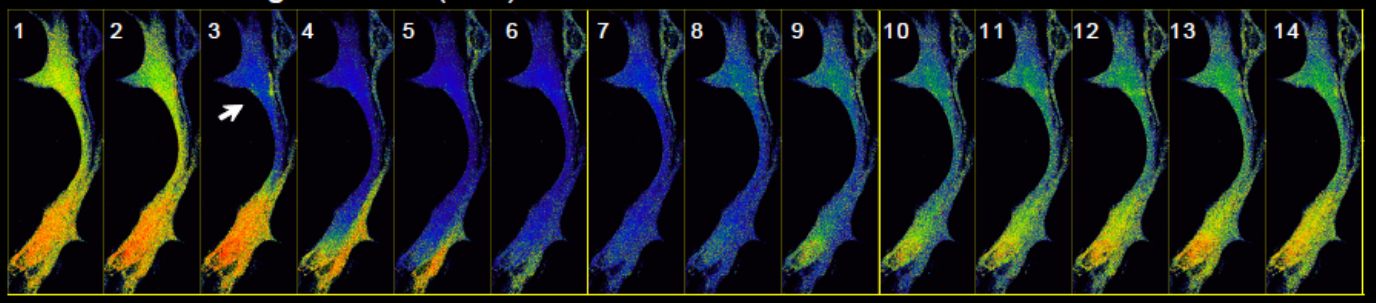

Oscilación \#2. Imágenes 15-28 (90 s)

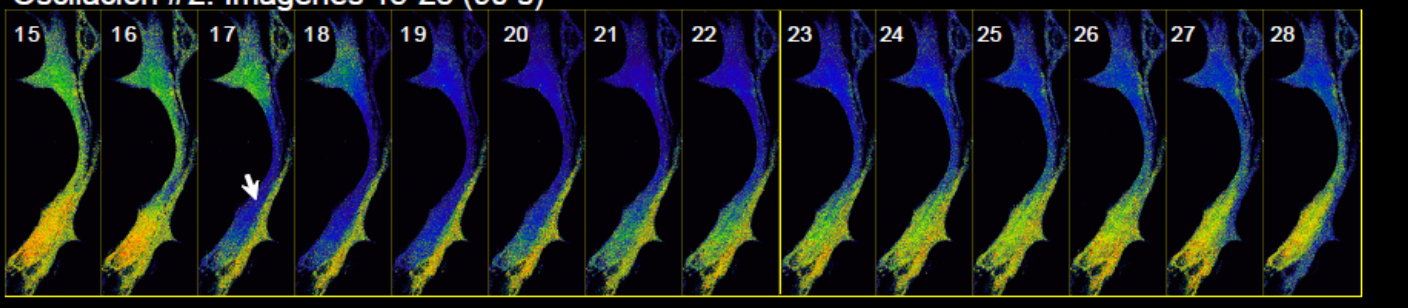

Figura 59. La progresión de una onda intercelular de vaciamiento del RE en un cultivo de astrocitos. Se muestran ondas de la $\left[\mathrm{Ca}^{2+}\right]_{\mathrm{RE}}$ inducidas por la perfusión de un medio con bajo $\mathrm{K}^{+}(0.2 \mathrm{mM})$ en astrocitos cultivados en monocapa que expresaban erGAP3. Se observan 4 núcleos (n1-n4) de cada uno de los 4 astrocitos (1-4) delimitados con líneas de puntos. A. Se muestra una imagen en escala de grises de la fluorescencia a $470 \mathrm{~nm}$ de GAP3 dirigida al RE. Se muestra la imagen del cociente de fluorescencia en pseudocolor, además de la respuesta máxima con $(100 \mu \mathrm{M})$. B. Escala de pseudocolor y el trazo de la célula 2. C. Se muestra una serie de 28 imágenes correspondientes a las dos primeras oscilaciones a una frecuencia de adquisición de una imagen cada 10 segundos. La $\left[\mathrm{Ca}^{2+}\right]_{\mathrm{RE}}$ comienza a disminuir en la célula 1 (imagen 3; punta de la flecha), progresa hacia la célula 2 (imagen 4) e invade la célula 3 (imágenes 5 y 6 ). En la imagen 8 comienza el rellenado del RE. En la imagen 17 se inicia la segunda onda de vaciamiento de $\mathrm{Ca}^{2+}$ reticular. Notar que la célula 4 oscila de manera independiente.

En la serie de imágenes de la Figura 59C se puede observar como la liberación de $\mathrm{Ca}^{2+}$ invade el soma completo de las diferentes células, saltando de a otra. El vaciamiento total se completa en la imagen 8, empezando luego un rellenado progresivo que se completa en la imagen 14. El descenso de 
$\left[\mathrm{Ca}^{2+}\right]_{\mathrm{RE}}$ en esta oscilación \#1 comienza en la célula 1 (imagen 3, punta de flecha) y se extiende invadiendo completamente dicha célula (color azul, imagen 3). El vaciamiento reticular "salta" hacia la célula 2, (imagen 4), viaja a lo largo de esa célula hasta que alcanza la célula 3, (imagen 5) cuyo RE también se vacía (imágenes 6 y 7). En la imagen 8 comienza el rellenado del $\mathrm{RE}$ en todas las células, hasta alcanzar su nivel basal anterior al vaciamiento (imagen 16). En la imagen 17 se inicia una segunda oscilación de $\left[\mathrm{Ca}^{2+}\right]_{\mathrm{RE}}$. El vaciamiento comienza esta vez en la célula 2 (imagen 17; flecha) y progresa hacia la 1 (imágenes 18 y 19), sin invadir esta vez la célula 3 (imágenes 21-27). Según nuestra información, esta es la primera vez que se registran ondas del $\mathrm{Ca}^{2+}$ reticular intra- e intercelulares.

Nuestros resultados sugieren que las oscilaciones del $\mathrm{Ca}^{2+}$ del $\mathrm{RE}$ pueden ser inducidas por la entrada de $\mathrm{Ca}^{2+}$ a través de la membrana plasmática, que desencadenaría, a su vez, liberación de $\mathrm{Ca}^{2+}$ desde el RE por el mecanismo de $\mathrm{CICR}$. Las oscilaciones de la $\left[\mathrm{Ca}^{2+}\right]_{\mathrm{RE}}$ y la $\left[\mathrm{Ca}^{2+}\right]_{\mathrm{C}}$ continúan mientras la entrada de calcio permanezca activada por el bajo $\mathrm{K}^{+}$.

Respecto a la propagación de célula a célula, la secuencia temporal sugiere que sucede, aunque con cierta variabilidad, como demuestra el diferente orden de reclutamiento celular en las oscilaciones \#1 y \#2 (Fig. 59C). La Figura 60 compara el curso temporal en distintas células próximas (ver localizaciones en la parte A de la Figura). La liberación inducida por ATP es, sincrónica en todas las células, pero en las oscilaciones también existe cierto grado de sincronía, lo que sugiere que hay mecanismos que transmiten la excitación de una célula a las vecinas. Esta sincronía es, no obstante, imperfecta. En la Figura 60B se muestra la primera descarga del RE en los astrocitos estimulados con bajo $\mathrm{K}^{+}$. Se observa el desfase temporal que se produce al propagarse la onda de liberación de $\mathrm{Ca}^{2+}$ entre las células 1-3 y finalmente a la 8 . La liberación de $\mathrm{Ca}^{2+}$ del $\mathrm{RE}$ parece originarse en la célula 1 y propagarse al resto en la oscilación de la Figura 60B. 

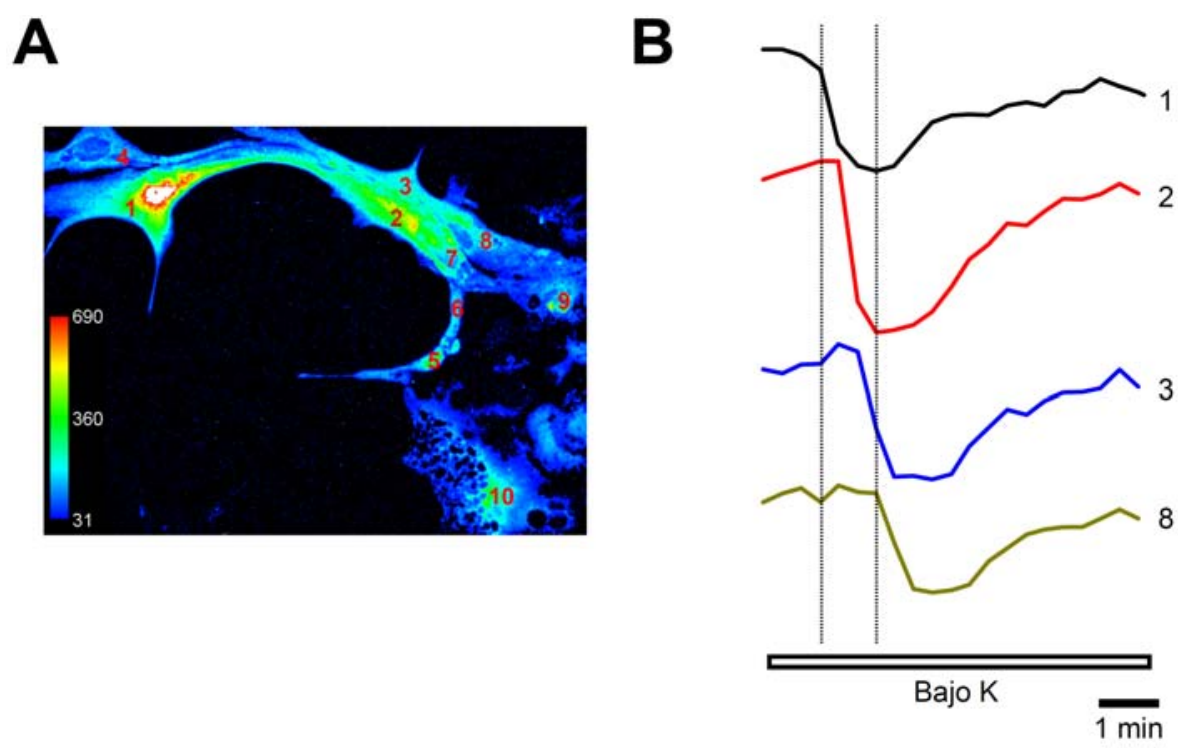

Figura 60. Propagación de la liberación de $\mathrm{Ca}^{2+}$ del $\mathrm{RE}$ de astrocitos vecinos. Corresponde al mismo experimento mostrado en la Fig. 59. Las regiones de interés se definieron en diferentes células como se muestra en la imagen de pseudocolor, que es la media de todas las imágenes del experimento completo. Ordenada: $R_{470 / 405} / R_{0}$ en unidades arbitrarias. Los trazos corresponden a los astrocitos individuales marcados. Nótese como se encuentra desplazada en el tiempo la liberación del RE en diferentes células estimuladas con bajo $\mathrm{K}^{+}(0.2 \mathrm{mM})$.

\section{Oscilaciones inducidas por glutamato y por cafeína}

Otros receptores expresados por los astrocitos son los de glutamato, tanto los ionotrópicos (AMPA, NMDA y KA) como los metabotrópicos (mGlu 1 y 5). La Figura 61 muestra como la estimulación con glutamato genera oscilaciones en astrocitos en cultivo primario. Se muestran ejemplos representativos de la $\left[\mathrm{Ca}^{2+}\right]_{\mathrm{RE}}$ y la $\left[\mathrm{Ca}^{2+}\right]_{\mathrm{C}}$ de células estimuladas con glutamato $(20$ o $100 \mu \mathrm{M}, 3-5$ minutos). En el $31 \%$ de las células ( $n=20$ de 64) se desencadenaron oscilaciones en la $\left[\mathrm{Ca}^{2+}\right]_{\mathrm{RE}}$ y la $\left[\mathrm{Ca}^{2+}\right]_{\mathrm{C}}$, que se detuvieron al lavar el estímulo (Fig. 61A y B). En algunos astrocitos que ya estaban oscilando, el agonista produjo una liberación del $\mathrm{Ca}^{2+}$ del $\mathrm{RE}$ que se correlacionó con un gran pico citosólico, y la $\left[\mathrm{Ca}^{2+}\right]_{\mathrm{RE}}$ se estabilizó en un nuevo nivel basal más bajo que el inicial en presencia del estímulo, dando como resultado oscilaciones de mucha menor amplitud pero de mayor frecuencia. 
A

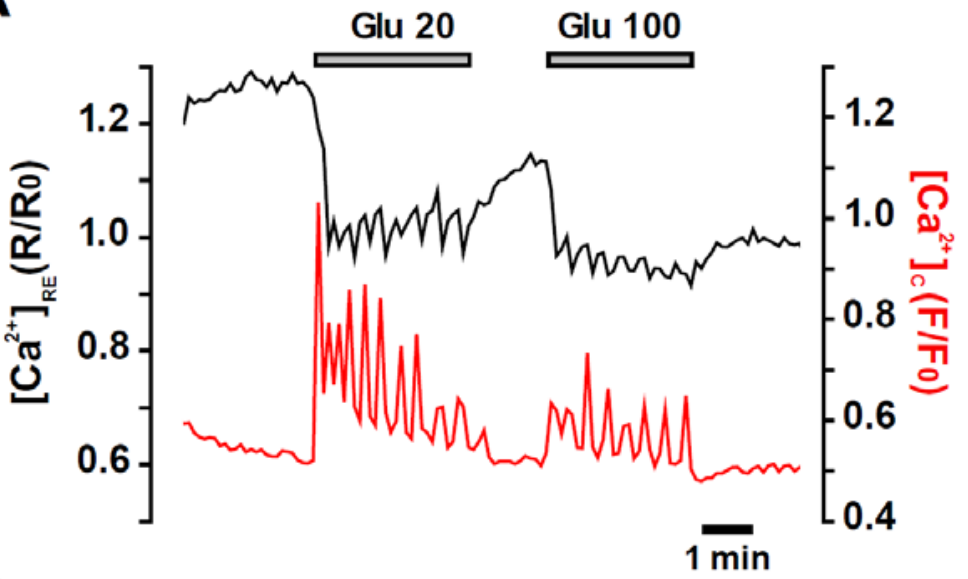

$\mathbf{B}$

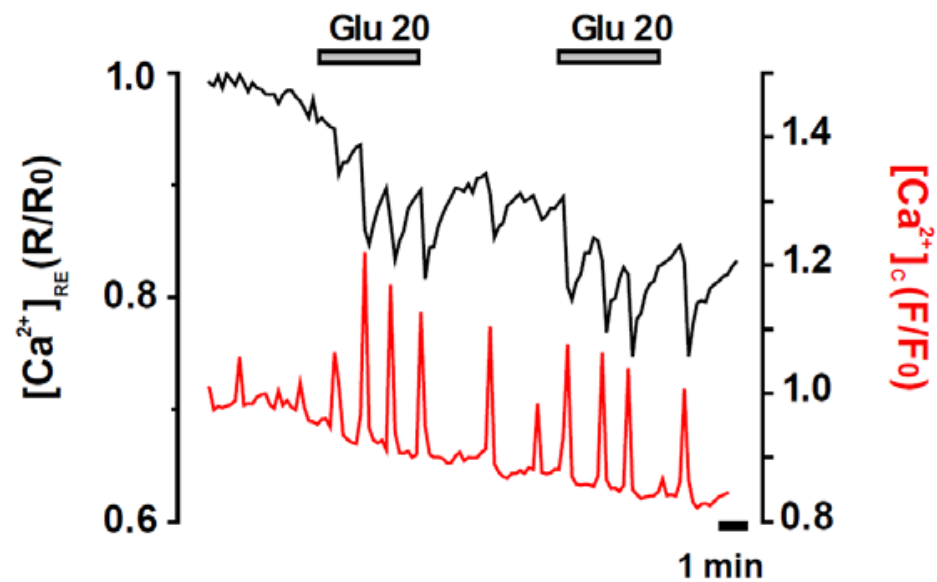

C

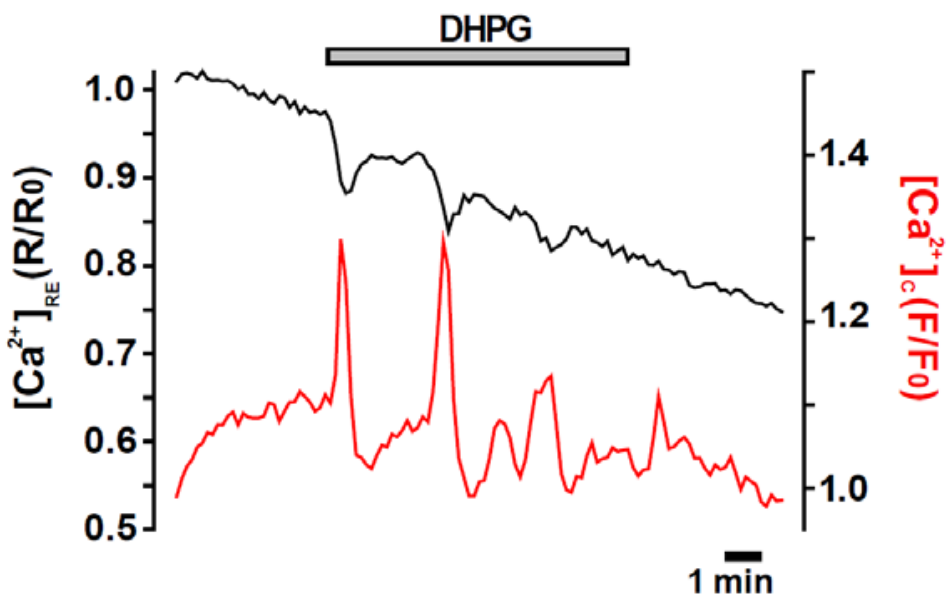

Figura 61. El glutamato induce oscilaciones coordinadas de la $\left[\mathrm{Ca}^{2+}\right]_{\mathrm{RE}}$ y la $\left[\mathrm{Ca}^{2+}\right]_{c}$ en astocitos primarios. Los trazados representan la dinámica de la $\left[\mathrm{Ca}^{2+}\right]_{R E} \mathrm{y}$ la $\left[\mathrm{Ca}^{2+}\right]_{c}$ de astocitos primarios medidas con erGAP3 y Rhod-2 que muestran diferentes comportamientos al estimularlos con glutamato (20 o $100 \mu \mathrm{M})$. Los cultivos celulares y las medidas se realizaron como en la Figura 55A. A-B. Respuestas representativas de 2 astrocitos estimuladas con glutamato. D. Efecto del agonista de receptores metabotrópicos de glutamato DHPG $(20 \mu \mathrm{M})$. 
Las dos concentraciones de glutamato utilizadas $(20 \circ 100 \mu \mathrm{M})$ tuvieron efecto máximo. Como el glutamato activa tanto receptores ionotrópicos como metabotrópicos, no se puede saber a partir del experimento de la Figura 61 cuales son los receptores implicados, por ello utilizamos como estímulo el DHPG, agonista selectivo de receptores metabotrópicos acoplados a la cascada del $\mathrm{IP}_{3}$. Este agonista también produjo oscilaciones simultáneas en el RE y en el citosol, aunque mucho menos frecuentes que las inducidas por el glutamato (Fig. 61C).

Otro agonista probado fue la cafeína, agonista del RyR, para la que se ha descrito previamente que provoca oscilaciones citosólicas en astrocitos (Tashiro y col., 2002). En la Figura 62 se muestran los registros individuales superpuestos del $\mathrm{Ca}^{2+}$ citosólico de 3 astrocitos de un mismo campo medidos con Fura-2. Tanto la amplitud como las frecuencias de las oscilaciones aumentaron con la concentración de cafeína en un rango de 5 a $50 \mathrm{mM}$. Estos resultados indican que las oscilaciones observadas pueden, además de activarse por $\mathrm{IP}_{3}$, ser secundarias a la activación de RyR. 


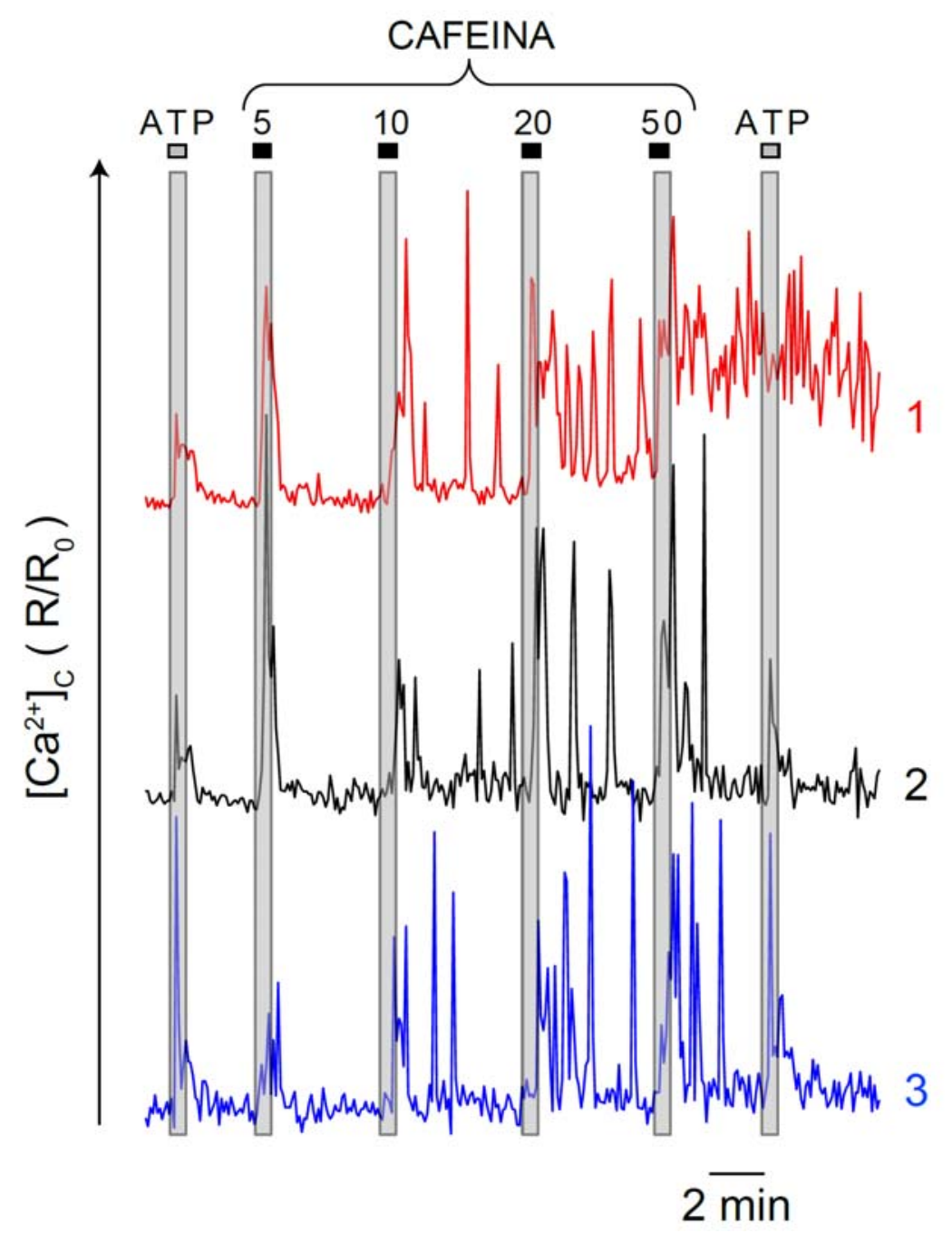

Figura 62. Oscilaciones del calcio citosólico inducidas por cafeína en astrocitos en cultivo primario. Medidas de la $\left[\mathrm{Ca}^{2+}\right]_{\mathrm{c}}$ en astrocitos cultivados en monocapa cargados con Fura- 2 y estimulados con concentraciones crecientes de cafeína $(5,10$, 20 y $50 \mathrm{mM})$ o ATP $(100 \mu \mathrm{M})$. Las medidas se representan como $R / R_{0}$, otros detalles como en la Figuras 37 . Se han superpuesto los registros de la $\left[\mathrm{Ca}^{2+}\right]_{\mathrm{C}}$ de tres astrocitos individuales.

\subsection{Oscilaciones de $\mathrm{Ca}^{2+}$ de los astrocitos en cultivos organotípicos}

Por último, quisimos confirmar la presencia de oscilaciones en los astrocitos de un cultivo organotípico de corteza de cerebro de ratón, un modelo más cercano al fisiológico (Fig. 63). Los resultados obtenidos confirmaron la existencia de oscilaciones de $\mathrm{Ca}^{2+}$ en el RE inducidas por el ATP y la cafeína (Fig. 63). El ATP a una concentración máxima (100 $\mu \mathrm{M}, 30$ segundos), provocó una gran liberación de $\mathrm{Ca}^{2+}$ del $\mathrm{RE}$, similar a la encontrada en astrocitos en monocapa. A continuación, se perfundió ATP a una dosis baja $(5 \mu \mathrm{M})$ durante 
6 minutos, lo que provocó un rellenado parcial y relativamente lento del RE durante el cual se observó la aparición de oscilaciones (Fig. 63A).
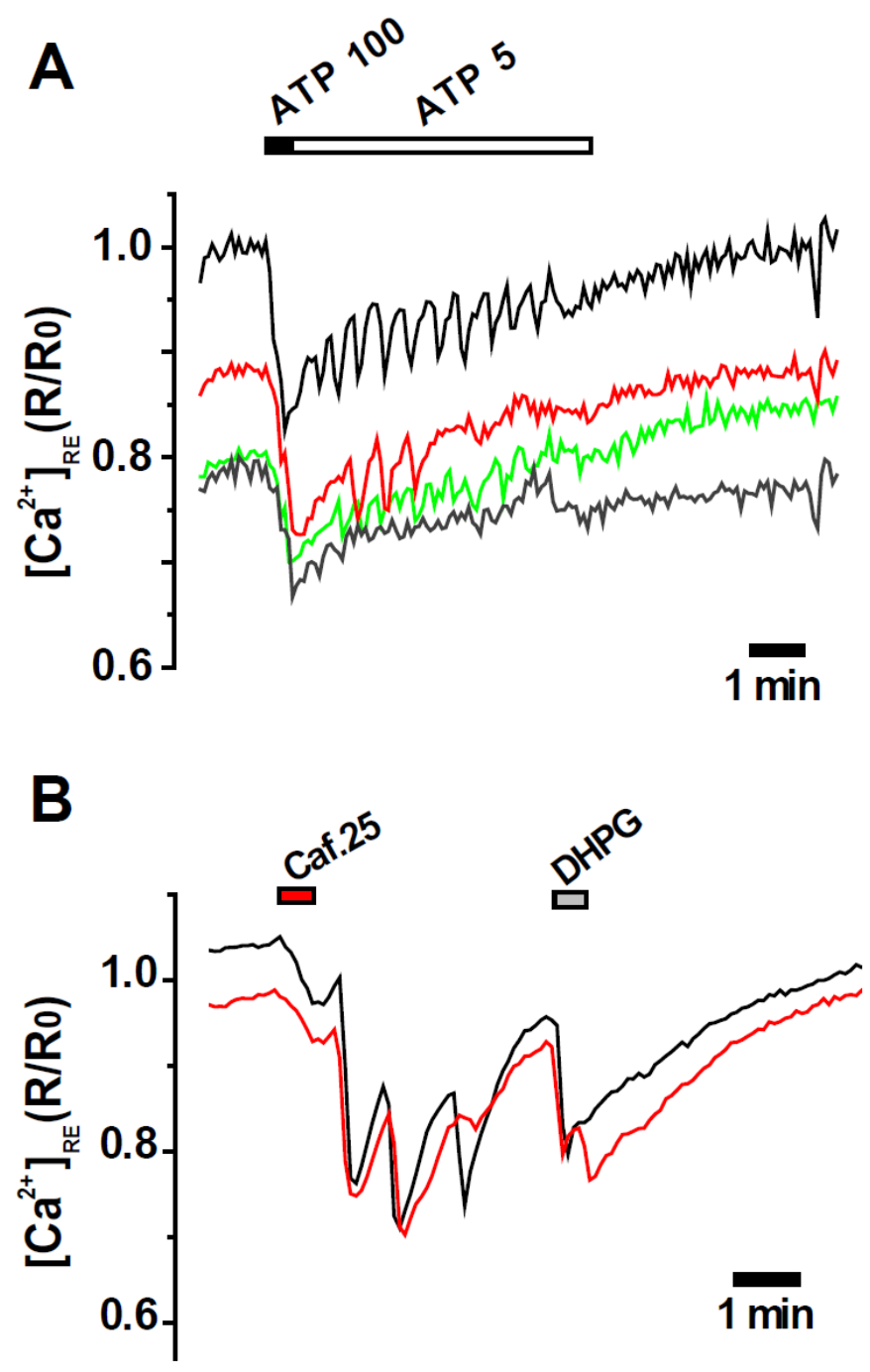

Figura 63. Oscilaciones de la $\left[\mathrm{Ca}^{2+}\right]_{\mathrm{RE}}$ en astrocitos de secciones de corteza cerebral. El indicador erGAP3 se expresó específicamente en astrocitos de corteza cerebral de ratones neonatos mediante la infección con AAV-GFAP-erGAP3. Otros detalles como en la Figuras 53. A. Los trazados muestran la dinámica de la $\left[\mathrm{Ca}^{2+}\right]_{R E}$ de cuatro astrocitos individuales de una sección de corteza tras la estimulación con un pulso máximo de ATP (100 $\mu \mathrm{M}, 30$ segundos) y seguido de ATP $(5 \mu \mathrm{M}, 4$ minutos). B. Los trazados muestran la dinámica de la $\left[\mathrm{Ca}^{2+}\right]_{\mathrm{RE}}$ de dos astrocitos individuales de una sección de corteza estimulados con cafeína ( $25 \mathrm{mM}, 30$ segundos). 
La cafeína ( $25 \mathrm{mM}, 30$ segundos) provocó una pequeña liberación del $\mathrm{Ca}^{2+}$ reticular, pero esto fue suficiente para desencadenar oscilaciones reticulares, que aparecen después de haber lavado la cafeína. (Fig. 63B). Esto concuerda con los resultados obtenidos con Fura-2 en los cultivos en monocapa.

Considerados globalmente, los resultados de esta sección indican que las oscilaciones citosólicas son consecuencia casi siempre de las oscilaciones del $\mathrm{Ca}^{2+}$ reticular. El desencadenante es la liberación rápida y parcial del $\mathrm{Ca}^{2+}$ reticular que puede retroalimentarse por la entrada de $\mathrm{Ca}^{2+}$ desde el medio extracelular. El mecanismo de las oscilaciones es incierto. Las oscilaciones del $\mathrm{Ca}^{2+}$ del RE pueden ser inducidas por CICR, desencadenado, a su vez, por el $\mathrm{Ca}^{2+}$ que entra a través de la membrana plasmática. Parece, finalmente, que la propia disminución de la concentración de calcio del RE conduce a la inhibición de la liberación de calcio luminal, un mecanismo que hemos estudiado en detalle en las células cromafines (Alonso y col., 1999), Por el contrario, al captarse el calcio y rellenarse el RE se produce nuevamente la activación del CICR liberando el $\mathrm{Ca}^{2+}$ del RE. 

Discusión 



\section{Desarrollo de un nuevo sensor de $\mathrm{Ca}^{2+}$ para medir la $\left[\mathrm{Ca}^{2+}\right]_{\mathrm{RE}}$}

La aequorina fue el primer indicador de calcio utilizado para medidas en células vivas. En un principio, las medidas pioneras de $\mathrm{Ca}^{2+}$ se llevaron a cabo en células de gran tamaño, inyectando la holoaequorina purificada (Baker y col., 1971). A partir del clonaje del gen (Inouye y col., 1985; Prasher y col., 1985) comenzó a utilizarse la proteína recombinante, expresándola en diferentes tipos celulares y organismos. Además, la aequorina recombinante puede dirigirse a orgánulos como la mitocondria o el RE (Kendall y col., 1992; Rizzuto y col., 1992; Montero y col., 1995). La proteína se aisló originalmente de la medusa Aequorea victoria (Shimomura y col., 1962), donde se encuentra asociada a la proteína fluorescente verde, GFP, en los órganos de la luz. La aequorina transfiere energía de resonancia de bioluminiscencia (BRET) a la GFP y se produce la emisión de luz verde dependiente de la concentración de $\mathrm{Ca}^{2+}$. Emulando la reacción que se produce en la medusa, se han desarrollado diferentes fusiones de la aequorina con otras proteínas fluorescentes de longitudes de onda mayores (Baubet y col., 2000; Manjarres y col., 2008; Bakayan y col., 2011). La fusión de aequorina con proteínas fluorescentes tiene varias ventajas sobre la aequorina sola: mejora su estabilidad, incrementa la emisión de luz total y, permite seguir la localización de la aequorina y su nivel de expresión gracias a la proteína trazadora fluorescente.

Tradicionalmente, los indicadores de $\mathrm{Ca}^{2+}$ codificados genéticamente (GECI) se clasifican en dos tipos principales: los indicadores fluorescentes, basados en la fusión de una variante de proteína fluorescente con una proteína de unión a $\mathrm{Ca}^{2+}$ como la calmodulina o la troponina; y los bioluminiscentes, la mayoría, basados en la proteína aequorina o sus derivados (Clapham, 2007a; Palmer y col., 2011). Recientemente hemos descrito la familia de los indicadores de $\mathrm{Ca}^{2+}$ GAP (GFP-Aequorin-Protein), basados en la fusión de la aequorina a una GFP determinada (GFPuv). Una variante de baja afinidad, denominada GAP1, se diseñó para medir $\mathrm{Ca}^{2+}$ en célula única mediante imagen de fluorescencia en los orgánulos de alto contenido de $\mathrm{Ca}^{2+}$ (Rodriguez-Garcia y col., 2014). En esta Tesis hemos desarrollado el sensor GAP1 en modo bioluminiscente. Para ello, la aequorina de GAP se reconstituyó 
con el cofactor coelenterazina y se dirigió a orgánulos de alto $\mathrm{Ca}^{2+}$ como el RE (Fig. 28) o el aparato de Golgi. Esta característica bifuncional, fluorescencia y bioluminiscencia, hace de GAP un sensor único, y ventajoso en ciertas situaciones. Por ejemplo, podemos combinar ambos tipos de mediciones utilizando el mismo cultivo: la señal promedio de todas las células, obtenida a partir de poblaciones celulares en el modo luminiscente; y, la señal de célula única medida en el modo fluorescente por análisis de imagen. Las señales de luminescencia son particularmente apropiadas en preparaciones con alta autofluorescencia, mejorando la relación total de señal/ruido. A este respecto, erGAP1 proporciona una valiosa herramienta para realizar ensayos bioluminiscentes de alto rendimiento. Estos ensayos, actualmente en preparación, permitirán que permita estudiar diferentes aspectos de la dinámica de $\mathrm{Ca}^{2+}$ en el RE (por ejemplo, la captación del $\mathrm{Ca}^{2+}$ a través de la bomba SERCA, la liberación de $\mathrm{Ca}^{2+}$ a través de canales intracelulares o el leak de $\left(a^{2+}\right)$.

A diferencia de la GFP-aequorina (GA) utilizada anteriormente, que porta la sustitución D119A, la GAP1 contiene otras dos mutaciones adicionales, D117A y D163A, en la segunda y tercera manos EF de la aequorina, respectivamente (Rodriguez-Garcia y col., 2014). Además, con el objetivo de disminuir aún más la afinidad por $\mathrm{Ca}^{2+}$, la aequorina se reconstituyó con la coelenterazina $\mathrm{n}$, un análogo sintético de la coelenterazina que reduce la afinidad de la aequorina por $\mathrm{Ca}^{2+}$ en alrededor de un orden de magnitud (Barrero y col., 1997). La combinación de ambos efectos dio como resultado una disminución de la afinidad por $\mathrm{Ca}^{2+}$ de unas 10 veces respecto a GA. Por otro lado, el consumo de GAP1 es mucho más lento, lo que permite realizar experimentos más largos que con la sonda GA, pudiendo extenderse hasta los 60 minutos (Fig. 28). La sonda GAP1 dirigida al RE (IgGAP1) permitió realizar medidas de la $\left[\mathrm{Ca}^{2+}\right]_{\mathrm{RE}}$ por luminiscencia, y determinar el nivel de reposo de diferentes tipos de células, como líneas celulares inmortalizadas HeLa, HEK, $\mathrm{CHO}$ (Fig. 30), o en cultivos neuronales primarios (Tabla 8). Se obtuvieron valores basales de la $\left[\mathrm{Ca}^{2+}\right]_{\mathrm{RE}}$ de entre 400 y $600 \mu \mathrm{M}$, valores comparables a los previamente medidos con aequorinas (Alonso y col., 1998), con erGA (Chamero y col., 2008), o con otras proteínas de fusión (Manjarres y col., 
2008). Como consecuencia de la disminución del consumo, la señal luminal basal se mantiene estable a lo largo del experimento y los estímulos repetidos sucesivos producen efectos mucho más reproductibles que con la sonda anterior GA (Fig. 28). Recientemente se ha descrito otro sensor fluorescente llamado CEPIA (C alcium - measuring organelle entrapped protein indicator), cuya versión de baja afinidad, el GEM-CEPIA1 se expresó el RE (Suzuki y col., 2014). Los valores que se estimaron estaban entre 620-860 $\mu \mathrm{M}$, ligeramente mayores a los obtenidos en este trabajo.

En esta Tesis nos hemos centrado en las medidas de la $\left[\mathrm{Ca}^{2+}\right]$ en el RE, aunque GAP1 también puede expresarse en el aparato de Golgi y registrar los cambios de $\mathrm{Ca}^{2+}$ tras aplicar estímulos que producen $\mathrm{IP}_{3}$. Esta vez hemos dirigido GAP1 al transGolgi y nuestros resultados concuerdan con los obtenidos previamente en nuestro laboratorio usando otra sonda basada en la fusión GA (Aulestia y col., 2011).

Recientemente se ha descrito otra aequorina de baja afinidad (de la Fuente y col., 2012; de la Fuente y col., 2013), que contiene las mutaciones N28L y D119A. Su afinidad por $\mathrm{Ca}^{2+}$ es un orden de magnitud menor que GAP1, y esto permite hacer medidas de $\mathrm{Ca}^{2+}$ sin necesidad de vaciar previamente los depósitos de alto $\mathrm{Ca}^{2+}$. Esta propiedad puede resultar muy ventajosa en células o en compartimentos que no se vacían fácilmente o en tipos celulares sensibles a las condiciones experimentales de vaciamiento. Nosotros también hemos probado a hacer medidas con erGAP1 sin vaciar de los depósitos, y comprobamos que era factible realizarlas, aunque el rendimiento total de cuentas era de un orden de magnitud menor, lo que disminuía la relación señal/ruido. Por esta razón, todos los experimentos mostrados en esta Tesis se realizaron vaciando previamente el RE y reconstituyendo la aequorina de GAP1 con celenterazina $n$. 


\section{Desarrollo de nuevas herramientas selectivas para estudiar la señal de $\mathrm{Ca}^{2+}$ en astrocitos}

Cada astrocito del sistema nervioso central es capaz de recibir información de varias miles de sinapsis procedentes de distintos circuitos, y procesarlas con distintas escalas espaciotemporales. ¿Cómo puede el astrocito decodificar esa ingente cantidad de información y convertirla en señales de $\mathrm{Ca}^{2+}$ que informen del estado de la célula y su entorno? Estudios recientes han puesto de manifiesto que las señales de $\mathrm{Ca}^{2+}$ pueden ocurrir de forma independiente, tanto espacial como temporalmente, en distintas regiones del astrocito. Concretamente, se ha demostrado que los procesos más finos presentan picos de $\mathrm{Ca}^{2+}$ espontáneos e independientes de las señales del soma (Haustein y col., 2014; Kanemaru y col., 2014). Esto ha provocado una revisión completa del campo de la señalización por $\mathrm{Ca}^{2+}$ en la glía, y actualmente se está cuestionando la visión parcial y quizás demasiado simplista de la señal de $\mathrm{Ca}^{2+}$ registrada hasta ahora en astroglía (Volterra y col., 2014). Esto es debido a la extraordinaria complejidad de este tipo celular in situ y a la limitación de las técnicas para monitorizar el $\mathrm{Ca}^{2+}$ disponibles hasta la fecha. Se hace necesario, por tanto, desarrollar nuevas técnicas que proporcionen una información más precisa y completa de la señalización por $\mathrm{Ca}^{2+}$ en los astrocitos. En este sentido, esta Tesis aporta nuevas herramientas que son específicas para astrocitos y que redundarán en una mejor comprensión de la función del $\mathrm{Ca}^{2+}$ en estas células.

La excitabilidad glíal se basa fundamentalmente en los flujos de $\mathrm{Ca}^{2+}$ a través de la membrana de las organelas subcelulares y a la generación de señales de $\mathrm{Ca}^{2+}$ procedente de los depósitos intracelulares. En los astrocitos, como en el resto de células animales, el RE ocupa la mayor parte del citoplasma, extendiéndose desde el soma hasta los finos procesos y constituye la principal organela de reserva de $\mathrm{Ca}^{2+}$. Numerosos experimentos in vitro, in situ e in vivo han demostrado la expresión de una enorme variedad de receptores metabotrópicos en los astrocitos. Cuando se activan fisiológicamente, desencadenan la producción de $\mathrm{IP}_{3}$ y la consecuente liberación de $\mathrm{Ca}^{2+}$ dependiente de $\mathrm{IP}_{3}$ (Verkhratsky, 2013). 
En la mayoría de los casos, la monitorización de $\mathrm{Ca}^{2+}$ citosólico sólo refleja vagamente los cambios espacio temporales que se producen en el RE, $y$, aunque tengan su origen en dicho orgánulo, no puede sustituir los cambios de $\mathrm{Ca}^{2+}$ luminal. Para descifrar las señales de $\mathrm{Ca}^{2+}$ procedentes del interior del $\mathrm{RE}$ es esencial registrar directamente el $\mathrm{Ca}^{2+}$ reticular. Hay una extensa bibliografía sobre distintos aspectos del $\mathrm{Ca}^{2+}$ en astrocitos. En realidad, bajo las entradas "astrocyte and calcium" aparecen 4492 citas, sin embargo, la inmensa mayoría analizan únicamente el $\mathrm{Ca}^{2+}$ citosólico.

En este trabajo se ha investigado la dinámica del $\mathrm{Ca}^{2+}$ de astrocitos $\mathrm{y}$, con este fin, se han generado una serie de herramientas, algunas específicas para este tipo celular, que se enumeran a continuación. En primer lugar, se utilizó la sonda bioluminiscente IgGAP1 (descrita en el apartado anterior) para medir la $\left[\mathrm{Ca}^{2+}\right]_{\mathrm{RE}}$ por bioluminiscencia en astrocitos en cultivo. En segundo lugar, se midió la $\left[\mathrm{Ca}^{2+}\right]_{\mathrm{RE}}$ en astrocitos in situ mediante la sonda de $\mathrm{Ca}^{2+}$ fluorescente dirigida al RE erGAP3 (Navas-Navarro y col., 2016). Este indicador se expresó específicamente en astrocitos infectando cortes de cerebro de ratón con vectores derivados de virus adenoasociados y que expresaban erGAP3 bajo el promotor específico GFAP, que garantiza niveles altos de expresión en astrocitos (Brenner y col., 1994). En tercer lugar, se desarrolló la metodología para medir simultáneamente las concentraciones de $\mathrm{Ca}^{2+}$ en el RE y en el citosol de astrocitos con erGAP3 y Rhod-2, respectivamente (Fig. 51), aprovechando una ventaja de los indicadores de $\mathrm{Ca}^{2+}$ codificados genéticamente, que pueden combinarse con los colorantes de $\mathrm{Ca}^{2+}$ sintéticos. Se eligió la familia de los Rhod (Rhod 2 y 3) por su afinidad (Kd=570 nM a 22 ${ }^{\circ} \mathrm{C}$ ), adecuada para registrar el $\left[\mathrm{Ca}^{2+}\right]_{\mathrm{C}}$; por presentar fluorescencia roja, compatible con la verde que emiten los GAPs; y, porque en los cultivos neurales mixtos el Rhod se carga preferentemente en los astrocitos. Por último, para abordar el estudio de señales de $\mathrm{Ca}^{2+}$ más complejas, como son las oscilaciones de $\mathrm{Ca}^{2+}$ reticular. Empleamos cultivos de astrocitos procedentes de ratones transgénicos para erGAP3, que expresaban altos niveles de GAP3 en el RE de la astroglía de corteza cerebral, entre otras regiones cerebrales. Este tiene una doble ventaja: por un lado, todas las células del cultivo expresan el indicador (erGAP3), lo que es esencial para estudiar la propagación de 
ondas entre células vecinas; $y$, por otro lado, no es necesario utilizar vectores virales, que nunca son completamente inócuos, especialmente en estudios finos de $\mathrm{Ca}^{2+}$ como son las oscilaciones espontáneas en astrocitos.

\section{Medidas de la $\left[\mathrm{Ca}^{2+}\right]_{\mathrm{RE}}$ en astrocitos}

Las medidas pioneras de la $\left[\mathrm{Ca}^{2+}\right]_{\mathrm{RE}}$ en astrocitos se realizaron con el indicador sintético fluorescente de baja afinidad Mag-Fura-2, (también llamado Furaptra; Kd, $\sim 50 \mu \mathrm{M}$ (Raju y col., 1989) al que siguieron otros como el MagIndo o el Mag-Fluo. Esta técnica, muy utilizada en su momento, tiene la desventaja de la falta de especificidad de la señal para el RE y de que la calibración es complicada. A pesar de sus desventajas, se consiguió registrar niveles de reposo de la [ $\left.\mathrm{Ca}^{2+}\right]_{\mathrm{RE}}$ de unos $153 \mu \mathrm{M}$ (Golovina y Blaustein, 2000). Nosotros hemos registrado con aquorinas, valores mucho más altos, de 400 $\mu \mathrm{M}$, en el mismo rango que el resto de las líneas celulares estudiadas en este trabajo (HeLa, 523; HEK, 388; CHO, 473) (Tabla 8). Los datos obtenidos a partir de cultivos puros de astrocitos fueron $(418 \mu \mathrm{M}$; Fig. 38) con la sonda IgGAP1, y (375 $\mu \mathrm{M}$; Fig. 53) con la sonda fluorescente GAP3. Estos valores están en el mismo rango que los obtenidos en astrocitos en cultivo con el indicador proteico fluorescente erCEPIA (Suzuki y col., 2014). Se ha propuesto que el contenido de $\mathrm{Ca}^{2+}$ en el RE de los astrocitos sería inferior al de neuronas (Verkhratsky, 2013). Nosotros registramos la $\left[\mathrm{Ca}^{2+}\right]_{\mathrm{RE}}$ en neuronas y astrocitos del mismo cultivo mixto de la corteza cerebral (Fig. 52). En esos experimentos, los niveles de $\mathrm{Ca}^{2+}$ luminal fueron similares en ambos tipos celulares y no muy diferentes a los obtenidos en cultivos de astrocitos puros.

Aunque todavía no se ha definido bien el perfil de expresión de los diferentes receptores de neurotransmisores expresados en las distintas regiones del cerebro, está bien demostrado que los astrocitos corticales responden a ATP, a glutamato y a acetilcolina (Verkhratsky y Kettenmann, 1996; Takata y col., 2011). En el presente estudio, realizando medidas directamente en el RE, se ha comprobado el efecto liberador de $\mathrm{Ca}^{2+}$ de estos tres agonistas. En primer lugar, confirmamos el origen metabotrópico de la señal de $\mathrm{Ca}^{2+}$ citosólica producida por el ATP, que induce una rápida descarga 
del $\mathrm{Ca}^{2+}$ luminal que prácticamente vacía el RE (Fig. 38). Esto concuerda plenamente con los resultados en el citosol, medidos con Fura-2, donde tres pulsos sucesivos de ATP en ausencia de $\mathrm{Ca}^{2+}$ externo producen picos de $\mathrm{Ca}^{2+}$ progresivamente menores hasta que el tercer pico apenas tiene efecto, señal inequívoca de vaciamiento del RE (Fig. 37). En línea con estas observaciónes, la señal citosólica prácticamente se abole en presencia de inhibidores de la SERCA (Fig. 46). Al comparar el pico citosólico provocado por el ATP en presencia y ausencia de $\mathrm{Ca}^{2+}$, se observa que el primero es algo mayor que el segundo, indicación de una pequeña contribución ionotrópica a la señal global, como se ha descrito previamente (Golovina y Blaustein, 2000). Respecto al glutamato y su agonista metabotrópico DHPG también provocaron liberación de $\mathrm{Ca}^{2+}$ desde el RE, aunque en general su efecto fue menos potente que el del ATP (Figs. 54 y 61). Por otra parte, al comparar directamente la respuesta a ATP en un mismo cultivo mixto, encontramos que tanto las neuronas como la glía responden a glutamato y a acetilcolina, mientras que sólo las glías responden al ATP, siendo éste precisamente el estímulo más potente de todos los probados en astrocitos. Similares diferencias neurona/glía se han encontrado en el cerebelo (Nunez y col., 1996) (Fig. 52).

Se ha propuesto que podrían existir distintos compartimentos en el RE de los astrocitos, y que la distribución de bombas y canales podría ser heterogénea en las distintas regiones del RE (Golovina y Blaustein, 2000). En conjunto, nuestros resultados no apoyan esta tesis, sino que más bien que todo el $\mathrm{Ca}^{2+}$ almacenado es rápidamente movilizable (Fig. 45A), y que el RE se comporta como un único reservorio de $\mathrm{Ca}^{2+}$, que es la idea generalmente aceptada en la mayor parte de las células. Sería interesante contar con sondas específicas de subregiones del RE. En esta dirección, recientemente se ha desarrollado una nueva sonda de la familia CEPIA dirigida a la cara externa del RE de astrocitos (Niwa y col., 2016). Quizás los autores pretendieran con esta nueva sonda registrar microdominios de alto $\mathrm{Ca}^{2+}$ en el lado externo del RE, pero, de hecho, los niveles de $\mathrm{Ca}^{2+}$ obtenidos fueron superponibles a los citosólicos. 


\section{Activación del mecanismo de la liberación de $\mathrm{Ca}^{2+}$ inducida por $\mathrm{Ca}^{2+}$ (CICR) en los astrocitos}

El proceso de CICR está muy estudiado en células cardiacas y se ha descrito también en neuronas (Solovyova y col., 2002) y en otras células excitables como las cromafines (Alonso y col., 1999). Sin embargo, hasta la fecha este mecanismo no se había demostrado de forma directa en astrocitos, células típicamente no excitables.

En esta Tesis hemos utilizado distintos protocolos para estimular la entrada de $\mathrm{Ca}^{2+}$ desde el medio extracelular. En primer lugar, se utilizaron pulsos despolarizantes con alta concentracion de $\mathrm{KCl}$, uno de los protocolos más utilizados en células excitables para provocar la entrada de $\mathrm{Ca}^{2+}$. En los primeros experimentos, registrando sólo el calcio citosólico, nos sorprendió encontrar que pulsos despolarizantes de $80 \mathrm{mM} \mathrm{KCl}$ provocaran incrementos transitorios del $\mathrm{Ca}^{2+}$ citosólico, similares a los picos que se registraban en neuronas (Fig. 42). Después, registrando simultáneamente el $\mathrm{Ca}^{2+}$ citosólico y el reticular, obtuvimos cambios en direcciones opuestas: con un aumento del calcio citosólico y una disminución del $\mathrm{Ca}^{2+}$ reticular, que indica liberación desde el RE (Fig. 51). Ambas respuestas, entrada y liberación, eran dependientes de la prescencia de $\mathrm{Ca}^{2+}$ extracelular, y se inhibían en presencia de bloqueantes inespecíficos de canales de $\mathrm{Ca}^{2+}$ como el níquel (Fig. 45B). Sugieren entonces nuestros resultados que existen las dos cosas, entrada de $\mathrm{Ca}^{2+}$ inducida por la despolarización con alto $\mathrm{K}^{+}$y liberación de $\mathrm{Ca}^{2+}$ del RE mediada por el mecanismo de CICR. En concordancia con estos resultados, los inhibidores de la SERCA, tapsigargina o $\mathrm{TBH}$, que provocan un vaciamiento pasivo del RE, produjeron una inhibición de un $80 \%$ del transitorio citosólico (medido con Fura-2 o con Fluo-3) (Fig. 46), sugiriendo que la mayor parte del $\mathrm{Ca}^{2+}(80 \%)$ procede de la amplificación por el RE. Además, existía una correlación entre la amplitud de la liberación del $\mathrm{Ca}^{2+}$ luminal y la entrada del $\mathrm{Ca}^{2+}$ a través de membrana, al menos en el rango de 40 a 120 mM K ${ }^{+}$(Fig. 44). Es interesante señalar que la liberación de $\mathrm{Ca}^{2+}$ a través de CICR durante el tiempo que duraban los pulsos estimulantes (30 s) fue como máximo de un $20-50 \%$ del $\mathrm{Ca}^{2+}$ almacenado en el RE. El inhibidor rianodina no produjo un 
efecto claro de inhibición sobre la respuesta al alto $\mathrm{K}^{+}$, pero estos resultados son difíciles de interpretar, pues la rianodina producía una disminución pasiva y relativamente lenta de la señal reticular. La adición del alto $\mathrm{K}^{+}$en presencia de rianodina produjo una liberación de la misma amplitud que en la situación control, pero que no se recuperó tras el lavado (Fig. 45C). Estos resultados sugieren una unión irreversible dependiente del uso de la rianodina. El RyR, se encontraría entonces parcialmente abierto en condiciones basales.

Un segundo protocolo utilizado para activar la entrada de $\mathrm{Ca}^{2+}$ desde el medio extracelular fue la reducción del $\mathrm{K}^{+}$extracelular. Esta maniobra promueve la entrada de $\mathrm{Ca}^{2+}$ a través de un canal de $\mathrm{K}^{+}$(el rectificador hacia adentro, Kir) que pierde su selectividad iónica y permite la entrada de $\mathrm{Ca}^{2+}$ (Dallwig y col., 2000). Este protocolo se ha utilizado previamente para distinguir las respuestas de astrocitos y de neuronas, ya que estas últimas no responden a bajo $\mathrm{K}^{+}$. En efecto, la reducción de la concentración de $\mathrm{KCl}$ desde $5 \mathrm{mM}$ a 0.2 $\mathrm{mM}$ provocó en los astrocitos la rápida salida desde el RE y el pico simultáneo en el citosol (Fig. 58A).

En tercer lugar, se utilizó un protocolo de eliminación y posterior reposición del $\mathrm{Ca}^{2+}$ extracelular. La readición del $\mathrm{Ca}^{2+}$, en lugar de provocar el rellenado del $\mathrm{RE}$, provoca en algunas células una rápida liberación del $\mathrm{Ca}^{2+}$ luminal con su correlativo aumento transitorio de $\mathrm{Ca}^{2+}$ citosólico (Fig. 57A y 57B). Este resultado demuestra claramente la existencia de liberación de $\mathrm{Ca}^{2+}$ inducida por $\mathrm{Ca}^{2+}$ y suele ocurrir cuando el RE no está completamente vacío tras el tratamiento con EGTA. Es interesante apreciar la disociación entre el $\mathrm{Ca}^{2+}$ reticular y citosólico en esta segunda caída del $\mathrm{Ca}^{2+}$ reticular: el $\mathrm{Ca}^{2+}$ citosólico permanece alto constantemente mientras que la luz del RE luminal se vacía y rellena de $\mathrm{Ca}^{2+}$ inmediatamente después.

En cuarto lugar, se utilizó un agonista de los RyRs, la cafeína, que actúa sensibilizando el RyR al $\mathrm{Ca}^{2+}$. Pudimos demostrar que la cafeína en el rango de decenas de milimolar, produce liberación del $\mathrm{Ca}^{2+}$ reticular en estas células (Fig. 39C), en concordancia con los picos de $\mathrm{Ca}^{2+}$ citosólicos registrados (Fig. 39A). La magnitud de la respuesta es comparable a la obtenida con alto $\mathrm{K}^{+}$, 
liberandose un 20-30\% del contenido total del $\mathrm{Ca}^{2+}$ del RE. En paralelo con estos resultados funcionales, corroboramos la expresión del mRNA del RyR tipo 3 en los astrocitos corticales de ratón (Fig. 48), en concordancia con los datos anteriores (Matyash y col., 2002). Una prueba indirecta de la implicación del RyR en el mecanismo de CICR viene dada por los efectos de la sobreexpresión del $\mathrm{RyR}_{3}$ en células HEK293. Estas células apenas responden a cafeína y la sobreexpresión produjo un notable aumento de la liberación de $\mathrm{Ca}^{2+}$ del RE (Fig. 49). Es importante recordar que la liberación del $\mathrm{Ca}^{2+}$ no solo se controla por el $\mathrm{Ca}^{2+}$ desde el lado citosólico, sino también desde el luminal (Alonso y col., 1999). Así pues, el nivel de $\mathrm{Ca}^{2+}$ en la luz del RE es determinante para que el RE actúe alternativamente como un almacén, captando más $\mathrm{Ca}^{2+}$, o como una fuente de $\mathrm{Ca}^{2+}$, liberándolo al citosol. Esto se demostró claramente en los experimentos realizados con astrocitos permeabilizados, rellenando el RE a distintos niveles de $\mathrm{Ca}^{2+}$. A las $\left[\mathrm{Ca}^{2+}\right]_{\mathrm{RE}}$ más bajas, la adición de $\mathrm{Ca}^{2+}$ provoca un rápido rellenado del $\mathrm{RE}$, mientras a las $\left[\mathrm{Ca}^{2+}\right]_{\mathrm{RE}}$ más altas, el $\mathrm{Ca}^{2+}$ provoca una liberación (Fig. 47).

En astrocitos de hipocampo se había identificado un mecanismo de CICR en respuesta a la activación colinérgica de los receptores nicotínicos (Sharma y Vijayaraghavan, 2001). Globalmente, nuestros resultados demuestran de forma inequívoca la existencia del CICR en astrocitos de la corteza cerebral, tanto en cultivo (Fig. 51), como in situ, en cultivos organotípicos de rodajas de corteza cerebral (Fig. 55). Este último resultado valida el modelo de astrocitos en cultivo, que se ha utilizado más ampliamente en este trabajo, por resultar más accesible.

\section{Posibles vías de entrada de $\mathrm{Ca}^{2+}$ en el citosol}

Los protocolos descritos en el apartado anterior para activar el CICR implican una o varias vías de entrada a través de la membrana plasmática. La primera que exploramos fue a través de los VOCCs. La presencia de los VOCCs en los astrocitos fue originalmente muy cuestionada y generó una gran controversia, pero hoy día se acepta plenamente. La primera evidencia de que los astrocitos presentan VOCCs se obtuvo mediante estudios electrofisiológicos 
en astrocitos corticales de rata en cultivo, donde se registraron picos de $\mathrm{Ca}^{2+}$ en respuesta a la inyección de corriente, usando $\mathrm{Ba}^{2+}$ como sustituto de carga (MacVicar, 1984). Más tarde, otros estudios corroboraron estos resultados registrando las corrientes de $\mathrm{Ca}^{2+}$ operadas por voltaje, tanto en astrocitos en cultivo (MacVicar y Tse, 1988; Latour y col., 2003; D'Ascenzo y col., 2004) como en los astrocitos inmaduros de rodajas de hipocampo (Akopian y col., 1996). Además, los VOCCs se han implicado en las oscilaciones espontáneas de $\mathrm{Ca}^{2+}$ en los astrocitos de rodajas del tálamo ventrobasal (Parri y Crunelli, 2003). En concordancia con estos datos funcionales, se ha identificado expresión de mRNA de todos los tipos de VOCCs ( $L, N, P / Q, R$ y $T$ ) en astrocitos en cultivo (Verkhratsky, 2013). En contraste con estos datos, existe poca evidencia de la expresión funcional de los VOCCs in vivo, y en astroglía madura aún no se han demostrado corrientes medibles de $\mathrm{Ca}^{2+}$ operadas por voltaje.

Usando el bloqueante específico de los VOCCs de tipo L furnidipina obtuvimos una inhibición parcial, de un $20 \%$ del pico citosólico de $\mathrm{Ca}^{2+}$ inducido por alto $\mathrm{K}^{+}$(Fig. 42A). Como el pico citosólico sobre todo reflejaba la amplificación debida a la liberación desde el RE (Fig. 46), decidimos realizar medidas directas de la $\left[\mathrm{Ca}^{2+}\right]_{\mathrm{RE}}$. El efecto combinado con la agatoxina IV A (bloqueante específico de los VOCCs tipo P) resultó en un máximo de $50 \%$ de inhibición (resultados no mostrados), pero en ningún caso se obtuvo una inhibición completa. De estos datos concluimos que el $\mathrm{Ca}^{2+}$ estaría entrando a través de los VOCCs de varios tipos, y adicionalmente, existirían otras vías de entrada de $\mathrm{Ca}^{2+}$. Estos resultados están en discrepancia con los obtenidos recientemente por Cheli et al. (Cheli y col., 2016), en que obtienen un $80 \%$ de inhibición del pico de alto $\mathrm{K}^{+}$con nifedipina. Quizás la dosis de $\mathrm{KCl}$ utilizada (50 $\mathrm{mM})$, menor que la utilizada en nuestro estudio $(80 \mathrm{mM})$, o el tiempo del estímulo (2 min), podría justificar estas diferencias.

Una segunda posible vía de entrada de $\mathrm{Ca}^{2+}$ activada al estimular los astrocitos con alto $\mathrm{K}^{+}$es el intercambiador $\mathrm{Na}^{+} / \mathrm{Ca}^{2+}(\mathrm{NCX})$, actuando en modo reverso. Esta actividad podría producirse al estimular las células con alto $\mathrm{K}^{+}$ porque la composición isosmolar del alto $\mathrm{K}^{+}$requiere que el exceso de $\mathrm{K}^{+}$ 
extracelular $(80 \mathrm{mM})$ se compense con una disminución de la $\left[\mathrm{Na}^{+}\right]$, desde la habitual (145 mM), a $70 \mathrm{mM}$. Los gradientes iónicos y el potencial de membrana favorecen la entrada de $\mathrm{Ca}^{2+}$ al citosol en intercambio por $\mathrm{Na}^{+}$. Las tres isoformas de este transportador (NCX 1, 2 y 3 ) se expresan en astrocitos (Kirischuk y col., 2012). Se ha comprobado que el NCX puede activarse en modo reverso dependiendo de los gradientes iónicos transmembrana ( $\mathrm{Yu}$ y Choi, 1997). Para explorar esta vía de entrada de $\mathrm{Ca}^{2+}$ se realizaron dos tipos de experimentos. En el primero se estudió un inhibidor específico del modo reverso de NCX, el KB-R7943, que no tuvo efecto sobre la amplitud de la liberación provocada por el alto $\mathrm{K}^{+}$. En un segundo abordaje experimental, se sustituyó el $\mathrm{Na}^{+}$extracelular por $\mathrm{Li}^{+}$, probando una solución de $80 \mathrm{mM} \mathrm{LiCl}$, con intención de activar el modo reverso de la actividad NCX y provocar la entrada de $\mathrm{Ca}^{2+}$. Esta solución no provocó salida del $\mathrm{Ca}^{2+}$ reticular, por lo que concluimos que no hay pruebas de que el NCX no está activándose con el alto $\mathrm{K}^{+}$.

Por último, también consideramos la entrada de $\mathrm{Ca}^{2+}$ a través de los canales TRP, canales catiónicos no selectivos y permeables a $\mathrm{Ca}^{2+}$. En astrocitos se han descrito diversos tipos de TRPs (Verkhratsky y col., 2014). Concretamente, los canales TRPA1 se han implicado en la entrada de $\mathrm{Ca}^{2+}$ necesaria para mantener la $\left[\mathrm{Ca}^{2+}\right]_{\mathrm{c}}$ basal (Shigetomi y col., 2016). Estos resultados se han obtenido, tanto en cultivos de astrocitos primarios como en preparaciones de astrocitos in situ en cortes de tejido. La existencia de TRPA1 funcionales en la astroglía es hoy objeto de debate. Así, algunos autores propugnan que estos canales estarían regulando la $\left[\mathrm{Ca}^{2+}\right]_{\mathrm{C}}$ basal mientras que otros autores no obtienen efecto alguno con inhibidores específicos de los TRPA1 (Rungta y col., 2016). Por otra parte, en astrocitos in situ de ratones knockout para TRPA1 se registran todavía señales espontáneas de $\mathrm{Ca}^{2+}$, lo que indica que estos canales sólo contribuirían parcialmente a la entrada de $\mathrm{Ca}^{2+}$ a través de membrana (Shigetomi y col., 2013). Se ha propuesto que la función de esta vía de entrada sería regular la $\left[\mathrm{Ca}^{2+}\right]$ basal, relevante para la regulación de la actividad sináptica (Shigetomi y col., 2013). Otra función, recientemente propuesta es la regulación del diámetro de la arteriola en reposo (Rosenegger y col., 2015). 
Los astrocitos son capaces de segregar un gran número de gliotransmisores en respuesta a estímulos químicos, mecánicos o despolarización. De hecho, se ha descrito que el alto $\mathrm{K}^{+}$extracelular estimula la secreción de vesículas de glutamato (Yaguchi y Nishizaki, 2010). Una última posibilidad es que la despolarización con alto $\mathrm{K}^{+}$pudiese estimular la secreción de glutamato de forma secundaria, y este, actuando de modo autocrino, podría activar sus propios receptores. En nuestros experimentos, se probaron tres tipos de inhibidores de los mGluR tipo I: el MPEP (inhibidor del mGluR5), el LY 367385 y el MCPG sobre la liberación de $\left[\mathrm{Ca}^{2+}\right.$ inducida por alto $\mathrm{K}^{+}$. No observamos ningún efecto inhibitorio sobre la respuesta del alto $\mathrm{K}^{+}$, lo que indica que la secreción de glutamato no estaría involucrada (datos no mostrados).

En conclusión, aunque no hemos identificado completamente la vía de entrada de $\mathrm{Ca}^{2+}$, es muy posible que coexistan varios tipos de canales y/o transportadores. Nuestros datos muestran que el componente de entrada de $\mathrm{Ca}^{2+}$ representa como máximo un $20 \%$ de la respuesta de $\mathrm{Ca}^{2+}$ global al estímulo despolarizante (Fig. 46). Esto implica que se produce una gran amplificación de la señal de $\mathrm{Ca}^{2+}$, lo cual no es sorprendente en una célula que presenta una señalización por $\mathrm{Ca}^{2+}$ especial, basada en la presencia de bombas y canales en las endomembranas (Verkhratsky y col., 2012).

Durante la actividad fisiológica normal del Sistema Nervioso Central (CNS), la concentración extracelular del $\mathrm{K}^{+}\left(\left[\mathrm{K}^{+}\right]\right)$raramente excede de 3-5 mM. Sin embargo, en ciertas condiciones patológicas como los ataques epilépticos, la isquemia o el trauma cerebral, la $\left[\mathrm{K}^{+}\right]$puede alcanzar picos de 50-60 mM (Katayama y col., 1990; Nilsson y col., 1993). Este incremento transitorio de la $\left[\mathrm{K}^{+}\right]$podría despolarizar la membrana de los astrocitos quiescentes y provocar la entrada de $\mathrm{Ca}^{2+}$ a través de los VOCCs. Precisamente se ha demostrado que la expresión de los VOCCs de tipo L está elevada en los astrocitos reactivos tras una lesión cerebral, una hipomielinización o una isquemia (Westenbroek y col., 1998; Willis y col., 2010). Esta señal podría contribuir a la secreción de gliotransmisores como el glutamato o el ATP. 


\section{Oscilaciones y ondas de $\mathrm{Ca}^{2+}$ en astrocitos}

Uno de los hallazgos originales de este trabajo es la existencia de oscilaciones de $\mathrm{Ca}^{2+}$ en el RE de astrocitos (Fig. 56). Ocurren de forma espontánea y asincrónica en aproximadamente un $20 \%$ de las células del cultivo. Estas oscilaciones reticulares son lentas (periodo promedio de $67 \mathrm{seg}$ ), van siempre paralelas a las oscilaciones citosólicas, tanto en frecuencia como en amplitud, y, en general, no producen una onda de $\mathrm{Ca}^{2+}$ intercelular. Estas oscilaciones del $\mathrm{Ca}^{2+}$ luminal se inhiben, como es previsible, por vaciamiento del RE con inhibidores de la SERCA (TBH; Fig. 56) o por vaciamiento pasivo por eliminación del $\mathrm{Ca}^{2+}$ extracelular (Fig. 57). Esta inhibición es reversible, recuperándose las oscilaciones tanto reticulares como citosólicas tras el lavado del inhibidor. Además, estas oscilaciones requieren $\mathrm{Ca}^{2+}$ extracelular, que debe estar continuamente entrando al citosol para garantizar el continuo rellenado del RE (Fig. 57). El aumento del $\mathrm{Ca}^{2+}$ citosólico como consecuencia de la entrada a través de membrana plasmática no es suficiente para desencadenar las oscilaciones, sino que requiere un umbral mínimo de la $\left[\mathrm{Ca}^{2+}\right]_{\mathrm{RE}}$; por debajo de ese umbral, la entrada de $\mathrm{Ca}^{2+}$ provoca rellenado del $\mathrm{RE}$, pero no un patrón oscilatorio.

La oscilaciones espontáneas de $\mathrm{Ca}^{2+}$ citosólico se habían demostrado previamente en astrocitos en cultivo y en rodajas de hipocampo y de tálamo (Nett y col., 2002; Parri y Crunelli, 2003), aunque no se han encontrado in vivo. Dichas oscilaciones eran independientes de la actividad neuronal y sensibles a los inhibidores de la SERCA. Nuestros resultados con medidas directas del $\left[\mathrm{Ca}^{2+}\right]_{\mathrm{RE}}$ demuestran que el origen de dichas oscilaciones citosólicas está en el RE.

El mecanismo de las oscilaciones citosólicas de $\mathrm{Ca}^{2+}$ es todavía objeto de debate (Dupont y col., 2011). Aunque se ha demostrado que el aumento del $\mathrm{Ca}^{2+}$ citosólico produce la exocitosis de vesículas de glutamato (Reyes y Parpura, 2009), las oscilaciones no parecen dependientes de la secreción de gliotransmisores metabotrópicos como ATP o glutamato (Parri y Crunelli, 2003). Nuestros resultados son compatibles con la activación de un proceso de tipo 
CICR, comentado en el apartado anterior de esta sección. Este se dispararía por el propio $\mathrm{Ca}^{2+}$ que permea a través de los canales de la membrana plasmática, quizás a través de un canal de TRPs aún no identificado, que activaría un canal de la membrana del $\mathrm{RE}$, provocando así la liberación del $\mathrm{Ca}^{2+}$ luminal, con el consiguiente incremento del $\mathrm{Ca}^{2+}$ citosólico.

La identidad del canal del $R E$ podría ser el $I_{3} R$ ya que las oscilaciones se bloqueaban con heparina, un antagonista conocido de este sistema. Para su activación se requeriría la presencia de $\mathrm{IP}_{3}$, pero no debe olvidarse que probablemente se encuentren concentraciones bajas de $\mathrm{IP}_{3}$ en el citosol incluso en reposo. Aparte de las oscilaciones espontáneas, también hemos registrado oscilaciones inducidas por agonistas como el glutamato o su agonista metabotrópico DHPG, que activan la cascada del $\mathrm{IP}_{3}$ (Fig. 61). Está ampliamente aceptado que todos los gliotransmisores metabotrópicos señalizan a través del $I P_{3} R$ tipo 2 , única isoforma detectada en los astrocitos (Sharp y col., 1999). Esto no es fácilmente conciliable con el hecho de que los ratones nulos para $\mathrm{IP}_{3} \mathrm{R} 2$ no presenten ningún fenotipo identificable en el SNC (Li y col., 2005). Como ya se ha mencionado, actualmente se está revisando esta idea al registrarse transitorios espontáneos de $\mathrm{Ca}^{2+}$ localizados en los procesos, sin aumento de $\mathrm{Ca}^{2+}$ en el soma. En el presente trabajo, las oscilaciones estudiadas se han registrado en el soma debido a limitaciones en la resolución óptica.

Otra posibilidad es que el canal de las endomembranas fuera un hipotético TRP, que podría activarse por $\mathrm{Ca}^{2+}$ y facilitar la salida de $\mathrm{Ca}^{2+}$ desde el $R E$, o bien, que interaccionase directamente con el $I P_{3} R$ activado. Cada vez se están descubriendo más familias de TRPs, que además de expresarse en la membrana plasmática, también son funcionales en endomembranas como la del RE (Gees y col., 2010; Bakowski y col., 2012).

Las oscilaciones espontáneas generadas por los astrocitos pueden tener un papel importante en la comunicación astrocito-neurona, y las observaciones recientes indican que los astrocitos son capaces de iniciar un proceso de señalización para controlar la actividad neuronal. 
Además de oscilaciones de $\mathrm{Ca}^{2+}$, los astrocitos también presentan otra forma de señales de $\mathrm{Ca}^{2+}$ más sofisticada, que son las ondas de $\mathrm{Ca}^{2+}$ que progresan a través del tejido (Scemes y Giaume, 2006). En condiciones fisiológicas, la glía se estimula de forma muy breve y localizada por su exposición a los neurotransmisores. Esta estimulación local produce eventos también locales de liberación de $\mathrm{Ca}^{2+}$ a través de los $\mathrm{IP}_{3} \mathrm{Rs}$, y estos eventos pueden eventualmente dar lugar a una señal que se propague e invada el resto de la célula (onda intracelular). Esta onda intracelular puede saltar de una célula a otra, e incluso extenderse a lo largo de grandes distancias en el sincitio astrocítico (onda intercelular). Las ondas intercelulares citosólicas se han registrado en cultivos de astrocitos y en rodajas estimuladas con glutamato de forma local (Scemes y Giaume, 2006) o por estimulación mecánica (Leybaert y Sanderson, 2012). Nuestros datos demuestran que estas ondas implican también al RE y que se propagan a través de el para invadir toda la célula. Además, son capaces de saltar, posiblemente con la ayuda de un mensajero químico, de célula a célula provocando liberación del RE en la célula vecina (Fig. 59 y 60). 


\section{Conclusiones}



1- Se ha desarrollado y caracterizado un nuevo sensor bioluminiscente de $\mathrm{Ca}^{2+}$ de baja afinidad, que está basado en la fotoproteína aequorina, y que permite realizar medidas en compartimentos con alta concentración de $\mathrm{Ca}^{2+}$ durante tiempos largos. Esta sonda es funcional en el retículo endoplásmico (RE) y en el aparato de Golgi, y se ha expresado en distintos tipos celulares con vectores virales de tipo herpes $y$ adenoasociados.

2- Midiendo directamente en el lumen del RE, observamos que la entrada de $\mathrm{Ca}^{2+}$ provocada por un pulso despolarizante desencadena una liberación de $\mathrm{Ca}^{2+}$ (liberación de $\mathrm{Ca}^{2+}$ inducida por $\mathrm{Ca}^{2+}, \mathrm{CICR}$ ). El CICR se observó en astrocitos puros de corteza cerebral de ratón, en cultivos mixtos de astrocitos y neuronas, así como en cultivos organotípicos. El CICR se abolió tanto al inhibir la entrada de $\mathrm{Ca}^{2+}$ desde el medio extracelular, como al vaciar los depósitos intracelulares.

3- Hemos medido simultáneamente la concentración de $\mathrm{Ca}^{2+}$ en el citosol y en el RE utilizando Rhod-2 y GAP3, respectivamente. Las medidas se realizaron en célula única, tanto en astrocitos en monocapa, como en cultivos organotípicos, que reproducen un ambiente más cercano al fisiológico. En ambos modelos se observaron transitorios del $\mathrm{Ca}^{2+}$ citosólico y liberaciones desde el $\mathrm{RE}$ en respuesta a cafeína y a agonistas metabotrópicos, como el ATP, el glutamato y la dihidroxifenilglicina (DHPG).

4- Por primera vez hemos registrado oscilaciones de $\mathrm{Ca}^{2+}$ simultáneamente en el RE y en el citosol de los astrocitos, tanto en cultivo primario como en cultivo organotípico de corteza cerebral. Las oscilaciones espontáneas de la $\left[\mathrm{Ca}^{2+}\right]_{\mathrm{RE}}$ tienen diferentes frecuencias y amplitudes en distintas células. Además, hemos registrado oscilaciones inducidas por diferentes maniobras experimentales que afectan a la entrada de $\mathrm{Ca}^{2+}$ como la baja concentración del $\mathrm{K}^{+}$extracelular, que fuerza la entrada de $\mathrm{Ca}^{2+}$ a través de la membrana plasmática, la retirada y reposición del 
$\mathrm{Ca}^{2+}$ del medio extracelular, o por agonistas como el glutamato, el DHPG o la cafeína.

5- La excitación que desencadena la liberación de $\mathrm{Ca}^{2+}$ del RE se propaga tanto a través del espacio intracelular, extendiendose a toda la célula, como entre astrocitos vecinos. Esta propagación puede seguirse a partir de la señal de GAP3.

6- Los astrocitos no generan potenciales de acción, pero no deben clasificarse como células no excitables. Su excitabilidad está mediada por la liberación de $\mathrm{Ca}^{2+}$ del RE, tanto a través de los receptores de inositol-trisfosfato como de rianodina, que pueden activarse y ser modulados por una gran variedad de estímulos. De este modo, el sistema origina señales complejas que dan lugar tanto a liberaciones de $\mathrm{Ca}^{2+}$ altamente localizadas como a fenómenos propagados, como oscilaciones y ondas de $\mathrm{Ca}^{2+}$. 


\section{Bibliografía}





\section{Bibliografía}

Abbracchio MP, Boeynaems JM, Cattaneo M, Di Virgilio F, Illes P, Inoue K, Jacobson KA, Teresa Miras-Portugal M, Ralevic V, Robson SC, Verkhratsky A, Zimmermann H (2013) Reply to: 'the discovery of a new class of synaptic transmitters in smooth muscle fifty years ago and amelioration of coronary artery thrombosis'. Acta Physiol (Oxf) 208:139140.

Agulhon C, Petravicz J, McMullen AB, Sweger EJ, Minton SK, Taves SR, Casper KB, Fiacco TA, McCarthy KD (2008) What is the role of astrocyte calcium in neurophysiology? Neuron 59:932-946.

Akopian G, Kressin K, Derouiche A, Steinhauser C (1996) Identified glial cells in the early postnatal mouse hippocampus display different types of Ca2+ currents. Glia 17:181-194.

Alonso MT, Barrero MJ, Carnicero E, Montero M, Garcia-Sancho J, Alvarez J (1998) Functional measurements of [Ca2+] in the endoplasmic reticulum using a herpes virus to deliver targeted aequorin. Cell Calcium 24:87-96.

Alonso MT, Barrero MJ, Michelena P, Carnicero E, Cuchillo I, Garcia AG, Garcia-Sancho J, Montero M, Alvarez J (1999) Ca2+-induced Ca2+ release in chromaffin cells seen from inside the ER with targeted aequorin. J Cell Biol 144:241-254.

Alvarez J, Montero M (2002) Measuring [Ca2+] in the endoplasmic reticulum with aequorin. Cell Calcium 32:251-260.

Araque A, Parpura V, Sanzgiri RP, Haydon PG (1998) Glutamate-dependent astrocyte modulation of synaptic transmission between cultured hippocampal neurons. Eur J Neurosci 10:2129-2142.

Arcuino G, Lin JH, Takano T, Liu C, Jiang L, Gao Q, Kang J, Nedergaard M (2002) Intercellular calcium signaling mediated by point-source burst release of ATP. Proc Natl Acad Sci U S A 99:9840-9845.

Aulestia FJ, Redondo PC, Rodriguez-Garcia A, Rosado JA, Salido GM, Alonso MT, Garcia-Sancho J (2011) Two distinct calcium pools in the endoplasmic reticulum of HEK-293T cells. Biochem J 435:227-235.

Bakayan A, Vaquero CF, Picazo F, Llopis J (2011) Red fluorescent proteinaequorin fusions as improved bioluminescent $\mathrm{Ca} 2+$ reporters in single cells and mice. PLoS ONE 6:e19520.

Baker PF, Meves H, Ridgway EB (1971) Phasic entry of calcium in response to depolarization of giant axons of Loligo forbesi. J Physiol 216:70P-71P. 
Bakowski D, Nelson C, Parekh AB (2012) Endoplasmic reticulum-mitochondria coupling: local $\mathrm{Ca}(2)(+)$ signalling with functional consequences. Pflugers Arch 464:27-32.

Barrero MJ, Montero M, Alvarez J (1997) Dynamics of [Ca2+] in the endoplasmic reticulum and cytoplasm of intact HeLa cells. A comparative study. J Biol Chem 272:27694-27699.

Baubet V, Le Mouellic H, Campbell AK, Lucas-Meunier E, Fossier P, Brulet P (2000) Chimeric green fluorescent protein-aequorin as bioluminescent $\mathrm{Ca} 2+$ reporters at the single-cell level. Proc Natl Acad Sci U S A 97:7260-7265.

Beck A, Nieden RZ, Schneider HP, Deitmer JW (2004) Calcium release from intracellular stores in rodent astrocytes and neurons in situ. Cell Calcium 35:47-58.

Berridge MJ (2014) Cell Signalling Biology. Portland Press, London.

Berridge MJ, Bootman MD, Roderick HL (2003) Calcium signalling: dynamics, homeostasis and remodelling. Nat Rev Mol Cell Biol 4:517-529.

Bers DM, Patton CW, Nuccitelli R (1994) A practical guide to the preparation of Ca2+ buffers. Methods Cell Biol 40:3-29.

Bezprozvanny I, Watras J, Ehrlich BE (1991) Bell-shaped calcium-response curves of Ins $(1,4,5) \mathrm{P} 3-$ and calcium-gated channels from endoplasmic reticulum of cerebellum. Nature 351:751-754.

Bird GS, Burgess GM, Putney JW, Jr. (1993) Sulfhydryl reagents and cAMPdependent kinase increase the sensitivity of the inositol 1,4,5trisphosphate receptor in hepatocytes. J Biol Chem 268:17917-17923.

Bowman CL, Kimelberg HK (1984) Excitatory amino acids directly depolarize rat brain astrocytes in primary culture. Nature 311:656-659.

Bowser DN, Khakh BS (2007) Vesicular ATP is the predominant cause of intercellular calcium waves in astrocytes. J Gen Physiol 129:485-491.

Brenner M, Kisseberth WC, Su Y, Besnard F, Messing A (1994) GFAP promoter directs astrocyte-specific expression in transgenic mice. $\mathrm{J}$ Neurosci 14:1030-1037.

Brini M, Carafoli E, Cali T (2016) The plasma membrane calcium pumps: focus on the role in (neuro)pathology. Biochem Biophys Res Commun. 
Bultynck G, Kiviluoto S, Henke N, Ivanova H, Schneider L, Rybalchenko V, Luyten T, Nuyts K, De Borggraeve W, Bezprozvanny I, Parys JB, De Smedt H, Missiaen L, Methner A (2012) The C terminus of Bax inhibitor1 forms a Ca2+-permeable channel pore. J Biol Chem 287:2544-2557.

Burnstock G, Fredholm BB, Verkhratsky A (2011) Adenosine and ATP receptors in the brain. Curr Top Med Chem 11:973-1011.

Butenko O, Dzamba D, Benesova J, Honsa P, Benfenati V, Rusnakova V, Ferroni S, Anderova M (2012) The increased activity of TRPV4 channel in the astrocytes of the adult rat hippocampus after cerebral hypoxia/ischemia. PLoS One 7:e39959.

Carafoli E, Stauffer T (1994) The plasma membrane calcium pump: functional domains, regulation of the activity, and tissue specificity of isoform expression. J Neurobiol 25:312-324.

Catterall WA (2011) Voltage-Gated Calcium Channels. Cold Spring Harb Perspect Biol 3.

Clapham DE (1995) Calcium signaling. Cell 80:259-268.

Clapham DE (2007a) Calcium signaling. Cell 131:1047-1058.

Clapham DE (2007b) SnapShot: mammalian TRP channels. Cell 129:220.

Coco S, Calegari F, Pravettoni E, Pozzi D, Taverna E, Rosa P, Matteoli M, Verderio C (2003) Storage and release of ATP from astrocytes in culture. J Biol Chem 278:1354-1362.

Codazzi F, Teruel MN, Meyer T (2001) Control of astrocyte Ca(2+) oscillations and waves by oscillating translocation and activation of protein kinase $\mathrm{C}$. Curr Biol 11:1089-1097.

Cornell-Bell AH, Finkbeiner SM, Cooper MS, Smith SJ (1990) Glutamate induces calcium waves in cultured astrocytes: long-range glial signaling. Science 247:470-473.

Cuthbertson KS, Cobbold PH (1985) Phorbol ester and sperm activate mouse oocytes by inducing sustained oscillations in cell Ca2+. Nature 316:541542.

Chamero P, Manjarres IM, Garcia-Verdugo JM, Villalobos C, Alonso MT, Garcia-Sancho J (2008) Nuclear calcium signaling by inositol trisphosphate in GH3 pituitary cells. Cell Calcium 43:205-214. 
Charles AC, Naus CC, Zhu D, Kidder GM, Dirksen ER, Sanderson MJ (1992) Intercellular calcium signaling via gap junctions in glioma cells. J Cell Biol 118:195-201.

Cheli VT, Santiago Gonzalez DA, Smith J, Spreuer V, Murphy GG, Paez PM (2016) L-type voltage-operated calcium channels contribute to astrocyte activation In vitro. Glia 64:1396-1415.

Chen SR, Li P, Zhao M, Li X, Zhang L (2002) Role of the proposed poreforming segment of the $\mathrm{Ca} 2+$ release channel (ryanodine receptor) in ryanodine interaction. Biophys J 82:2436-2447.

Chen SR, Li X, Ebisawa K, Zhang L (1997) Functional characterization of the recombinant type $3 \mathrm{Ca} 2+$ release channel (ryanodine receptor) expressed in HEK293 cells. J Biol Chem 272:24234-24246.

D'Ascenzo M, Vairano M, Andreassi C, Navarra P, Azzena GB, Grassi C (2004) Electrophysiological and molecular evidence of L-(Cav1), N- (Cav2.2), and R- (Cav2.3) type Ca2+ channels in rat cortical astrocytes. Glia 45:354-363.

Dallwig R, Vitten H, Deitmer JW (2000) A novel barium-sensitive calcium influx into rat astrocytes at low external potassium. Cell Calcium 28:247-259.

De Bock M, Decrock E, Wang N, Bol M, Vinken M, Bultynck G, Leybaert L (2014) The dual face of connexin-based astroglial $\mathrm{Ca}(2+)$ communication: a key player in brain physiology and a prime target in pathology. Biochim Biophys Acta 1843:2211-2232.

de la Fuente S, Fonteriz RI, de la Cruz PJ, Montero M, Alvarez J (2012) Mitochondrial free $[\mathrm{Ca}(2+)]$ dynamics measured with a novel low- $\mathrm{Ca}(2+)$ affinity aequorin probe. Biochem J 445:371-376.

de la Fuente S, Fonteriz RI, Montero M, Alvarez J (2013) Ca2+ homeostasis in the endoplasmic reticulum measured with a new low-Ca2+-affinity targeted aequorin. Cell Calcium 54:37-45.

De Stefani D, Patron M, Rizzuto R (2015) Structure and function of the mitochondrial calcium uniporter complex. Biochim Biophys Acta 1853:2006-2011.

Duffy S, MacVicar BA (1995) Adrenergic calcium signaling in astrocyte networks within the hippocampal slice. J Neurosci 15:5535-5550.

Dupont G, Combettes L, Bird GS, Putney JW (2011) Calcium Oscillations. Cold Spring Harbor Perspectives in Biology 3:10.1101/cshperspect.a004226 a004226. 
Essin K, Gollasch M (2009) Role of ryanodine receptor subtypes in initiation and formation of calcium sparks in arterial smooth muscle: comparison with striated muscle. J Biomed Biotechnol 2009:135249.

Faddy HM, Smart CE, Xu R, Lee GY, Kenny PA, Feng M, Rao R, Brown MA, Bissell MJ, Roberts-Thomson SJ, Monteith GR (2008) Localization of plasma membrane and secretory calcium pumps in the mammary gland. Biochem Biophys Res Commun 369:977-981.

Fatatis A, Russell JT (1992) Spontaneous changes in intracellular calcium concentration in type I astrocytes from rat cerebral cortex in primary culture. Glia 5:95-104.

Fiacco TA, Agulhon C, Taves SR, Petravicz J, Casper KB, Dong X, Chen J, McCarthy KD (2007) Selective stimulation of astrocyte calcium in situ does not affect neuronal excitatory synaptic activity. Neuron 54:611-626.

Fiacco TA, McCarthy KD (2004) Intracellular astrocyte calcium waves in situ increase the frequency of spontaneous AMPA receptor currents in CA1 pyramidal neurons. J Neurosci 24:722-732.

Fill M, Copello JA (2002) Ryanodine receptor calcium release channels. Physiol Rev 82:893-922.

Foskett JK, White C, Cheung KH, Mak DO (2007) Inositol trisphosphate receptor $\mathrm{Ca} 2+$ release channels. Physiol Rev 87:593-658.

Fresu L, Dehpour A, Genazzani AA, Carafoli E, Guerini D (1999) Plasma membrane calcium ATPase isoforms in astrocytes. Glia 28:150-155.

Fumagalli M, Brambilla R, D'Ambrosi N, Volonte C, Matteoli M, Verderio C, Abbracchio MP (2003) Nucleotide-mediated calcium signaling in rat cortical astrocytes: Role of P2X and P2Y receptors. Glia 43:218-203.

Gallego-Sandin S, Rodriguez-Garcia A, Alonso MT, Garcia-Sancho J (2009) The endoplasmic reticulum of dorsal root ganglion neurons contains functional TRPV1 channels. J Biol Chem 284:32591-32601.

Gees M, Colsoul B, Nilius B (2010) The role of transient receptor potential cation channels in $\mathrm{Ca} 2+$ signaling. Cold Spring Harb Perspect Biol 2:a003962.

Golovina VA, Blaustein MP (2000) Unloading and refilling of two classes of spatially resolved endoplasmic reticulum $\mathrm{Ca}(2+)$ stores in astrocytes. Glia 31:15-28. 
Gourine AV, Kasparov S (2011) Astrocytes as brain interoceptors. Exp Physiol 96:411-416.

Grynkiewicz G, Poenie M, Tsien RY (1985) A new generation of Ca2+ indicators with greatly improved fluorescence properties. J Biol Chem 260:3440-3450.

Hamilton N, Vayro S, Kirchhoff F, Verkhratsky A, Robbins J, Gorecki DC, Butt AM (2008) Mechanisms of ATP- and glutamate-mediated calcium signaling in white matter astrocytes. Glia 56:734-749.

Haustein MD, Kracun S, Lu XH, Shih T, Jackson-Weaver O, Tong X, Xu J, Yang XW, O'Dell TJ, Marvin JS, Ellisman MH, Bushong EA, Looger LL, Khakh BS (2014) Conditions and constraints for astrocyte calcium signaling in the hippocampal mossy fiber pathway. Neuron 82:413-429.

Haydon PG, Carmignoto G (2006) Astrocyte control of synaptic transmission and neurovascular coupling. Physiol Rev 86:1009-1031.

Heneka MT, Rodriguez JJ, Verkhratsky A (2010) Neuroglia in neurodegeneration. Brain Res Rev 63:189-211.

Hirrlinger J, Hulsmann S, Kirchhoff F (2004) Astroglial processes show spontaneous motility at active synaptic terminals in situ. Eur $\mathrm{J}$ Neurosci 20:2235-2239.

Hollmann M, Heinemann S (1994) Cloned glutamate receptors. Annu Rev Neurosci 17:31-108.

Hua X, Malarkey EB, Sunjara V, Rosenwald SE, Li WH, Parpura V (2004) $\mathrm{C}(\mathrm{a} 2+)$-dependent glutamate release involves two classes of endoplasmic reticulum $\mathrm{Ca}(2+)$ stores in astrocytes. J Neurosci Res 76:86-97.

Imler E, Zinsmaier KE (2014) TRPV1 channels: not so inactive on the ER. Neuron 84:659-661.

Inouye S, Noguchi M, Sakaki Y, Takagi Y, Miyata T, Iwanaga S, Tsuji FI (1985) Cloning and sequence analysis of cDNA for the luminescent protein aequorin. Proc Natl Acad Sci U S A 82:3154-3158.

Inscho EW (2001) P2 receptors in regulation of renal microvascular function. Am J Physiol Renal Physiol 280:F927-944.

Irving AJ, Collingridge GL, Schofield JG (1992) Interactions between Ca2+ mobilizing mechanisms in cultured rat cerebellar granule cells. J Physiol 456:667-680. 
Jabs R, Matthias K, Grote A, Grauer M, Seifert G, Steinhauser C (2007) Lack of $P 2 X$ receptor mediated currents in astrocytes and GluR type glial cells of the hippocampal CA1 region. Glia 55:1648-1655.

Jaiswal JK (2001) Calcium - how and why? J Biosci 26:357-363.

Jiang D, Wang R, Xiao B, Kong H, Hunt DJ, Choi P, Zhang L, Chen SR (2005) Enhanced store overload-induced $\mathrm{Ca} 2+$ release and channel sensitivity to luminal Ca2+ activation are common defects of RyR2 mutations linked to ventricular tachycardia and sudden death. Circ Res 97:1173-1181.

Kaech S, Banker G (2006) Culturing hippocampal neurons. Nat Protoc 1:24062415.

Kandel ER, (2000) "Sinaptic Integration" en "Principles of neural science" pp220 McGraw-Hill Companies, United States of America.

Kanemaru K, Sekiya H, Xu M, Satoh K, Kitajima N, Yoshida K, Okubo Y, Sasaki T, Moritoh S, Hasuwa H, Mimura M, Horikawa K, Matsui K, Nagai T, lino M, Tanaka KF (2014) In vivo visualization of subtle, transient, and local activity of astrocytes using an ultrasensitive $\mathrm{Ca}(2+)$ indicator. Cell Rep 8:311-318.

Kastritsis CH, Salm AK, McCarthy K (1992) Stimulation of the P2Y purinergic receptor on type 1 astroglia results in inositol phosphate formation and calcium mobilization. J Neurochem 58:1277-1284.

Katayama Y, Becker DP, Tamura T, Hovda DA (1990) Massive increases in extracellular potassium and the indiscriminate release of glutamate following concussive brain injury. J Neurosurg 73:889-900.

Kendall JM, Sala-Newby G, Ghalaut V, Dormer RL, Campbell AK (1992) Engineering the $\mathrm{CA}(2+)$-activated photoprotein aequorin with reduced affinity for calcium. Biochem Biophys Res Commun 187:1091-1097.

Khakh BS, McCarthy KD (2015) Astrocyte calcium signaling: from observations to functions and the challenges therein. Cold Spring Harb Perspect Biol 7:a020404.

Kirischuk S, Parpura V, Verkhratsky A (2012) Sodium dynamics: another key to astroglial excitability? Trends Neurosci 35:497-506.

Kofuji P, Newman EA (2004) Potassium buffering in the central nervous system. Neuroscience 129:1045-1056.

Kraft R (2015) STIM and ORAl proteins in the nervous system. Channels (Austin) 9:245-252. 
Kriegstein A, Alvarez-Buylla A (2009) The glial nature of embryonic and adult neural stem cells. Annu Rev Neurosci 32:149-184.

Kwon J, An H, Sa M, Won J, Shin JI, Lee CJ (2017) Orai1 and Orai3 in Combination with Stim1 Mediate the Majority of Store-operated Calcium Entry in Astrocytes. Exp Neurobiol 26:42-54.

Lalo U, Pankratov Y, Kirchhoff F, North RA, Verkhratsky A (2006) NMDA receptors mediate neuron-to-glia signaling in mouse cortical astrocytes. $J$ Neurosci 26:2673-2683.

Lalo U, Pankratov Y, Parpura V, Verkhratsky A (2011) lonotropic receptors in neuronal-astroglial signalling: what is the role of "excitable" molecules in non-excitable cells. Biochim Biophys Acta 1813:992-1002.

Lang S, Benedix J, Fedeles SV, Schorr S, Schirra C, Schäuble N, Jalal C, Greiner M, Haßdenteufel S, Tatzelt J, Kreutzer B, Edelmann L, Krause E, Rettig J, Somlo S, Zimmermann R, Dudek J (2012) Different effects of Sec61a, Sec62 and Sec63 depletion on transport of polypeptides into the endoplasmic reticulum of mammalian cells. J Cell Sci 125:1958-1969.

Langley D, Pearce B (1994) Ryanodine-induced intracellular calcium mobilisation in cultured astrocytes. Glia 12:128-134.

Latour I, Hamid J, Beedle AM, Zamponi GW, Macvicar BA (2003) Expression of voltage-gated $\mathrm{Ca} 2+$ channel subtypes in cultured astrocytes. Glia 41:347-353.

Lee YS, Ondrias K, Duhl AJ, Ehrlich BE, Kim DH (1991) Comparison of calcium release from sarcoplasmic reticulum of slow and fast twitch muscles. J Membr Biol 122:155-163.

Leybaert L, Sanderson MJ (2012) Intercellular Ca(2+) waves: mechanisms and function. Physiol Rev 92:1359-1392.

Li X, Zima AV, Sheikh F, Blatter LA, Chen J (2005) Endothelin-1-induced arrhythmogenic $\mathrm{Ca} 2+$ signaling is abolished in atrial myocytes of inositol1,4,5-trisphosphate(IP3)-receptor type 2-deficient mice. Circ Res 96:1274-1281.

MacVicar BA (1984) Voltage-dependent calcium channels in glial cells. Science 226:1345-1347.

MacVicar BA, Tse FW (1988) Norepinephrine and cyclic adenosine 3':5'-cyclic monophosphate enhance a nifedipine-sensitive calcium current in cultured rat astrocytes. Glia 1:359-365. 
Malarkey EB, Ni Y, Parpura V (2008) Ca2+ entry through TRPC1 channels contributes to intracellular $\mathrm{Ca} 2+$ dynamics and consequent glutamate release from rat astrocytes. Glia 56:821-835.

Manjarres IM, Chamero P, Domingo B, Molina F, Llopis J, Alonso MT, GarciaSancho J (2008) Red and green aequorins for simultaneous monitoring of Ca2+ signals from two different organelles. Pflugers Arch 455:961970.

Martin JL, Feinstein DL, Yu N, Sorg O, Rossier C, Magistretti PJ (1992) VIP receptor subtypes in mouse cerebral cortex: evidence for a differential localization in astrocytes, microvessels and synaptosomal membranes. Brain Res 587:1-12.

Matsumoto M, Nakagawa T, Inoue T, Nagata E, Tanaka K, Takano H, Minowa O, Kuno J, Sakakibara S, Yamada M, Yoneshima H, Miyawaki A, Fukuuchi Y, Furuichi T, Okano H, Mikoshiba K, Noda T (1996) Ataxia and epileptic seizures in mice lacking type 1 inositol 1,4,5-trisphosphate receptor. Nature 379:168-171.

Matyash M, Matyash V, Nolte C, Sorrentino V, Kettenmann H (2002) Requirement of functional ryanodine receptor type 3 for astrocyte migration. FASEB J 16:84-86.

McCarthy AM, McMahan L, Schaffer PA (1989) Herpes simplex virus type 1 ICP27 deletion mutants exhibit altered patterns of transcription and are DNA deficient. J Virol 63:18-27.

Meissner G (1986) Ryanodine activation and inhibition of the Ca2+ release channel of sarcoplasmic reticulum. J Biol Chem 261:6300-6306.

Mikoshiba K (2007) The IP3 receptor/Ca2+ channel and its cellular function. Biochem Soc Symp 9-22.

Miller RT, Cattley RC, Marsman DS, Lyght O, Popp JA (1995) TGF alpha differentially expressed in liver foci induced by diethylnitrosamine initiation and peroxisome proliferator promotion. Carcinogenesis 16:7782.

Minelli A, Castaldo P, Gobbi P, Salucci S, Magi S, Amoroso S (2007) Cellular and subcellular localization of $\mathrm{Na}+-\mathrm{Ca} 2+$ exchanger protein isoforms, NCX1, NCX2, and NCX3 in cerebral cortex and hippocampus of adult rat. Cell Calcium 41:221-234.

Missiaen L, De Smedt H, Droogmans G, Casteels R (1992) Luminal Ca2+ controls the activation of the inositol 1,4,5-trisphosphate receptor by cytosolic Ca2+. J Biol Chem 267:22961-22966. 
Montero M, Brini M, Marsault R, Alvarez J, Sitia R, Pozzan T, Rizzuto R (1995) Monitoring dynamic changes in free $\mathrm{Ca} 2+$ concentration in the endoplasmic reticulum of intact cells. EMBO J 14:5467-5475.

Moore GA, Kass GE, Duddy SK, Farrell GC, Llopis J, Orrenius S (1990) 2,5Di(tert-butyl)-1,4-benzohydroquinone--a novel mobilizer of the inositol 1,4,5-trisphosphate-sensitive $\mathrm{Ca}+$ pool. Free Radic Res Commun 8:337-345.

Morita M, Nakane A, Maekawa S, Kudo Y (2015) Pharmacological characterization of the involvement of protein kinase $C$ in oscillatory and non-oscillatory calcium increases in astrocytes. J Pharmacol Sci 129:3842.

Mothet JP, Pollegioni L, Ouanounou G, Martineau M, Fossier P, Baux G (2005) Glutamate receptor activation triggers a calcium-dependent and SNARE protein-dependent release of the gliotransmitter D-serine. Proc Natl Acad Sci U S A 102:5606-5611.

Nakahara K, Okada M, Nakanishi S (1997) The metabotropic glutamate receptor mGluR5 induces calcium oscillations in cultured astrocytes via protein kinase C phosphorylation. J Neurochem 69:1467-1475.

Nakajima Y, Masu M, Ueda Y, Nakahara K, Watanabe D, Yamaguchi S, Kawabata S, Okada M Brain Res Brain Res Rev 1998 May;26(2-3):2305.

Nakamura K, Zuppini A, Arnaudeau S, Lynch J, Ahsan I, Krause R, Papp S, De Smedt H, Parys JB, Müller-Esterl W, Lew DP, Krause KH, Demaurex N, Opas M, Michalak M (2001) Functional specialization of calreticulin domains. J Cell Biol 154:961-972.

Nakanishi S (1992) Molecular diversity of glutamate receptors and implications for brain function. Science 258:597-603.

Navarrete M, Araque A (2008) Endocannabinoids mediate neuron-astrocyte communication. Neuron 57:883-893.

Navarrete M, Araque A (2014) The Cajal school and the physiological role of astrocytes: a way of thinking. Front Neuroanat 8:33.

Navas-Navarro P, Rojo-Ruiz J, Rodriguez-Prados M, Ganfornina MD, Looger LL, Alonso MT, Garcia-Sancho J (2016) GFP-Aequorin Protein Sensor for Ex Vivo and In Vivo Imaging of $\mathrm{Ca}(2+)$ Dynamics in High-Ca(2+) Organelles. Cell Chem Biol 23:738-745. 
Nett WJ, Oloff SH, McCarthy KD (2002) Hippocampal astrocytes in situ exhibit calcium oscillations that occur independent of neuronal activity. J Neurophysiol 87:528-537.

Nilsson GE, Perez-Pinzon M, Dimberg K, Winberg S (1993) Brain sensitivity to anoxia in fish as reflected by changes in extracellular $\mathrm{K}+$ activity. Am $\mathrm{J}$ Physiol 264:R250-253.

Niwa F, Sakuragi S, Kobayashi A, Takagi S, Oda Y, Bannai H, Mikoshiba K (2016) Dissection of local $\mathrm{Ca}(2+)$ signals inside cytosol by ER-targeted $\mathrm{Ca}(2+)$ indicator. Biochem Biophys Res Commun 479:67-73.

North RA (2002) Molecular physiology of P2X receptors. Physiol Rev 82:10131067.

Nunez L, Sanchez A, Fonteriz RI, Garcia-Sancho J (1996) Mechanisms for synchronous calcium oscillations in cultured rat cerebellar neurons. Eur $\mathrm{J}$ Neurosci 8:192-201.

Oakes SA, Scorrano L, Opferman JT, Bassik MC, Nishino M, Pozzan T, Korsmeyer SJ (2005) Proapoptotic BAX and BAK regulate the type 1 inositol trisphosphate receptor and calcium leak from the endoplasmic reticulum. Proc Natl Acad Sci U S A 102:105-110.

Olivera BM, Miljanich GP, Ramachandran J, Adams ME (1994) Calcium channel diversity and neurotransmitter release: the omega-conotoxins and omega-agatoxins. Annu Rev Biochem 63:823-867.

Olsen ML, Sontheimer H (2008) Functional implications for Kir4.1 channels in glial biology: from $\mathrm{K}+$ buffering to cell differentiation. J Neurochem 107:589-601.

Orellana JA, Stehberg J (2014) Hemichannels: new roles in astroglial function. Front Physiol 5:193.

Owsianik G, Talavera K, Voets T, Nilius B (2006) Permeation and selectivity of TRP channels. Annu Rev Physiol 68:685-717.

Palmer AE, Qin Y, Park JG, McCombs JE (2011) Design and application of genetically encoded biosensors. Trends Biotechnol 29:144-152.

Palygin O, Lalo U, Verkhratsky A, Pankratov Y (2010) lonotropic NMDA and $\mathrm{P} 2 \mathrm{X} 1 / 5$ receptors mediate synaptically induced $\mathrm{Ca} 2+$ signalling in cortical astrocytes. Cell Calcium 48:225-231. 
Parker I, Miledi R (1989) Nonlinearity and facilitation in phosphoinositide signaling studied by the use of caged inositol trisphosphate in Xenopus oocytes. J Neurosci 9:4068-4077.

Parpura V, Basarsky TA, Liu F, Jeftinija K, Jeftinija S, Haydon PG (1994) Glutamate-mediated astrocyte-neuron signalling. Nature 369:744-747.

Parpura V, Grubisic V, Verkhratsky A (2011) Ca(2+) sources for the exocytotic release of glutamate from astrocytes. Biochim Biophys Acta 1813:984991.

Parri HR, Crunelli V (2003) The role of Ca2+ in the generation of spontaneous astrocytic Ca2+ oscillations. Neuroscience 120:979-992.

Parri HR, Gould TM, Crunelli V (2001) Spontaneous astrocytic Ca2+ oscillations in situ drive NMDAR-mediated neuronal excitation. Nat Neurosci 4:803812.

Pasti L, Volterra A, Pozzan T, Carmignoto G (1997) Intracellular calcium oscillations in astrocytes: a highly plastic, bidirectional form of communication between neurons and astrocytes in situ. J Neurosci 17:7817-7830.

Pekny M, Pekna M (2014) Astrocyte reactivity and reactive astrogliosis: costs and benefits. Physiol Rev 94:1077-1098.

Pellerin L, Magistretti PJ (1994) Glutamate uptake into astrocytes stimulates aerobic glycolysis: a mechanism coupling neuronal activity to glucose utilization. Proc Natl Acad Sci U S A 91:10625-10629.

Perea G, Araque A (2010) GLIA modulates synaptic transmission. Brain Res Rev 63:93-102.

Petravicz J, Fiacco TA, McCarthy KD (2008) Loss of IP3 receptor-dependent $\mathrm{Ca} 2+$ increases in hippocampal astrocytes does not affect baseline CA1 pyramidal neuron synaptic activity. J Neurosci 28:4967-4973.

Pfrieger FW, Barres BA (1996) New views on synapse-glia interactions. Curr Opin Neurobiol 6:615-621.

Pin JP, Duvoisin R (1995) The metabotropic glutamate receptors: structure and functions. Neuropharmacology 34:1-26.

Porter JT, McCarthy KD (1996) Hippocampal astrocytes in situ respond to glutamate released from synaptic terminals. J Neurosci 16:5073-5081. 
Pozzan T, Rizzuto R, Volpe P, Meldolesi J (1994) Molecular and cellular physiology of intracellular calcium stores. Physiol Rev 74:595-636.

Prasher D, McCann RO, Cormier MJ (1985) Cloning and expression of the cDNA coding for aequorin, a bioluminescent calcium-binding protein. Biochem Biophys Res Commun 126:1259-1268.

Raju B, Murphy E, Levy LA, Hall RD, London RE (1989) A fluorescent indicator for measuring cytosolic free magnesium. Am J Physiol 256:C540-548.

Ralevic V, Burnstock G (1998) Receptors for purines and pyrimidines. Pharmacol Rev 50:413-492.

Reyes RC, Parpura V (2008) Mitochondria modulate Ca2+-dependent glutamate release from rat cortical astrocytes. J Neurosci 28:9682-9691.

Reyes RC, Parpura V (2009) The trinity of Ca2+ sources for the exocytotic glutamate release from astrocytes. Neurochem Int 55:2-8.

Rizzuto R, De Stefani D, Raffaello A, Mammucari C (2012) Mitochondria as sensors and regulators of calcium signalling. Nat Rev Mol Cell Biol 13:566-578.

Rizzuto R, Pozzan T (2006) Microdomains of intracellular Ca2+: molecular determinants and functional consequences. Physiol Rev 86:369-408.

Rizzuto R, Simpson AW, Brini M, Pozzan T (1992) Rapid changes of mitochondrial $\mathrm{Ca} 2+$ revealed by specifically targeted recombinant aequorin. Nature 358:325-327.

Rodriguez-Garcia A, Rojo-Ruiz J, Navas-Navarro P, Aulestia FJ, GallegoSandin S, Garcia-Sancho J, Alonso MT (2014) GAP, an aequorin-based fluorescent indicator for imaging $\mathrm{Ca} 2+$ in organelles. Proc Natl Acad Sci U S A 111:2584-2589.

Rodriguez-Prados M, Rojo-Ruiz J, Aulestia FJ, Garcia-Sancho J, Alonso MT (2015) A new low-Ca(2)(+) affinity GAP indicator to monitor high $\mathrm{Ca}(2)(+)$ in organelles by luminescence. Cell Calcium 58:558-564.

Rosenegger DG, Tran CH, Wamsteeker Cusulin JI, Gordon GR (2015) Tonic Local Brain Blood Flow Control by Astrocytes Independent of Phasic Neurovascular Coupling. J Neurosci 35:13463-13474.

Rossi D, Sorrentino V (2002) Molecular genetics of ryanodine receptors Ca2+release channels. Cell Calcium 32:307-319. 
Rungta RL, Bernier LP, Dissing-Olesen L, Groten CJ, LeDue JM, Ko R, Drissler S, MacVicar BA (2016) Ca2+ transients in astrocyte fine processes occur via Ca2+ influx in the adult mouse hippocampus. Glia 64:2093-2103.

Saeki Y, Fraefel C, Ichikawa T, Breakefield XO, Chiocca EA (2001) Improved helper virus-free packaging system for HSV amplicon vectors using an ICP27-deleted, oversized HSV-1 DNA in a bacterial artificial chromosome. Mol Ther 3:591-601.

Sarkadi B, Szasz I, Gardos G (1980) Characteristics and regulation of active calcium transport in inside-out red cell membrane vesicles. Biochim Biophys Acta 598:326-338.

Scemes E, Giaume C (2006) Astrocyte calcium waves: what they are and what they do. Glia 54:716-725.

Schatzmann HJ (1989) The calcium pump of the surface membrane and of the sarcoplasmic reticulum. Annu Rev Physiol 51:473-485.

Schatzmann HJ, Scheidegger HR (1975) Postnatal decline of (Ca2+ + Mg2+)activated membrane ATPase in cattle red cells. Experientia 31:12601261.

Seifert G, Steinhauser C (2001) lonotropic glutamate receptors in astrocytes. Prog Brain Res 132:287-299.

Serrano A, Haddjeri N, Lacaille JC, Robitaille R (2006) GABAergic network activation of glial cells underlies hippocampal heterosynaptic depression. J Neurosci 26:5370-5382.

Sharma G, Vijayaraghavan S (2001) Nicotinic cholinergic signaling in hippocampal astrocytes involves calcium-induced calcium release from intracellular stores. Proc Natl Acad Sci U S A 98:4148-4153.

Sharp AH, Nucifora FC, Jr., Blondel O, Sheppard CA, Zhang C, Snyder SH, Russell JT, Ryugo DK, Ross CA (1999) Differential cellular expression of isoforms of inositol 1,4,5-triphosphate receptors in neurons and glia in brain. J Comp Neurol 406:207-220.

Shelton MK, McCarthy KD (1999) Mature hippocampal astrocytes exhibit functional metabotropic and ionotropic glutamate receptors in situ. Glia 26:1-11.

Shelton MK, McCarthy KD (2000) Hippocampal astrocytes exhibit Ca2+elevating muscarinic cholinergic and histaminergic receptors in situ. J Neurochem 74:555-563. 
Shigetomi E, Jackson-Weaver O, Huckstepp RT, O'Dell TJ, Khakh BS (2013) TRPA1 channels are regulators of astrocyte basal calcium levels and long-term potentiation via constitutive D-serine release. J Neurosci 33:10143-10153.

Shigetomi E, Patel S, Khakh BS (2016) Probing the Complexities of Astrocyte Calcium Signaling. Trends Cell Biol 26:300-312.

Shimizu H, Watanabe E, Hiyama TY, Nagakura A, Fujikawa A, Okado H, Yanagawa Y, Obata K, Noda M (2007) Glial Nax channels control lactate signaling to neurons for brain [Na+] sensing. Neuron 54:59-72.

Shimomura O, Johnson FH, Morise H (1974) Mechanism of the luminescent intramolecular reaction of aequorin. Biochemistry 13:3278-3286.

Shimomura O, Johnson FH, Saiga Y (1962) Extraction, purification and properties of aequorin, a bioluminescent protein from the luminous hydromedusan, Aequorea. J Cell Comp Physiol 59:223-239.

Shimomura O, Musicki B, Kishi Y, Inouye S (1993) Light-emitting properties of recombinant semi-synthetic aequorins and recombinant fluoresceinconjugated aequorin for measuring cellular calcium. Cell Calcium 14:373378.

Simpson PB, Holtzclaw LA, Langley DB, Russell JT (1998) Characterization of ryanodine receptors in oligodendrocytes, type 2 astrocytes, and O-2A progenitors. J Neurosci Res 52:468-482.

Simpson PB, Russell JT (1997) Role of sarcoplasmic/endoplasmic-reticulum $\mathrm{Ca} 2+-\mathrm{ATPases}$ in mediating $\mathrm{Ca} 2+$ waves and local $\mathrm{Ca} 2+-$ release microdomains in cultured glia. Biochem J 325 ( Pt 1):239-247.

Smith SJ (1994) Neural signalling. Neuromodulatory astrocytes. Curr Biol 4:807-810.

Solovyova N, Veselovsky N, Toescu EC, Verkhratsky A (2002) $\mathrm{Ca}(2+)$ dynamics in the lumen of the endoplasmic reticulum in sensory neurons: direct visualization of $\mathrm{Ca}(2+)$-induced $\mathrm{Ca}(2+)$ release triggered by physiological $\mathrm{Ca}(2+)$ entry. EMBO J 21:622-630.

Sontheimer H, Minturn JE, Black JA, Waxman SG, Ransom BR (1990) Specificity of cell-cell coupling in rat optic nerve astrocytes in vitro. Proc Natl Acad Sci U S A 87:9833-9837.

Stoppini L, Buchs PA, Muller D (1991) A simple method for organotypic cultures of nervous tissue. J Neurosci Methods 37:173-182. 
Suzuki J, Kanemaru K, Ishii K, Ohkura M, Okubo Y, lino M (2014) Imaging intraorganellar $\mathrm{Ca} 2+$ at subcellular resolution using CEPIA. Nat Commun $5: 4153$.

Takata N, Mishima T, Hisatsune C, Nagai T, Ebisui E, Mikoshiba K, Hirase H (2011) Astrocyte calcium signaling transforms cholinergic modulation to cortical plasticity in vivo. J Neurosci 31:18155-18165.

Takeshima H, Ikemoto T, Nishi M, Nishiyama N, Shimuta M, Sugitani Y, Kuno J, Saito I, Saito H, Endo M, lino M, Noda T (1996) Generation and characterization of mutant mice lacking ryanodine receptor type 3 . J Biol Chem 271:19649-19652.

Tashiro A, Goldberg J, Yuste R (2002) Calcium oscillations in neocortical astrocytes under epileptiform conditions. J Neurobiol 50:45-55.

Tong J, Du GG, Chen SR, MacLennan DH (1999) HEK-293 cells possess a carbachol- and thapsigargin-sensitive intracellular $\mathrm{Ca}+$ store that is responsive to stop-flow medium changes and insensitive to caffeine and ryanodine. Biochem J 343 Pt 1:39-44.

Tu H, Nelson O, Bezprozvanny A, Wang Z, Lee SF, Hao YH, Serneels L, De Strooper B, Yu G, Bezprozvanny I (2006) Presenilins form ER Ca2+ leak channels, a function disrupted by familial Alzheimer's disease-linked mutations. Cell 126:981-993.

Verkhratsky A, Butt A, (2013) Glial Physiology and Pathofhysiology. WileyBlakwell. Oxford.

Verkhratsky A, Kettenmann H (1996) Calcium signalling in glial cells. Trends Neurosci 19:346-352.

Verkhratsky A, Kirchhoff F (2007a) Glutamate-mediated neuronal-glial transmission. J Anat 210:651-660.

Verkhratsky A, Kirchhoff F (2007b) NMDA Receptors in glia. Neuroscientist 13:28-37.

Verkhratsky A, Krishtal OA, Burnstock G (2009) Purinoceptors on neuroglia. Mol Neurobiol 39:190-208.

Verkhratsky A, Noda M, Parpura V, Kirischuk S (2013a) Sodium fluxes and astroglial function. Adv Exp Med Biol 961:295-305.

Verkhratsky A, Orkand RK, Kettenmann H (1998) Glial calcium: homeostasis and signaling function. Physiol Rev 78:99-141. 
Verkhratsky A, Reyes RC, Parpura V (2014) TRP channels coordinate ion signalling in astroglia. Rev Physiol Biochem Pharmacol 166:1-22.

Verkhratsky A, Rodriguez JJ, Parpura V (2012) Calcium signalling in astroglia. Mol Cell Endocrinol 353:45-56.

Verkhratsky A, Rodriguez JJ, Parpura V (2013b) Astroglia in neurological diseases. Future Neurol 8:149-158.

Verkhratsky A, Steinhauser C (2000) lon channels in glial cells. Brain Res Brain Res $\operatorname{Rev} 32: 380-412$.

Volterra A, Liaudet N, Savtchouk I (2014) Astrocyte $\mathrm{Ca}(2)(+)$ signalling: an unexpected complexity. Nat Rev Neurosci 15:327-335.

Walz W, Gimpl G, Ohlemeyer C, Kettenmann H (1994) Extracellular ATPinduced currents in astrocytes: involvement of a cation channel. J Neurosci Res 38:12-18.

Wang QC, Zheng Q, Tan H, Zhang B, Li X, Yang Y, Yu J, Liu Y, Chai H, Wang $X$, Sun Z, Wang JQ, Zhu S, Wang F, Yang M, Guo C, Wang H, Li Y, Chen Q, Zhou A, Tang TS (2016) TMCO1 Is an ER Ca(2+) LoadActivated $\mathrm{Ca}(2+)$ Channel. Cell 165:1454-1466.

Watkins NJ, Campbell AK (1993) Requirement of the C-terminal proline residue for stability of the $\mathrm{Ca}(2+)$-activated photoprotein aequorin. Biochem $\mathrm{J}$ 293 ( Pt 1):181-185.

Westenbroek RE, Bausch SB, Lin RC, Franck JE, Noebels JL, Catterall WA (1998) Upregulation of L-type Ca2+ channels in reactive astrocytes after brain injury, hypomyelination, and ischemia. J Neurosci 18:2321-2334.

Willis M, Kaufmann WA, Wietzorrek G, Hutter-Paier B, Moosmang S, Humpel C, Hofmann F, Windisch M, Knaus HG, Marksteiner J (2010) L-type calcium channel $\mathrm{CaV} 1.2$ in transgenic mice overexpressing human AbetaPP751 with the London (V717I) and Swedish (K670M/N671L) mutations. J Alzheimers Dis 20:1167-1180.

Winther AM, Bublitz M, Karlsen JL, Moller JV, Hansen JB, Nissen P, BuchPedersen MJ (2013) The sarcolipin-bound calcium pump stabilizes calcium sites exposed to the cytoplasm. Nature 495:265-269.

Yaguchi T, Nishizaki T (2010) Extracellular high K+ stimulates vesicular glutamate release from astrocytes by activating voltage-dependent calcium channels. J Cell Physiol 225:512-518. 
Yamada S, Yamamoto T, Tonomura Y (1970) Reaction mechanism of the Ca2 plus-dependent ATPase of sarcoplasmic reticulum from skeletal muscle. 3. Ca plus-uptake and ATP-splitting. J Biochem 67:789-794.

Yanez M, Gil-Longo J, Campos-Toimil M (2012) Calcium binding proteins. Adv Exp Med Biol 740:461-482.

Yokose J, Ishizuka T, Yoshida T, Aoki J, Koyanagi Y, Yawo H (2011) Lineage analysis of newly generated neurons in organotypic culture of rat hippocampus. Neurosci Res 69:223-233.

Yu SP, Choi DW (1997) $\mathrm{Na}(+)-C a 2+$ exchange currents in cortical neurons: concomitant forward and reverse operation and effect of glutamate. Eur $\mathrm{J}$ Neurosci 9:1273-1281. 